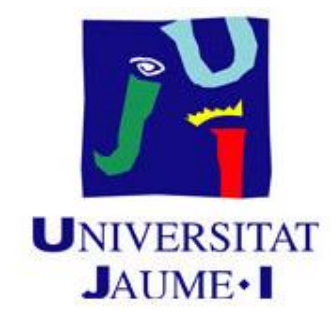

TESIS DOCTORAL

Facultad de Ciencias Jurídicas y Económicas

Departamento de Administración de Empresas y Marketing

Doctorado en Administración de Empresas y Marketing

\title{
INFLUENCIA DE LA EXPERIENCIA DE COMPRA EN EL VALOR DE MARCA DEL COMERCIO DETALLISTA: UNA APLICACIÓN AL COMERCIO DE LA COMUNIDAD VALENCIANA
}

\author{
Autor: \\ Valentín Gallart Camahort \\ Directores: \\ Dr. Luis Callarisa Fiol \\ Dr. Javier Sánchez García
}





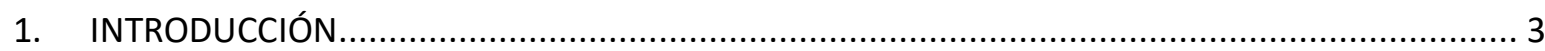

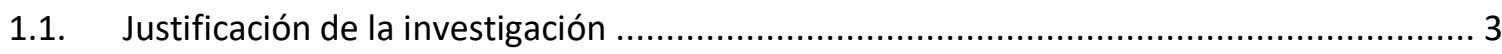

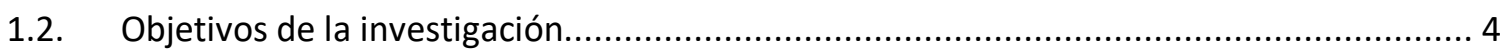

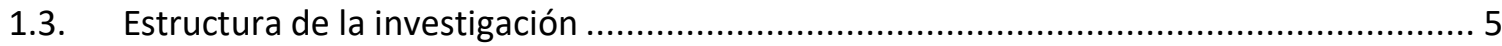

2. EL COMERCIO DETALLISTA Y SU ENTORNO COMPETITIVO ….......................................... 9

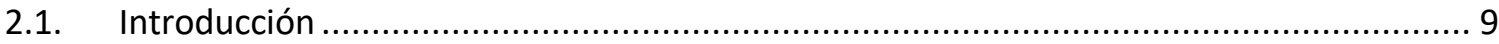

2.2. Tipologías de comercio detallista y evolución......................................................... 16

2.2.1. Tendencias del comercio detallista............................................................ 29

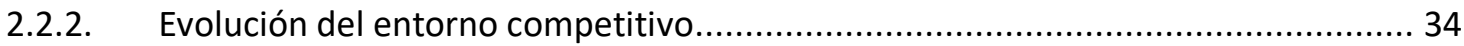

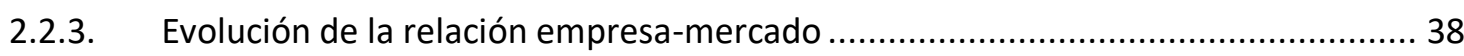

2.3. El comercio detallista y las tecnologías de la información y la comunicación ................. 48

2.4. Comercio detallista tradicional y comercio online: estrategias de integración ................69

3. IMPORTANCIA DE LA MARCA EN EL COMERCIO DETALLISTA...................................... 113

3.1. Concepto de marca y su gestión (Brand Management) ........................................... 114

3.2. Perspectivas de análisis del Valor de Marca ........................................................ 136

3.3. Valor de Marca en el comercio detallista .............................................................. 165

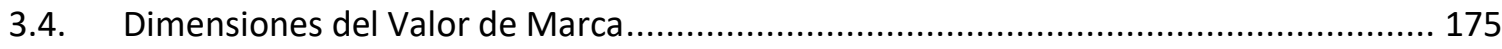

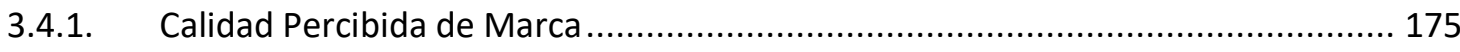

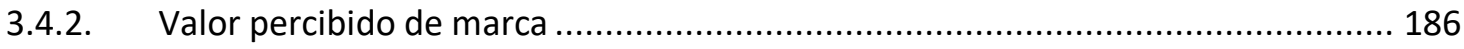

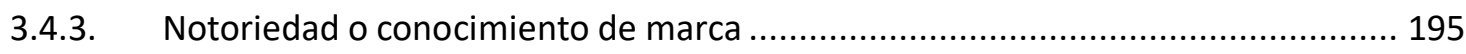

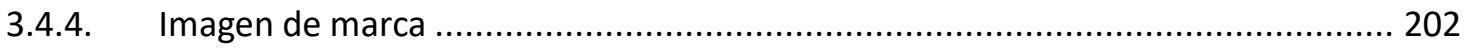

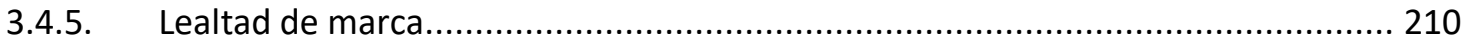

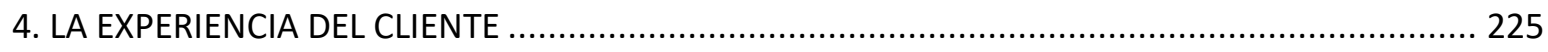

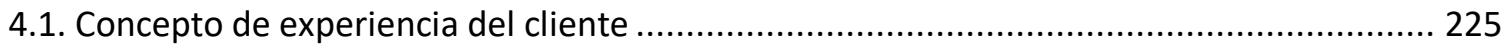

4.2. La experiencia del cliente y el Valor de Marca del comercio detallista....................... 252

4.3. La experiencia del cliente y las tecnologías de la información y comunicación ............. 261 


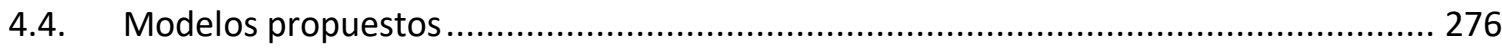

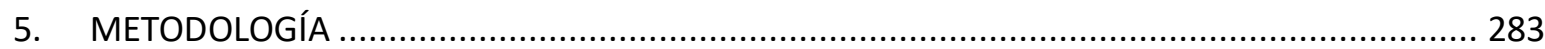

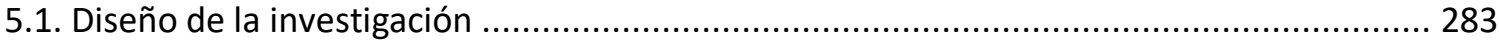

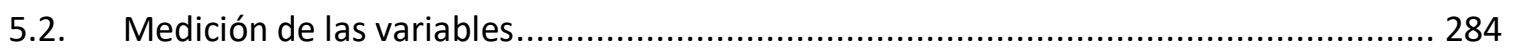

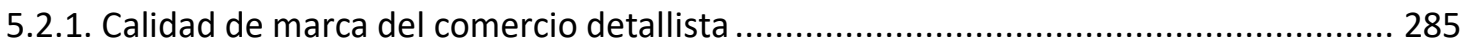

5.2.2. Valor Percibido de marca del comercio detallista ................................................. 287

5.2.3. Notoriedad de marca del comercio detallista......................................................... 289

5.2.4. Imagen de marca del comercio detallista .......................................................... 291

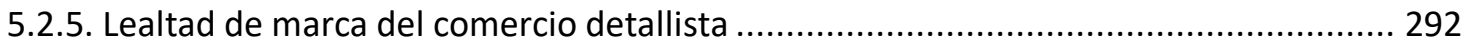

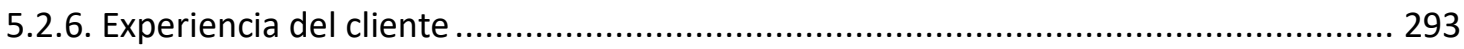

5.2.7. Valor de Marca (Brand Equity) del comercio detallista .......................................... 294

5.2.8. Tecnologías de la Información y la Comunicación .................................................. 295

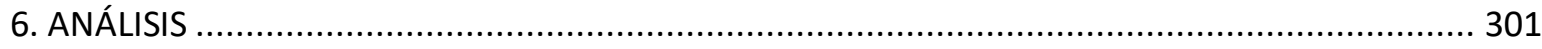

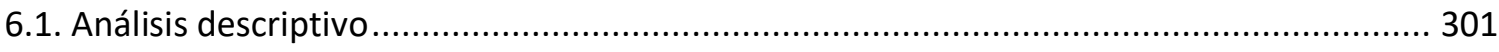

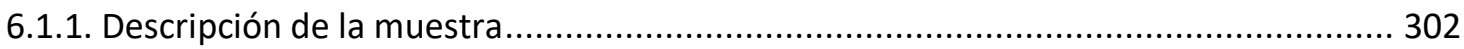

6.1.2 Análisis de los valores medios de las variables ..................................................... 311

6.2. Dimensionalidad, fiabilidad y validez de las escalas de medida .................................... 321

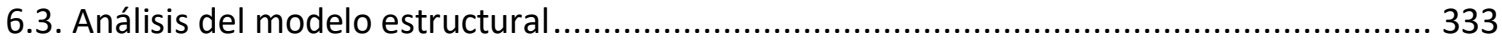

6.3.1. Calidad percibida de marca y Valor percibido de marca del establecimiento comercial 335

6.3.2. Calidad percibida de marca y Lealtad de marca del establecimiento comercial ......... 336

6.3.3. Calidad percibida de marca e Imagen de marca del establecimiento comercial ......... 336

6.3.4. Valor percibido de marca y experiencia de compra del cliente .............................. 337

6.3.5. Notoriedad de marca y Calidad percibida de marca del establecimiento comercial ... 338

6.3.6. Notoriedad de marca y Valor percibido de marca del establecimiento comercial ...... 338

6.3.7. Notoriedad de marca y Lealtad de marca del establecimiento comercial ................. 339

6.3.8. Imagen de marca y Valor percibido de marca del establecimiento comercial ............ 339

6.3.9. Imagen de marca y Lealtad de marca del establecimiento comercial........................ 340

6.3.10. Experiencia de compra y Lealtad de marca del establecimiento comercial .............. 340 
6.3.11. Lealtad de marca y Valor de marca del establecimiento comercial ......................... 342

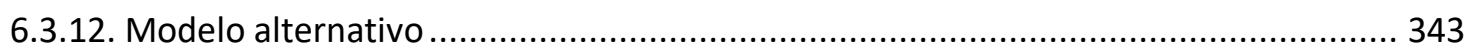

7. CONCLUSIONES, LIMITACIONES Y FUTURAS LÍNEAS DE INVESTIGACIÓN ............................. 349

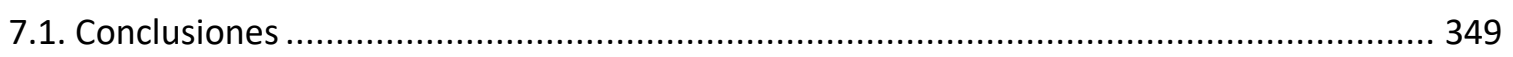

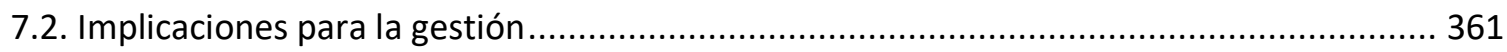

7.3. Limitaciones y futuras líneas de investigación .............................................................. 366

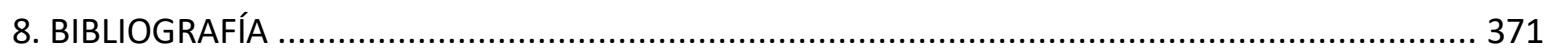



Tabla 2.1. Índice de ventas corregido por formatos comerciales............................................ 15

Tabla 2.2. Tipologías de comercio minorista con presencia física ............................................... 20

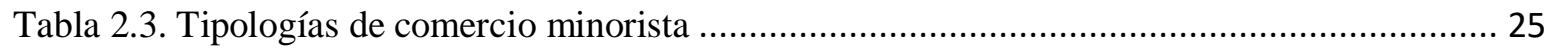

Tabla 3.1. Evolución del concepto de Marca .............................................................................. 123

Tabla 3.2. Definiciones del Valor de Marca....................................................................... 154

Tabla 3.3. Dimensiones del Valor de Marca ........................................................................ 160

Tabla 3.4. Definiciones de valor percibido por el consumidor ............................................... 191

Tabla 3.5. Definiciones de lealtad de marca del consumidor .............................................. 215

Tabla 4.1. Definiciones de experiencia del cliente .......................................................... 249

Tabla 5.1. Ficha técnica de la investigación .......................................................................... 283

Tabla 5.2. Calidad de Marca.................................................................................................. 285

Tabla 5.3. Valor Percibido de Marca ................................................................................. 288

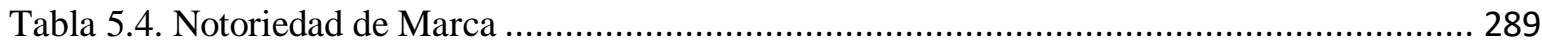

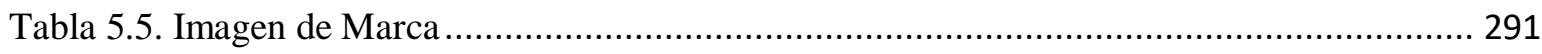

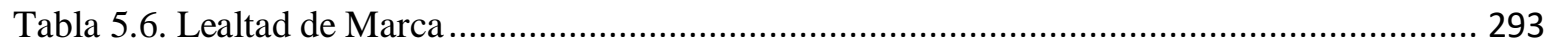

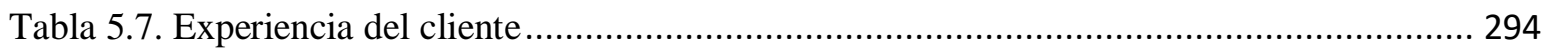

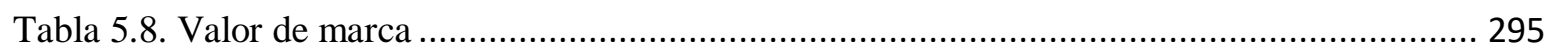

Tabla 5.9. Tecnologías de la Información y la Comunicación .................................................... 296

Tabla 6.1. Distribución de la muestra por edad................................................................. 302

Tabla 6.2. Comercios sobre los que se realizaron las entrevistas .......................................... 303

Tabla 6.3. Comercios en función de su tipología .............................................................. 310

Tabla 6.4. Frecuencia de compra …........................................................................ 310

Tabla 6.5. Descriptivos de calidad de marca....................................................................... 312

Tabla 6.6. Descriptivos valor percibido de marca ......................................................... 313

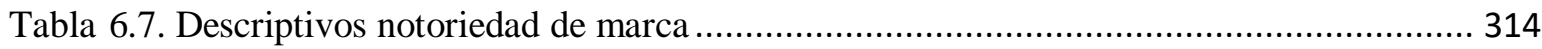


Tabla 6.8. Descriptivos Imagen de Marca ...................................................................... 315

Tabla 6.9. Descriptivos Lealtad de Marca .......................................................................... 317

Tabla 6.10. Descriptivos Experiencia de Compra.............................................................. 318

Tabla 6.11. Descriptivos Valor de Marca ........................................................................... 319

Tabla 6.12. Descriptivos Tecnologías de la Información y Comunicación ................................. 321

Tabla 6.13. Análisis de escalas de medida (I).................................................................... 324

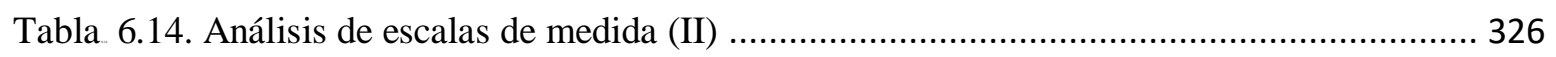

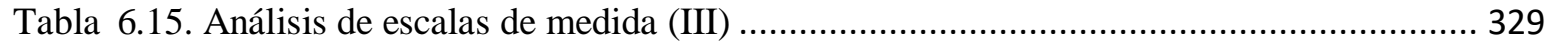

Tabla 6.16. Análisis de escalas de medida (IV) .............................................................. 331

Tabla 6.17. Análisis de escalas de medida (V) ................................................................. 332

Tabla 6.18. Relaciones causales y contrastes de hipótesis modelo I ....................................... 343

Tabla 6.19. Relaciones causales y contrastes de hipótesis modelo II..................................... 346 
Figura 2.1. Locales comerciales minoristas en la Comunitat Valenciana según estrato de asalariados

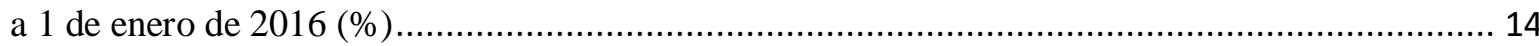

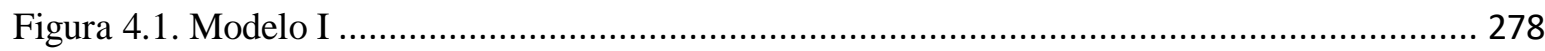

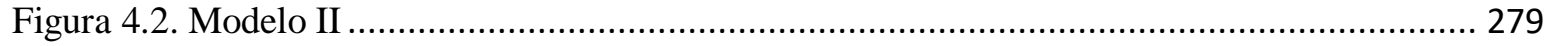

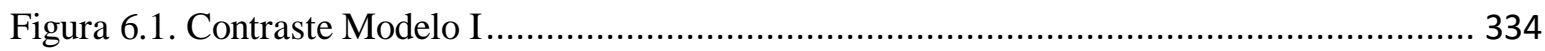

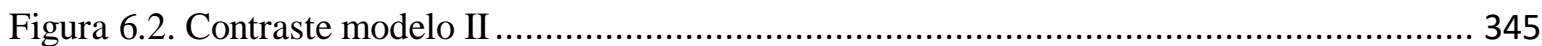




\section{1 - INTRODUCCIÓN}




\section{INTRODUCCIÓN}

\subsection{Justificación de la investigación}

La venta detallista en el siglo XXI supone hacer negocios con los consumidores en sus propios términos. Ello conlleva vender no sólo en tiendas, sino también a través de la Web, catálogos, call centers, televisión interactiva o dispositivos móviles. La preocupación inicial por el rápido crecimiento de las alternativas online ha dado paso a una comprensión de cómo los diferentes canales detallistas pueden incrementar el valor en diferentes condiciones de compra (Mathwick et al, 2002).

En el actual entorno competitivo en el que se mueve el comercio detallista conviven diferentes formatos que van desde el pequeño comercio tradicional, muchas veces de carácter familiar, hasta las grandes multinacionales dedicadas a la venta de alimentación y otros productos en formato de hipermercado, pasando por los supermercados de proximidad o las cadenas franquiciadas.

Además de las diferentes tipologías, se da también la convivencia de distintos canales de distribución y comunicación en los que puede estar presente el comercio minorista. Así, nos encontramos con canales físicos y canales virtuales, lo que propicia que haya empresas que tan solo tengan presencia en un único canal, en varios de ellos o en la totalidad de canales disponibles. Aparecen así conceptos como el de empresa multicanal (con presencia en varios canales) o incluso empresa "omnicanal" para referirnos a empresas presentes en todos los canales.

Con la evolución de los formatos comerciales, propiciada o facilitada en muchas ocasiones por la adopción de las nuevas tecnologías de la información y la comunicación, se está produciendo, paralelamente, una transformación de la relación entre la empresa comercial y su mercado. El consumidor actual ya no interactúa con el detallista a través de un único canal, sino que utiliza varios de los que tiene a su disposición. El paradigma de esa situación es el consumidor capaz de entrar en contacto con la empresa detallista a través de todos los canales y en diferentes momentos. 
En este entorno complejo, en el que la empresa interactúa con el cliente a través de numerosos puntos de contacto, no resulta extraño ver casos en los que la idea que se transmite al consumidor con respecto a lo que es el comercio, no siempre es compacta ni coherente, sino que más bien, difiere en función del canal de que se trate.

Cobra especial importancia en este punto la gestión del Valor de Marca del comercio detallista. Para ello la presente tesis propone un análisis de este concepto y las diferentes variables que lo integran, a fin de llegar a conclusiones válidas que permitan ver qué peso tienen dichas variables y cómo gestionarlas, de manera que se pueda aumentar el Valor de Marca del comercio minorista, haciéndolo más competitivo dentro de su entorno.

Además, las tecnologías de la información y la comunicación no solo influyen en la aparición de nuevos canales, sino que también pueden propiciar la creación de experiencias de compra, tanto en el punto de venta como fuera de él, es decir, permiten la gestión de la éstas a través de todos los puntos de contacto entre el comercio detallista y el consumidor.

Son numerosos los estudios relativos al Valor de Marca, si bien son menos los que se centran en el comercio al por menor. Además, la presente tesis propone la inclusión de la experiencia puesto que ésta se considera como particularmente importante en la relación empresa-consumidor.

Así pues, partiendo del modelo propuesto por Boo et al. (2008) para el Valor de Marca, que a su vez tiene como base el modelo de Aaker (1991), tomando la imagen de marca de la propuesta de Keller (1993), se incluirá, como se ha apuntado, la experiencia de compra, tomada de Berry (2000) y se hará una aplicación al comercio detallista.

\subsection{Objetivos de la investigación}

La presente investigación se centra en el análisis del Valor de Marca del comercio detallista, con el fin de hacer una aplicación concreta a este ámbito. Además, teniendo en 
cuenta las posibilidades que ofrecen las nuevas tecnologías de la información y la comunicación en la manera de relacionarse de la empresa con el consumidor y su influencia en la generación de experiencias de compra, también se analizará ésta última y su aportación a la creación de Valor de Marca para el minorista.

Así pues, se plantean como objetivos la aplicación de un modelo de Valor de Marca para el ámbito del comercio detallista, así como la incorporación de la experiencia de compra en el mismo.

Para ello se ha realizado un estudio entre compradores de distintos establecimientos comerciales de diversos sectores (moda y complementos, alimentación, librería, etcétera) de la Comunidad Valenciana, partiendo de una muestra compuesta por 623 compradores.

\subsection{Estructura de la investigación}

La tesis se estructura en cuatro grandes bloques. Así, tras presentar la justificación y objetivos de la investigación, se plantea un capítulo en el que se analiza la situación actual del comercio detallista. De esta forma, se presentan las distintas tipologías de comercio detallista actuales y se apuntan las principales líneas de evolución.

Dentro de este apartado también se analiza la influencia que las tecnologías de la información y la evolución ejercen sobre el comercio detallista, tanto por lo que se refiere a la aparición de nuevos canales, como al aspecto que las relaciona con la creación de experiencias, tanto dentro como fuera del punto de venta físico.

El tercer capítulo de la tesis recoge otro bloque en el que se profundiza en el concepto de marca y su importancia para el comercio detallista, así como también se plantea el Valor de Marca y sus dimensiones en el ámbito del minorista.

El cuarto capítulo supone la última parte empírica de la tesis. Así, en él se analiza la experiencia del cliente y su relación a la hora de contribuir a la creación de Valor de 
Marca del comercio detallista. En este capítulo se presentan, además, los dos modelos propuestos.

La última parte de la tesis está dedicada a la presentación de la metodología de la investigación llevada a cabo, así como al análisis de resultados, dedicándose el capítulo octavo a la presentación de las principales conclusiones, así como a exponer algunas recomendaciones para la gestión del Valor de Marca del comercio detallista, las limitaciones encontradas en el desarrollo de la investigación y la propuesta de futuras líneas de trabajo. 
2 - EL COMERCIO DETALLISTA Y SU ENTORNO COMPETITIVO 



\section{EL COMERCIO DETALLISTA Y SU ENTORNO COMPETITIVO}

\subsection{Introducción}

En cualquier economía moderna destaca el papel del sector comercial por su importancia como fuente de creación de trabajo, así como por ejercer una función estructuradora entre fabricantes y consumidores. Desde esta perspectiva, la presente tesis se enmarca dentro de la literatura del comercio detallista, y la importancia de la adecuada gestión de su valor de marca como plataforma de diferenciación y de crecimiento y en un entorno muy dinámico y cambiante. De esta manera, en este capítulo se pretende destacar la importancia que el comercio minorista tiene en la economía, así como aportar una visión sobre las distintas tipologías que el mismo puede presentar.

Además, también se analizará la relación del detallista con las tecnologías de la información y la comunicación y las posibles utilizaciones que éste hace de las mismas, así como las distintas opciones que se le presentan en el canal electrónico o presencia online del mismo.

Dada su situación en el canal (entre fabricantes o mayoristas y consumidores), la distribución comercial agrupa al conjunto de actividades que son necesarias para que los bienes y servicios producidos puedan ponerse a disposición del consumidor final en el lugar, tiempo, forma y en la cantidad necesitada por éste, desarrollando funciones tanto para los mayoristas como para los consumidores. Para ello se requerirán determinadas funciones de carácter material como puede ser el transporte de las mercancías, el fraccionamiento de éstas para poder ofrecer la cantidad necesaria o su almacenamiento (Kotler y Keller, 2016).

Además, por otra parte, tal y como señalan los citados autores, habrá determinadas actividades de marketing como las comunicaciones y promociones relativas a productos y servicios, los intercambios de información o las funciones de financiación entre los 
distintos miembros del canal de distribución, entendiendo éste como el camino que deberá seguir un producto o servicio desde el momento en que se produce hasta que es adquirido por el consumidor final, pasando en ese recorrido por una serie de organizaciones independientes que participarán en ese proceso y que incluyen tanto a fabricantes como a intermediarios mayoristas y minoristas o detallistas.

Para la Ley 7/1996, de 15 de enero, de Ordenación del Comercio Minorista el comercio detallista es "aquella actividad desarrollada profesionalmente con ánimo de lucro consistente en ofertar la venta de cualquier clase de artículos a los destinatarios finales de los mismos, utilizando o no un establecimiento".

La distribución comercial representa un sector económico de gran importancia en nuestro país, tanto por su contribución al producto interior bruto (P.I.B.), como a la población activa total, así como por el elevado número de empresas que comprende.

Según datos del Ministerio de Economía y Productividad publicados en el Plan Integral de Competitividad del Comercio Minorista 2015, el comercio supone el 12,3\% del PIB total a precios básicos de la economía española. Concretamente, el comercio minorista constituye por sí solo el 5,5\% del PIB total, y las 469.817 empresas de comercio minorista equivalen al 15,1\% del total de empresas existente en España. Siguiendo con los datos de dicho informe, el número de establecimientos de comercio al por menor es de 583.908, lo que supone el 16,6\% del total de establecimientos de la economía española. Si nos centramos en datos de empleabilidad, las 1.892 .500 personas ocupadas en el comercio minorista en el cuarto trimestre de 2014 suponen el 10,8\% del total de ocupados de la economía.

Así, según la Encuesta Anual de Comercio 2014, publicada por el Instituto Nacional de Estadística en diciembre de 2015, el Comercio se caracteriza por el predominio de empresas muy pequeñas. De hecho, en 2014 más del 95\% de las empresas del sector tenía menos de 10 ocupados. Estas empresas dieron empleo al 48,4\% del personal, pero su facturación apenas representó la tercera parte del total de la cifra de negocios del sector. Por su parte, las empresas grandes (con 250 o más ocupados) 
representaron el 0,1\% de las empresas del Comercio y facturaron el 29,2\% del total del sector. Estas empresas ocuparon al 23,7\% del personal.

Según esta misma Encuesta, el 40,0\% de la facturación del Comercio al por menor, excepto de vehículos de motor y motocicletas en el año 2014 correspondió a la venta de Productos alimenticios, bebidas y tabaco. La venta de Productos textiles y calzado representó un $14,4 \%$ del total y la de Productos médicos, farmacéuticos y cosméticos un $11,9 \%$.

La venta de productos alimenticios, bebidas y tabaco aumentó un $0,9 \%$, mientras que la de productos no alimenticios bajó un $1,1 \%$. Dentro de esta última, Productos médicos, farmacéuticos y cosméticos registró el mayor descenso $(-5,1 \%)$. En cuanto al sistema de venta, la ambulante fue la que más se incrementó en 2014 en el comercio minorista $(26,9 \%)$. Por el contrario, la venta a domicilio fue la que sufrió el mayor descenso $(-23,9 \%)$.

La distribución comercial se encuadra, según la clasificación sectorial desagregada del Instituto Nacional de Estadística (INE), en la actividad económica perteneciente al sector servicios. Teniendo en cuenta la Clasificación Nacional de Actividades Económicas (CNAE) de 2009, la distribución comercial se computa en la Sección G, en la cual se encuentran la división 45 (venta y reparación de vehículos de motor y motocicletas), la división 46 (comercio al por mayor e intermediarios del comercio, excepto los incluidos en la división anterior) y la división 47 (comercio al por menor, excepto los incluidos en la división 45).

Teniendo en cuenta los datos relativos al comercio al por menor y según el Informe de Evolución de Comercio Minorista de enero a abril de 2016 elaborado por el Ministerio de Economía y Competitividad, se observan los siguientes datos estructurales:

- En 2014 el comercio supuso el 12,2\% del PIB total de la economía española.

- En 2013 el comercio minorista representaba el 5,3\% del PIB. 
- En 2015 había en España 469.938 empresas de comercio minorista que representaban el 14,7\% del total de empresas existentes.

- En 2015 había 583.796 establecimientos dedicados al comercio minorista que suponían el $16,2 \%$ del total de establecimientos.

- El número de afiliados del Comercio minorista (60,2\% del Comercio) alcanzó los 1.865.983 en junio de 2016, 34.590 afiliados más que en junio de $2015(1,9 \%$ interanual) y 26.467 afiliados más que en el mes anterior (1,4\% intermensual), resultado del incremento de 25.195 afiliados en el Régimen General y del incremento de 1.272 en el Régimen Especial de Trabajadores Autónomos. En la evolución reciente, el Comercio al por menor muestra una evolución favorable en las tasas de variación anual desde junio de 2013, con tasas positivas a partir de febrero de 2014, que se estabilizan a partir de junio de 2014.

- En términos interanuales, en el sector del Comercio (sección G: venta y reparación de vehículos, comercio mayorista y comercio minorista), en junio de 2016 el número de afiliados creció en todas las Comunidades Autónomas., excepto en Extremadura (0,5\%), así como también creció en Ceuta y Melilla. Las Comunidades Autónomas que más crecieron fueron Illes Balears $(4,9 \%)$ y Comunidad Valenciana $(2,8 \%)$ y las que menos La Rioja $(0,9 \%)$ y Castilla y León $(1,0 \%)$. En Andalucía creció un 2,8\%, en Cataluña un 2,4\%, en la Comunidad de Madrid un 2,3\% y en el País Vasco un 1,4\%.

Si tenemos en cuenta los datos de la Comunidad Valenciana, por ser éste el ámbito geográfico en el que se ha realizado el trabajo de campo de la presente tesis, vemos que, según la Encuesta Trimestral del Comercio Minorista que realiza el Consejo de Cámaras de la Comunitat Valenciana, dentro de su Plan de Acción Territorial (PATECO), la confianza del comercio minorista valenciano disminuyó en el tercer trimestre de 2016, continuando con la tendencia de años anteriores. Esto es así, a pesar de que las ventas del comercio valenciano en el segundo trimestre del mismo año crecieron a un ritmo del 5,7\%. Aunque la afluencia de clientes a los comercios aumentó ligeramente, el gasto medio por compra continuó estacionario, sin mostrar grandes cambios. 
Además, según esta misma Encuesta, no se observan evidencias que indiquen que la inversión en el establecimiento vaya a experimentar un incremento sustancial en el corto plazo. Así, el tímido avance de la confianza del comerciante respalda la prudencia a la hora de realizar inversiones en el negocio pese a los bajos niveles de tipo de interés.

Por otra parte, y siempre según los datos de la Encuesta Trimestral del Comercio Minorista, la Comunitat Valenciana contaba a 1 de enero de 2016 con 62.999 locales comerciales minoristas, lo que suponía 1.055 locales menos que el año anterior. A nivel nacional también se registraba una pérdida neta de 7.585 locales con respecto a 2015, siendo así que la mejora de las ventas en ese año no se vio reflejada en un crecimiento de la oferta comercial minorista. Sin embargo, el crecimiento del empleo, especialmente el asalariado, sí que se ha reflejado en la oferta comercial con un incremento de locales comerciales minoristas que cuentan entre 10 y 49 empleados. En el año 2015 se registraron 160 locales más en este tipo de comercio en la Comunitat Valenciana. No obstante, el grueso de la oferta comercial minorista valenciana sigue caracterizándose por su atomización. Los locales formados por un autónomo o 1-2 trabajadores suponen el 84\% de toda la oferta comercial minorista valenciana. Los locales comerciales dedicados a las actividades de "Comercio al por menor de productos alimenticios, bebidas y tabaco en establecimientos especializados" (CNAE 472) y "Comercio al por menor de otros artículos de uso doméstico en establecimientos especializados" (CNAE 475) fueron los que más locales perdieron a lo largo de 2015, 458 locales y 385 locales menos, respectivamente. Mientras que las actividades "Comercio al por menor no realizado ni en establecimientos, ni en puestos de venta ni en mercadillos" (CNAE 479), entre las que se enmarca el comercio electrónico, han incrementado en 75 locales su presencia en la Comunitat Valenciana. 
Figura 2.1. Locales comerciales minoristas en la Comunitat Valenciana según estrato de asalariados a 1 de enero de $2016(\%)$

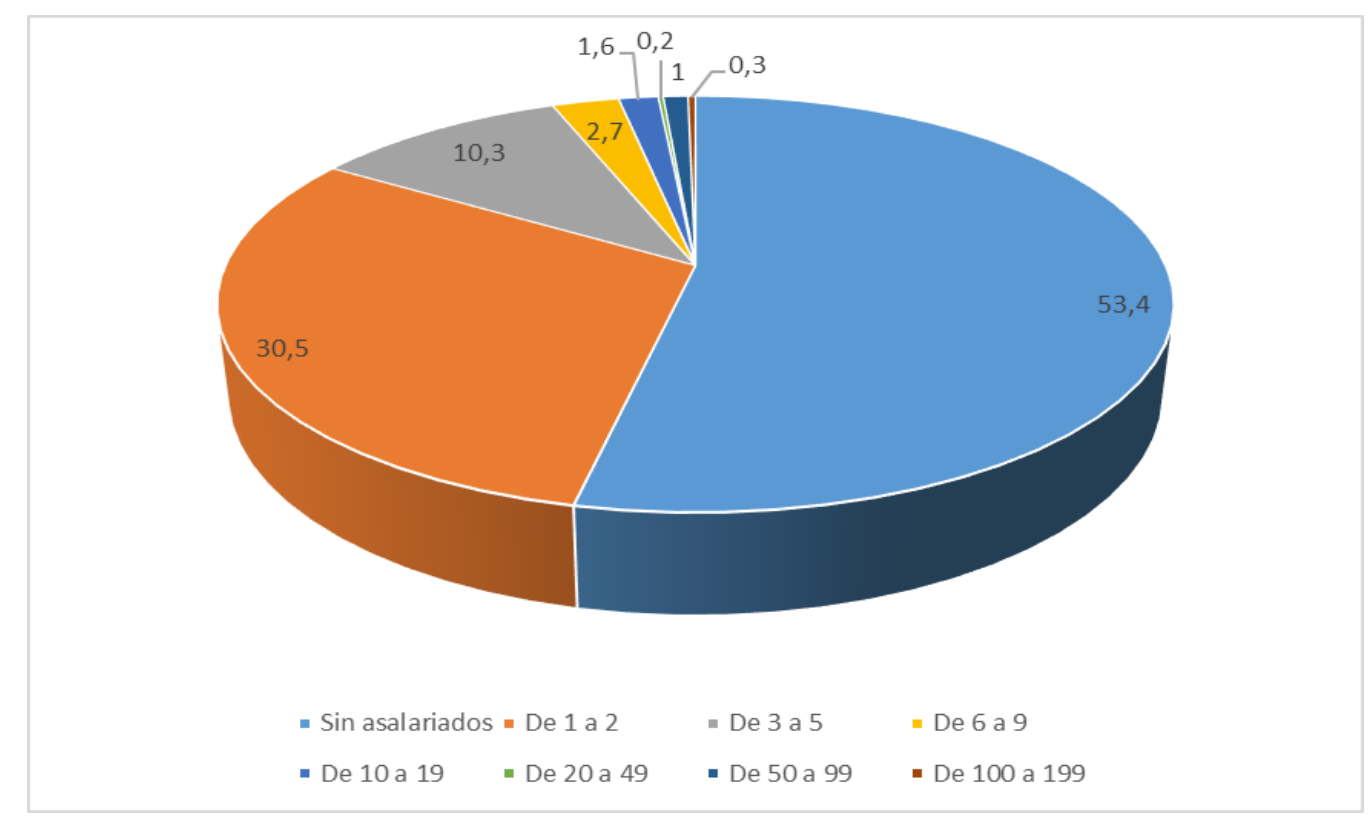

Fuente: elaboración propia a partir de datos del PATECO

Dentro de este sector, como se puede apreciar, se encuentran las grandes empresas de distribución, a menudo conocidas como "grandes superficies", que presentan un proceso claro de modernización y dinamismo, así como también los pequeños comerciantes y empresas de tamaño medio, es decir, las pymes de distribución, que representan un elevado porcentaje del sector.

Analizando los datos proporcionados por el Instituto Nacional de Estadística a fecha de julio de 2016, en función de los distintos formatos comerciales los índices de ventas señalaban que en ese período del año las grandes cadenas habían visto crecer sus ventas un $6,1 \%$ respecto al año anterior, siendo junto con las grandes superficies $(4,7 \%)$ las que en mayor medida habían experimentado el crecimiento de las ventas. Por su parte, las pequeñas cadenas, con un 3,5\% de crecimiento y las empresas con un único punto de venta 
(unilocalizadas), con un $5,0 \%$ de incremento de ventas, también evolucionaron positivamente, en relación con el mismo período del año anterior.

Tabla 2.1. Índice de ventas corregido por formatos comerciales

\begin{tabular}{lcccc}
\hline & Deflactado & Mensual & Anual & Media anual \\
\hline Índice General & $\mathbf{9 1 , 6}$ & $\mathbf{1 , 7}$ & $\mathbf{5 , 6}$ & $\mathbf{4 , 0}$ \\
\hline Empresas unilocalizadas & 85,0 & 1,0 & 5,0 & 3,3 \\
\hline Pequeñas cadenas & 85,5 & 1,1 & 3,5 & 2,2 \\
\hline Grandes cadenas & 106,6 & 2,2 & 6,1 & 4,6 \\
\hline Grandes superficies & 89,1 & 1,1 & 4,7 & 3,7 \\
\hline
\end{tabular}

Fuente: Instituto Nacional de Estadística, 2016.

De esta forma, vemos que en el sector comercial nos encontramos con empresas de gran tamaño que cada vez abarcan mercados más amplios y competitivos, junto con otras de tamaño mucho más reducido e independientes que en muchas ocasiones presentan un carácter más tradicional y cuyos mercados son cada vez más pequeños. Por lo general, para la gestión y dirección de las empresas del primero de los grupos citados (empresas de distribución de gran tamaño) se requiere un alto nivel de profesionalización de sus empleados, a la vez que se trata de empresas que introducen las tecnologías de la información y comunicación tanto en el punto de venta y en el contacto con el cliente (online y offline), como en el resto de sus funciones. 
Es por esto que el hablar de comercio detallista conlleva distintas controversias, como, por ejemplo, el continuo debate sobre si los grandes distribuidores acabarán con el pequeño comercio o incluso si esto supondrá la decadencia de los centros de las ciudades en los que se suelen ubicar estos pequeños minoristas (Fernie et al., 2003).

Tanto las empresas de mayor tamaño como las más pequeñas de carácter tradicional tienen en común el hecho de ocupar una posición intermedia entre fabricantes o mayoristas y consumidores, ya que son quienes venden los bienes y servicios a los consumidores o usuarios finales.

Debido a su posición en el canal prestan una serie de servicios, tanto a consumidores como a fabricantes, ya que compran grandes lotes de productos que luego fraccionan, prestan servicios de financiación, información, etcétera.

Ante la importancia de este sector, destacada por los datos aportados, y la diversidad de formatos que el comercio detallista puede presentar, en el siguiente punto se profundizará en la distinta tipología y las diferentes clasificaciones que del mismo se han hecho, así como también en la evolución de formatos que se está viviendo en el sector.

\subsection{Tipologías de comercio detallista y evolución}

Como se ha apuntado anteriormente, a efectos de la Ley 7/1996, de 15 de enero, de Ordenación del Comercio Minorista el comercio detallista es "aquella actividad desarrollada profesionalmente con ánimo de lucro consistente en ofertar la venta de cualquier clase de artículos a los destinatarios finales de los mismos, utilizando o no un establecimiento".

A pesar de esto, no hay consenso en lo que se refiere a la denominación y descripción de las diversas formas comerciales de venta al detalle (Parra et al., 1998). 
Teniendo en cuenta esta diversidad, en el presente apartado se va a profundizar en la definición que diversos autores han ido aportando, tanto en lo que se refiere a las distintas clasificaciones que se han hecho del comercio detallista, como a las diferentes tipologías. Así pues, a continuación, veremos las distintas definiciones que la literatura ha dado de las dos principales tipologías de comercio detallista, diferenciando entre comercio independiente y comercio organizado. Se tendrán en cuenta, también, las clasificaciones que los autores han ofrecido del comercio detallista en función de las distintas variables utilizadas en cada caso (tipología de venta, presencia física, etcétera), para acabar ofreciendo una descripción del concepto de comercio tradicional, antes de entrar a definir la actual situación de competencia entre los distintos formatos de comercio minorista.

La venta al detalle o venta al por menor (retailing) comprende, según Armstrong et al. (2011), todas las actividades de venta de productos y servicios directamente al consumidor final para su uso personal. Así, cualquier organización que venda al consumidor final (sea fabricante, mayorista, minorista o detallista) estará haciendo venta al por menor. Además, lo será independientemente de que la venta se produzca en persona, mediante correo electrónico, a través de máquinas de venta o de Internet o del lugar en el que se lleve a cabo: en tienda, en la calle o incluso en el domicilio del propio consumidor.

Las empresas dedicadas a la venta minorista han dejado de ser únicamente pequeñas empresas de carácter familiar, para llegar a adoptar, en muchos casos, tipologías incluso de grandes multinacionales, con aspiraciones globales en cuanto a su implantación y que han crecido en un período de tiempo relativamente breve y en donde atienden a distintos canales a la vez (Neslin et al., 2006).

Siguiendo a Sainz de Vicuña (1999), una concepción básica de la empresa de distribución sería la de una "persona jurídica con más de dos empleados y varios puntos de venta que, normalmente utiliza el autoservicio como régimen de venta, se aprovisiona de una central de compras (propia o ajena) y, en general, es un comercio asociado o integrado". 
Según Maraver et al. (2006) tanto los mayoristas como los detallistas (todos ellos intermediarios) pueden clasificarse en tres grupos en función de cómo actúan en el mercado. De esta manera nos encontramos con el comercio independiente (caracterizado por desarrollar funciones de distribución sin asociarse a otras u otras empresas), el comercio asociado (empresas independientes desarrollan conjuntamente algunas o todas sus funciones de distribución, buscando así aumentar su poder de negociación, competitividad, etcétera.) y el comercio integrado (una misma empresa desarrolla funciones de mayorista, detallista e incluso puede llegar a fabricar sus propios productos, controlando de esta manera mucho más todo el proceso de distribución).

En base a una primera gran clasificación, ampliamente adoptada por la literatura, Davies y Harris (1990) se refieren al comercio minorista independiente como aquel que no forma parte de una empresa mayor y en el cual el propietario toma las principales decisiones de gestión al margen de cualquier control externo.

Siguiendo con las definiciones de comercio minorista independiente, Santos y González (2000) consideran que la noción de independiente agrupa de un modo más o menos conciso a todos aquellos minoristas modestos caracterizados por un desarrollo básico en cuanto a tamaño, asociación, integración, forma jurídica y demás dimensiones vinculadas al crecimiento empresarial. Por tanto, conceptos como comercio tradicional, pequeño comercio, empresa familiar o pequeño empresario resultan estrechamente ligados a este colectivo de minoristas.

Por su parte, Díez de Castro (1997) define el comercio independiente como el conjunto de empresas de distribución de pequeñas o medianas dimensiones, que son propiedad de una persona física o de una familia que lleva directamente su explotación y gestión, mientras que Sainz de Vicuña (2001) considera que el comercio independiente es aquel que no está integrado ni asociado. En esta misma línea se desarrollan los trabajos de distintos autores, tales como De Juan (2005), Miquel et al. (2008) o García et al. (2013).

Ramakrishnan (2010) considera el comercio organizado como una cadena de tiendas que están corporativizadas, que aplican modernas técnicas de gestión y que tienden 
al autoservicio, mientras que el comercio detallista tradicional suele ser pequeño, de un solo propietario y basado mayormente en la comunidad. Este sector suele estar compuesto por tiendas familiares que sirven a sus vecindarios, que tienen una superficie de ventas pequeña y que están gestionadas por su propietario, teniendo poco stock y un número limitado de productos.

A su vez, Praharsi et al. (2014), definen al comercio minorista organizado como una cadena de gran escala de tiendas que están corporativizadas y que aplican técnicas modernas de gestión, tales como hipermercados, supermercados y pequeños supermercados (mini market). Por su parte, el pequeño comercio minorista independiente o tradicional suele ser una única tienda individual, bien de un único propietario o bien de propiedad familiar.

Por otra parte, atendiendo al método de venta empleado, tal y como señala Sainz de Vicuña (2001), el comercio minorista se puede clasificar en comercio tradicional (venta con dependientes o despacho directo), autoservicio (cuando el producto está expuesto al alcance del cliente que se sirve directamente y paga en las cajas situadas en la salida del establecimiento), venta automática (una máquina suministra directamente el producto solicitado), venta por correo (a distancia, con elección de producto a través de un catálogo y entrega a domicilio) y venta online (realizada a través de medio electrónico).

Fernández (1999) señala que es frecuente identificar comercio independiente y comercio tradicional, o pequeño comercio y comercio tradicional, e incluso hablar de tienda clásica de alimentación frente a la especializada y demás tipos de establecimiento.

En la actualidad, dentro de la distribución comercial conviven diferentes formatos. Así, según Kotler y Keller (2012 y 2016), dentro de los minoristas con tienda física, nos encontramos con diferentes formatos que se resumen en la Tabla 2.2, que se muestra a continuación. 
Tabla 2.2. Tipologías de comercio minorista con presencia física

\begin{tabular}{|c|c|}
\hline Tipo de comercio & Características \\
\hline Tiendas especializadas & Surtido de productos estrecho. \\
\hline Grandes almacenes & Distintas líneas de productos. \\
\hline Supermercados & $\begin{array}{l}\text { Satisfacen las necesidades globales de alimentación y productos } \\
\text { para el hogar; amplia cartera de productos, bajos costes y } \\
\text { márgenes, grandes volúmenes y formato de autoservicio. }\end{array}$ \\
\hline $\begin{array}{l}\text { Tiendas de } \\
\text { conveniencia }\end{array}$ & $\begin{array}{l}\text { Pequeños comercios en zonas residenciales, con amplios horarios } \\
\text { y pocas líneas de productos. }\end{array}$ \\
\hline $\begin{array}{l}\text { Farmacias y } \\
\text { parafarmacias }\end{array}$ & $\begin{array}{l}\text { Medicamentos y productos relacionados con la salud, belleza y } \\
\text { cuidados personales. }\end{array}$ \\
\hline Tiendas de descuento & $\begin{array}{l}\text { Productos generalistas o de especialidad, bajos precios y } \\
\text { márgenes, grandes volúmenes de venta. }\end{array}$ \\
\hline $\begin{array}{l}\text { Tiendas de valor } \\
\text { extremo o grandes } \\
\text { descuentos }\end{array}$ & $\begin{array}{l}\text { Presentan una mezcla de productos más limitado que las de las } \\
\text { tiendas de descuento, pero a precios incluso más bajos. }\end{array}$ \\
\hline $\begin{array}{l}\text { Detallistas de precio } \\
\text { rebajado }\end{array}$ & $\begin{array}{l}\text { Restos de producción, excedentes, irregulares o fuera de temporada } \\
\text { que son vendidos a precios inferiores que el resto de detallistas. }\end{array}$ \\
\hline
\end{tabular}




\begin{tabular}{l|l}
\hline \multirow{5}{*}{ Supertienda } & $\begin{array}{l}\text { Puntos de venta muy grandes, donde se venden productos de } \\
\text { alimentación y para el hogar, además de servicios (lavandería, } \\
\text { reparaciones de calzado, tintorería, cambio de cheques, ...) } \\
\text { Kategory Killers (con un amplio surtido de una categoría de } \\
\text { productos), tiendas combinadas como Jewel-Osco; } \\
\text { Hipermercados (grandes superficies que combinan supermercado } \\
\text { con tienda de descuento y tiendas más especializadas, como es el } \\
\text { caso de Carrefour o Alcampo. }\end{array}$ \\
\hline Salas de exhibición de & $\begin{array}{l}\text { Amplia selección de productos de marca con margen elevado y } \\
\text { gran rotación que se venden por catálogo a precios de descuento. } \\
\text { catálogo }\end{array}$ \\
\hline
\end{tabular}

Fuente: elaboración propia a partir de Armstrong et al. (2011) y Kotler y Keller (2016)

Por otra parte, nos encontramos con que, si bien muchos comercios detallistas son independientes, cada vez es más habitual que muchos de ellos formen parte de organizaciones corporativas de minoristas y las franquicias, de manera que esto les permita alcanzar economías de escala, mayor poder de compras, mayor reconocimiento de marca o incluso una mejor preparación de sus empleados (Vázquez et al., 2006; de Juan, 2005; Martín Cerdeño, 2012; Santesmases, 2012).

Los principales formatos de organizaciones corporativas de minoristas, definidas por Armstrong et al. (2011) son las cadenas de establecimientos (constituidas por dos o más puntos de venta que centralizan sus compras, lo que les permite comprar mayores cantidades a precios menores), cadenas voluntarias (asociación de comerciante independientes que actúan bajo una misma denominación y con un mismo merchandising, ganando poder de compra), cooperativas de detallistas (distribuidores independientes que crean una organización central de compra y que realizan acciones conjuntas de promoción), cooperativas de consumidores (empresas de distribución de las cuales son propietarios sus mismos clientes), franquicias (asociación contractual entre un franquiciador (fabricante o mayorista) y un franquiciado (persona que compra el derecho a operar con una o más unidades del sistema de franquicia) basada en algún producto, 
servicio o método único para realizar una actividad económica en relación con una marca comercial o patente desarrollada por el franquiciador) y conglomerado de formas de venta (constituidos por empresas de forma libre que aúnan varios tipos de distribución minorista a través de una integración de funciones de distribución y dirección).

Además de los detallistas con tienda física, tenemos también la venta minorista sin tienda física o nonstore retailing. A pesar de que no es el tipo de venta mayoritaria, se puede decir que en los últimos años ha experimentado un crecimiento importante (Kotler y Keller, 2012 y 2016). Estos autores diferencian cuatro grandes grupos de venta sin tienda física.

En primer lugar, estaría la venta directa, también conocida como venta multinivel. Se trata de un tipo de venta minorista a través del sistema de puerta a puerta, mediante el cual un vendedor acude a casa del cliente o bien al hogar de un huésped que ha organizado una reunión para amigos y conocidos a los que el vendedor mostrará y venderá el producto, llevándose una comisión por cada venta realizada. A nivel mundial, la revista Direct Selling News (DSN), dio a conocer la séptima edición anual de la lista DSN Global 100, donde publicó el ranking 2016 de las 100 mejores empresas de venta directa y multinivel del mundo, que viene encabezado por la empresa Amway, que tuvo unos ingresos de 9.500 millones de dólares en ventas, seguido de la reconocida empresa Avon, con ingresos por 6.160 millones de dólares, y en tercer lugar aparecía la empresa Herbalife con unos ingresos de 4.470 millones de dólares. Según el último informe de la Federación Mundial de Asociaciones de Venta Directa (WFDSA), la industria de la venta directa a nivel mundial en 2015 representó un volumen de 182,823 millones de dólares. En el participan empresas tan renombradas, además de las señaladas, como Mary Kay (3.700 millones de dólares) en cosmética, o Tupperware (2.280 millones de dólares) en productos de almacenaje para el hogar, entre otras. Como señala Fiore (2016), la venta directa puede ser considerada como clave en determinados sectores para conseguir el crecimiento de las empresas, así como para lograr una ventaja competitiva.

Otro formato de venta minorista sin tienda física es el marketing directo, que tiene sus orígenes en la venta a través de catálogo. Dentro de este formato se encuadran el 
telemarketing, la venta por televisión a través de respuesta directa y la venta electrónica. Esta última está siendo cada año mayor, no solo en cuanto al volumen de facturación, sino también en cuanto a la tipología de productos y servicios que se venden a través de una cada vez mayor red de páginas web. Esto es así debido a que el consumidor mundial está habituándose a medida que pasa el tiempo a realizar compras a través de Internet, superando barreras que en los primeros años de la aparición de este medio suponían un impedimento a su desarrollo.

Esto se ve reflejado en las ventas online realizadas en los últimos años. Así, según los últimos datos de comercio electrónico disponibles en el portal de la Comisión Nacional de los Mercados y la Competencia, la facturación del comercio electrónico en España aumentó un 23\% en el último trimestre de 2015 hasta alcanzar los 5.309 millones de euros, siendo los sectores de actividad con mayores ingresos de ventas las agencias de viajes y los operadores turísticos. Este dato supone el mayor ritmo de crecimiento desde el primer trimestre de 2010, cuando aumentó un 34,8\%.

Estos datos están en línea con los publicados por la consultora A.T. Kearney en su informe "The 2015 Global Retail e-commerce Index", en el que indica que el comercio electrónico mundial incrementó sus ventas durante ese año un $20 \%$ en todo el mundo, alcanzando los 840.000 millones de dólares.

La venta automática a través de máquinas expendedoras situadas en numerosos emplazamientos, ofrece durante las 24 horas del día y todos los días del año, una gran variedad de producto que va desde las bebidas y refrescos hasta los snacks, pasando por comidas, café, revistas, libros, periódicos, etcétera.

El cuarto formato de venta sin tienda física que identifican Kotler y Keller (2016) es el servicio de compra. En este caso, el detallista vende a una clientela específica (normalmente empleados de grandes organizaciones) que tiene derecho a comprar de una lista de minoristas que ofrecen descuentos a cambio de su pertenencia a un programa. 
Sainz de Vicuña (1999), define el comercio tradicional como "un negocio independiente, no asociado ni vinculado a ningún tipo de establecimiento; de tamaño pequeño por el número de puntos de venta, la cifra de empleados y la dimensión del establecimiento; que dispone de una tecnología tradicional por el régimen de venta utilizado, el equipamiento disponible y la formación de su personal; y cuya forma jurídica es la de persona física". Se identifica, por tanto, el comercio tradicional con el comercio independiente, definido en párrafos anteriores como aquel que, habitualmente, no práctica ningún tipo de asociacionismo espacial (mercados, centros comerciales o galerías comerciales). El comercio tradicional tiene una gran presencia en actividades como las de venta de tabaco, equipamiento del hogar, farmacia y droguería o equipamiento personal (Godás, 2007).

En cuanto a su dimensión física, el comercio tradicional suele contar con un espacio de ventas inferior a los $100 \mathrm{~m} 2$, cuenta con no más de dos empleados y normalmente sólo tiene un punto de venta. Además, su forma jurídica suele ser la persona física, se aprovisiona de un mayorista y no está ubicado en mercados o centros comerciales (Sainz de Vicuña, 2001).

Martínez et al. (1997) entienden como pequeño comercio urbano, aquel comercio tradicional independiente, no asociado ni vinculado a ningún otro tipo de establecimiento; de tamaño pequeño, por el número de puntos de venta con que cuenta, la cifra de empleados y la dimensión del establecimiento y que dispone de una tecnología tradicional, por el régimen de venta utilizado, el equipamiento disponible y la formación de su personal; y cuya forma jurídica es una persona física. Además, también señalan estos autores que el ejercicio del comercio bajo el sistema tradicional se corresponde fundamentalmente con cuestiones de apariencia, es decir, se trata de una forma de compraventa en la que se da una intensa relación entre vendedor y cliente, de forma que éste tiene que exponer su necesidad y ser asesorado directamente por el vendedor en el modo de satisfacerla. Esta relación suele producirse en locales de pequeña dimensión, ubicados en los entornos residenciales de las poblaciones, que están regentados muy directamente por sus propietarios. 
En base a esto, Fernández (1999) considera que "el comercio tradicional es un comercio independiente, no asociado ni vinculado a ningún tipo de establecimiento; de tamaño pequeño, por el número de puntos de venta con que cuenta; la cifra de empleados y la dimensión del establecimiento; que dispone de una tecnología tradicional, por el régimen de venta utilizado, el equipamiento disponible y la formación de su personal; y cuya forma jurídica es una persona física”.

Por otra parte, en cuanto a aspectos tecnológicos, el comercio tradicional utiliza un régimen de venta tradicional con un bajo nivel de equipamiento (terminales de punto de venta, poca utilización de tecnologías de la información y la comunicación, etcétera.) y, además, la formación de los empleados suele ser escasa.

Como se puede apreciar son diversas y variadas las definiciones de comercio minorista aportadas por la literatura, así como las diferentes maneras de referirse al mismo en función del autor que aporte la definición. Ante esto, en la Tabla 2.3, presentada a continuación se hace un repaso cronológico de estas definiciones, indicando los distintos autores que las aportan, así como el tipo de comercio minorista al que hacen referencia.

Tabla 2.3. Tipologías de comercio minorista

\begin{tabular}{l|l}
\hline Autor y definición & Denominación \\
\hline Davies y Harris (1990) & Comercio minorista \\
$\begin{array}{l}\text { Aquel que no forma parte de una empresa mayor y en el cual el propietario } \\
\text { toma las principales decisiones de gestión al margen de cualquier control } \\
\text { externo. }\end{array}$ & \begin{tabular}{l} 
independiente \\
\hline Ley 7/1996, de 15 de enero, de Ordenación del Comercio Minorista
\end{tabular} \\
$\begin{array}{l}\text { Aquella actividad desarrollada profesionalmente con ánimo de lucro } \\
\text { consistente en ofertar la venta de cualquier clase de artículos a los } \\
\text { destinatarios finales de los mismos, utilizando o no un establecimiento. }\end{array}$ & Comercio detallista \\
\hline
\end{tabular}


Díez de Castro (1997)

Empresas de distribución de pequeñas o medianas dimensiones, que son propiedad de una persona física o de una familia que lleva directamente su explotación y gestión.

\section{Comercio}

independiente

Martínez et al. (1997)

Suele producirse en locales de pequeña dimensión, ubicados en los entornos residenciales de las poblaciones, que están regentados muy directamente por sus propietarios.

Sainz de Vicuña (1999)

Negocio independiente, no asociado ni vinculado a ningún tipo de establecimiento, de tamaño pequeño por el número de puntos de venta, la cifra de empleados y la dimensión del establecimiento, que dispone de una Comercio tradicional tecnología tradicional por el régimen de venta utilizado, el equipamiento disponible y la formación de su personal y cuya forma jurídica es la de persona física.

Fernández (1999)

Comercio independiente, no asociado ni vinculado a ningún tipo de establecimiento; de tamaño pequeño, por el número de puntos de venta con que cuenta; la cifra de empleados y la dimensión del establecimiento; que

Comercio tradicional dispone de una tecnología tradicional, por el régimen de venta utilizado, el equipamiento disponible y la formación de su personal; y cuya forma jurídica es una persona física.

Santos y González (2000)

Aquellos minoristas modestos caracterizados por un desarrollo básico en cuanto a tamaño, asociación, integración, forma jurídica y demás dimensiones vinculadas al crecimiento empresarial.

\section{Comercio} independiente 


\section{Ramakrishnan (2010)}

Suele ser pequeño, de un solo propietario y basado mayormente en la comunidad. Normalmente tiendas familiares que sirven a sus vecindarios, que tienen una superficie de ventas pequeña y que están gestionadas por su propietario, teniendo poco stock y un número limitado de productos.

\section{Ramakrishnan (2010)}

Cadena de tiendas que están corporativizadas, que aplican modernas técnicas de gestión y que tienden al autoservicio.

\section{Kotler y Keller (2016)}

Todas las actividades de venta de productos y servicios directamente al consumidor final para su uso personal.

Praharsi et al. (2014)

Una única tienda individual, bien de un único propietario o bien de propiedad familiar.

Comercio organizado

Venta al detalle o al por menor

Fuente: elaboración propia

Tal y como señala Tena (2016), “a lo largo de los últimos años, los pequeños comercios urbanos tradicionales se han visto afectados por un gran número de fuerzas macro ambientales que han cambiado el panorama de la industria. Estos incluyen la propagación de las tiendas de descuento, la proliferación de centros comerciales suburbanos y el papel de internet como una plataforma alternativa/complementaria”.

Ante esta situación no es de extrañar que este tipo de comercio esté perdiendo competitividad y cuota de mercado con respecto a otras fórmulas que hacen un uso mucho más intensivo de las tecnologías de la información y comunicación lo que les permite mayor contacto con el cliente (no sólo en el punto de venta físico), mayor conocimiento de sus necesidades y de las tendencias, prestar mejor servicio al cliente, etcétera. 
Como indica Meiseberg (2016), los comercios minoristas con presencia en Interent utilizan cada vez más distintas herramientas de comunicación online, entre las que destacan la presentación del producto en redes (sistema de recomendadores), características sociales (boca-oído electrónico y diversos tipos de contenido generado por los propios usuarios), pruebas gratuitas y contenido vivo o activo. Estas prácticas de comunicación online están dirigidas a estimular las ventas, tanto de los productos más populares como de aquellos dirigidos a nichos del mercado. Así, este autor señala que estas herramientas ayudan a vender ambos tipos de producto, es decir, tanto los dirigidos a grandes segmentos como los enfocados en nichos.

Por su parte, apuntan Praharsi et al. (2014) que en la actualidad se da una fuerte competencia entre los minoristas organizados, como, por ejemplo, los mini-market, y los pequeños comercios minoristas independientes, dado que los primeros se han ido expandiendo incluso a ciudades pequeñas.

En este sentido, Goodman y Remaud (2015) indican que los diferentes tipos de comercio pueden convivir en el mercado. Para ello deben darse cuenta de que no comparten posiciones similares en la mente del consumidor y que, por tanto, no deben competir utilizando los mismos puntos de diferenciación. Generalmente, las pequeñas empresas tendrán éxito si son capaces de crear y ofrecer valor a determinados clientes y consumidores. Ahora bien, deberá tratarse de un valor que sea difícil de ofrecer por parte de las grandes empresas. Como apuntan estos autores, esto será posible porque el mercado está segmentado y puede presentar diversas demandas.

Con el nuevo entorno económico y social surgido como consecuencia de la crisis iniciada a finales de la década pasada, muchos comercios minoristas han visto como el entorno en el que se movían ha ido sufriendo importantes cambios, lo que les ha obligado a replantearse muchas de las cosas que hasta entonces venían haciendo (Olabarrieta y Zorrilla, 2016). 


\subsubsection{Tendencias del comercio detallista}

Si bien algunas de estas acciones pueden ser válidas para el corto plazo, Kotler y Keller (2016) apuntan algunas tendencias que los comerciantes deberían tener en cuenta, ya que se refieren tanto a los hábitos de compra del consumidor, como a la forma de competir entre empresas minoristas.

Estos autores hablan de nuevas formas y combinaciones de comercio detallista para satisfacer mejor las necesidades del consumidor. Así, tenemos, entre otras opciones, librerías que cuentan con zona de cafetería, gasolineras que incorporan tiendas de alimentación y zonas de comidas preparadas, o algunas tiendas que están experimentando con zonas de exposición temporal (pop-up stores) que permiten ofrecer determinadas marcas durante períodos limitados de tiempo y que a su vez dan una imagen dinámica a la tienda. Ejemplo de ello lo encontramos en los Almacenes Santa Eulalia de Barcelona, propiedad del Grupo Inditex, en los que hay determinadas zonas destinadas a estos pop-up stores y en los que las marcas expuestas cambian cada mes. Otra opción es la que utiliza la empresa española Desigual abriendo tiendas temporales (dos o tres semanas de duración) en distintas ciudades de España.

Otra de las tendencias apuntadas es el crecimiento de la competencia intertipo, es decir, distintos formatos de minoristas están ampliando su surtido, de manera que pueden chocar con otros formatos con los que hasta entonces no competían.

Así, según Goodman y Remaud (2015), se produce el aumento de la competencia entre el comercio con tienda física y el comercio online (u otros formatos sin tienda física), ya que los consumidores reciben constante información a través de medios como el marketing directo, la televisión, teléfono móvil, Internet, etcétera, lo que, a su vez, hace que se eliminen barreras geográficas. Ante esto, muchos comerciantes tradicionales han optado por tener presencia en Internet, a la vez que intentan atraer al consumidor a su tienda física para proporcionarle experiencias en su proceso de compra. 
No solo esto, sino que algunos efectos de las acciones realizadas en un canal pueden afectar a los resultados del resto de canales, incluso cuando se trata de un mismo comercio (con presencia física y online). En este sentido, Breugelmans y Campo (2016) indican que las promociones de venta en un canal pueden tener efectos negativos en el comportamiento de compra en otro canal, especialmente si las promociones difieren entre ellos. Así, las promociones en un canal pueden tener efectos negativos sobre otro canal mientras están vigentes, pero también pueden causar esos efectos negativos en las futuras promociones que puedan hacerse a través de un canal distinto. Además, los efectos negativos son más importantes en los clientes fieles.

El crecimiento de los grandes minoristas es una realidad cada vez más palpable. Estos nuevos competidores son capaces de ofrecer un buen servicio y alcanzar unos grandes volúmenes de ventas, llegando a multitud de consumidores gracias a sus precios competitivos. Esto puede hacer mucho daño a los pequeños comercios detallistas que no son capaces de ofrecer esos precios ni alcanzar esos volúmenes.

Una clara tendencia apuntada por Kotler y Keller (2016) se refiere a la disminución de los minoristas dirigidos al segmento medio. A medida que los grandes minoristas reducen sus precios y ofrecen buenos servicios, al resto se le hace difícil competir en ese segmento, por lo que parece que el crecimiento venga dado en los extremos, es decir, por una parte, el citado tipo de comercio y por otra aquel dirigido o enfocado al segmento alto del mercado.

En este mismo sentido, las cadenas de detallistas pueden competir mejor en costes con su posibilidad de generar mayores economías de escala gracias a la compra de grandes cantidades, mayor volumen de ventas y el reparto de los gastos de comunicación entre un mayor número de puntos de venta en el mercado, mientras que el comercio independiente puede encontrar sus ventajas competitivas en una mayor diferenciación, apoyada en la prestación de servicios personalizados a sus clientes (Goodman y Remaud, 2015; Watson et al., 2015). 
En este entorno, el aumento de la inversión en tecnología es un aspecto necesario si la empresa detallista quiere ser competitiva. El comercio minorista actual hace uso de las tecnologías para hacer mejores previsiones de venta y aprovisionamiento, para controlar su inventario e incluso para hacer los pedidos a sus proveedores de manera electrónica y en ocasiones, automatizada (Krafft et al, 2015; Watson et al., 2015). Las tecnologías también se utilizan en el punto de venta: televisores que muestren cómo utilizar el producto, terminales que permitan ver catálogos, etiquetas electrónicas en los lineales que permiten cambiar los precios automáticamente y con gran rapidez, etcétera. En esta línea, Roggenveen et al. (2015) estudian el impacto de pantallas y displays digitales en el punto de venta, concluyendo que su presencia en hipermercados contribuye al aumento de las ventas.

Además, las grandes empresas de venta al por menor tienen un perfil cada vez más global, debido a que su fortaleza de marca les permite expandirse a otras zonas geográficas, gracias a su buen posicionamiento en el mercado. Así, como señala Hyman (2012), las ventas al consumidor final a través de los distintos canales de distribución suponen aproximadamente un tercio del producto interior bruto mundial. Para alcanzar las ventas en el mercado global los canales han tenido que adaptarse a cambios significantes en el mercado, tales como el crecimiento de las economías basadas en los servicios, el desarrollo de nuevos formatos para los canales, el aumento de la compra online y la globalización de los negocios (Palmatier et al., 2014).

Por otra parte, el desarrollo de las tecnologías de la información y la comunicación también está jugando un papel importante en la evolución de la distribución (Meiseberg, 2016). La tecnología permite al consumidor disponer de mayor tiempo, ya que los distintos equipamientos para el hogar sustituyen, en ocasiones, las tareas realizadas por las personas. Además, estas mismas tecnologías hacen que la comunicación entre compradores y vendedores fluya de una manera mucho más rápida y constante, permitiendo, a su vez, llegar a una mayor amplitud de mercados. 
Además, tal y como indican Krafft et al. (2015), los minoristas están adoptando las nuevas tecnologías de la información compartiendo datos con proveedores y poniéndose en contacto con sus clientes, intentando llegar a la fidelización de los mismos.

Como consecuencia de estos cambios, tanto empresas como mercados están creciendo al amparo de las innovaciones y de la tecnología. Ahora bien, si esto parece más claro en el caso de las grandes empresas de distribución, por lo que respecta al comercio minorista de menor tamaño o el considerado más tradicional, parece que la adopción de las nuevas tecnologías no está tan extendida.

Es esta evolución hace que el sector de la distribución sea uno de los más dinámicos de la economía actual. Consecuencia de esta continua evolución son algunas innovaciones en cuanto al formato de las empresas de distribución minorista. De esta forma, tal y como apuntan Fernie et al. (2003), algunos formatos o formas particulares de operar dentro de este sector, vienen asociadas con algunas empresas o incluso países de origen, como es el caso de los hipermercados que empezaron a desarrollarse en Francia a mitad de la década de 1960 para extenderse al resto de países hasta acabar siendo uno de los formatos dominantes en la distribución actual. Un caso similar lo tenemos en las empresas tipo hard discount o descuento duro, cuyo origen se encuentra en el mercado alemán, así como también el caso de la venta por correo. La aparición de estos formatos respondía, en su momento, a las necesidades del mercado de un determinado país, si bien, como se puede observar, posteriormente se han extendido a otras zonas, dentro de un mercado cada vez más globalizado.

Todos estos factores, tanto sociales como legales o tecnológicos, están afectando al comercio tradicional obligándolo a encontrar su hueco en el panorama actual.

Esto mismo es lo que pretende reflejar la Ley 1/2010, de 1 de marzo, de reforma de la Ley 7/1996, de 15 de enero, de Ordenación del Comercio Minorista, cuando indica en su exposición de motivos que "estamos ante una economía cada vez más globalizada y liberalizada en la que el mercado de referencia del comerciante es el europeo. El modelo comercial español se caracteriza por una elevada densidad comercial (establecimientos por 
habitante), característico de los países mediterráneos y de una determinada forma de estructurar los núcleos urbanos en torno al comercio. (...). Asimismo, es preciso considerar a la hora de regular el comercio las nuevas demandas de los consumidores y los cambios en las pautas y hábitos de consumo de la población, fruto de un nuevo modelo sociocultural, así como las preferencias de los consumidores en relación con los distintos formatos, enseñas comerciales y modalidades de venta”.

Ante la actual situación del sector detallista, tal y como señalan Chardon et al. (2009), Moutaftsi y Kyratsis (2016) y OgilvyAction a través de su estudio "Shopper Decisions Made In-Store” (SDMIS) (2008 y 2016), cada vez más se hace necesaria la correcta gestión del marketing en el punto de venta enfocado al comprador, puesto que cerca del $80 \%$ de las decisiones de compra se toman dentro de la tienda (Chardon et al. 2009).

Teniendo en cuenta la amplia diversidad de tipologías de comercio detallista apuntada por la literatura y puesto que no hay consenso en lo que se refiere a la denominación y descripción de las diversas formas comerciales de venta al detalle (Parra et al., 1998), en la presente tesis se va a optar por diferenciar el comercio detallista independiente del asociado u organizado, intentando detectar posibles diferencias entre ellos en lo que a la gestión de su Valor de Marca se refiere. Esta clasificación es también la seguida por el Instituto Nacional de Estadística cuando agrupa las distintas formas comerciales en empresas unilocalizadas, pequeñas cadenas y grandes cadenas.

Como hemos visto, autores como Davis y Harris (1990), hasta otros como Praharsi et al. (2014), pasando por Díez de Castro (1997), Sainz de Vicuña (2001) o Kotler y Keller (2016), independientemente de las distintas clasificaciones en función de tipología de venta, etcétera, coinciden en diferenciar el comercio independiente del comercio organizado. Teniendo esto en cuenta, a la hora de definir el trabajo de campo de esta tesis, se ha tomado en cuenta esta diferenciación para analizar el Valor de Marca del comercio minorista. 


\subsubsection{Evolución del entorno competitivo}

A lo largo del tiempo todos los sectores participantes en la economía han ido evolucionando y sufriendo diferentes transformaciones. A su vez, la orientación de las empresas hacia el mercado también ha cambiado.

Como se ha señalado en el apartado anterior, son diversas las tipologías y formatos de comercios detallistas que están presentes en el mercado. Esta diversidad viene dada en función de los criterios que se utilicen para su definición, pero también se puede apreciar como con el paso del tiempo los distintos formatos se han ido adaptando a la evolución del entorno en el que competían e incluso han aparecido nuevas tipologías de comercio minorista, estando alguna de ellas relacionadas con el desarrollo de las tecnologías de la información y la comunicación, como es el caso del comercio detallista online.

En el presente epígrafe se va a analizar el entorno en el que se desenvuelve el comercio detallista y su evolución durante las últimas décadas, puesto que la competitividad del minorista vendrá condicionada, en parte, por las condiciones del mercado en el que va a competir.

Kotler (1992) define el mercado como el conjunto de consumidores potenciales que comparten una necesidad o deseo y que podrían estar dispuestos a satisfacerlo a través del intercambio de otros elementos de valor. En función de esta concepción del mercado, el tamaño de éste vendría dado por el número de personas que tuviesen una determinada necesidad, así como recursos que pudiesen interesar a la otra parte y que además haya un interés común de intercambiar esos recursos por lo que estas personas desean.

Siempre según este autor, desde la óptica del especialista en marketing se considera a los vendedores como industria, mientras que los compradores constituirían, en si mismos, el mercado. En este caso, industria y mercado entran en contacto a través de cuatro flujos: los vendedores envían bienes, servicios y comunicaciones al mercado, quien, a cambio, les proporciona dinero e información. 
En este punto podemos decir que el comercio detallista realiza esa función de intermediación, adquiriendo productos, bien de fabricantes o bien de otros intermediarios, para ponerlos a disposición del consumidor.

Ahora bien, en un entorno tan competitivo como el actual, será de vital importancia para este tipo de comercio, identificar lo más correctamente posible el mercado en el que se está compitiendo. Para ello, será necesario que el minorista haga un análisis detallado de quién y cómo es su mercado, es decir, quiénes son y qué características, peculiaridades y necesidades tiene el conjunto de personas a las que se va a dirigir. No podrá quedarse, por tanto, en una definición excesivamente amplia del mercado, puesto que cuanto más profundo sea su conocimiento sobre el mismo, mayores posibilidades de competir en él con éxito.

El entorno que caracteriza hoy en día al comercio minorista viene marcado por un cambio constante, así como por márgenes más reducidos que antaño. No es de extrañar, tal y como señalan Tajeddini et al. (2013) que en muchas áreas el comercio minorista esté dominado por grandes empresas globales como Carrefour, Wal-Mart, Toys'r'Us o Ikea que pueden conseguir beneficios derivados de sus economías de escala y de recursos humanos amplios.

A su vez, y a pesar de esto, el pequeño comercio detallista sigue siendo necesario puesto que ocupa un lugar importante en la cadena de distribución en muchos países. Así, este sector da empleo a mucha gente, es capaz de atender a los nichos de mercado y tiene la flexibilidad necesaria como para diferenciar sus servicios y satisfacer una amplia variedad de necesidades del mercado. El pequeño comercio minorista proporciona oportunidades que pueden ser ignoradas por las grandes empresas y además, identifica las necesidades de un mercado cambiante de manera que puede proveer valor a los consumidores a la vez que genera rentabilidad para el negocio (Smith y Sparks, 2001).

Abell (1980) analiza el mercado desde la perspectiva del comprador, teniendo en cuenta tres dimensiones como son las funciones o necesidades del cliente (qué necesidad se satisface), el grupo de clientes a los que se pretende satisfacer esas necesidades (a quién 
se está satisfaciendo) y las tecnologías que se van a utilizar para hacerlo (cómo se satisfacen esas necesidades).

Munuera y Rodríguez (2007) definen el mercado como el conjunto de consumidores que comparten una necesidad o función y que están dispuestos a satisfacerla a través del intercambio. Así, estos autores establecen el concepto de mercado en la intersección de un conjunto de productos sustitutivos que satisfacen una necesidad o función concreta del conjunto de compradores potenciales.

Concretando más la definición de mercado, Lambin (2003) se refiere a un mercado producto como un grupo de clientes o compradores específicos que buscan una función específica o un surtido de funciones basadas en una sola tecnología. Así pues, vemos como en esta definición convergen unas necesidades concretas con un grupo de clientes o compradores específico y que se pueden satisfacer con una determinada tecnología.

Lambin et al. (2009) utilizan el marco tridimensional del mercado de referencia definido por Adell para distinguir entre un mercado producto, un mercado solución y una industria. Así, para estos autores el mercado producto quedaría definido tal y como se ha indicado en el párrafo anterior, mientras que el mercado solución se podría definir por el desempeño de determinadas funciones en grupos de clientes dados, pero incluye todas las tecnologías sustitutas para desempeñar esas funciones. Por último, la industria se basa en una sola tecnología, pero cubre varios negocios, es decir, varias funciones o surtidos de funciones y varios grupos de clientes.

Teniendo en cuenta estas definiciones que se dirigen hacia la concreción del concepto de mercado, parece difícil que una empresa pueda abarcar o ser competitiva en todos los productos mercados que puedan resultar de la concreción de su mercado de referencia. Lo normal es que ésta se centre tan sólo en una parte de ese mercado a la que pueda llegar con posibilidades de éxito. Munuera y Rodríguez (2007) denominan a esta parte mercado relevante $\mathrm{y}$, según estos autores, se trata del conjunto de productos mercados en los que la empresa decide competir en función de sus alternativas tecnológicas y de los macrosegmentos a los que se dirige. 
Como se ha apuntado a lo largo de estos párrafos, el mercado sufre cambios y evoluciona con el tiempo. De esta forma, teniendo en cuenta el concepto de mercado de referencia definido por estos autores, podría suceder que entrasen nuevos grupos de consumidores, distintos de los que en un principio se había planteado la empresa como su público objetivo, que se diese una redefinición de la necesidad genérica inicial satisfecha, por ejemplo, por la aparición de nuevos productos que pudiesen satisfacer varias necesidades de forma conjunta o incluso que la aparición de nuevas tecnologías diese la posibilidad de ampliar ese mercado de referencia.

Así pues, podríamos afirmar que el mercado de referencia puede verse ampliado a través de tres procesos:

- $\quad$ Proceso de adopción o difusión hacia nuevos grupos de consumidores.

- Proceso de sistematización, extendiendo el mercado de referencia hacia nuevas necesidades.

- Proceso de sustitución tecnológica o cambio tecnológico producido por la aparición de nuevas tecnologías que complementan o sustituyen a las anteriores.

Este último aspecto, es decir, el relativo a la tecnología, va a ser tenido en cuenta en la presente tesis, puesto que las tecnologías de la información y la comunicación y el gran desarrollo que están teniendo durante las últimas décadas, suponen un punto de vital importancia para el comercio detallista, en el sentido de que no solo van a servir para la mejora de su gestión, sino que también se deberán tener en cuenta a la hora de proporcionar experiencias de compra satisfactorias, no solo en el punto de venta físico, sino también en internet. Como se verá más adelante, las nuevas tecnologías propician la presencia de las empresas de comercio minorista en internet, lo que supondrá que éstas deberán tener claro en qué canales quieren estar presente (canal físico y canal online), así como las estrategias a seguir para gestionar dicha presencia en uno o varios de estos canales. 
Como señalan Anderl et al. (2016) el término marketing online se utiliza para describir los instrumentos que los detallistas usan para contactar con sus potenciales clientes en Internet. Puesto que cada vez son más las empresas que usan indistintamente diversos canales de marketing online, los consumidores potenciales pueden interactuar con ellas en distintos sentidos a lo largo de su "viaje online del consumidor".

En esta línea, Lee (2010) define el "viaje online del consumidor" (online customer journey) como aquel que incluye todos los contactos de cada consumidor individual con el detallista a través de todos los canales de marketing online, previos a la toma de decisión de la compra. Haan et al. (2013) y Xu et al. (2014) se refieren a este viaje como el camino hacia la compra (path to purchase).

Los contactos suponen las visitas directas al sitio web del detallista, clicks en la publicidad online y visualizaciones de publicidad online que no conducen a un click sobre la misma. Los recientes avances tecnológicos permiten a los detallistas seguir y monitorizar los viajes de los clientes incluso a nivel individual, pudiendo recoger datos que ayuden a un análisis profundo de las decisiones individuales en los procesos de compra, de manera mucho más exhaustiva que en décadas pasadas. Analizar estos "viajes" puede ayudar al comercio minorista a predecir el comportamiento de compra individual y a desarrollar así estrategias individualizadas de marketing (Anderl et al. 2016).

Así pues, vemos como el entorno competitivo en el que se mueve el comercio minorista no se limita ya únicamente a un mercado "físico", sino que las empresas se van a ver obligadas a tener en cuenta otro entorno como es el "virtual" u online en el que serán necesarias nuevas estrategias. Esto afectará al Valor de Marca del comercio detallista que deberá ser gestionado teniendo en cuenta esta evolución del mercado si la empresa quiere ser competitiva.

\subsubsection{Evolución de la relación empresa-mercado}


Como se ha visto en el apartado anterior, el mercado en el que actúan las empresas dedicadas al comercio minorista ha ido evolucionando en las últimas décadas hasta el punto de aparecer un canal novedoso en el entorno online que ha supuesto, en muchos aspectos, una ruptura con los canales físicos más tradicionales. Así, según los datos expuestos en el informe de la consultora PwC, "Total Retail 2015: las empresas de distribución y consumo en la era de la disrupción”, realizado entre usuarios online de 19 países, se ve como si bien el 36\% de los entrevistados indican que acuden a la tienda física semanalmente, el 20\% realiza compras semanales online a través de su PC, el 11\% desde su Smartphone y el $10 \%$ desde su Tablet.

Por su parte, la Encuesta sobre Equipamiento y Uso de Tecnologías de la Información y Comunicación en los Hogares, realizada por el Instituto Nacional de Estadística en septiembre de 2016, indica que durante el año 2015 el 30,1\% de valencianos realizó compras por Internet, lo que supone un 5,5\% más que en 2014. Además, también señala que desde el año 2008 el número de valencianos que realizaron compras online se ha triplicado.

A nivel nacional, el 32,1\% de los españoles realizaron compras online durante 2015, siendo el País Vasco y Madrid las autonomías con mayor volumen de compras por Internet.

Al igual que se ha ido produciendo esta evolución del mercado, se ha ido también experimentando un cambio en la manera en la que las empresas se han ido relacionando con sus mercados. En este punto se pretende realizar un análisis de cómo ha sido la evolución de las empresas en su relación con el consumidor, teniendo en cuenta los diversos aspectos que han afectado y afectan al comercio detallista.

Así como vemos que hay distintas concepciones del concepto mercado, en función del punto de vista utilizado o de su mayor concreción, etcétera, también hay una evolución en la manera en la que las empresas tienden a relacionarse con este mercado o bien, como apunta Kotler (1992), distintos enfoques bajo los cuales las empresas pueden organizar sus actividades de intercambio con sus mercados. 
La relación de las empresas con los consumidores ha ido evolucionando a la par que lo han hecho los mercados. Así, se ha producido una evolución en la comercialización y el marketing, en consonancia con dicha evolución. De esta manera, para Kotler et al. (2010) el Marketing ha ido evolucionando desde lo que denominan Marketing 1.0 (centrado en el producto), hacia el Marketing 2.0, que nace en la era actual de las tecnologías de la información y en el cual el valor del producto viene definido por el cliente y surgiendo en los últimos años lo que estos autores denominan como Marketing 3.0 o marketing basado en los valores que tiene en cuenta al consumidor desde un amplio punto de vista como ser humano y que considera que el consumidor busca soluciones a sus necesidades y también a sus deseos de que el mundo sea un lugar mejor. Para estos autores, las empresas en la era del Marketing 3.0 se diferencian gracias a sus valores, lo cual es especialmente importante en épocas turbulentas y de crisis.

Si profundizamos más en este punto, podemos señalar que el Marketing 1.0 viene claramente escenificado en el concepto de "miopía del marketing" de Levitt (1960) quien señalaba que cualquier gran industria de su tiempo, con anterioridad había sido una industria en crecimiento y que si el dicho crecimiento se había visto ralentizado o incluso detenido, no era por una saturación del mercado, sino que el problema estaba en la gestión realizada, principalmente por los altos ejecutivos, ya que son estos los responsables de establecer las políticas de las organizaciones. El error, según Levitt, radica en que las empresas se centran en una orientación hacia su producto en vez de orientarse hacia el consumidor. Las empresas se han centrado, en numerosas ocasiones, en mejorar la eficiencia en la fabricación de su producto, en lugar de mejorar el producto genérico o incluso su mercado.

En esta misma línea, autores como Keith (1960), a finales de la década de los cincuenta ya anticipaban que el consumidor debía estar en el centro de la economía, no la empresa. Alrededor de él tenía que girar todo el universo del negocio. Es por esto que, ya entonces, el autor anticipaba que el marketing debería tener un papel principal en la empresa. En su artículo "The Marketing Revolution", Keith decía que la atención de la empresa se desplazaba de los problemas de producción hacia los problemas del mercado, 
desde el producto que la empresa puede fabricar al producto que el consumidor quiere que haga, es decir, un desplazamiento de la empresa hacia el mercado. De esta manera se iniciaba un movimiento que el autor denominó como revolución del marketing, augurando que este enfoque de las empresas iría creciendo en años sucesivos.

Doz et al. (2004) hacen una revisión de la teoría de la miopía del marketing cuando consideran que esta miopía deben tenerla también en cuenta las empresas en el sentido de que no pueden limitarse a tener una visión local o regional de su negocio. Así, los autores consideran que aquellas empresas que realmente quieran ser competitivas deberán expandir de manera global su red para llegar a nuevas fuentes de conocimiento. Necesitarán buscar no sólo nuevas tecnologías que resulten interesantes, sino también nuevas tendencias de los consumidores más allá de las regiones y localizaciones que dominan en la actualidad, de manera que puedan encontrar nuevas oportunidades de negocio.

El concepto de orientación al cliente se basa en la teoría de elección individual que se da a través del principio de soberanía del consumidor (Lambin et al., 2009)

Desde esta perspectiva la organización se debería centrar en identificar cuáles son las necesidades y los deseos de su público objetivo, de manera que pueda ofrecerle un producto o servicio con las características necesarias para satisfacerlos de manera más efectiva y eficiente que la competencia.

Por tanto, no se trataría de encontrar clientes para los productos de la empresa, sino de crear los productos adecuados para sus clientes, puesto que lo primero sería una visión a corto plazo centrada en el producto en si mismo y en sus características (Marketing 1.0) que destacaría las transacciones entre la empresa y el cliente, que como señalan distintos autores, se trataría de una concepción del marketing poco adecuada para el entorno competitivo en el que operan las empresas en la actualidad (Alrubaiee y Al-Nazer, 2010; Huang, 2015; Yoganathan et al., 2015; Tena 2016). 
Más allá de esta visión a corto plazo, tal y como indican Keller y Kotler (2016), el enfoque de marketing se basa en cuatro pilares: por una parte, la correcta definición del mercado, por otra la orientación de la organización hacia el cliente, en tercer lugar la coordinación de los esfuerzos de marketing de la empresa y en cuarto lugar, la búsqueda de la rentabilidad de las acciones realizadas.

Como vemos, el enfoque marketing parte del hecho de que una empresa no puede atender correctamente todos los mercados ni satisfacer todas las necesidades de los mismos. Es por esto que las empresas deben definir de la mejor manera posible cuál es su público objetivo, ya que sólo de esta manera podrán adaptar sus acciones de marketing al mismo.

Además, la orientación de la empresa hacia el cliente supone una perspectiva en la línea del Marketing 2.0 según la cual se deben tener en cuenta las necesidades de este último con la finalidad de lograr su satisfacción y conseguir, de esta manera, retener a los clientes habituales. Para esto, todas las funciones de marketing deberán estar coordinadas, no sólo entre ellas, sino también con el resto de departamentos de la empresa. Todo esto debe llevar a la empresa a maximizar el beneficio y obtener rentabilidad a través de la satisfacción de los consumidores mejor que su competencia.

El pequeño comercio tradicional evoluciona gradualmente desde un marketing puramente transaccional a un marketing relacional, centrado en la atracción de clientes y en el aporte de un valor añadido para los mismos (Badi et al., 2016). Como señalan estos autores, el pequeño comercio detallista más tradicional está discurriendo poco a poco hacia un marketing relacional, enfocado hacia la atracción de clientes y hacia el aporte de un valor añadido. Así pues, también en el comercio detallista tradicional se produce la misma evolución en su relación con los mercados, pasando de una perspectiva más propia del Marketing 1.0 hacia un marketing más centrado en el cliente, puesto que es éste quien definirá el valor del producto.

Ante la creciente competitividad de los mercados y la aparición de nuevos formatos comerciales con agresivas políticas de precios, se hace especialmente importante para las 
pequeñas y medianas empresas de la distribución, desarrollar estrategias que añadan valor tanto a los productos como a los servicios ofrecidos con el fin de conseguir diferenciarse (Palmatier et al., 2009; Ndubisi y Matanda, 2011; Badi et al., 2016)

En la primera década del s. XXI se da un nuevo paso de las empresas con respecto al marketing, cobrando protagonismo el concepto de marketing holístico. Éste, según Keller y Kotler (2016) se basa en el desarrollo, diseño e implementación de programas de marketing, procesos y actividades que reconocen su amplitud e interdependencia. El marketing holístico parte de una perspectiva amplia e integral, teniendo en cuenta distintos aspectos que van más allá de los que tradicionalmente se tenían en cuenta.

Las empresas, para ser competitivas, llevan a cabo diversas estrategias de marketing. Una nueva perspectiva del marketing debe tener en cuenta los numerosos aspectos relacionados con el mismo, desarrollándose, así, el concepto de marketing holístico (Rao, 2011) el cual, para Blythe (2005) es una evolución natural del marketing en la cual la empresa debe confiar en sus habilidades, más que en centrarse únicamente en el objetivo de la venta en sí mismo.

El marketing sirve a directivos, gobernantes, propietarios, empleados y otras partes interesadas, así como a clientes y proveedores. Prosenak et al. (2008) van más allá del punto de vista empresarial u orientado a la obtención de beneficios para la empresa y se plantean la función que el marketing puede desempeñar en la creación de bienestar global para la sociedad. Para estos autores, las nuevas formas del marketing (social, de relaciones, asociado a causas, ecológico, etcétera.) pueden contribuir a alcanzar ese bienestar. Para ello, consideran que será necesario la adopción de una visión amplia del marketing por parte de las empresas, de manera que éstas puedan desarrollar productos innovadores, coherentes y en línea con su responsabilidad social. La línea apuntada por estos autores sería coincidente con una visión del Marketing 3.0, tal y como se ha definido anteriormente.

Para Keller y Kotler (2016), el concepto de marketing holístico recoge toda la complejidad de las actividades relacionadas con el marketing. Así, se tendrá en cuenta el 
marketing de relaciones, el marketing integrado, el marketing interno y el marketing de resultados o "performance marketing”.

En este sentido, una de las claves del marketing moderno, es el establecimiento de relaciones duraderas y estrechas, no sólo con los consumidores, sino también con otras organizaciones participantes en el mercado. Este tipo de relaciones serán importantes para que la empresa alcance sus objetivos y logre mantenerse en un mercado cada vez más competitivo. Así, la intensificación de la competencia obliga a las empresas a buscar nuevos sistemas de producción que permitan optimizar costes, a la vez que buscan ventajas de las relaciones con proveedores y clientes (Bello y Gómez, 1997). Como ya señalaba Anderson et al. (1994) la correcta creación de este tipo de redes con las partes interesadas conducirá a la obtención de beneficios por parte de la empresa.

Eiriz et al (2006) se refieren al marketing de relaciones como al conjunto de actividades de marketing orientadas a establecer, desarrollar, mantener y llevar a cabo intercambios relacionales, comprendiendo relaciones dentro y fuera de la propia organización, así como relaciones con individuos.

Este aspecto relacional no puede ser dejado de lado por parte del comercio detallista. De esta manera, Badi et al. (2016) señalan como los pequeños negocios del sector minorista, más tradicionales, están evolucionando de manera gradual y a escasa velocidad hacia un marketing relacional, centrado en la atracción de clientes y en el aporte de un valor añadido, dejando atrás un enfoque más propio del Marketing 1.0 y adentrándose en una perspectiva más propia del Marketing 2.0.

En este punto cobran especial relevancia las tecnologías de la información y la comunicación, ya que éstas pueden proveer de las herramientas necesarias para facilitar la interacción entre las partes que intervienen en el proceso comercial. Como consecuencia de estas tecnologías se introduce el concepto de marketing electrónico, el cual engloba el conjunto de actividades y procesos de marketing con los que la organización intenta satisfacer las necesidades de sus clientes en el entorno virtual. Más concretamente "el marketing electrónico comprende el uso de las redes de telecomunicación y las tecnologías 
digitales relacionadas para conseguir los objetivos de marketing de la organización, de acuerdo con el enfoque actual de la disciplina de marketing", tal y como señala Rodríguez (2008). Desde la aplicación de las tecnologías de la información y la comunicación al marketing en la década de los ochenta del siglo pasado se ha venido facilitando el desarrollo del marketing de relaciones, gracias a la facilidad para una comunicación interactiva convertida en el máximo exponente del mantenimiento de la relación entre la empresa y el cliente (Möller y Halinen, 2000; Lindgren, 2004; Zablah et al., 2005).

Por otra parte, para Armstrong et al. (2011) el marketing integrado se da cuando la empresa diseña programas de marketing dirigidos a crear valor para el consumidor. Para ello se debe tener en cuenta que el valor puede provenir de diversas actividades. Así pues, a la hora de definir cómo crear valor para sus clientes, las empresas deberán tener en cuenta que todos los aspectos relacionados con el marketing sean coherentes y transmitan mensajes uniformes.

El marketing interno es el tercero de los cuatro aspectos que componen el marketing holístico. En las últimas décadas el marketing se ha ocupado de la fuerza laboral considerando al empleado como un cliente interno de la empresa y el puesto de trabajo como el producto ofrecido a ese cliente interno. A diferencia de la gestión de los recursos humanos de la empresa, el marketing interno tiene un propósito más amplio, ya que se centra en mejorar la satisfacción del empleado para lograr así la satisfacción del cliente externo (Gounaris, 2008).

El cuarto aspecto que consideran Keller y Kotler (2016) dentro del marketing holístico es el marketing de resultados (performance marketing). Esta visión del marketing tiene en cuenta tanto los retornos financieros como no financieros que los distintos programas y acciones de marketing pueden suponer, no solo para la empresa, sino también para la sociedad. Es por esto que el marketing deberá tener en cuenta los efectos que sus actividades pueden suponer en las ventas, en la cuota de mercado, en los índices de pérdida de clientes, calidad del producto, etcétera, pero también deberá ir más allá y tener en cuenta las posibles consecuencias legales, éticas, sociales y medioambientales que puedan producirse. Así, puesto que las distintas acciones de marketing pueden tener consecuencias 
más allá de la propia empresa, ésta deberá tener en cuenta el marketing de responsabilidad social, no perdiendo de vista estos otros aspectos. Como señalan Porter y Kramer (2006) la adopción por parte de las empresas del marketing de responsabilidad social no siempre ha sido por iniciativa propia, sino que en muchas ocasiones se han visto obligadas a ello por presiones de la sociedad en general, grupos activistas, imperativos legales, etcétera.

Así pues, a modo de resumen, podría decirse que el marketing holístico integra aspectos básicos como son el satisfacer las necesidades de los distintos clientes de la empresa, mantener relaciones duraderas con las distintas partes, integrar todas las actividades de marketing de manera coherente, destacar la orientación al cliente de todos los departamentos de la empresa y adoptar un comportamiento socialmente responsable, puesto que sus acciones tendrán impacto en la sociedad, llegando así a una concepción definida como Marketing 3.0.

Tal y como señala Pedraza (2015) nos encontramos en un momento en el que la investigación de mercados (lo que se conoce en el entorno online como big data) cobra especial importancia y las empresas van a tener que predecir lo que el consumidor quiere, antes de que éste lo pida, siendo por ello necesaria la investigación, tanto online como offline.

Como indican Martín- Guart y Fernández (2015), se está evolucionando hacia el Marketing 4.0, en el sentido de que "surgen nuevos puntos de contacto con el consumidor, derivados de la interacción con los dispositivos móviles y las redes sociales". En este nuevo marketing "prevalece la predicción y la capacidad de anticipar tendencias, ya que cada marca debe conocer lo que el cliente necesita antes de que lo requiera”.

El entorno económico y social ha cambiado de manera significativa en la última década. El surgimiento de las nuevas tecnologías de la información, su conocimiento y aplicación por parte de las empresas, organizaciones y consumidores ha cambiado la forma de relacionarse de unos y otros. En este contexto, la distribución comercial se enfrenta a un entorno cada vez más cambiante, sofisticado y complejo, que afecta tanto a las economías domésticas como al mercado internacional. 
Como hemos visto a lo largo del análisis realizado en este apartado, no solo ha cambiado el entorno competitivo en el que se mueven las empresas dedicadas al comercio minorista, sino que también se ha producido una modificación en la forma en la que las empresas se relacionan con el mercado.

Esto supone que el comercio detallista también viene sufriendo cambios constantes en una búsqueda de adaptarse a los nuevos paradigmas que se presentan en el mercado. Es por ello que la presente tesis quiere profundizar en el aspecto relacionado con el Valor de Marca de estos comercios puesto que se presenta como un punto importante a la hora de conseguir la competitividad de los mismos, teniendo en cuenta que su relación con el mercado ya no se va a limitar a un punto de venta físico, sino que podrá producirse a través de distintos canales, con lo que se deberá seguir una correcta estrategia para gestionar el Valor de Marca tanto en cada uno de ellos, como de manera conjunta. Debido a esto, en los dos apartados siguientes de esta tesis se abordará la relación y la utilización de las tecnologías de la información y la comunicación por parte del comercio detallista, tanto en el punto de venta físico como fuera de él, así como las distintas estrategias a disposición del mismo a la hora de integrar diversos canales.

El aspecto de las tecnologías de la información se ha tenido en cuenta en la realización del trabajo de campo de la presente tesis, puesto que se pretende ver qué papel pueden jugar en la gestión del Valor de Marca del comercio detallista, puesto que como señalan diversos estudios, como el apuntado anteriormente de la consultora PwC, "Total Retail 2015: las empresas de distribución y consumo en la era de la disrupción", la tecnología marcará dos de los cambios que tendrán efectos disruptivos sobre la industria: por un lado el uso que los consumidores hacen de las tecnologías y, por otro, el posible impacto en las ventas de las interacciones entre usuarios y marcas en las redes sociales. 


\subsection{El comercio detallista y las tecnologías de la información y la comunicación}

El entorno del comercio detallista se ha visto afectado, como otros muchos sectores, por el rápido desarrollo de las nuevas tecnologías de la información y la comunicación. Los cambios acontecidos en los últimos años se suceden a un ritmo tan rápido que en ocasiones incluso se hace difícil estar al día de las últimas tecnologías que van apareciendo.

Las nuevas tecnologías para vender tanto productos como servicios que constantemente irrumpen en el mercado, se hacen cada vez más habituales y disponibles gracias a nuevos sistemas capaces de dar soporte tanto a los consumidores a la hora de hacer su compra, como a los comerciantes para conseguir una información rápida y actualizada sobre las tendencias de mercado y los procesos de venta (Pantano, 2014).

Para Juaneda-Ayensa et al. (2016) el avance de Internet y las nuevas tecnologías en las últimas décadas ha transformado el panorama del comercio minorista. Continuamente están emergiendo nuevos canales, haciendo que el consumidor cambie sus hábitos y su comportamiento de compra.

A pesar de esto, no existe una definición consensuada con respecto a lo que se entiende por tecnologías de la información y la comunicación. Además, no resulta común el que se elabore una definición de las mismas. Así, muchas de las fuentes utilizan de manera indistinta "tecnologías de la información", "nuevas tecnologías", "nuevas tecnologías de la información", "nuevas tecnologías de la información y la comunicación" y sus respectivas siglas: TI, TIC, NTIC (Cobo, 2009).

Para Fernández (2005) las Tenologías de la Información y la Comunicación (TIC) se definen colectivamente como innovaciones en microelectrónica, computación (hardware y software), telecomunicaciones y optoelectrónica - microprocesadores, semiconductores, fibra óptica - que permiten el procesamiento y acumulación de enormes 
cantidades de información, además de una rápida distribución de la información a través de redes de comunicación.

Por su parte, la Fundación Telefónica (2007) apuntaba que las tecnologías de la información y comunicación son aquellas que se necesitan para la gestión y transformación de la información, y muy en particular el uso de ordenadores y programas que permiten crear, modificar, almacenar, proteger y recuperar esa información. Las TICs, como elemento esencial de la Sociedad de la Información, habilitan la capacidad universal de acceder y contribuir a la información, las ideas y el conocimiento. En base a esto, se podría decir que las tecnologías de la información y la comunicación son aquellas herramientas computacionales e informáticas que procesan, almacenan, sintetizan, recuperan y presentan información en diversas formas y formatos. Están compuestas por un conjunto de herramientas, soportes y canales para el tratamiento y acceso a la información, entre los que se encuentran tanto los ordenadores como los sistemas y los programas necesarios para su gestión.

Como señala Deulofeu (2002), aspectos como la globalización, la sociedad de la información, las redes sociales o el comercio electrónico son fenómenos actuales que suponen un reto para la continuidad del comercio detallista de menores dimensiones o, si se prefiere, más tradicional. Por ello, la adopción de las nuevas tecnologías puede resultar imprescindible para su supervivencia, ya que su uso presenta un gran número de posibilidades que pueden favorecer el incremento de la competitividad del comercio (Anderl et al., 2016b).

"Hoy, los compradores incorporan el toque digital en todo el proceso de compra, desde ver los productos en línea en su casa, hasta usar smartphones como asistentes personales de compra en la tienda" (Nielsen, 2016).

En los últimos años los avances en la tecnología han permitido la digitalización del comercio minorista, así como también han supuesto algunos retos para éste. Concretamente, la evolución de los medios interactivos ha hecho que el proceso de venta al 
consumidor sea más complejo (Crittenden et al., 2010; Medrano et al. 2016; Anderl et al, 2016b).

Con la incorporación del canal móvil, tabletas, redes sociales y la integración de estos nuevos canales y dispositivos en el comercio minorista, tanto online como offline, el paisaje ha ido evolucionando, llevando a profundos cambios en el comportamiento del consumidor (Verhoef et al., 2015; Deloitte, 2016; Forrester, 2016).

Así pues, como indica Castells (2009), la incorporación de las nuevas tecnologías se hace de vital importancia para las empresas en un entorno competitivo en el que cobra relevancia la orientación de marketing enfocado en el cliente. Aparecen así nuevas herramientas que permiten la obtención y gestión de datos relativos al comportamiento del consumidor, el cual, a su vez, también ha experimentado cambios en su comportamiento de compra como consecuencia de su uso de las nuevas tecnologías. Todo ello permitirá, por tanto, un mejor conocimiento del consumidor, lo que, a su vez, puede resultar en una mejor adaptación y satisfacción de la oferta de la empresa a sus necesidades.

Por otra parte, las tecnologías de la información y la comunicación también encuentran un ámbito de aplicación en la tienda física (escaparates virtuales, probadores virtuales, terminales interactivos en el punto de venta, menús dinámicos de información o terminales que permitan hacer el pedido para recogerlo en ese mismo instante o con posterioridad), así como códigos QR (Quick Response) que a través de los dispositivos móviles de los usuarios permiten la interacción de la tienda con ellos (Fundación Telefónica, 2016). Innovaciones tales como las gafas que permiten la visión en tres dimensiones o las impresoras 3D todavía llevan más allá la evolución del entorno minorista (Piotrowicz y Cuthbertson, 2014).

Un ejemplo de esta evolución lo vemos en el grupo Inditex, el cual, en los últimos años ha llevado a cabo una importante apuesta por los servicios digitales que le ha permitido desarrollar nuevas experiencias de compra entre sus clientes. Así, las tiendas insignia (flagship store) de Massimo Dutti en el Paseo de Gracia de Barcelona o de Zara en A Coruña, están equipadas con mejoras tecnológicas para adaptarse a las nuevas demandas 
de los consumidores. En esta línea, ambos locales cuentan con probadores interactivos. Las prendas son escaneadas antes de que el cliente entre y éstas aparecen automáticamente en una pantalla integrada en el vestidor. El consumidor puede además pedir un cambio de talla, consultar datos sobre las prendas o incluso pagar productos dentro de este habitáculo. Estas acciones se han puesto en marcha dentro de la estrategia omnicanal del grupo Inditex que pretende conectar el mundo virtual con la tienda física tradicional.

Es tal la evolución de las nuevas tecnologías en el actual entorno competitivo que, como señalan Liang y Zhang (2012) el debate del efecto de las TIC como una de las principales dimensiones en los procesos innovadores de los comercios, se ha incrementado notablemente. Aun así, como señalan Marín y Gil-Saura (2016), a pesar del interés despertado por el concepto de innovación en el comercio detallista, "son pocos los estudios llevados a cabo con el objetivo de aportar luz sobre su naturaleza y alcance".

En relación con los consumidores, el crecimiento del uso de las redes sociales y el acceso a la información a través de dispositivos móviles hace que éstos puedan comprar cualquier cosa en cualquier momento y desde cualquier lugar según indica el estudio del Comercio Global Conectado (2016) realizado por la consultora Nielsen. Es más, incluso les habilita para acceder a la información sobre un producto estando en el propio punto de venta físico, lo que puede tener una influencia decisiva en la decisión sobre la compra, tal y como recoge el Informe La Sociedad de la Información 2015, presentado por la Fundación Telefónica en febrero de 2016. Esto, por tanto, supone un reto a gestionar adecuadamente por el comercio detallista, del cual pueden surgir nuevas oportunidades.

El incremento en el uso de nuevas tecnologías (teléfonos móviles inteligentes, redes sociales, etcétera) y la creciente importancia de las soluciones tecnológicas para el punto de venta crean nuevas oportunidades y retos para el comercio detallista (Piotrowicz y Cuthbertson, 2014; Sanmartin et al., 2015). Para estos autores los cambios vienen propiciados por las nuevas tecnologías, tales como dispositivos móviles inteligentes (tabletas y teléfonos móviles) y los programas de software relacionados con ellos (aplicaciones apps, pago a través de móvil, cupones y publicidad digital o servicios basados en la localización del usuario). Algunos cambios relacionados con las propias 
tecnologías (fácil acceso, coste reducido y acceso a bases de datos y cloud computing) permiten tanto la personalización como la optimización de los precios.

En este sentido son destacables los datos aportado por el informe de Ditrendia (2016), según el cual la penetración de los teléfonos móviles en el mundo ascendió al 97\% en 2015, superando el número de estos dispositivos al número de personas que hay en el planeta. En el caso concreto de España, este informe señala que un $80 \%$ de los españoles tiene un teléfono inteligente (Smartphone), mientras que solo el 73\% tiene ordenador (bien sea de sobremesa o portátil).

En cuanto a la aplicación de las tecnologías de la información en el entorno virtual, para Turban et al. (2008) “el comercio electrónico hace referencia al proceso de comprar, vender o intercambiar productos, servicios e información a través de redes de ordenadores, incluyendo Internet". Desde esta perspectiva, el comercio al por menor ha cambiado de manera significativa en las últimas dos décadas debido al aparición del entono online y la digitalización de la economía y por consiguiente de las empresas. Proceso, que sigue siendo incipiente tanto en los países desarrollados como en los países en vías de desarrollo. En determinados mercados minoristas, el canal online se ha convertido en muy dominante y puede considerarse que ha tenido un desarrollo muy importante (Christensen y Raynor, 2003; Sanmartín et al., 2015) y en algunos casos ha obligado a cambios drásticos en determinados sectores, como el del turismo, o en el de los viajes organizados. En este nuevo entorno dinámico, cambiante, incierto y volátil, muchos modelos de negocios de los minoristas se han visto afectados (Sorescu et al., 2011), ya que el mix minorista ha cambiado y sus clientes se comportan de manera diferente debido a estos desarrollos (Sanmartín et al., 2015).

Las tecnologías relacionadas con el comercio electrónico se consideran como innovaciones que facilitan el crecimiento de las pequeñas y medianas empresas, así como un factor clave para que tengan éxito. A pesar de ello, para la mayor parte de este tipo de empresas, incorporar estas innovaciones se hace difícil debido a sus recursos limitados y a su falta de experiencia (Kurnia et al., 2015; Nielsen, 2016). 
Así pues, para el minorista es importante la gestión de las innovaciones en el sector tecnológico, ya que ello conllevará tanto un mejor conocimiento del consumidor como una mejor gestión del negocio, pudiendo orientarlo hacia la satisfacción de las necesidades de sus clientes, quienes, a su vez, también tendrán más conocimiento de los productos y servicios existentes en el mercado, gracias al constante incremento del uso de estas nuevas tecnologías por su parte (Anderl et al., 2016b; Nielsen, 2016).

Normalmente el comercio minorista se centra en las actividades de venta, siendo un sector orientado al servicio y sometido a continuar innovaciones. Como tal, la participación e implicación del consumidor puede aumentar la calidad del servicio que se le va a prestar. Es por ello importante el grado de aceptación que el cliente tenga con respecto a las nuevas tecnologías en términos de actitud, comportamiento y uso efectivo de las mismas, ya que de ello dependerá la selección que el comercio haga de ellas para su implementación, unido a la inversión económica que puedan requerir (Pantano, 2014). El minorista deberá introducir en su negocio aquellas tecnologías que el consumidor vaya a utilizar habitualmente, así como las que le permitan gestionar la información de cara a detectar tendencias, comportamientos de compra, etcétera (Deloitte, 2016; Geoffney, 2015).

La digitalización de las economías con la llegada de Internet, su difusión y aceptación por la sociedad, ha supuesto uno de los cambios más notables y que más ha impactado en el comportamiento del consumidor. La Red está cambiando la forma de relacionarse con el mercado, con lo que las empresas deben, en algunos casos, incluso replantearse sus modelos de negocio. Las actuales tecnologías digitales (tales como videoconferencias, apps para móviles o realidad aumentada), proporcionan un entorno altamente personalizado que permite la interactividad y enriquece el intercambio de información entre la marca y el consumidor (Parise et al, 2016). Como indican Sexton et al. (2002) en su estudio sobre los factores que influyen en su uso por parte del público, Internet es un medio flexible, interactivo y eficiente que ofrece múltiples servicios de entretenimiento, información, educación, comunicación y comercio, disponibles tanto para las empresas como para los particulares. De esta manera, podemos ver como Internet tiene 
una vertiente enfocada a la comunicación y a la información y otra centrada en la comercialización, la cual, alcanza en la actualidad una sofisticación elevada gracias a las nuevas tecnologías que, por ejemplo, en el caso del comercio detallista online proporcionan herramientas como la realidad virtual, opción de ver los productos desde todas las perspectivas, ampliaciones de los mismos, numerosas posibilidades de personalización e incluso modelos virtuales en tres dimensiones para ver cómo se adapta el producto (Juaneda-Ayensa et al., 2016; Parise et al., 2016; Stein y Ramaseshan, 2016).

Con la aparición de estas tecnologías y de Internet, se le brinda al comercio la posibilidad de ir más allá en su relación con el consumidor, gracias a la interactividad que éstas proporcionan (Anderl et al., 2016a; Juaneda-Ayensa, 2016). Como se ha apuntado con anterioridad, cobra relevancia el marketing electrónico, entendido como aquel que utiliza las redes de telecomunicaciones y las tecnologías para conseguir los objetivos de marketing de la empresa (Rodríguez, 2008).

Cuando el comercio electrónico y las tecnologías asociadas al mismo se manejan correctamente por parte de la empresa, pueden suponerle grandes oportunidades de mejora en aspectos clave del negocio como son las relaciones comerciales, el intercambio de información, la coordinación de la logística y las comunicaciones a lo largo de toda la cadena de distribución (Kurnia et al., 2015).

A pesar de esto, las nuevas tecnologías no sólo se han desarrollado y han permitido el desarrollo del entorno virtual, sino que también pueden estar presentes en el espacio físico del comercio detallista (Stein y Ramaseshan, 2016), ayudando a ofrecer una mejor experiencia del cliente en el punto de venta, tal y como se señala en el informe de Global Powers of Retailing de Deloitte (2016).

Algunos comercios han introducido novedades e innovaciones tecnológicas en sus puntos de venta, tales como grandes pantallas en los escaparates con proyecciones de personas utilizando los productos (sustituyendo a los maniquíes), terminales en el exterior de la tienda que permiten hacer pedidos incluso fuera del horario de apertura, probadores 
virtuales que permiten ver cómo quedaría el producto en el cliente, sin necesidad de ponérselo físicamente, etcétera (Pantano, 2014).

En el comercio minorista físico, a medida que los detallistas se enfrentan a la creciente competencia por parte de competidores de e-commerce como Amazon, Privalia, Primeriti, Venta Privee y otros, la señalización digital en el punto de venta se convierte en un punto clave para incrementar sus ventas (Roster, 2012).

En esta línea de investigación, Roggeveen et al. (2016) analizan el impacto que los displays o pantallas digitales (digital signage) tienen en las ventas de tipologías diferentes de comercio minorista, llegando a la conclusión de que las ventas en el formato de hipermercado mejoran con la instalación de estos dispositivos. Sin embargo, en los supermercados tiene un efecto mínimo en los resultados, mientras que en los comercios de pequeño formato (como tiendas de conveniencia) los displays tienen un efecto negativo. También señalan que estos dispositivos resultan más eficaces para el incremento de las ventas cuando el mensaje que contienen hace relación a la promoción del precio de los productos.

Además, también en el punto de venta se pueden aplicar las tecnologías de autoservicio, consistentes en dispositivos que permiten al consumidor colaborar en la producción del servicio, de manera independiente al servicio directo que puedan prestar los empleados del establecimiento (Kallweit et al., 2014).

Ejemplos de estas tecnologías de autoservicio son las cajas de pago automáticas, los terminales para hacer pedidos o los quioscos multimedia, tal y como señalan Wang et al. (2015). Estos autores destacan la evolución que las tecnologías están teniendo en los últimos tiempos, ya que se da una creciente aplicación de las mismas para ofrecer información a los usuarios y mejorar la provisión de servicios personalizados, más allá de su aplicación sólo a la ejecución de transacciones en el punto de venta.

Así, las tecnologías de autoservicio de la información hacen a los clientes más independientes respecto a los vendedores y reducen sus costes de búsqueda ofreciéndoles 
la información necesaria y de manera más personalizada (Pantano, 2014), lo cual es especialmente relevante en el caso de productos complejos que puedan requerir de una explicación adecuada y que conlleven un mayor riesgo de compra. En este sentido, tal y como indican Kallweit et al. (2014) son tecnologías especialmente útiles para minoristas con grandes espacios de venta y un relativamente bajo número de vendedores, como es el caso del segmento de las tiendas de bricolaje o do-it-yourself.

Los canales de distribución en general han vivido una importante modernización como consecuencia de la adopción de las nuevas tecnologías, el uso de las cuales proporciona importantes ventajas a los modernos comercios detallistas frente a aquellos más tradicionales que no están haciendo uso de ellas. De esta forma, además del ya citado Internet, el minorista puede aprovecharse de tecnologías que contribuyen a incrementar su competitividad puesto que mejoran la gestión de inventarios, ahorran tiempo en la realización de tareas, permiten un mejor control de las operaciones de venta, facilitan el conocimiento del cliente, etcétera (Singh, 2014).

Además, según el informe "The Digital Consumer" de la empresa de consultoría Nielsen (2014) casi el 87\% de los propietarios de dispositivos móviles (tabletas, teléfonos inteligentes, etcétera) los utilizan como parte de sus experiencias y actividades de compra. No solo esto, sino que, además, el último informe "Economía móvil" de esta misma consultora, realizado a nivel mundial entre el 1-23 de marzo de 2016, y cuyos resultados han sido publicados en octubre de ese mismo año, una cuarta parte (24\%) está totalmente dispuesto a comprar ya con su móvil. También según el Informe Ditrendia: Mobile en España y en el Mundo (2016), en España el 80\% de los usuarios de Smartphone utilizan el móvil para investigar sobre productos y, además, un $25 \%$ de los usuarios con smartphone realiza ya compras con este dispositivo, siendo casi dos de cada tres compradores los que efectúan este tipo de compras al menos una vez al mes. Esto es importante, ya que el comercio detallista puede hacer uso de aplicaciones para dispositivos móviles (apps) que ayuden a crear experiencias en el punto de venta.

Como se puede apreciar, la aplicación de las nuevas tecnologías, tanto en el punto de venta físico como fuera de él, supone una serie de retos y de ventajas para el comercio 
minorista que deberá ser capaz de adaptarlas si quiere mejorar su competitividad, siempre teniendo en cuenta las características y necesidades de su negocio y de su público, tal y como señala el informe de Nielsen, El comercio global conectado (2016). En este sentido, como dicen Pantano y Viassone (2014), comprender las expectativas de los consumidores y de los comercios cobra especial importancia para el éxito de la adopción y la difusión de las innovaciones.

En esta línea, tal y como señala Verhoef (2009) y como refrenda el Estudio Global del Comercio Interconectado (2016), en el comercio detallista moderno la creación de experiencias del cliente memorables se ha convertido en un objetivo principal de cara a la diferenciación del resto de competidores y a intentar conseguir la lealtad de sus clientes. La incorporación de las nuevas tecnologías en la gestión del comercio puede contribuir a la generación de estas experiencias, tanto en el entorno físico tradicional como en el virtual e incluso puede servir de puente entre ambos, eliminando posibles barreras entre distintos canales y ayudando a crear experiencias del cliente desde un punto de vista holístico.

La relación de las tecnologías de la información y la creación de experiencias para el consumidor se analizan con más profundidad en el punto 4.3 de la presente tesis, si bien aquí queremos destacar la utilidad de éstas a la hora de contribuir a la creación de experiencias que aporten valor a los clientes del comercio minorista.

Profundizando en la aplicación de las tecnologías de la información por parte del comercio de venta al detalle, señalan Kang et al. (2015) que las aplicaciones para móviles desarrolladas por el detallista conectan el canal móvil con la experiencia del cliente en el punto de venta, ofreciéndole herramientas de planificación que le ayuden a tomar decisiones de compra y generando tráfico hacia el punto de venta, apoyándose en aplicaciones (apps) de localización, tal y como también recogen el Informe de Ditrendia: Mobile en España y en el Mundo (2016) y Estudio Global del Comercio Interconectado (2016). El consumidor utiliza estas apps para navegar y buscar productos, ofertas, cupones u otras ofertas promocionales, así como para comprar productos una vez ha realizado su búsqueda en el punto de venta. Además, La geolocalización permite aproximar comercios y establecimientos que se encuentren cerca de la ubicación del usuario móvil y le posibilita 
tomar decisiones con rapidez. Según Kang et al. (2015), algunos comercios detallistas multicanal desarrollan promociones basadas en estas aplicaciones para enviar notificaciones a sus clientes cuando se detecta que éstos están dentro o cerca del establecimiento comercial.

Así, las aplicaciones móviles se han ido introduciendo por algunos minoristas con fines comunicativos y promocionales o para que el consumidor pueda localizar el establecimiento físico más próximo a su ubicación actual o incluso para calcular en tiempo real el coste de los productos que está seleccionando en el punto de venta. Como ejemplo, la marca de lujo Tiffany ha desarrollado una aplicación móvil que permite elegir un anillo, probárselo virtualmente y compartirlo en las redes sociales, a la vez que posibilita la opción de concertar una cita con un punto de venta físico para poder realizar la prueba de ese producto en la misma tienda (Pantano, 2014).

Estos ejemplos de adopción de las tecnologías de la información y la comunicación deberían ser tenidos en cuenta por el comercio minorista más tradicional, puesto que, según la investigación de Wang et al. (2015) llevada a cabo en el segmento de tiendas de alimentación, el comportamiento de compra de los consumidores que adoptan las tecnologías de compra a través de dispositivos móviles cambia, dando mejores resultados para el comercio, ya que en sus conclusiones se observa que el número de pedidos por año aumenta. No sólo eso, sino que, además, el importe de cada compra también se incrementaba a medida que el consumidor se acostumbraba a la "compra móvil". La tendencia de compra de estos clientes era la de usar los dispositivos móviles para comprar productos con los cuales ya tenían un historial de compras, es decir, para productos que ya conocían.

En este sentido, Amazon ha decidido entrar en el sector de la venta de productos de alimentación, aspecto que venía ya realizando en Estados Unidos y que en septiembre de 2015 empezó en España y un año más tarde, en septiembre de 2016 ha decidido redoblar su esfuerzo en este sector, ofreciendo productos frescos, y aliándose para ello con proveedores estratégicos como son la cadena de supermercado Dia, la web de vinos Lavinia y el Mercado de la Paz de Madrid, y con un servicio de entrega ultrarápido Prime 
Now. De momento este servicio, con un catálogo de 7.000 productos, lo ofrece solo en Madrid capital, aunque espera ampliar esta experiencia en otras ciudades pronto.

Sin embargo, para el comercio tradicional no siempre resulta asequible el satisfacer completamente las necesidades de sus clientes debido, entre otros problemas, a la dificultad para ofrecerles los productos más adecuados, no tener siempre el stock suficiente en su almacén, falta de preparación o profesionalidad del personal o incluso que el cliente tenga que hacer colas para pagar su compra.

Tal y como se ha comentado anteriormente, muchos comercios con presencia física ven Internet como una herramienta para crecer dirigiéndose a nuevos mercados, principalmente en el sentido geográfico (Roster, 2012; Cao y Li, 2015; Parise et al., 2016). Utilizar las nuevas tecnologías de la información y comunicación para llegar a mercados lejanos no es siempre la única opción. A veces ni siquiera es una buena opción, ya que la mayor parte de pequeños comercios o de negocios locales no suelen estar preparados para competir en este nuevo escenario más amplio. Parece lógico pensar que si no se es competitivo en el propio mercado natural difícilmente lo será en otros mercados más lejanos donde la logística y la confianza juegan un papel importante. Frente a esta opción, ya con el cambio de siglo y el progresivo asentamiento de las nuevas tecnologías, apuntaban Steinfield et al., (1999) que Internet podía servir también para fortalecer la posición de una empresa en su ámbito local, es decir, en su mercado local habitual. En este sentido, una opción a tener en cuenta es el desarrollo de estrategias online diseñadas para crear sensibilización del cliente hacia el aspecto físico (Cao y Li, 2015; SanMartin et al., 2015).

El avance de Internet y las nuevas tecnologías en la última década ha transformado el panorama del comercio detallista. Más y más canales están emergiendo, provocando que los consumidores cambien sus hábitos y su comportamiento de compra. Una estrategia omnicanal es una forma de comercio detallista que, permitiendo la interacción real, da al consumidor la oportunidad de comprar a través de distintos canales en cualquier momento y lugar (Juaneda-Ayesa et al., 2016). 
De esta manera, se aprecia como el coste de tener presencia en la web es relativamente bajo y una vez en ella, cualquier empresa de cualquier parte del mundo puede parecer como si estuviese situada al otro lado de la calle. En ocasiones parece que sea relativamente sencilla la creación de una presencia en Internet que permita la realización del comercio electrónico y llegar de una manera rápida a un mayor número de mercados y consumidores (Herhausen et al., 2015). No se tiene en consideración, muchas veces, la necesidad de una infraestructura física y de una logística y gestión que permitan realizar las acciones necesarias para entrar en el nuevo canal de distribución con posibilidades de éxito. Allred et al. (2007) destacan la importancia de la planificación para el éxito del pequeño comercio, calificándola como esencial, a pesar de que, como indican los datos de su estudio, la mayor parte de directivos de este tipo de empresas dedican más tiempo a la planificación informal que a la realización de una planificación formal por escrito.

Además, a la hora de potenciar el comercio detallista con presencia física, hay un aspecto importante en juego como es el carácter hedónico de la compra. Determinados estudios (Gil y Ruiz, 2012) revelaban que en un proceso de compra de marcado carácter hedónico, el uso de aplicaciones tecnológicas por parte del minorista con una finalidad utilitarista parece contribuir escasamente a la mejora de la experiencia de compra del cliente. Como se verá en el apartado siguiente del presente trabajo, tal y como señalan estos autores, algunos modelos de negocio y estrategias del comercio detallista pasan por la integración de los distintos canales que utilice, para fortalecer su competitividad aprovechando las características particulares que le ofrece cada canal y que pueden colaborar a la creación de una mejor experiencia de compra para sus clientes.

En este punto, el comercio físico o comercio local es conocedor de las características de su mercado y de su cliente, con lo que una opción de la utilización de las tecnologías de la información y la comunicación puede ser la adaptación del producto y de los servicios prestados a las características de su mercado local. Estaríamos así ante lo que Porter (2001) denomina marketing hecho a medida del cliente a través del conocimiento de su perfil, cuando habla de cómo Internet puede influir en la cadena de valor de la empresa. 
Esto se debe, en gran parte, a la interactividad personal que supone el comercio físico tradicional. El contacto (físico u online) con el cliente ayuda a su mejor conocimiento. Ahora bien, la interactividad persona a persona tiene unas características que la diferencian de la interactividad a través de Internet, ya que aquella permite obtener una información extra gracias a la observación directa de aspectos como la gesticulación, la entonación, lenguaje corporal e incluso, quizás, el contacto a través del sentido del tacto (Florenthal et al., 2010).

La aparición de Internet supuso, por tanto, un cambio en el concepto de interactividad. Se debe distinguir entre la interactividad física y la interactividad online y se debe tener presente que ésta no se produce únicamente en las relaciones en Internet, a pesar de que, en los últimos tiempos, cuando se utiliza este término suele hacerse, casi siempre, en relación a su aspecto online.

La interactividad que proporcionan los distintos canales no tiene por qué suponer una oposición o enfrentamiento entre ellos. Más bien al contrario, cada vez parece más importante la oferta de productos y servicios a través de varios canales a los clientes (Herhausen et al., 2015; Cao y Lin, 2015). Es por esto que muchas empresas abandonan sus modelos de negocio con un único canal, como son las empresas de venta por catálogo o los detallistas de tiendas físicas, para pasar a estrategias multicanal o cómo señalan autores como Verhoeff et al (2015), la venta minorista multicanal se está moviendo hacia la venta minorista omnicanal, donde se busca una mayor integración de producto, servicio, precio, comunicación y gestión de relaciones con los clientes desde una perspectiva más ecléctica, lo que afectará la forma en que operan los minoristas y a sus resultados.

Dentro de este contexto, la empresa minorista debe decidir cómo y para qué puede y quiere hacer uso de las nuevas tecnologías de la información y comunicación, siempre respetando la coherencia con las estrategias que esté utilizando para competir en el mercado. En este entorno cambiante cobrará especial importancia la rapidez con la que la empresa sea capaz de reaccionar y adaptarse al mismo. Para ello será necesario la correcta gestión de los datos y de la información que pueda manejar, así como las distintas formas y 
medios a través de las cuales pueda conseguir dicha información e incluso transmitirla a sus mercados y clientes (Rodríguez, 2008).

Así, vemos la importancia que la rápida adopción de las tecnologías de la información y la comunicación puede tener para el pequeño comercio detallista, tanto para la gestión del mismo de la forma más eficiente posible, como para detectar nuevas oportunidades en un mercado en constante evolución (Fundación Telefónica, 2016; Deloitte, 2016; Mastercar, 2016).

En general, se aprecia que este tipo de comercios tiene importantes problemas para llevar a cabo este cometido: no siempre tienen personal con la formación adecuada, el precio de estas herramientas no siempre es accesible e incluso en ocasiones, no se da un planteamiento estratégico de la empresa que contemple la importancia de estas tecnologías de cara al medio y largo plazo, ya que, muchas veces, el pequeño comercio no tiene, ni siquiera, una planificación a medio plazo y sus acciones suelen plantearse siempre mirando al futuro más cercano, como consecuencia de problemas que se van planteando en el día a día (Guillén, 2007).

Como apunta Keller (2010) la multiplicidad de canales y medios de comunicación de marketing supone también un esfuerzo de gestión para las empresas de venta minorista. Así, éstas deberán gestionar cada uno de los distintos canales y opciones de comunicación de manera que se maximicen no solo sus ventas directas, sino también los efectos sobre su valor de marca, tanto directos como indirectos que le pueden suponer el que se le asocie con un determinado canal. Los distintos medios de contacto con el cliente deberán ser diseñados y gestionados de forma que se puedan aprovechar las sinergias creadas entre ellos de cara a la mejora de sus resultados.

En este contexto, a medida que crece el comercio electrónico y el uso de nuevas tecnologías de la información y la comunicación, su impacto en los comercios locales e incluso en las comunidades en las que éstos se encuentran, es mayor (Steinfield, et al., 1999, Bell et al., 2014) o como también recogen informes más recientes como el de Forrester (2016) y el de la Sociedad de la Información en España 2015. El comercio local o 
comercio con presencia "física", normalmente intenta aumentar su competitividad usando Internet para acceder a mercados lejanos. El razonamiento para ello suele ser que, si sus competidores están entrando en su mercado local gracias a Internet, él también puede hacer lo mismo, es decir, puede utilizar el comercio electrónico para acceder a otros mercados. Como ya apuntaban estos autores, los comerciantes locales podrían explotar las sinergias generadas entre su presencia física y su presencia en la web, entre otras cosas para mejorar el aspecto de la confianza, ayudar a los consumidores a gestionar el riesgo de la compra, ofrecer diversidad de preferencias de compra y, en general, aprovechar las ventajas complementarias que ofrecen los aspectos físicos y virtuales.

Así, según datos obtenidos del Observatorio Nacional de las Telecomunicaciones y de la Sociedad de la Información (ONTSI), solo el 18\% de las pequeñas empresas (de 10 a 49 empleados), ha manifestado haber realizado ventas a través comercio electrónico (ONTSI, 2016).

De acuerdo con lo indicado, la dotación de algunas infraestructuras tecnológicas por parte de los establecimientos de comercio minorista en España, aunque ha mejorado notablemente en los últimos años, es aún baja en comparación con otros sectores (ONTSI, 2016), a pesar de que son muchas las aplicaciones que se pueden implantar en las tiendas: tecnologías para la gestión de clientes, gestión integral del negocio, tecnologías de respuesta rápida, datos de punto de venta, códigos universales de producto, medios de pago a través de las tecnologías de la información y la comunicación (pago vía teléfono móvil, internet o transferencia bancaria) o tecnologías de autoservicio, entre otras (Weber y Kantamneni, 2002; Liljander et al., 2006; ONTSI, 2008; Parise et al., 2016, Fundación Telefónica, 2016).

A esto habría que añadir que, según datos obtenidos del Observatorio Nacional de las Telecomunicaciones y de la Sociedad de la Información (ONTSI), solo el 18\% de las pequeñas empresas (de 10 a 49 empleados), ha manifestado haber realizado ventas a través comercio electrónico (ONTSI, 2016). 
Este mismo informe indica que sólo el 20.1\% del total de las empresas españolas ha realizado ventas a través de internet durante el periodo 2013-2016. De ellas, si analizamos según el tamaño de empresas, son las de más de 249 empleados las que más venden mediante comercio electrónico con un 39,8\%. Mientras que en las empresas de 50 a 249 empleados este porcentaje alcanza un 29\%. Por último, en las empresas pequeñas, de 10 a 49 empleados, sólo un $18 \%$ ha manifestado haber realizado ventas a través comercio electrónico. De esta forma, la realización de ventas de este tipo es más intensa en las empresas grandes, de más de 249 empleados, estando 10,8 puntos porcentuales por encima de las de 50 a 249 empleados. A su vez, las de 50 a 249 empleados están 11 puntos porcentuales por encima de las de 10 a 49 empleados.

A la vista de estos datos, parece que el pequeño comercio hace poco uso de las nuevas tecnologías para aumentar su competitividad, ya que generalmente las asocian a herramientas propias de empresas de mayor tamaño.

Sin embargo, nos encontramos con estudios que nos señalan las ventajas de las aplicaciones tecnológicas en términos de ganancia en eficiencia de los procesos internos de la empresa y mejora en el servicio ofrecido al cliente (Gil y Ruiz, 2012). Así, desde el punto de vista de la empresa minorista, la aplicación de las tecnologías de la información y la comunicación ofrece una serie de beneficios para el comercio, entre los que se encuentran los siguientes: ahorro de tiempo, ahorro de gastos de personal, fiabilidad, exactitud, reducción de errores, mejora en la gestión del inventario, mejora de la productividad a través de la mecanización de tareas intensivas en mano de obra, etcétera. (Herhausen et al., 2015; El-Adly y Eid, 2016).

Desde el punto de vista del cliente, las aplicaciones tecnológicas del minorista permiten ahorrar tiempo de compra, al poder disponer de un mayor surtido y realizar las compras en un único viaje (Parise et al., 2016). Adicionalmente, la superior eficacia en los procesos internos de la empresa repercutirá positivamente en un mejor servicio al cliente (Gurau y Ranchhod, 2002; Cao y Li, 2015). Las tecnologías de la información y la comunicación pueden contribuir asimismo a crear un ambiente agradable y aportar elementos tangibles al servicio prestado por el minorista, facilitando las inferencias 
positivas acerca de la calidad de la tienda (Stein y Ramaseshan, 2016). Sin embargo, cabe plantearse si las mejoras en el servicio son percibidas por el cliente y si se traducen en una mayor satisfacción (Bitner et al., 2002).

Por otra parte, la inversión en tecnología puede representar un coste importante para la empresa minorista, especialmente si se trata del pequeño comercio independiente. Adicionalmente, algunos estudios alertan de los peligros de invertir en exceso en tecnología (Sethuraman y Parasuraman, 2005). Con el fin de determinar el nivel de tecnología adecuado, la satisfacción del consumidor ha sido considerada como una variable fundamental (Gil et al., 2008a y 2008b). En este sentido, señala Gaffney (2016) que es el consumidor y no el canal quien ha definido y continuará definiendo lo que es el comercio minorista.

Por otra parte, la actual sociedad de la información y el conocimiento afecta de diversas maneras al comercio detallista, empezando por el hecho de que las nuevas tecnologías han supuesto el cambio de las barreras geográficas existentes (Fundación Telefonica, 2016, Cao y Li, 2015). Como indican Deepa y Chitramani (2013) la economía digital permite a los consumidores acceder a productos y servicios mediante los medios digitales, pero, a su vez, también suponen una oportunidad y un reto para los comercios detallistas en cuanto a la construcción de su marca. En este escenario, crear y comunicar una marca puede ser más complicado para los comercios detallistas multimarca que para los que únicamente comercializan una sola marca. Aun así, la creación de marca es igualmente esencial para ambos tipos de comercio.

Es por esto que el presente trabajo trata de analizar la importancia que el Valor de Marca tiene para los minoristas, incluyendo en el modelo para su análisis la experiencia del cliente con el comercio, así como también la situación de éste con respecto al uso de las nuevas tecnologías de la información y la comunicación para mejorar su competitividad en y su efecto en la satisfacción del consumidor final. Para ello, se hará una revisión de diversos estudios publicados hasta la fecha y relacionados con esta temática, de manera que se intentará destacar aquellos aspectos que pueden ser de utilidad al comercio al por menor a fin de mejorar su competitividad. 
Por otra parte, y a pesar de lo apuntado en las últimas líneas, tampoco es habitual que el pequeño comercio local independiente tenga en cuenta el aspecto o la posibilidad de ofrecer nuevos servicios a través de estas nuevas tecnologías, así como tampoco las usan para realizar acciones en la web dirigidas a generar atracción hacia el punto de venta físico (Informe ONTSI, 2016). Sin embargo, el comercio detallista formado por canales franquiciados o por cadenas de minoristas sí que tiene más presente estas posibilidades.

Como apuntan Pauwels et al. (2011) en su estudio sobre las relaciones entre el canal online y el canal físico, el efecto de una página web únicamente informativa (es decir, que no de opción de compra online) sobre las ventas en el canal físico o tienda tradicional, depende en gran medida de la categoría del producto y de sus características, así como del segmento del mercado al que se dirige. Los autores del estudio comentado también destacan que las ventas en el comercio físico se ven incrementadas en mayor medida en los casos de clientes que visitan con mayor asiduidad la página web informativa del comercio.

Se debe tener en cuenta este aspecto, ya que Internet es una herramienta de marketing que puede llegar a ser muy útil para el comercio detallista como instrumento de comunicación, ya que es el lugar al que acuden los consumidores para buscar información, con lo que la empresa también puede plantearse educarlos en lo que se refiere a los productos y servicios que les presta (Informe Deloitte, 2016).

Tanto si el comercio tradicional se decide por tener una presencia virtual en la que ofrezca opción de compra, como si únicamente tiene una página web informativa, no se deberá perder de vista que el consumidor moderno no persigue sólo la realización de una compra, sino que va más allá, buscando experiencias en su relación con la empresa (Informe Deloitte, 2016; Verhoef et al., 2009).

En este sentido, la web del comercio ofrece la posibilidad de interactuar gracias a diferentes tecnologías, teniendo como objetivo en muchos casos atraer la atención del consumidor y dirigirlo hacia la realización de la compra (Cho, 2015). 
En cualquier caso, independientemente de la opción elegida por el comercio detallista con respecto a su presencia online, tal y como apuntaban Verhoef et al. (2009) y que también aparece reflejado en el Informe de Deloitte (2016), sobre el poder global del comercio y el informe de Nielssen (2016) sobre el comercio global conectado, no se podrá perder de vista que uno de sus objetivos prioritarios deberá ser siempre el ofrecer experiencias al cliente (Informe Deloitte, 2016).

Cuando se habla de la interacción con el cliente en el medio virtual, cobra especial relevancia el concepto de flujo, entendido como todo el entorno sensorial que envuelve al usuario con el servicio del canal electrónico y con la calidad de la página web (Cho, 2015).

Puesto que la búsqueda en la Red no sólo se limita a la página de un determinado comercio, es lógico pensar que también pueden producirse ciertos efectos no tan positivos. Así, Van Nierop et al. (2011) destacan que pueden darse ciertas consecuencias negativas si se considera que la información online hace a los clientes más eficientes en sus compras, con lo que harán menos visitas a los comercios físicos y se verá reducida la posibilidad de realizar más ventas cruzadas. Aunque también existen estudios como el de Herhausen et al., (2015) que nos dicen que la omnicanalidad no produce canibalización sino la consecución de ventajas competitivas y sinergias entre los canales off y on que mejoran o pueden mejorar los resultados de las empresas.

Por otra parte, la disponibilidad de distintos canales de contacto con el cliente también puede tener sus efectos, además de en el aspecto de la confianza, en el caso de no poder suministrar de inmediato un producto por falta de stock de la empresa en un momento determinado (Sanmartín et al., 2015). Cuando una empresa no dispone de un producto en su almacén para hacer frente a un pedido del cliente, esto, lógicamente, afectará de manera negativa a la percepción que éste tenga de la primera. Además, es posible que, al no encontrar lo que busca o, mejor dicho, al no poder adquirir el producto de manera inmediata, se dirija a la competencia buscando una alternativa para realizar su compra. Esto implica, como señalan Bendoly et al. (2005) que una rotura de stock del comercio puede tener consecuencias para la empresa, tanto de inmediato como a largo plazo. Los autores apuntan que el impacto inicial y posterior de la falta de producto en la 
decisión de compra y la magnitud de los efectos negativos, se ve amortiguada cuando los clientes perciben que los distintos canales a través de los que interactúan con la empresa están integrados y coordinados (Gaffney, 2016). Así, en su estudio llegan a la conclusión de que la percepción por parte del cliente de altos niveles de integración entre el comercio físico y la tienda online supone mayores niveles de lealtad y un mayor aprecio por las empresas que hacen que la coordinación sea lo suficientemente clara y transparente para los clientes.

Como indican Biyalogorsky y Naik (2003) Internet no sabe de barreras geográficas y los comerciantes detallistas no pueden impedir el acceso de los consumidores a la Red. Esto limita a los minoristas respecto al control ejercido en los canales tradicionales y hace que la competencia del nuevo canal en Internet sea mucho más severa.

Más allá de posibles amenazas, como se ha visto a lo largo del presente epígrafe, las nuevas tecnologías de la información y la comunicación cobran especial importancia a la hora de gestionar el comercio minorista. La gran cantidad de información que pueden proporcionar al comerciante debe ser gestionada de manera correcta, ya que puede suponer la consecución de ventajas competitivas. Además, estas tecnologías pueden suponer una opción para que el comercio con presencia geográfica limitada pueda llegar a otros mercados distantes o incluso a otros segmentos. A su vez, también tienen su aplicación en el punto de venta físico, ayudando a crear una mejor experiencia del cliente.

Ante esta situación a la que es enfrenta el sector detallista, en el siguiente punto se plantearán diferentes opciones según las cuales se puede gestionar la presencia del comercio minorista en distintos canales. Se analizará el punto de vista de los deseos y necesidades del consumidor con respecto a los mismos, así como la perspectiva del comerciante, teniendo en cuenta cuál es su modelo de negocio, incluso cuál debería ser en función de los distintos canales en los que se considere que debe estar presente, así como posibles limitaciones y barreras a la hora de implantar nuevas tecnologías. 


\subsection{Comercio detallista tradicional y comercio online: estrategias de integración}

Como hemos visto en el punto anterior, las nuevas tecnologías de la información y la comunicación permiten al comercio detallista la posibilidad de tener presencia no solo en un establecimiento físico, sino también en otros canales. Ante este nuevo escenario el comerciante deberá decidir cómo quiere competir en lo que se refiere a estar en contacto con el consumidor en un abanico de posibilidades que van desde la utilización de un único canal hasta la presencia en todos los disponibles.

A la hora de gestionar su presencia en diversos canales, son varias las opciones que se plantean para el comercio detallista. La aparición de Internet supuso un punto de inflexión importante para este sector, ya que hasta la fecha la presencia de tiendas físicas era lo habitual, junto con otros canales como la venta a domicilio o la venta por catálogo. Así, con la llegada de las nuevas opciones que facilitaban las tecnologías de la información y la comunicación, el minorista empezó a plantearse cómo y dónde quería competir.

En este punto de la tesis se van a analizar las distintas opciones que el comercio detallista tiene con respecto al entorno online, desde su presencia únicamente en este canal o en el canal físico, hasta la gestión de la presencia del mismo en diversos canales. La presencia multicanal u omnicanal según recientes estudios (Verhoeff et al., 2015) del comercio detallista ha sido analizada por diversos autores desde el punto de vista académico y se pretende reflejar en este apartado las distintas opiniones que al respecto han sido elaboradas en los últimos años.

Para Pookulangara et al. (2011), la modificación en el comportamiento de los consumidores y la llegada de las nuevas tecnologías han cambiado el sector minorista. Con consumidores cada vez más proactivos en sus decisiones de compra y mejor educados sobre los productos, con la posibilidad de comunicar a otros sus ideas sobre el valor de una empresa y sus servicios a través de Internet, se encuentran preparados para cambiar de un canal a otro, así como de un detallista a otro si no están contentos con los que se les está ofreciendo. De esta manera, los consumidores cambiarán de canal o de minorista en 
función de los beneficios de compra que perciban. Para un comercio detallista será, por tanto, crucial, tal y como señala Madlberger (2006), no solo conocer los costes y beneficios asociados a los distintos canales, sino también desarrollar una arquitectura de canales optimizada, dirigida a ofrecer al consumidor el canal óptimo, sin tener que esperar a que sea éste quien elija. En este sentido Gaffney (2016), en el Informe que desarrolló la multinacional Mastercard (2016) sobre el consumidor omnichannel, muestra que los clientes son más inteligentes y más propensos a permanecer con las actuales opciones de venta al por menor. Sin embargo, para los minoristas significa que la retención de clientes se ha convertido en un objetivo crítico, debido al incremento de opciones de las que dispone el consumidor actualmente, y el "marketing de compromiso" se ha convertido en la nueva estrategia a seguir, a través de la generación de engagement, y confianza, y la consecución de lealtad y la creación de afinidad.

En el entorno actual se aprecian diversas opciones mayoritarias seguidas por el comercio detallista. Así, se pueden encontrar empresas que únicamente tienen presencia física o, como se les denomina en inglés brick and mortar, otras únicamente operando en Internet, algunas de venta por catálogo, otras que combinan la presencia física con el canal online (también llamadas empresas click and mortar), etcétera, hasta las últimas tendencias que hablan no ya de empresas multicanal, sino de empresas omnicanal, es decir, presentes en todos los canales disponibles (Massimo et al, 2013; Herhausen et al., 2015; Verhoeff et al., 2015).

Como lo más habitual suele ser que la empresa tenga presencia como mínimo en un par de canales, sea cual sea la opción que se elija, ésta deberá ser consciente de la necesidad de planteares un modelo de negocio adecuado, así como de realizar una gestión que contemple los distintos canales como un todo que no deberían ser considerados como partes distintas de una misma empresa (Herhausen et al., 2015). En el presente apartado se pretende hacer un análisis de cuáles son las diferentes alternativas que se presentan al comerciante, así como las posibles ventajas y desventajas de cada una de ellas.

En el camino que va desde la ausencia de integración de canales a la completa integración, los detallistas, con bastante frecuencia, realizan una integración asimétrica, es 
decir, no comercializan ni ofrecen los mismos productos y servicios en todos los canales. De hecho, algunos autores como Zhang et al. (2010) defienden que el canal online ofrezca un surtido más amplio, ya que sus costes a la hora de gestionarlo son menores.

En este sentido, algunos autores (Anderson, 2004 y 2006; Emrich et al., 2014; Verhoeff et al., 2015), entienden que el canal online puede servir para la venta de los productos que constituyen el longtail de las empresas, es decir, aquellos productos de baja rotación, pero que aún se encuentran en su cadena de producción o en su cartera de servicios. Incluso autores como Emrich et al., (2014), examinaron el efecto relativo de los surtidos que se superponen a través de los canales online y offline de un minorista. Específicamente, examinaron la no integración completa de canales (es decir, la misma empresa ofrece diferentes surtidos on y offline) la integración completa o total (es decir, ofrecen los mismos surtidos on y offline), y la integración asimétrica (es decir, un canal lleva todos los artículos del otro canal, así como productos o surtido adicional). Para ello realizaron dos experimentos a gran escala para comprobar la sinergia que se producía entre la venta off y online, y evaluar los beneficios percibidos de las compras de los clientes y sus intenciones de recomendación. En su investigación, encontraron que la integración total prevalece sobre la no total, pero la integración total no siempre es superior a la integración asimétrica. La integración completa aumenta de manera notable las intenciones de recomendación de la clientela de los minoristas de línea limitada cuyos surtidos tienen una alta profundidad de artículos que pueden canibalizarse o sustituirse unos a otros (por ejemplo, distintos tipos de reproductores de DVD). En comparación con la integración asimétrica, la integración completa es menos efectiva para los minoristas de línea amplia, cuyos surtidos tienen una gran amplitud de productos con relaciones complementarias (por ejemplo, un reproductor de DVD y una película de DVD). Por lo tanto, para dichos autores, la teoría de la larga cola funciona mejor para los detallistas que venden online líneas de productos con mayor profundidad que aquellos que presentan mayor amplitud de sus líneas de productos, pero con menor profundidad.

En los primeros años de la aparición de Internet en el comercio, algunos negocios detallistas no se lanzaron de inmediato a la utilización de este nuevo canal por miedo a que 
sus actividades online pudieran afectar de manera negativa a sus resultados en el canal tradicional. Ante un nuevo entorno algunas empresas se mostraron reticentes a la incorporación de un canal que hasta entonces desconocía.

Alba et al. (1997) ya destacaban el temor de las empresas a que sus actividades a través de la Red pudieran canibalizar sus negocios fuera de ella y afectar de manera negativa a sus resultados.

Como indican Huang et al. (2016), de acuerdo con la literatura existente sobre la compra multicanal, la introducción de un nuevo canal podría influir en el comportamiento de compra del consumidor de dos maneras. Por una parte, el nuevo canal puede atraer la atención del consumidor, corriendo las ventas del canal existente el riesgo de ser canibalizadas (Deelersnyder et al, 2002). Por otra parte, el nuevo canal, como canal adicional de distribución, puede aumentar la disponibilidad del minorista (Pauwels y Neslin, 2015), así como generar un efecto mutuo positivo que realce los servicios que éste ofrece, tanto en el nuevo canal como en el existente (Neslin y Shankar, 2009).

El efecto de canibalización tiene más posibilidades de producirse cuando el nuevo canal ofrece características más atractivas para facilitar los objetivos de compra del público objetivo (Deelersnyder et al, 2002).

Las aproximaciones de las empresas a este nuevo medio electrónico eran más bien cautelosas, a pesar de que, estudios como el de Biyalogorsky y Naik (2003) llegaban a la conclusión de que las ventas a través de Internet no canibalizan de una manera importante a las ventas realizadas a través de medios offline o tradicionales y, por el contrario, las acciones de la empresa en la web ayudan a la generación de valor en el largo plazo.

Verhoeff et al., (2015) señalan que las actuales investigaciones sobre la multicanalidad de las empresas avanzan en tres sentidos hacia una mayor integración de planificación, objetivos, estrategias y acciones, que llevan de la multicanalidad a la omnicanalidad. Estas tres vías de trabajo son: analizar mejor los resultados de los canales, 
analizar mejor el comportamiento de los compradores entre los canales y a analizar el surtido entre los canales.

En la actualidad, tras el desplome de la burbuja de Internet, se vio como los negocios detallistas están en disposición de dominar el canal online, siendo las empresas que únicamente tenían presencia en Internet las que han pasado por mayores apuros. Así, ante esta situación la clave para el minorista se encuentra en cómo gestionar los distintos canales de manera que se puedan aprovechar sinergias, minimizando al máximo los posibles efectos negativos que pudieran darse de una mala gestión.

Paralelamente, las investigaciones en esta área opinaban que el comercio detallista a través de Internet era mejor que el comercio tradicional físico, puesto que ampliaba la disponibilidad para hacer las compras en cualquier momento y prácticamente desde cualquier lugar, sin necesidad de tener que desplazarse al punto de venta. Algunos autores incluso consideraban que el comercio minorista en Internet reemplazaría al detallista con punto de venta físico. Como señala Singh (2014) con el paso del tiempo esto se ha demostrado que no es así y en esta línea, los estudios se centran más bien en analizar cuáles son los motivos por los que un detallista puede adoptar el canal virtual, qué factores le afectan al tomar esta decisión, cómo deberían diseñarse los modelos de negocio y las estrategias de marketing para el nuevo canal o incluso cómo las empresas deberían gestionar al mismo tiempo su presencia online y offline.

En este sentido, Bláquez y Puelles (2014) señalan que en tiempos de recesión económica ésta tiene más impacto en las tiendas físicas que en los comercios online. Dawson y Larke (2004) encontraron que los distribuidores que eligieron abrir más tiendas como estrategia para generar más ventas en tiempos de recesión generaron altos niveles de deuda y baja productividad, por lo que la estrategia resultó un fracaso. Sin embargo, los distribuidores que eligieron invertir en el canal digital tuvieron más éxito.

Como apuntan Steinfield et al. (2002), los clientes quieren poderse mover de un canal a otro en los diferentes estadios de un proceso de transacción aunque sea simple. 
Cuando los canales están verdaderamente integrados, son posibles muchas rutas en el proceso de compra, incluso cambiar de canal en el mismo estadio del proceso.

Las empresas que gestionan independientemente sus canales tendrán mayor dificultad en facilitar el movimiento de sus clientes de un canal a otro. Cuando realmente los canales están integrados, el paso de uno a otro es posible incluso en un momento determinado del proceso de compra. Como apuntan los citados autores, la integración de los canales físicos y el comercio electrónico posibilita buscar sinergias que no existen para las empresas que tratan estos canales de forma independiente.

Para que los canales por los que ha optado la empresa funcionen de manera correcta, evitando conflictos entre ellos, éstos deberán ser susceptibles de ser utilizados de manera simultánea, intentando siempre satisfacer las necesidades y preferencias de los distintos públicos a los que se dirigen. Tal y como indican Kotler y Keller (2012) los clientes esperan que los distintos canales utilizados para ponerse en contacto por una misma empresa estén totalmente integrados, para lo cual, se deberá dar la opción de hacer el pedido mediante el canal electrónico y recoger la compra en el establecimiento físico, devolver el producto adquirido a través de la compra online en un establecimiento cercano o incluso conseguir posibles descuentos y promociones acumulables independientemente del canal utilizado.

Siebel (2001) también indica que los clientes pueden pasar de un canal a otro de manera aleatoria y en cada situación eligen el que consideran más adecuado. Pero, no sólo esto, sino que, además, el cliente espera que la empresa le reconozca independientemente del canal en que se encuentre; espera que el siguiente canal recoja la línea de comunicación que inició en el canal anterior.

Por lo tanto, vemos como los distintos canales no sólo no tienen por qué ser incompatibles, sino que antes de realizar una gestión independiente de los mismos, es preferible que se realice una dirección coordinada de los diferentes canales a través de los cuales la empresa puede entrar en contacto con el cliente. Ya hemos visto la importancia 
que tiene para el cliente el hecho de ser reconocido cuando cambia aleatoriamente de uno a otro canal.

Pookulangara et al. (2011) indican que la actitud hacia el cambio de canal está significativamente influenciada por las creencias hedónicas y utilitarias en el caso de las tiendas físicas y la compra por catálogo, mientras que en el caso de la compra en el canal Internet, la actitud hacia el cambio de canal está únicamente influenciada por las creencias utilitarias.

Según un estudio llevado a cabo por Huang et al. (2016) sobre la relación entre las ventas a través de página web y del teléfono móvil, los autores señalan que, tras la adopción del canal móvil, las compras a través de la web se vieron ligeramente canibalizadas, si bien las compras totales por cliente se vieron aumentadas, sugiriendo que hay una sinergia positiva del nuevo canal, que compensa el efecto negativo de la canibalización.

Autores como Van Birgelen et al. (2006) entienden que la adopción de una estrategia por parte de la empresa que suponga la utilización de diferentes canales puede derivar en la comentada canibalización y en la consecuente reducción de las ventas de la empresa. Sin embargo, en el lado opuesto encontramos evidencias de cómo una correcta gestión de la estrategia multicanal puede suponer un impacto positivo. En esta línea, Herhausen et al. (2015) señalan que los comercios detallistas con tiendas físicas están empezando a darse cuenta de que pueden tener una ventaja física sobre su competencia que únicamente tiene presencia online.

Los minoristas con presencia únicamente online tienden a dominar el mercado de ciertas categorías de productos, mejorando los resultados de sus competidores con presencia tanto online como física, mientras que algunos detallistas multicanal con tiendas físicas, todavía luchan para responder a la pregunta de si pueden crear alguna ventaja competitiva partiendo de una estrategia multicanal (Neslin y Shankar, 2009). Esto se debe, según Herhausen et al. (2015), a la falta de integración entre el canal en Internet y el físico. 
Así, Verhoef et al. (2007) muestran que el hecho de que un canal se diseñe de manera atractiva para el consumidor, conlleva que éste provoque mayores intenciones de uso del resto de canales de la misma empresa. Es más, algunos estudios como el de Zettelmeyer (2000) concluyen que Internet no significa siempre un aumento de la competencia en precios, sino que, en realidad, incluso puede ayudar a reducir dicha competencia.

Como indican Arce-Urriza y Cebollada (2013), a pesar de la creciente importancia del comercio en Internet, no parece que este canal vaya a sustituir al canal físico tradicional. Más bien se puede pensar que los consumidores actuarán en ambos canales, disponiendo de ellos en función de sus intereses, puesto que cada canal tiene unas características propias diferenciales que lo puede hacer más atractivo que otro, según el perfil del consumidor y el momento concreto de la compra.

Tal y como destacan Neslin et al. (2006) uno de los cambios más radicales en las tendencias de los entornos de compra ha sido la proliferación de canales, es decir, de puntos de contacto a través de los cuales interactúan empresa y cliente. Esto supone un reto para la empresa de cara a realizar una gestión efectiva, pero también puede suponer oportunidades de mejora en su relación con el cliente. Si para las grandes empresas esto puede suponer un reto, para el comercio tradicional, como es lógico, el esfuerzo necesario puede ser incluso mayor.

Internet supone un medio para competir con los canales tradicionales, por eso, las empresas que actúan en ellos tendrán que abordar las cuestiones relativas a este medio y a la posible canibalización, si bien, se trata de problemas que no solo están presentes con la actividad online sino que son similares a los conflictos que pueden surgir por la utilización simultanea de distintos canales, sean cuales fueren. Bien es cierto que estos conflictos, cuando se habla de Internet, parecen más importantes debido a que este medio rompe las barreras tanto geográficas como temporales (el consumidor tiene acceso desde cualquier parte y en cualquier momento), pero no es menos cierto que la correcta gestión de una estrategia multicanal podrá reportar mayores beneficios. 
Vemos como, con la aparición de las nuevas tecnologías y el auge que cobró Internet, se presentó un entorno competitivo nuevo para el comercio detallista tradicional. Para muchos de estos comercios se planteaba la disyuntiva de si estar o no presente en Internet e incluso de cómo estar presente. El paso del tiempo ha ido descubriendo diferentes opciones para las empresas. Ahora bien, en cualquier caso, a la hora de gestionar la presencia en Internet siempre se deberán tener en cuenta sus diferencias con respecto al más tradicional comercio físico, así como las de la propia empresa.

El segmento de mercado que prefiere Internet presenta diferencias con respecto al que utiliza otros canales, como el físico o la venta por catálogo. Por tanto, los canales deberán también diferenciarse en la propuesta de valor que hacen al consumidor. Como indican Verhoef et al. (2007) Internet propone la comodidad y las comparativas gracias a la gran cantidad de información que proporciona, mientras que el canal físico puede ser mejor en la prestación de servicio, apoyo post-venta y reducción del riesgo percibido por el cliente.

De esta manera, si el comercio minorista quiere aprovechar la posible interacción entre los distintos canales en los que opera, deberá ser consciente de las particularidades y diferencias que se pueden presentar de cara al consumidor, de manera que, teniéndolas en cuenta, pueda desarrollar las acciones necesarias para mejorar el valor que ofrezca a sus clientes.

Verhoef et al. (2007) y Konus (2008) indican que la búsqueda en Internet y la compra en una tienda física es la manera más común de búsqueda de compra, radicando aquí, según Pauwels et al. (2011) la importancia de Internet como fuente de información.

Partiendo de esto, la integración de canales viene definida por Bendoly et al. (2005) como el grado en el que diferentes canales interactúan entre sí. Para estos autores hay dos aproximaciones al concepto de integración de canales: por una parte, proveer acceso y conocimiento sobre la tienda en internet en las tiendas físicas y, por otra, facilitar información y acceso sobre la tienda física desde la tienda online. Así pues, la integración 
de canales puede darse tanto desde la tienda física hacia Internet como en el sentido contrario.

En esta misma línea Herhausen et al. (2015) llegan a la conclusión de que una correcta integración de canales no tiene por qué suponer efectos negativos para el comercio físico, ya que más bien pueden ser complementarios y no necesariamente sustitutivos. De hecho, otra de sus claras conclusiones es que la integración ayuda a una mayor percepción de la calidad del servicio prestado en el medio online y que los consumidores no muestran menores intenciones de compra, ni tampoco hay efectos negativos sobre su intención de pago en ambos canales, es más, la integración es un factor que puede contribuir a mejorar las percepciones del cliente y a aceptar mayores precios en distintos canales. Como apuntan los citados autores, una correcta integración de la presencia online y offline de la empresa puede aportar ventajas a la misma. Así, ésta puede, por ejemplo, poner terminales conectados a Internet en el punto de venta físico o bien en su página web añadir localizadores de las tiendas físicas o informar de la disponibilidad de producto en las mismas, etcétera. Así, estos autores definen la integración online-offline como la integración del acceso y de la información sobre el canal offline en el entorno online, a través de, por ejemplo, facilitar un localizador de tiendas físicas en la Web de la empresa o información de la disponibilidad de productos en la tienda física. En un estudio llevado a cabo por estos autores, se llega a la conclusión de que las actividades más comunes de integración son la posibilidad de búsqueda de tiendas físicas, la posibilidad de comprobar la disponibilidad de producto en la tienda offline, la posibilidad de reservar productos online para recogerlos en el punto de venta físico o de devolver de esa misma manera productos adquiridos en la tienda online. A través de sus investigaciones también concluyen que el bajo porcentaje de detallistas multicanal que ponen en práctica acciones de integración confirma que ésta es un fenómeno reciente que debería ser analizado con mayor profundidad.

"Mientras la adopción de la tecnología y las mejoras a la infraestructura llevan a los consumidores a compras en línea y la familiaridad con estas plataformas se incrementa, el crecimiento del comercio conectado es inevitable. Sin embargo, hoy existe mucha 
incertidumbre acerca de la convergencia entre los comportamientos de compra en línea y tradicionales y el cómo impulsar el margen y las ganancias en ambos" (Nielsen, 2016).

A la vista de esto, y puesto que la integración de canales puede representar tanto oportunidades como amenazas, el comercio minorista debe plantearse con claridad cuál quiere que sea su modelo de negocio y cómo pretende llevarlo a cabo, teniendo siempre en cuenta las particularidades que se vienen comentando sobre cada uno de los canales, así como del propio consumidor.

En primer lugar, como indican Pavlou y Fygenson (2006) el minorista deberá tener en cuenta que la utilización del comercio electrónico supone la adopción por parte del consumidor de las tecnologías de la información y la comunicación, ya que aquel es consecuencia de éstas. Además, hay una serie de diferencias notables entre el comercio online y el comercio tradicional en lo que se refiere al comportamiento del consumidor. En este sentido, la separación espacial y temporal entre comprador y vendedor aumenta los miedos a un posible oportunismo relacionado tanto con el producto en si mismo como con la identidad del comerciante. Por otra parte, también están los riesgos percibidos por el consumidor en cuanto a que su información personal puede ser recogida fácilmente por las empresas con las que se relaciona directamente, pero también puede ser utilizada por otros no relacionados directamente con la transacción.

Estas diferencias entre ambas tipologías de comercio detallista hacen que aumente la incertidumbre del entorno virtual y realzan la importancia de conseguir la confianza del cliente en este medio. Como se ha venido apuntando en apartados anteriores, tanto el tener una marca valorada por los consumidores como el tener un punto de venta físico conocido, pueden contribuir a reducir estos riesgos percibidos a la hora de establecer relaciones comerciales. Los partidarios de la integración señalan que ésta puede mejorar la propuesta de valor para el consumidor (Gulati y Garino, 2000). Sin embargo, las ventajas de la integración de canales no están libre de riesgo, ya que pueden llevar a un incremento de la búsqueda de compra (entendida como la propensión de los consumidores a buscar información en un canal y a comprar en otro) de más de un $25 \%$, puesto que reduce los efectos de bloqueo de un único canal específico (Verhoef et al., 2007). 
Ante los cambios radicales del mercado global experimentados en las últimas décadas (incluido los últimos años de recesión y turbulencias tecnológicas), los consumidores han cambiado no sólo su comportamiento de compra, sino también sus percepciones de valor. Para responder adecuadamente, el comercio detallista debe monitorizar su entorno para identificar posibles cambios en el mercado. Estando atento a esto y aprovechando los avances tecnológicos, el comercio detallista puede estar más en contacto con las preferencias del consumidor, conseguir ventajas de las oportunidades que se presentan con las nuevas preferencias de los consumidores y aumentar el valor que ofrecen al cliente (Grewal et al., 2012).

Además, se debe tener en cuenta que el comportamiento del consumidor no es el mismo en los distintos canales. Su proceso de toma de decisiones de compra cambia en función del canal en el que se encuentre. Como señalan Pauwels y Nieslin (2015) el consumidor de Internet suele estar más enfocado a una compra en función de un objetivo previo, mientras que la compra en el punto de venta físico suele moverse por un componente más recreativo. El consumidor que se mueve buscando conseguir un objetivo que ya tiene establecido tendrá un comportamiento de compra más planificado, mientras que el comprador que no tenga este objetivo, realizará una compra más experiencial, enfocada a los beneficios hedónicos que proporciona el propio hecho de "ir de compras".

Cuando el comerciante tradicional o local se da cuenta de que está perdiendo ventas a favor de empresas que actúan en Internet, se plantea la introducción del comercio electrónico para recuperar su cuota de mercado, pero no es usual que se plantee Internet como parte de una estrategia dirigida a mejorar o a reforzar su mercado físico local. $\mathrm{Su}$ primera idea es que, si hay compañías de fuera compitiendo en su mercado local, para recuperar esas ventas él puede intentar vender en otros mercados. Como ya apuntaban Steinfield et al. (1999) los comerciantes locales normalmente acuden a la presencia online para atender a clientes y mercados distantes y muchas veces no les resulta positiva la iniciativa por su falta de experiencia o de recursos. Ahora bien, en un entorno dinámico como el actual, el uso de Internet para la comunicación con los clientes está relacionado de 
manera positiva y muy significativa con la flexibilidad estratégica en un mercado cambiante (Murphy et al., 2007).

De esta manera, las empresas click \& mortar, es decir, con presencia física y online, que utilicen el comercio electrónico pueden atraer a nuevos clientes o clientes poco frecuentes de zonas distantes que normalmente no están en disposición de desplazarse hasta la ubicación física del comercio (Adelaar et al, 2004).

Añadir un canal de distribución virtual puede ayudar a la empresa a expandir su mercado más allá del alcance de sus tiendas físicas tradicionales, llegando a nuevos mercados geográficos, a nuevos mercados para sus productos y a nuevos tipos de compradores (Steinfield, 2002).

Ahora bien, como indican Zott y Amit (2010), independientemente del tamaño que tenga la empresa, un modelo de negocio sólido será imprescindible para el éxito de la compañía. Será necesario tener claro cuál ese modelo, tanto en el entorno físico como en el virtual. En este sentido, como señalan estos autores, será incluso un reto mayor replantear el modelo de negocio para una empresa que haya tenido éxito en el entorno tradicional durante años y que se vea ante la necesidad de replantearlo debido a las fuerzas y cambios del nuevo entorno competitivo. Normalmente, la inercia y la propensión a mantener los logros conseguidos anteriormente serán un obstáculo a la hora de plantearse la entrada en el entorno online. Para estos autores, el modelo de negocio articula la propuesta de valor de una empresa, sus fuentes de ingresos y sus recursos, así como la dirección de los mecanismos que unen a la empresa con sus stakeholders.

Así, como señalan Sorescu et al. (2011) muchos grandes detallistas se han transformado en empresas multicanal en las que el consumidor contacta con ellas a través de diferentes canales y con diferentes propósitos. Algunas, además, han expandido sus objetivos hacia la conexión con el consumidor con la finalidad de proporcionarle una mejor experiencia de cliente. Los minoristas actuales son conductores de una relación en la que el valor se crea y se ofrece a los clientes y, consecuentemente, la empresa consigue valor para ella y para sus socios. 
Tomando como punto de partida la definición de Zott y Amit (2010), Sorescu et al. (2011) consideran que un modelo de negocio es un sistema correctamente especificado de estructuras, actividades y procesos interdependientes, que sirve como lógica organizativa de una empresa para la creación de valor para sus clientes y para la obtención de valor para ella y para sus socios. En el caso del comercio detallista, el modelo de negocio está formado por uno o más formatos, junto con las actividades y los mecanismos de dirección que apoyan al formato, y las interdependencias entre estos tres elementos. Como señalan estos autores, los minoristas multicanal pueden utilizar más de un formato, pero todos ellos deberán estar integrados en un modelo de negocio cohesivo que preserve y desarrolle el Valor de Marca del comercio minorista.

De esta manera, un modelo de negocio sólido puede ser la clave para que la empresa consiga una posición competitiva superior a la de otros comercios detallistas, gracias a que pueda ofrecer un valor mayor a un grupo determinado de consumidores. Así, parte de los clientes pueden dar mayor valor a los servicios post-compra, otros a las distintas opciones de entrega del pedido, a la calidad, al precio, a la comodidad, etcétera y por ello, el modelo de negocio deberá tener en cuenta qué aspectos valora su público objetivo y como la empresa puede crear el valor percibido que desean sus clientes (Singh, 2010). Es por ello que las empresas deben tener en cuenta que un mismo cliente puede tener preferencias distintas en función del canal a través del cual esté interactuando con la empresa (Shankar et al, 2003).

La utilización combinada de ambos canales por parte del consumidor viene destacada por Arce-Urriza y Cebollada (2013), cuando opinan que, más que decidirse por uno u otro, el consumidor es multicanal y los utiliza en función de su conveniencia en cada momento. Así, el canal físico permite la inspección del producto con todos los sentidos, ofrece el asesoramiento personal de los vendedores del punto de venta (lo que genera confianza), se recibe el producto en ese mismo momento, etcétera. Por su parte, el canal online tiene otras características propias como son la disponibilidad total de horarios para comprar, el hecho de que no requiera desplazamientos o la amplia variedad de productos a disposición del consumidor. 
Por tanto, las diferentes características de los canales, unidas a las de cada consumidor en particular, hacen que los canales no tengan que ser necesariamente excluyentes, sino que, como se ha indicado, podrán utilizarse de manera alternativa por un mismo consumidor. En este sentido, Gensler et al. (2007) ya señalaban que los consumidores pueden ser considerados como multicanal debido a una disminución de la lealtad al canal.

En esta misma línea, Avery et al. (2012) hablan de la posibilidad de tener en cuenta que los canales no tienen por qué ser siempre sustitutivos, sino que se deben buscar los rasgos y características que los hagan complementarios. Así, en su análisis del impacto que puede suponer el añadir puntos de venta físicos sobre las ventas de Internet o a través de catálogo, identifican que en la medida en que las capacidades que ofrece el nuevo canal sean sustitutivas de las ofrecidas en otros canales, el impacto será negativo.

Si se opta por la presencia en diversos canales, para la correcta gestión de los mismos, los responsables de las empresas minoristas deberán analizar bien qué es lo que ofrecen en cada uno de ellos y buscar la complementariedad de forma que no se dé la confrontación u oposición de ofertas para que éstas no sean sustitutivas. Así, la correcta integración de canales puede ser una opción que aporte valor al consumidor y que, a su vez, se convierta en una ventaja competitiva para el comercio minorista.

Los consumidores esperan que su experiencia con el detallista sea consistente, uniforme e integrada, independientemente del canal que estén usando. Además, desean poder moverse entre los distintos canales (tienda física, online y móvil) sin barreras ni cambios bruscos, en función de sus preferencias, su situación, el momento del día o la categoría de producto de que se trate (Piotrowicz y Cuthbertson, 2014).

Si se opta por la presencia en diversos canales el comercio detallista deberá realizar una correcta gestión del consumidor multicanal. Neslin et al. (2006) definen esta gestión como "el diseño, despliegue, coordinación y evaluación de los canales para aumentar el valor del consumidor a través de una efectiva adquisición, retención y desarrollo de los mismos". Por ello, como señalan Pauwels et al. (2015), para evaluar el impacto que en los 
resultados de la empresa tendrá el añadir un canal, se necesitará considerar la ganancia de clientes, así como su retención e indicadores tales como la frecuencia de compra, tamaño de los pedidos, resultados por productos e intercambios con el cliente.

En la definición de gestión de Neslin et al. (2006) los canales se consideran como puntos de contacto con el consumidor o como el medio a través el cual interactúan la empresa y el cliente, es decir, no se consideran los canales más tradicionales de comunicación en una única dirección, tales como la publicidad en distintos medios, etcétera.

Como se ha dicho, alcanzar mercados lejanos suele ser el primer objetivo para los comercios locales a la hora de plantearse su presencia online. A veces éste puede ser un planteamiento adecuado si se hacen las cosas correctamente y si el comercio es capaz de reunir y utilizar los recursos adecuados para llevarlo a cabo. Para ello será necesaria una gestión multicanal por parte de la dirección del negocio. Esto es así, porque a partir de que se tome la decisión, la empresa va a tener presencia en diversos canales, es decir, sus contactos con el mercado ya no solo vendrán dados de manera física, sino también de manera virtual. Por ello, se deberá gestionar la relación con el cliente desde una perspectiva multicanal, teniendo en cuenta el diseño, despliegue, coordinación y evaluación de los canales a través de los cuales la empresa y el cliente van a interactuar, con el objetivo de añadir valor para el cliente mediante la correcta adquisición, retención y desarrollo de la cartera de clientes. Para ello, los autores Neslin, et al. (2006) identifican cinco aspectos que deben ser tenidos en cuenta para una correcta gestión del entorno multicanal en el que se va a competir: integración de datos, comprensión del comportamiento del consumidor, evaluación de los canales, distribución de los recursos entre los distintos canales y coordinación de las estrategias de los canales.

El rápido crecimiento de las ventas online frente a las ventas tradicionales en mercados físicos hace suponer que el comerciante local podría desarrollar una estrategia en Internet que le ayudase a incrementar sus beneficios. Así, tras la caída o la explosión de la burbuja de las empresas "punto com" (empresas que solo tenían una presencia virtual) los comercios tradicionales tienen cada vez una mayor presencia online comparada con el 
descenso de empresas que sólo tienen presencia en la Red y no física. La combinación del comercio físico con el comercio en Internet (e-commerce o comercio on-line) ha dado lugar a empresas click \& mortar es decir, de "clicks y hormigón" en referencia a su presencia en Internet (a la cual se accede mediante clics del ratón) y a su presencia física tradicional (con tienda de "ladrillo y hormigón" o en inglés brick \& mortar). Aparece así este nuevo modelo de negocio en Internet que se ha denominado click \& mortar (Steinfield et al. 2005). Ahora bien, esto no significa que el comercio físico tradicional pueda actuar en el nuevo entorno simplemente tal y como lo estaba haciendo hasta ahora en el medio físico, ya que, como indican Arce-Urriza y Cebollada (2007), actuar en el mercado online no es tan sencillo como únicamente transferir las estrategias del negocio offline al nuevo canal.

A pesar de esto, tradicionalmente la mayor parte de los detallistas multicanal han venido planteando estructuras en las que el canal físico y el electrónico operaban de manera independiente (Gallino y Moreno, 2014). Autores como los citados defienden que la integración de canales podría enriquecer la propuesta de valor de la empresa hacia el cliente. Piotrowicz y Cuthbertson (2014) coinciden con esta opinión en el sentido de que, incluso algunos detallistas que ofrecen acceso a multiplicidad de canales, los gestionan por separado, siendo gestionados por personas e incluso departamentos diferentes dentro de la empresa, produciéndose, por tanto, una falta de integración en lo referente a las políticas de precio, de comunicación o incluso de gestión de marca.

A la vista de sus investigaciones Herhausen et al. (2015) señalan que la integración ejerce un efecto directo en la percepción sobre la calidad del servicio de la tienda en Internet. Además, esta percepción aumenta los resultados tanto generales como en Internet. Sus conclusiones les llevan a considerar que la integración no afecta negativamente a la tienda física y que los consumidores eligen aquellos detallistas que les ofrecen canales integrados antes que los que no se los proporcionan.

Ante esta situación, resultará clave para el comercio detallista conocer las razones por las que el consumidor elige un canal u otro, ya que esto ayudará al desarrollo de la estrategia más adecuada para la empresa para cada uno de los canales en los que esté 
presente, así como para su estrategia global. Como señalan Arce-Urriza y Cebollada (2013), “determinar el perfil del consumidor que le hace más propenso a comprar online es importante para las empresas porque les permitirá establecer estrategias de marketing para dirigir a sus clientes, según su rentabilidad por canal, al entorno online u offline".

Pero son pocas las veces en las que estas empresas ven Internet como una herramienta para fortalecer su posición competitiva en su propio mercado local. La combinación de una tienda o punto de venta físico y la apropiada utilización de la web pueden ayudar a fortalecer y mejorar las ventas y ser más competitivo, defendiendo su territorio o mercado natural y ofreciendo mejor servicio a los clientes. En este sentido son interesantes las conclusiones de Pauwels y Neslin (2015) relativas a la inclusión de puntos de venta físicos para empresas que únicamente tenían presencia en Internet o venta por catálogo. Así, estos autores destacan que el impacto de añadir este nuevo canal físico incrementaba las ventas generales casi en un $20 \%$, como consecuencia, entre otras cosas, de la mayor frecuencia de compra de los clientes, ya que, como pudieron comprobar, el importe de las compras era muy similar al que se daba antes de incluir el nuevo canal. Esto, lógicamente, afecta a la retención de clientes, ya que los contactos con la empresa son mayores. Con respecto al impacto en cada canal, el estudio demostraba que las ventas en la tienda física canibalizaban a las ventas por catálogo, pero, sin embargo, no afectaban prácticamente en nada a las ventas a través de Internet, debido a que éstas últimas están más bien determinadas por tener un objetivo claro de compra, mientras que las ventas por catálogo y en la tienda física se consideran por el cliente como más experienciales.

Así pues, atendiendo a Adelaar et al., (2004) una concepción de negocio del tipo click \& mortar puede generar unas sinergias que aumenten el valor final para el cliente, tanto en el caso de los ya existentes, como de los nuevos clientes. Este valor aportado se debe entender como la adaptación del producto aumentado a las necesidades del cliente y, además, puede conducir a una mejoría de los resultados financieros del comercio. El valor para el cliente se generará cuando la empresa sea capaz de interactuar con sus clientes. La combinación de la presencia online con una tienda física puede generar valor para el cliente, puesto que la posibilidad de añadir o cambiar de canal en cada etapa del proceso de 
compra puede servir para adaptarse mejor a las necesidades del cliente. Generando más valor para el cliente las empresas conseguirán en mayor medida retener y fidelizar a sus clientes.

En la revisión de la literatura realizada para la presente tesis se ha detectado que hay bastantes más estudios referentes únicamente al comercio electrónico o a la faceta online de las empresas que a la relación entre la presencia en Internet y la presencia física tradicional del comercio. Ante los diferentes trabajos de investigación parece que existen numerosas empresas tradicionales que deciden entrar en el campo del comercio electrónico, pero con la creación de un canal independiente de su canal físico ya existente (Gallino y Moreno, 2014; Herhausen et al., 2015; Verhoef, 2012). De esta forma, se da una presencia virtual que intenta aprovechar las ventajas económicas que puede suponer Internet sin los costes extras o la falta de innovación que podría suponer el aspecto físico.

Ante esto Steinfield (2002) proponía una aproximación al tema que ofreciera mayor relieve a la integración de los canales online con la infraestructura física que ya tienen los comercios tradicionales. Así, el autor apunta que la integración del canal físico con el canal online permite a la empresa capitalizar las sinergias generadas por ambos, creando ventajas competitivas sobre las empresas que únicamente actúan en Internet o incluso de aquellas que, aun teniendo instalaciones físicas, ofrecen el comercio electrónico o tienen presencia en Internet, pero de manera separada, es decir, sin integración de ambos canales.

Por otra parte, a la hora de que las empresas del comercio local se planteen su presencia online, se dan determinadas barreras que apuntan Steinfield et al. (2005) para la implementación de los modelos de negocio mixtos (click and mortar):

- La complejidad en la fijación del precio y las posibles diferencias entre los clientes de los distintos canales.

- $\quad$ El temor a que se produzca un conflicto entre los canales hace que muchas veces no se desarrolle suficientemente el canal electrónico. 
- Posible falta de recursos de la empresa.

- Un posible impacto negativo del uso de la marca en Internet por la falta de la integración de los distintos canales.

Además de los problemas que se pueden presentar para la incorporación de un canal virtual o para la integración de los distintos canales, desde el punto de vista de las barreras que tiene que superar el comercio detallista, otro posible inconveniente viene dado desde el punto de vista del consumidor, ya que uno de los principales problemas con los que se encuentran las empresas que actúan en Internet es el relacionado con la confianza de los clientes a la hora de hacer sus compras (Avery et al., 2012; Cao y Li, 2015; Coates, 1998; Verhoef et al., 2007). Este es un tema que las tiendas con punto de venta físico pueden fácilmente evitar a nivel local, pero también en Internet si son capaces de que el cliente asocie la web del comercio con su imagen física, ya que esta asociación facilitará la confianza y reforzará su decisión de compra online.

La confianza es un punto importante en muchas relaciones que implican transacciones, especialmente aquellas que puedan considerarse de riesgo, como pueden ser las que tienen lugar en Internet. En el marketing relacional la confianza puede ser esencial y un elemento clave para el éxito de la relación entre el comercio y la empresa (Liao et al., 2011). Además, el estudio de Kim et al. (2010) muestra como la confianza es el factor más crítico a la hora de explicar el éxito del comercio electrónico. Confianza que no solo debe darse entre la empresa y el cliente final sino también en el canal hacia atrás, hacia los proveedores. De esta forma las tendencias apuntan a la realización de esfuerzos de las empresas para desarrollar climas de confianza y fortalecer la cooperación, a través de contratos más largos con los proveedores seleccionados (Guimaraes, et al., 2002, Janda, y Seshadri, 2005). En semejantes términos apuntan otros autores como Campo et al., (2008), para quienes el creciente uso de las tecnologías de la información y de la comunicación permite a los minoristas mejorar la relación y la confianza con sus proveedores.

Tal y como indican Lin et al. (2011) antes de que el cliente adopte la nueva tecnología, sus contactos y experiencias anteriores con la empresa pueden afectar a su 
opinión sobre la nueva tecnología y, consecuentemente, a su aceptación. Así, en un estudio de estos autores se refleja que las empresas pueden aprovechar la confianza del cliente en sus servicios online para ofrecerle líneas de producto con niveles similares de confianza en el canal móvil. Además, según este estudio, la amplitud con la que la confianza en el canal online afecta a las percepciones en el canal móvil sugiere que ésta puede ser un factor clave a la hora de conseguir el éxito en la oferta de servicios a través del nuevo canal móvil.

Vemos, por tanto, la importancia de la gestión integrada de los distintos canales a través de los cuales la empresa se relaciona con el cliente. Así, esta integración supondrá, entre otras cosas, unos niveles de confianza similares en cada uno de los canales, lo que, a su vez, generará mayor aceptación por parte del cliente y, como hemos visto en apartados anteriores, el que se pueda mover libremente de un canal a otro durante las diferentes fases del proceso de compra. También hemos apuntado anteriormente los beneficios y ventajas que esto supondrá para la empresa de cara a la retención y fidelización de sus clientes.

Según el estudio de Shankar et al. (2003) la profundidad de la información ofrecida en la página web de una empresa incrementa la satisfacción del servicio de contacto con el cliente, lo que redunda en un incremento de la satisfacción global, lo que, a su vez, refuerza en su conjunto la lealtad del cliente hacia la empresa. El mismo estudio apunta que la facilidad para obtener la información tiene un efecto más fuerte sobre la satisfacción y la lealtad del cliente cuando se produce en el canal online que cuando se da en los canales físicos.

A menudo los clientes hacen una búsqueda en Internet para conocer las características del producto, imágenes, precios, etcétera, pero también acuden a las tiendas físicas para ver, tocar e incluso "sentir" el producto. En estas ocasiones, combinar el aspecto físico y el aspecto online puede facilitar una ventaja porque el cliente puede desplazarse al punto de venta para verificar características o incluso probar el producto. Una vez en la tienda, la confianza en el vendedor puede hacer más fácil la venta cruzada, es decir, vender al cliente no solo el producto que ha ido a buscar, sino otros que puedan tener relación con el mismo (venta cruzada). 
Como apuntan Florenthal y Shoham, (2010) la interacción multisensorial con los objetos físicos es imposible en un medio basado en el contexto de una página web. En muchos casos, en el ámbito del comercio al detalle, es de gran valor la interacción con el producto físico. El comercio minorista es valorado, en muchas ocasiones, tomando como base la cantidad de ocasiones en que el cliente puede interactuar con los productos. En esta línea, Pauwels y Neslin (2015) señalan que Internet es un canal más adecuado cuando el consumidor tiene claro un objetivo de compra, pero que, la tienda física se adapta más a los perfiles de consumidor que prefieren interactuar físicamente con el producto y que van buscando una experiencia en su compra, más allá de un producto determinado o de sus características.

Por último, la correcta utilización de las nuevas tecnologías puede servir para la realización de acciones personalizadas de comunicación, para una mejor comprensión del cliente y sus necesidades, e incluso para una hipotética adaptación de servicios y productos, de sus características, etcétera según las preferencias del cliente (Kalakota y Whinston, 1996). Así, la web puede ayudar a la creación de tráfico hacia el punto de venta a través de la comunicación, promociones, etcétera. La combinación de distintos canales anima a los consumidores del entorno online a comprar en tiendas físicas (Bendoly et al., 2005).

Como se viene viendo a lo largo de la revisión de la literatura realizada en el presente punto con respecto a la integración de los distintos canales por parte del comercio detallista, se puede destacar que, si bien en su inicio las decisiones de gestión de los canales se limitaban a considerar si los nuevos canales debían incorporarse a los tradicionales (decisiones a tomar principalmente por los negocios con presencia física), en la actualidad tanto a nivel práctico como a nivel académico se están planteando nuevos retos, a medida que van evolucionando las tecnologías de la información y la comunicación.

También se ha destacado el hecho de que muchas veces los distintos canales en los que el minorista está presente, se han desarrollado y gestionado de manera separada e independiente (Verhoef, 2012) 
Por otra parte, la inclusión de nuevos canales no ha sido únicamente partiendo del entorno físico y creando presencia virtual. Así, se ha visto como la integración también ha sido tenida en cuenta por los comercios con presencia únicamente virtual para abrir nuevos puntos de venta físicos (Avery et al., 2012).

Además, autores como Verhoef et al. (2015) se plantean si el comercio detallista está ante una nueva etapa de evolución del entorno multicanal, ya que recientemente se observa una creciente digitalización del entorno que conlleva nuevos retos para el marketing y para el sector detallista. Con la llegada del canal móvil, tabletas, redes sociales en Internet y la integración de estos nuevos canales en el comercio detallista, el entorno en el que éste compite presenta continuos cambios. Así, se ha destacado anteriormente cómo estas nuevas tecnologías afectan el comportamiento de compra del consumidor (Wang et al., 2015), no solo en el entorno virtual, sino también con aplicaciones tipo apps que permiten al comerciante interactuar con el cliente cuando éste se encuentra en el punto de venta físico.

Yendo más lejos, un paso más allá del comercio en Internet lo encontramos en el que ha venido a llamarse comercio móvil o m-commerce, es decir, aquel que tiene lugar a través de terminales móviles como teléfonos móviles, i-phones, i-pads, etcétera. En estos casos, la confianza puede llegar a tener incluso más importancia que en el comercio electrónico, ya que estamos hablando de conexiones a Internet que pueden tener lugar a través de redes públicas, etcétera. Son muchas las empresas que ya en estos momentos están apostando por este nuevo canal de contacto con el cliente. En esta línea Lu et al. (2005) consideran el comercio móvil como la segunda ola del comercio electrónico.

Esto es especialmente importante si se tiene en cuenta que, tal y como señalan Kang et al. (2015) el acceso a la web a través de dispositivos móviles por parte de los consumidores está aumentando comparado con el acceso a través de ordenadores. Además, según el informe de Nielsen (2014) casi el 87\% de los propietarios de dispositivos móviles (tabletas, teléfonos inteligentes, etcétera) los utilizan como parte de sus experiencias y actividades de compra. 
A pesar de que no es amplia la literatura relativa a los beneficios que para el cliente puede aportar la compra a través de dispositivos móviles, estudios recientes apuntan hacia la posibilidad de que el consumidor compre en una atmósfera excitante y estimulante, que esté al día con nuevos productos e innovaciones y que pueda tener un acceso fácil a productos con descuento (Lewis et al., 2014; Wang et al., 2015).

Aunque en teoría hay muchos aspectos y beneficios asociados al comercio minorista multicanal, también hay algunos obstáculos relacionados con la adopción de la tecnología (Zhang et al., 2010) y la literatura sugiere que estos obstáculos parten de la necesidad de que el comerciante adquiera nuevos recursos o destine parte de los que ya tiene a alcanzar la integración de forma que se usen con garantía de éxito los nuevos y múltiples canales (Singh, 2014; Herhausen et al., 2015; Verhoef et al., 2015).

Incrementar el número de canales que utiliza el comercio detallista supondrá aumentar el número de puntos de contacto con el consumidor, lo que requerirá que el comerciante construya los sistemas de tecnologías de la información y la comunicación necesarios para integrar todos los datos provenientes de todos los canales de forma que puedan ser analizados desde un punto de vista holístico. En la práctica, la adición de nuevos canales supondrá rediseñar las estructuras que hasta ese momento hayan sido utilizadas por el minorista (Lewis et al., 2014).

Como se ha visto a lo largo de las últimas páginas, el comercio detallista puede optar por diversas fórmulas a la hora de competir en el entorno actual. Así, puede decidir que su presencia se limite únicamente a un canal determinado, que se amplíe a algunos de ellos o, en el otro extremo, que esté presente en todos los canales disponibles. El estar en dos o más canales supondrá que, para hacer las cosas correctamente, como se ha indicado, deberá hacerse una gestión integrada de los distintos canales, lo que le llevará al mejor aprovechamiento de las características propias de cada uno de ellos y a la posibilidad de aprovechar las sinergias que puedan darse.

Tener más de un canal puede suponer la creación de oportunidades para el comercio, pero también puede suponerle ciertas complicaciones, ya que el minorista 
deberá valorar las posibilidades de cada canal para evitar la canibalización entre ellos y conseguir sinergias positivas (Verhoef et al., 2007). El que se llegue a unos resultados u a otros dependerá de la habilidad que la empresa tenga para gestionarlos y coordinarlos, ya que, como se ha visto anteriormente, se abren distintas posibilidades de gestión de los canales y, además, también se deberá tener en cuenta el modelo de negocio que se desea implantar.

Cao y Li (2015) hablan del término "integración a través de canales" para referirse a las decisiones que el minorista debe tomar para su correcta combinación de manera que se creen sinergias entre ellos.

El hecho de que una empresa se plantee una estrategia multicanal en su relación con el mercado debería tener como fin último una repercusión positiva en sus ventas y sus resultados. Este es un punto importante para el comercio detallista, a pesar de lo cual, no ha sido tratado con amplitud por la literatura. Por ello Cao y Li (2015) analizan el efecto que la integración a través de distintos canales puede tener en las ventas del comercio detallista. Estos autores definen el concepto de la siguiente manera:

"La integración a través de distintos canales es el grado en el que una empresa coordina los objetivos, diseña y despliega sus canales para crear sinergias para la empresa y ofrecer beneficios particulares a sus clientes".

Como se puede apreciar, esta definición tiene en cuenta algunos aspectos de la concepción que Neslin et al. (2006) hacen de la gestión del consumidor multicanal, tales como la coordinación, el diseño y el despliegue de los canales.

La integración a través de los canales se hace incluso más necesaria cuando las tecnologías se utilizan en el punto de venta. De hecho, las barreras tradicionales entre el canal físico y el virtual se difuminan cuando los dispositivos móviles pueden ser utilizados en la tienda. El comerciante no debe perder de vista que el consumidor puede usar su propio dispositivo (teléfono móvil, tableta, etcétera) cuando está en el interior del comercio para buscar consejo sobre un producto o marca, para buscar alternativas más económicas, 
etcétera. Es más, la revolución móvil, junto con el crecimiento de las redes sociales ha dado lugar a una situación en la que el consumidor "lleva" consigo a su red social dentro del punto de venta físico, pudiendo consultar con alguien o incluso con algún grupo aspectos relativos al producto o al propio comercio. Incluso es posible que espere que el propio comercio esté presente en esas redes sociales (Piotrowicz y Cuthbertson, 2014).

La utilización de canales online y offline a la hora de contactar con el mercado puede llevar a una serie de sinergias que el comerciante debería aprovechar. La utilización que algunos comercios físicos hacen de Internet para complementar su negocio conduce a unas dinámicas propias de los comercios mixtos o click and mortar. Así, entre algunas de las ventajas de integrar el comercio electrónico con las infraestructuras físicas cabe citar el ahorro de costes, la mejora de la diferenciación, el aumento de la confianza del consumidor y la ampliación de los mercados (Steinfield et al. 2002). Estas son las cuatro sinergias básicas que los citados autores apuntan como las principales oportunidades que generan las dinámicas de combinar el comercio electrónico con el comercio físico. Lógicamente, aquellas empresas que gestionen por separado su presencia online y su punto de venta físico, no estarán en disposición de aprovechar convenientemente y en plenitud estas oportunidades. En este punto se debe tener en cuenta que el cliente, a lo largo de un proceso de compra se puede mover en diferentes canales, es decir, puede pasar de uno a otro en función de sus deseos o necesidades. Así, por ejemplo, puede ser habitual hacer una búsqueda de información en Internet y desplazarse hasta el punto de venta físico para ver la mercancía, poder comprobarla, tocarla, etcétera. En este caso, sólo si se gestionan de manera coordinada las estrategias en la red y las estrategias en el comercio físico se tendrá ocasión de aprovechar de la mejor manera posible las ventajas y oportunidades que supone estar presente en ambos ámbitos. También se debe tener en cuenta que una gestión coordinada de ambos canales evitará cometer errores en cuanto a posibles incompatibilidades y problemas de imagen que sería más fácil que apareciesen si la dirección de ambos se hace de manera independiente.

La correcta gestión de los canales y su integración puede suponer ventajas, tanto para el cliente como para el comerciante. De esta manera, Van Birgelen et al. (2006) 
indican que para el consumidor la oportunidad de utilizar canales de contacto alternativos puede suponer más comodidad, ahorro de tiempo y fiabilidad, mientras que para la empresa puede aportar beneficios en forma de ventas cruzadas, innovación en la prestación de servicios, reducción de costes y mayor flexibilidad.

La gestión conjunta de los diversos canales en los que tenga presencia el comercio minorista hará que el consumidor perciba que está interactuando, no con un canal, sino con la marca (Piotrowicz y Cuthbertson, 2014).

Cao y Li (2015) confirman que hay una influencia positiva entre la integración a través de los diferentes canales y el crecimiento de las ventas del comercio detallista, de manera que las empresas capaces de coordinar de mejor manera los diferentes canales mejorarán la confianza del consumidor, incrementarán su lealtad y su ratio de conversión y crearán más oportunidades para hacer venta cruzada.

Los aspectos que señalan estos autores y cuyo efecto positivo sobre las ventas confirman, son los que la literatura existente viene reconociendo como mecanismos que afectan al crecimiento de las ventas del comercio. Por ello, cada vez más detallistas se plantean la integración a través de los distintos canales para crear sinergias y ofrecer mayores beneficios a sus clientes.

Así, en cuanto a la confianza, Zhang et al. (2010) ya señalaban que usando una combinación de canales los detallistas pueden explorar los beneficios y superar las deficiencias de cada uno de los canales para crear una experiencia de compra atractiva para el consumidor. La multiplicidad de canales facilita al consumidor la consecución de la información según sus necesidades. Además, los programas de marketing coordinados reducirán la confusión del cliente, tal y como señalan Cao y Li (2015), lo que llevará a un amento en la confianza su confianza hacia la empresa.

Se aprecia, por tanto, como la multiplicidad de canales correctamente gestionada no sólo mejora la confianza del consumidor hacia la empresa, sino que también propicia la creación de experiencias del cliente. Como se apunta más adelante en la presente tesis, este 
es un aspecto que se va a tener en cuenta a la hora de analizar el Valor de Marca del comercio detallista, junto al resto de dimensiones más habituales en la literatura sobre este tema.

Por lo que hace referencia al incremento de la lealtad del consumidor, la multiplicidad implica que el comercio puede ofrecer más servicios que aporten valor a sus clientes, lo que mejora su percepción, actitud, satisfacción y lealtad hacia la empresa (Berry et al., 2010). Con esto, tal y como indican Avery et al. (2012) los consumidores recompensan al detallista comprando más y concentrando sus compras en él. La integración entre diversos canales fortalece la relación del consumidor con la marca (Neslin et al., 2006).

La tercera consecuencia positiva que apuntan Cao y Li (2015) de la integración de canales es el alto ratio de conversión de consumidores. Para Neslin et al. (2006) el consumidor puede ser más fácilmente convencido de que ha tomado la decisión correcta en el momento de la compra. Buscando en Internet antes de visitar la tienda física, el consumidor puede descubrir qué atributos del producto le interesan más y seleccionarlo correctamente cuando está en la tienda. Verhoef et al. (2007) la integración también ayuda a retener a los consumidores en algunos de ellos, mientras que Bendoly et al. (2005) señalan que la combinación de canales propicia que el consumidor online compre en tiendas físicas.

Por último, como consecuencia positiva de la integración se apunta que ésta propicia más oportunidades para hacer venta cruzada. La integración ayuda a presentar a los consumidores que visitan un canal, el resto de canales de la empresa, lo que lleva a construir lealtad y compras cruzadas (Berry et al., 2010; Neslin et al., 2006).

Desde un punto de vista local el comercio debería ver Internet y las nuevas tecnologías no solo como una herramienta para llegar a otros mercados, sino también como una posibilidad para fortalecer su posición y competitividad en sus mercados locales (Auger y Gallaugher, 1997). Por ejemplo, Gil y Ruiz (2012), analizan el nivel de identificación y satisfacción de los consumidores con las tecnologías implantadas por 
distintos tipos de establecimiento comercial de bienes de consumo frecuente (alimentación y textil/calzado) y otros dos tipos que comercializan bienes de consumo duradero (electrónica y electrodomésticos, y muebles y decoración). Esta diferenciación la realizan en base a que las características del proceso de compra pueden depender en gran medida del tipo de producto adquirido. Para el sector del comercio de mueble y decoración es significativa sobre la satisfacción global sólo la influencia del uso del correo electrónico y la página web. Esto podría explicarse por el posible uso de la web del minorista con carácter previo a la visita al establecimiento. De forma similar, para los establecimientos de venta de productos de electrónica y electrodomésticos, la web del minorista, el uso del correo electrónico y el pago a través de transferencia bancaria correlacionan positiva y significativamente. Es decir, se produce una sinergia entre el comportamiento online y offfline.

En este sentido se debe tener en cuenta que la Red reduce la oportunidad de realizar compras sensoriales. Como señalan Citrin et al. (2003), la naturaleza multisensorial del consumo hace que aquellas personas con tendencia a tener grandes niveles de entrar en contacto táctil con el producto presenten menos predisposición a fiarse únicamente en sentidos como la vista o el oído a la hora de evaluar un producto y, consecuentemente, de adquirirlo a través de Internet.

Cabría aquí citar el comportamiento de "búsqueda de compra" analizado por Verhoef et al. (2007) consistente en buscar información en Internet, pero realizar la compra en el punto de venta físico.

Aquí, el comercio detallista podría aprovechar su presencia online para facilitar información al consumidor, tanto sobre las características de los productos, como sobre la disponibilidad de los mismos en el punto de venta físico, de manera que generase en este el interés por acudir a la tienda.

A pesar de la posibilidad de moverse entre diferentes canales, los consumidores todavía quieren ver, sentir, tocar y probar el producto, así como sentir la atmósfera de la tienda. Piotrowicz y Cuthbertson (2014) indican que, a pesar de que el papel que puede 
jugar el punto de venta físico en el futuro no está claro y que puede depender de la categoría de producto de que se trate y de las características del segmento del mercado al que se dirija, el comercio tradicional podría convertirse en una especie de centro que integrase todos los canales de venta. Así, podría ofrecer la posibilidad de integrar los canales, incluyendo opciones como hacer el pedido online y recogerlo en tienda, posibilidad de hacer devoluciones o cambios en el punto de venta, posibilidad de hacer el pedido a través de dispositivos móviles incluso estando en el propio establecimiento, etcétera.

Esto, siempre vendrá muy condicionado por aspectos tales como la tipología de producto de que se trate, características del cliente o incluso si es un tipo de compra más o menos hedónico. De esta manera, en un estudio de Pascual del Riquelme y Roman (2011), los autores investigan las diferencias en el perfil de los consumidores de productos electrodomésticos que compran a través de Internet frente al comercio tradicional, pudiendo afirmar que ambos perfiles tienden a converger gracias a la mayor penetración y accesibilidad de Internet. Sin embargo, dicha convergencia no se cumple en todos los productos tecnológicos, y sus resultados ponen de manifiesto diferencias en tipos de producto y segmentos de consumidores. Además, dichos autores resaltan en sus resultados, que la fusión entre la informática de consumo, comunicaciones y electrónica de consumo, puede suponer una demanda creciente de dispositivos que facilitan esta convergencia digital, y una oportunidad para los distribuidores del sector que sepan aprovechar la creciente importancia de algunos segmentos minoritarios, como las mujeres, los más jóvenes, o los mayores de 50 años, y de aquellos mercados más prometedores, como el de los productos Smart handheld o el comercio electrónico.

De esta manera, se observa como diferentes consumidores tendrán diferentes necesidades y buscarán distintos beneficios, pudiéndose distinguir entre las generaciones más jóvenes (nativos digitales) y aquellas de más edad que han ido adoptando las nuevas tecnologías a medida que iban apareciendo.

El modelo teórico de la cadena de valor, introducido por Porter (1998) ayuda a las empresas a definir aquellas actividades o competencias distintivas en las que se es capaz de 
generar una ventaja competitiva. El comerciante añade valor cuando es capaz de atender al cliente mejor que su competencia en un mercado geográfico determinado. Para conseguir esto, Katros (2000) propone algunas sinergias entre el canal online y el canal físico para conseguir una mejor experiencia del cliente:

- Realizar el pedido en la web y recoger la mercancía en la tienda.

- Facilitar la venta de productos táctiles. El consumidor completa parte de la transacción en la web y utiliza la tienda para revisar el producto y comprobarlo.

- Promociones de la web a la tienda.

- Promociones de la tienda a la web.

- Devoluciones pre-autorizadas.

- Utilización del personal de venta de la tienda para apoyar la venta online.

Como se viene diciendo, los comercios tradicionales tienden a integrar su presencia en Internet con su presencia física generando sinergias y creando valor para el cliente. Esto, lógicamente, tiene consecuencias por lo que se refiere al tipo de cliente al que se llega, así como a los mercados geográficos a los que la empresa puede servir. Trabajando sobre una muestra de empresas holandesas de distintos sectores Adelaar, et al. (2004) concluyen que el tipo de empresas mixtas (comercio tradicional apoyado con presencia online) pueden utilizar estos aspectos para estrechar relaciones con sus actuales clientes de los mercados en los que ya trabajan, pero también sirven para alcanzar a clientes que ya no están en su mercado físico por haberse desplazado, retomando el contacto con los mismos, así como también pueden aprovechar las sinergias generadas para hacer menos costosa y más fácil la compra de productos en sus instalaciones en el mercado físico.

Por otra parte, estas sinergias también pueden conducir a otros beneficios a nivel de empresa. Como apuntan Steinfield et al. (2002) algunas de los más destacables serían la 
reducción de costes, la mejora de la confianza, la diferenciación mediante la aportación de valor añadido o la extensión del mercado geográfico y de producto.

Guenzi y Pelloni (2004) estudian la relación entre el empleado y el cliente en la venta personal y en la venta minorista y apuntan que la calidad de la relación establecida entre ellos afectará a la calidad de la relación que el cliente tenga con la empresa. Así, la relación interpersonal entre el personal de ventas y el cliente tendrá un importante impacto en los resultados relacionales de la empresa vendedora, así como en las intenciones de recompra, facilidad para recomendar a la empresa o para dar buenas referencias de ésta. Además, por lo que respecta al contexto del comercio detallista, las buenas relaciones interpersonales afectan positivamente a la confianza del cliente con respecto al punto de venta (Wong y Sohal, 2003).

De esta manera, en cuanto a la parte de la presencia física del comercio minorista, parece clara la importancia del mantenimiento de buenas relaciones con el cliente, dado que esto afecta positivamente a la satisfacción de éste con la firma, así como a su lealtad y ello supone la reducción del riesgo de que el cliente cambie de proveedor. La generación de confianza en el canal físico es importante, ya que ayudará a reducir la percepción de riesgo que el consumidor pueda tener en el canal online que, como se ha visto anteriormente, supone una barrera para el comercio detallista a la hora de iniciar su presencia en un medio como Internet.

Como hemos apuntado con anterioridad, por otra parte, tenemos la relación online que se establece con los usuarios que entran en contacto con la empresa a través de medios electrónicos como puede ser Internet. Con respecto a esto, Fernández-Sabiote y Román (2012) llegan a la conclusión de que, a pesar de que la influencia del canal físico o tradicional es mayor, el canal online también contribuye al proceso de creación de lealtad del cliente. En este sentido, el valor que aporta el canal electrónico no solo es importante por sí mismo, sino que también se debe tener en cuenta la manera en que ambos se combinan para ofrecer una experiencia total de servicio. Así, el cliente valora el canal online no de manera independiente, sino teniendo en cuenta también sus experiencias previas en su relación con la empresa a través del canal tradicional. De ahí, como se ha 
apuntado en distintos apartados de esta tesis, la importancia de una correcta gestión de marketing que integre todos los canales de contacto de la empresa con el mercado y que no los considere como aspectos o herramientas independientes.

Entrando más en concreto con las ventajas que estas sinergias pueden reportar podríamos centrarnos en cómo puede afectar o qué beneficios puede aportar la existencia de una presencia online del comercio tradicional, independientemente de la posibilidad de que se ofrezca la posibilidad de realizar compras online. Se trataría de ver si es posible que se establezcan sinergias y posibilidad de aprovechamiento de la creación de una página $w e b$ con carácter meramente informativo. La presencia de este tipo de web podría estar relacionada con el comportamiento del consumidor y el proceso de compra. Van Nierop et al. (2011) se plantean la cuestión de si la existencia de una web tan solo informativa del comercio tiene efectos positivos en las ventas en tienda. En la misma línea, Pauwels et al. (2011) analizan si la información que las empresas ofrecen online genera beneficios en las ventas en la tienda física de los comercios. Así, realizan un amplio análisis que hace referencia a distintos aspectos. Por una parte, como se ha apuntado anteriormente, el impacto en las ventas depende mucho de la categoría de producto de que se trate y del segmento de clientes (Pascual del Riquelme y Román, 2012, Flavián y Gurrea, 2007). Parece claro que los costes de búsqueda de información son menores cuando ésta se produce online (Sandulli, 2011). Esto es especialmente beneficioso para clientes que físicamente se encuentran más alejados del punto de venta. En este estudio se concluye que para determinados segmentos se da un aumento de las compras y también del precio medio de los productos, es decir, se compran productos más caros.

A la vista de estos resultados, cabría la opción de plantearse cuáles son las acciones específicas que el comercio debería desarrollar online y sobre qué tipo de público más específico y qué categorías de productos, a fin de potenciar en ellos estos incrementos de ventas y de ingresos.

Siguiendo esta evolución de la integración de canales por parte del comercio minorista se aprecia como el detallista con punto de venta físico permite al consumidor tocar y sentir el producto, además de ofrecerle una entrega inmediata. Por su parte, Internet 
le ofrece una amplia selección de productos, posibilidad de comparar e incluso mejores precios. Todo ello dirigido a la mejor satisfacción de las necesidades del consumidor, si bien, nunca perdiendo de vista la necesidad de plantearse el modelo de negocio detallista adecuado, así como las tecnologías que deberán implantarse para ello y los recursos que les van a ser destinados.

Con la tendencia apuntada por Verhoef et al. (2015) hacia una presencia omnicanal, el comercio minorista puede ofrecer a su cliente una experiencia de compra en la que se eliminen las distinciones y los límites entre los diferentes canales. La gestión omnicanal conlleva un desarrollo de las estrategias del comercio minorista hacia una integración que permita la desaparición de barreras entre los distintos canales. Las empresas podrán ofrecer este tipo de experiencias, por ejemplo, con la presencia de terminales móviles en la tienda de manera que el consumidor pueda usarlos para buscar información, facilitando redes $\mathrm{Wi}$ $F i$ o a través de aplicaciones móviles con las que interactuar con el cliente, tanto en el punto de venta como fuera de él.

"Los omnicanales son la nueva realidad, y los retailers necesitan pensar de manera diferente. Las nociones tradicionales de 'viaje', 'experiencia de compra' o 'cumplimiento y entrega' se han redefinido. Hoy las marcas ganadoras usan una combinación de estrategias en línea y fuera de línea para no sólo ayudar a los consumidores a tomar decisiones informadas, pero también para agregar valor en toda la experiencia de compra dónde y cuándo sea que ésta suceda (Nielsen, 2016)".

Para Piotrowicz y Cuthbertson (2014) el concepto omnicanal se percibe como una evolución del multicanal, si bien, mientras que éste implica una división entre el canal físico y el virtual, en el omnicanal el consumidor se mueve libremente entre el entorno online (ordenadores, dispositivos móviles, etcétera) y el offline en un único proceso sencillo. Los canales móviles y las redes sociales se añaden a los canales más tradicionales, tanto físicos como virtuales para conseguir una transición suave entre ellos y que provea una experiencia única y unificada al consumidor, independientemente de los canales que use (Blázquez, 2014b). 
Posteriormente Verhoef et al. (2015) nos dicen que en la última década el mundo del comercio ha cambiado de forma significativa, pasando de la venta y distribución al por menor multicanal a la omnicanal. Para dichos autores, esta nueva perspectiva de venta al por menor omnicanal adopta una visión más amplia sobre los canales y cómo los compradores pueden verse influenciados y se mueven a través de éstos en su búsqueda y proceso de compra. Esta nueva perspectiva de análisis e investigación, para dichos autores debe desarrollarse en tres ámbitos. El de los canales y los resultados o rendimientos alcanzados como consecuencia de un mayor número de estudios sobre los efectos de las estrategias multicanal, de cómo el incremento de nuevos canales afecta al resultado o rendimiento final de las empresas, aunque se requiere más investigación sobre el efecto contrario, el de la eliminación de canales (Konus et al., 2014). El segundo ámbito es el comportamiento de compra entre los canales, la gestión de los distintos puntos de contacto de la empresa con sus clientes en los distintos canales que opera, y cómo afecta al resultado final de la empresa. Por último, el tercer ámbito de futuros estudios es el de mix del comercio al por menor a través de canales sigue siendo un importante campo de investigación. La necesidad de replantearse si la armonización y la integración entre los distintos canales es siempre bueno para las empresas. Como gestionar el showrooming en este contexto, si es necesario desarrollar distintas políticas de promoción entre canales, como afecta el comportamiento de compra del comprador en el punto de venta en acciones de showrooming, etc. son aspectos de futuros e interesantes debates.

El minorista multicanal utiliza dos o más canales para la venta de sus productos y servicios al consumidor. Normalmente esto vendrá dado por el hecho de que cada vez son más los consumidores que quieren comprar a través de una combinación de canales y, como consecuencia, el consumidor multicanal se está convirtiendo en mayoritario frente al perfil que únicamente utiliza un canal (Lewis et al., 2014).

Un creciente número de consumidores usan múltiples canales durante su "viaje de compra". Este tipo de compradores son conocidos como "omni-compradores" o omnishoppers y esperan tener una experiencia a través de los distintos canales que no presente fisuras (Yurova et al., 2016). 
En el entorno actual un "omnicomprador" podría buscar las características de un producto utilizando una app de su móvil, comparar precios en diferentes webs a través de su ordenador y finalmente comprar el producto en una tienda física. Este consumidor 3.0 usa las nuevas tecnologías para buscar información, ofrecer opiniones, explicar experiencias, hacer compras y hablar de la marca. En un entorno omnicanal los diferentes canales se usan de forma indiferente durante el proceso de búsqueda y compra y es difícil, sino virtualmente imposible, para los detallistas, controlar su uso (Neslin et al., 2014).

En este sentido, el informe de Nielsen (2016), Comercio Global Conectado, señala que las ventas en línea están al alza, pero el miedo de su impacto en el tráfico en las tiendas físicas puede estar inflado. La verdad es que, las compras en línea son un camino de dos vías. Los consumidores no sólo están "showrooming" (echando un vistazo por la tienda y después yendo en línea a buscar los precios más bajos). También están "webrooming" (investigando en línea y comprando en tiendas).

De hecho, no son solo los comercios físicos los que buscan presencia en el canal electrónico, sino que en ocasiones también se da este desplazamiento en sentido contario. Así, en diciembre de 2016, la empresa Amazon, conocida por haber revolucionado la industria del comercio online, dio un nuevo paso para ofrecer su experiencia de compra también fuera del mundo virtual, abriendo en la ciudad de Seattle un supermercado a pie de calle: Amazon Go. Para comprar en la nueva tienda del gigante del e-commerce el comprador debe descargar en su smartphone la aplicación de Amazon Go y contar con una cuenta en Amazon. La tienda cuenta con un alto nivel de tecnologías, ya que está equipada con una serie de sensores y sistemas de análisis de imágenes que sigue a los clientes en el punto de venta y es capaz de detectar en tiempo real los productos que éstos arrojan al carrito de la compra. Para finalizar las compras en Amazon Go el comprador no debe pasar por caja y puede dirigirse simplemente a la salida con los productos adquiridos. El sistema de la tienda lee la aplicación del cliente y cobra automáticamente las compras desde la cuenta del usuario asociada a Amazon. Con este nuevo concepto, esta empresa pretende dar respuesta a la posibilidad de una experiencia de compra sin colas, tal y como sucede de forma virtual. 
Como señalan Verhoef et al. (2015) el cambio del comercio detallista ha sido radical en las dos últimas décadas debido a la irrupción del canal de Internet. Además, nuevos canales digitales adicionales (como el canal móvil) y las Redes Sociales han cambiado los modelos de negocio minoristas, la ejecución del mix de marketing de las empresas y el comportamiento del consumidor. De hecho, estos autores hablan de la evolución del comercio detallista desde los modelos multicanal hacia los llamados modelos omnicanal.

El concepto omnicanal es una evolución del comercio detallista multicanal. Así, mientras este último implica la división entre el comercio físico y online, en el entorno omnicanal el consumidor se mueve libremente entre los canales (online, dispositivos móviles y tienda física), todo ello en un proceso de transacción único (Melero et al., 2016).

Los últimos años están siendo testigos de la emergencia de nuevos canales minoristas. Gracias a las nuevas tecnologías, los comerciantes detallistas pueden integrar toda la información procedente de los diversos canales en el fenómeno conocido como "minorista omnicanal" (Brynjolfsson et al., 2013).

Según Juaneda-Ayensa et al. (2016) una estrategia omnicanal es una forma de comercio minorista (retailing) que, a través de la interacción real, permite a los clientes comprar a través de canales en cualquier lugar y en cualquier momento, proporcionándoles de esta manera una experiencia única, completa y sin fisuras, que rompe las barreras entre canales.

Para estos mismos autores, si como se ha apuntado anteriormente, el comercio móvil se puede considerar como la segunda ola del comercio electrónico (Lu et al., 2005), el comercio omnicanal podría ser considerado como la tercera ola.

Puesto que en el entorno omnicanal los canales se gestionan conjuntamente por parte del minorista, la interacción percibida no es con el canal, sino con la marca (Piotrowicz y Cuthbertson, 2014). Como señalan Verhoef et al. (2015) el entorno omnicanal presta un creciente énfasis en la relación entre los canales y las marcas. 
La característica dominante del minorista omnicanal es que la estrategia se centra en el consumidor y en su experiencia de compra, buscando ofrecer al comprado una experiencia holística de compra (Gupta et al., 2004; Shah et al., 2006).

En este ámbito omnicanal Neslin et al. (2014) describen múltiples rutas de compra para mostrar cómo funciona la interrelación entre consumidor y detallista. Así, el mundo omnicanal no solo amplía el alcance de los canales, sino que también integra la consideración de las interacciones del consumidor con la marca del minorista.

Los consumidores esperan un servicio o una experiencia de compra consistente, uniforme e integrada, independientemente del canal que utilice. Desean moverse indistintamente entre canales (tienda tradicional, online o móvil) dependiendo de sus preferencias, su situación, el momento del día o la categoría del producto (Cook, 2014; Piotrowicz y Cuthbertson, 2014). El comprador omnicanal ya no solo quiere acceder al canal, sino que está siempre en él o incluso en varios a la vez, gracias a las posibilidades que ofrece la tecnología. Estos nuevos compradores quieren usar sus propios dispositivos para realizar búsquedas, comparar productos, pedir consejos o buscar alternativas más baratas durante su viaje de compra para conseguir ventajas de los beneficios que ofrece cada canal (Yurova et al., 2016).

En este sentido, Court et al. (2009) de la consultora McKinsey\&Company, hablan del viaje de decisión del consumidor (The Consumer Decision Journey) para explicar el nuevo comportamiento de compra del consumidor actual. Para estos autores el objetivo del marketing es alcanzar a los consumidores en el momento en el que más se influencie su decisión de compra. Durante muchos años, se ha considerado que el consumidor partía de un número de marcas potenciales que tenía en su mente para tomar la decisión. Sin embargo, debido a la proliferación actual de canales digitales y de posibilidades de elección, así como a un consumidor más informado, se necesita una aproximación más sofisticada que estos autores denominan el viaje de decisión del consumidor, ya que éste está cambiando la manera en la que busca y compra productos. Por ello los autores consideran que es importante no solo alinear todos los elementos del marketing con el 
viaje que el consumidor realiza cuando toma sus decisiones de compra, sino también integrar todos esos elementos en la organización.

El mapa del viaje del consumidor es una herramienta ampliamente utilizada para representar la experiencia del usuario con un servicio (Moon et al., 2016).

Como señalan Komarov y Avdeeva (2015) la gran cantidad de dispositivos conectados a Internet afectan a la forma de vida habitual de las personas. La gente, en la actualidad, intentan encontrar una manera de utilizar todos los dispositivos que poseen de la forma más eficaz posible.

En esta línea es destacable el hecho de que, según el informe de Ditrendia (2016), el móvil aparece cada vez con mayor frecuencia a lo largo de los procesos de compra. En el mundo, el $82 \%$ de los usuarios de móviles asegura que utiliza su teléfono móvil para buscar información sobre productos antes de realizar una compra. Además, en España, 9 de cada 10 usuarios asegura que utiliza el móvil en alguna ocasión durante el proceso de compra, ya sea para buscar información sobre los productos (80\%), para comparar precios (78\%) o buscar opiniones de otros usuarios (72\%).

La publicidad emplea diferentes canales para alcanzar a los consumidores en Internet, quienes, a su vez, toman contacto con la empresa a través de múltiples canales a lo largo de su "viaje del consumidor". A pesar de esto, evaluar el grado en que cada canal contribuye al éxito del marketing y las formas en las que los canales influyen entre ellos, sigue siendo un reto (Anderl et al., 2016).

Así, cabe destacar que la publicidad online es esencial en el mix de comunicación de muchas industrias, tal y como señalan Raman et al. (2012). En la actualidad, las empresas utilizan una variedad de canales de marketing online para llegar a sus potenciales clientes, incluyendo búsquedas pagadas y display marketing, así como correo electrónico, programas de afiliación, comparaciones de precios y publicidad en las redes sociales. A la vez, los consumidores también visitan las páginas web de las empresas por su propia iniciativa. Así, a través de distintos canales, muchos consumidores entran en contacto con 
la empresa numerosas veces antes de tomar su decisión de compra (Li y Kannan, 2014). Las visitas previas pueden influenciar a las posteriores, de forma que en su viaje el consumidor puede volver a la website de la empresa a través de un mismo canal o incluso de diferentes canales (Anderl et al., 2016).

El concepto de uso de la Web 3.0 en el comercio electrónico está en la actualidad estrechamente relacionado con el concepto de comercio inteligente (Komarov y Avdeeva, 2015).

Vemos, pues, como son cada vez más los canales a través de los cuales el comercio detallista puede entrar en contacto con su público objetivo. En este sentido, los distintos estudios citados con anterioridad destacan el cambio que esto ha supuesto en el comportamiento del consumidor que realiza un viaje de compra antes de tomar su decisión con respecto a la misma y cómo dicho cambio afecta a la forma en que el detallista se puede relacionar con su mercado.

Por otra parte, en un marco como el descrito en el que conviven múltiples canales, el minorista deberá tener en cuenta el tema de la gestión de la marca en un entorno diferente como es Internet y las particularidades que éste puede presentar. La ausencia de contacto físico con el cliente hace que la creación de marca online no sea fácil. Es por ello que las empresas poco conocidas o bien que tengan poca historia, tendrán mayor dificultad a la hora de ganarse la confianza el mercado (Porter, 2001). La marca cobra relevancia si el minorista es consciente de que una de las principales funciones de ésta en el entorno virtual es, tal y como apuntan Smith y Sivakumar (2004), el disminuir el costo de búsqueda y el riesgo percibido por el consumidor, así como aportar confianza y calidad.

La marca puede, por tanto, contribuir a minimizar el riesgo percibido por el consumidor, influyendo así en la probabilidad de que éste compre a través de Internet. Es por ello que los gestores de marketing deben intentar llevar a cabo nuevas estrategias que fortalezcan las asociaciones de marca para responder eficazmente al siempre cambiante entorno del mercado (Virutamasen et al, 2015). Así, el presente trabajo se plantea profundizar en el Valor de Marca del comercio detallista, introduciendo la influencia de la 
experiencia del cliente con el mismo, pero también analizando que papel pueden jugar las nuevas tecnologías en la valoración que los consumidores hacen de una marca. Además, el minorista no puede perder de vista el aspecto de la gestión de la marca en todos los canales en los que está presente, ya que no tenerlo en cuenta podría suponer crear confusión en el consumidor, con consecuencias como la falta de confianza o la pérdida de lealtad.

Del análisis realizado en este apartado se puede concluir que las tecnologías de la información y comunicación han supuesto un cambio en el comercio detallista tradicional que le ha llevado a plantearse cómo quiere competir en su entorno.

Por una parte, se ha destacado cómo estas tecnologías pueden ser usadas en el punto de venta a la hora de contactar con el cliente y facilitar la creación de experiencias, si bien, quizás uno de los aspectos que más ha impactado al comercio ha sido la irrupción de Internet como canal de ventas.

Ante esta situación se han analizado las distintas opciones que se pueden presentar para el minorista y que van desde mantener únicamente presencia en un canal hasta buscar la presencia en todos los disponibles. Una vez tomada esta decisión, se plantea para el comerciante la cuestión de cómo gestionar los canales. Como se ha podido apreciar, en este punto es especialmente relevante el planteamiento del modelo de negocio que se quiere para competir en el mercado. Así, se abren diversas posibilidades que abarcan desde la gestión independiente de los canales hasta su completa integración.

En el caso de optar por una presencia multicanal o incluso omnicanal, el detallista debe ser consciente de que una correcta integración puede propiciar una serie de sinergias positivas entre los distintos canales que le hagan mejorar los resultados globales de su empresa, mientras que una gestión equivocada puede suponer una serie de problemas de cara al consumidor que afecten a la imagen y a los resultados.

Ante esta situación en la presente tesis se tendrá en cuenta la importancia de las tecnologías de la información y la comunicación a la hora de crear experiencias de compra y cómo éstas pueden influir en la valoración que el consumidor hace de la marca del 
comercio detallista, puesto que, como se ha visto, pueden contribuir, no solo a la creación de experiencias en el punto de venta, sino que correctamente gestionadas en los distintos canales pueden ayudar a crear marca, confianza, lealtad, ventas cruzadas y otra serie de beneficios, tanto para la empresa como para el consumidor. 


\section{3 - IMPORTANCIA DE LA MARCA EN EL COMERCIO DETALLISTA}





\section{IMPORTANCIA DE LA MARCA EN EL COMERCIO DETALLISTA}

Como señalan De Chernatony et al. (2013) a la hora de hablar de la importancia de la marca debe quedar claro que no se trata solo de un producto físico, sino de una relación con el cliente, personificada en el nombre de la empresa o en el de la marca en el propio producto. Esto es así porque no son las fábricas las que producen beneficios, sino su relación con los clientes y es la empresa y la marca las que aseguran estas relaciones.

En opinión de estos autores las características físicas de los productos son cada vez más difíciles de diferenciar y fáciles de imitar. En una situación así, ante una ausencia de una marca fuerte, la decisión de compra del consumidor ser basará en el precio o en la disponibilidad del producto.

Para Berrozpe (2015), “en los altamente competitivos mercados de hoy en día es absolutamente necesario para las empresas encontrar a través de sus principales activos intangibles, las marcas, fuentes de ventaja competitiva que no sean imitables a corto plazo por los rivales".

En el presente punto se pretende hacer un análisis del concepto de marca, así como la evolución del mismo y de la gestión de la marca (Brand Management) a lo largo del tiempo. También se abordará la importancia del Valor de Marca para el comercio minorista como factor contribuyente a la mejora de su competitividad. Por último, se analizarán las distintas dimensiones del Valor de Marca, estableciendo diferentes hipótesis de trabajo para la presente tesis. 


\subsection{Concepto de marca y su gestión (Brand Management)}

Cuando se habla de marketing y de consumidores, no hay que olvidar la importancia de la marca como elemento diferenciador de la oferta de la empresa. Debido a esto, es relevante la correcta gestión que deben hacer las empresas en lo que se refiere a sus marcas. Esto es válido no solo para las grandes empresas sino también para las Pymes y los comercios detallistas, independientemente de cuál sea su tamaño. La marca ayudará a perfilar la relación que el cliente establece con la empresa.

La creciente competencia existente en el mercado hace necesario que las empresas entiendan, gestionen y construyan una fuerte posición para sus marcas (Celly y Knepper, 2010), haciéndose necesario para cualquier empresa la aplicación de técnicas de marketing para competir de manera eficaz, incluidas las relativas a la gestión de marca (Chapleo, 2011; Hemsley-Brown y Oplatka, 2006).

En el presente apartado se va a analizar el concepto de marca teniendo en cuenta la aportación de diversos autores, así como distintas perspectivas desde las cuales ha sido estudiado y definido el concepto. También se procederá a dar una visión de las diferentes opciones que se han venido planteando por la literatura a la hora de gestionar la marca (Brand Management).

A pesar de que en el ámbito académico se ha discutido y debatido ampliamente sobre las marcas, no se ha llegado a un concepto común entre los expertos (Kumar y Mishra, 2012). Como indica Kapferer (2004), cada experto aporta su nueva definición de marca o bien matices a las ya existentes, lo que incrementa la complejidad en la interpretación de lo que se considera marca y su gestión.

Así, la literatura ha procedido a conceptuar la marca desde distintos prismas. En ocasiones se da una definición basada en un punto de vista que tiene en cuenta el propósito de la marca, mientras que en otras se define en función de sus características o incluso hay conceptos desde un punto de vista más amplio y que tienen en cuenta el plus que una marca puede aportar a un producto. 
De Chernatony y Dall'Olmo (1998) ya en su momento hicieron un análisis de diferentes estudios publicados hasta esa fecha sobre el concepto de marca, identificando que ésta consta de doce elementos principales, en base a los cuales se han desarrollado las distintas definiciones del concepto. En primer grupo se encuentran aquellas interpretaciones que consideran la marca como un instrumento legal. Otro grupo entiende la marca como un logotipo. En ocasiones también se identifica marca con empresa, mientras que otras veces se considera como una abreviatura. Una quinta corriente se centra en la marca como un elemento reductor del riesgo. También se considera como un sistema de identidad. Otra corriente muy relacionada con el marketing, considera la marca como la imagen que se forma en la mente de los consumidores. En ocasiones se ve como un sistema de valores, se considera que tiene un elemento importante relacionado con la personalidad, se ve también como una relación entre la empresa y el consumidor, como algo que añade valor o incluso como una entidad en evolución a lo largo del tiempo.

Estos doce elementos no son excluyentes y, además, cada uno de ellos toma una perspectiva bien desde el punto de vista de la empresa o bien desde el punto de vista del cliente (aunque en algunos casos, ambas pueden coincidir). Como se verá más adelante, esto sucede también cuando se define Valor de Marca, ya que en ese caso se dan también distintas ópticas de análisis.

Así, la Asociación Americana de Marketing (AMA), en 1960 dio la siguiente definición de marca: "un nombre, símbolo o diseño, o una combinación de ellos, dirigida a identificar los productos o servicios de un vendedor o grupo de vendedores y a diferenciarlos del resto de competidores". Es decir, en la línea de los autores anteriores, esta definición identificaría marca con logo y destacaría el aspecto de herramienta de diferenciación.

Sin embargo, han sido numerosos los autores que han considerado que la definición de la American Marketing Association se centra demasiado en el producto y cómo la marca sirve para diferenciarlo en función de aspectos visuales como el símbolo o el diseño (Forero y Duque, 2014; Kotler y Keller, 2012; Morales, 2007; Benett, 1988). Como indican Kumar y Mishra (2012) la marca no debería limitarse a un nombre, término, 
diseño, símbolo o combinación de ellos, sino que debería añadir otras características. En esta línea, Benett (1988) ofrecía una ampliación con respecto a la definición de marca de la American Marketing Association. Para este autor la marca es un nombre, término, diseño, símbolo o cualquier otra característica que identifique el producto o servicio de un vendedor como distinto o diferente de los de otros vendedores.

En esta nueva definición, o más bien ampliación de la anterior, apreciamos como no se limita a aspectos únicamente visuales, sino que también se incluye "cualquier otra característica" que acompañe al producto o servicio y que, además, lo diferencie del resto de productos y servicios de la competencia que haya o pueda haber en el mercado (Aaker, 1992). Esto abre la puerta a aspectos intangibles y que tanta importancia han adquirido en los últimos tiempos como factores clave para conseguir la diferenciación (Forero y Duque, 2014).

Ante estas consideraciones y evolución del concepto, la American Marketing Asociation (2016) ofrece una nueva definición de marca como "nombre, término, diseño, símbolo, o cualquier otra característica que identifique el bien o servicio de un vendedor y lo diferencie de los demás vendedores de la competencia”.

En la evolución que se aprecia en cuanto a las distintas definiciones de marca que la literatura ha aportado a lo largo del tiempo, Kotler y Armstrong (2008) no se limitan a asociarla con un producto, sino que también tienen en cuenta los servicios, al tiempo que destacan su aspecto identificador y diferenciador cuando consideran la marca como "un nombre, un término, un signo, un diseño o una combinación de todos estos elementos, que identifica al fabricante o vendedor de un producto o servicio y que lo diferencia de la competencia”.

Sin embargo, algunos autores siguen opinando que la marca no puede limitarse o identificarse únicamente con un logo, sino que debería tener en cuenta otros aspectos que capturasen la esencia global del concepto (Kumar y Mishra, 2012). 
Otro gran grupo de definiciones toma como punto de partida de la marca su consideración como un instrumento legal. Así, para Crainer (1985) la marca es una declaración legal de propiedad. Esta descripción es similar a la que se puede encontrar en el Diccionario de la Real Academia de la Lengua (2016) cuando considera que la marca es un "distintivo o señal que el fabricante pone a los productos de su industria, y cuyo uso le pertenece exclusivamente".

Las definiciones encuadradas en esta línea están muy relacionadas con el concepto de Marca Registrada, ya que depende de la capacidad para proteger una marca en el sentido legal (Simonson e Itamar, 1994). En este caso, se aprecia como estas definiciones se centran en el fabricante y no capturan la esencia de la marca, ya que no tienen en cuenta el punto de vista del consumidor.

Otro grupo de concepciones de marca, tal y como señalaban De Chernatony y Dall'Olmo (1998) se producen partiendo desde el aspecto de marca como empresa. Así, la identidad corporativa es vital puesto que otorga una ventaja competitiva a las organizaciones (Van Reil y Balmer, 1979).

Una empresa es conocida por sus marcas (Varadaranjan et al., 2006). En este sentido, Kumar y Mishra (2012) señalan que, compartiendo el valor conseguido por el nombre corporativo, las líneas de producto se convierten en una extensión de la identidad corporativa.

En este punto hay que destacar las aportaciones de Aaker (1996) quien opina que la mayor parte de empresas se limitan a gestionar la marca en una única categoría de producto o en mercados concretos de su interés, mientras que, según el autor, la expansión de la perspectiva hacia diferentes categorías de productos y mercados puede tener un valor significativo que permitirá a la empresa gestionar su cartera de productos y mercados, realizar políticas de benchmarking frente a los líderes, así como desarrollar un sistema válido para medir el valor de la marca. 
Para una corriente de la literatura, la marca puede ser entendida en función de su capacidad para ser un referente sencillo de una oferta, es decir, que puede ser una manera simple de expresar o referirse a la oferta que una empresa propone al mercado tal y como indican Kumar y Mishra (2012). Brown (1992) ya señalaba que la marca es la suma de todas las conexiones mentales que la gente tiene sobre la misma. De esta manera, Keller (2003) indica que los nombres de marcas proporcionan accesos directos en la memoria. De esta manera, los consumidores, con el paso del tiempo son más propensos a comprar marcas cuyo nombre reconocen (Chevan, 1992). Sin embargo, como indica Kapferer (2004), las marcas son algo más que asociaciones mentales, puesto que las marcas fuertes también tienen una fuerte asociación emocional.

La marca también ha sido estudiada como reductora de riesgo para los consumidores, ya que estos perciben un riesgo cuando van a adquirir un producto o servicio (Bauer et al., 2009). En este sentido, la marca jugaría un papel importante a la hora de aumentar la confianza del cliente.

Para Kapferer (2004) el riesgo que los consumidores perciben puede ser tanto económico (unido al precio), como funcional (unido al rendimiento), psicológico (referido al autoconcepto), social (en función de la imagen social del individuo y experimental (relacionado con las experiencias que se van a ofrecer).

La importancia de la marca es destacada por Kotler y Keller (2012) cuando afirman que el consumidor puede evaluar un mismo producto de manera diferente en función de cuál sea su marca. Además, los consumidores aprenden sobre las marcas gracias a las experiencias que hayan tenido en el pasado con sus productos y programas de marketing, de manera que diferencian así las marcas que satisfacen correctamente sus necesidades de las que no lo hacen. La marca permite, de esta forma, simplificar las decisiones de compra de los consumidores y reducir los riesgos que conllevan. Una marca creíble es señal de un determinado nivel de calidad, lo que hace que los consumidores satisfechos vuelvan a elegir esa marca en el momento de la compra. 
En este sentido, Suri y Monroe (2003) demuestran que las percepciones de calidad y de sacrificio económico que tienen que hacer los consumidores, muestran diferentes modelos de respuesta en función de aspectos como la presión del tiempo disponible por parte de éstos, los niveles de precio y las motivaciones internas del sujeto a la hora de procesar la información que recibe.

Como se desprende de los distintos estudios enfocados al análisis del concepto de marca, ésta no es simplemente un nombre que se le da a un producto. Así, Davcik et al. (2015) consideran que la marca es una garantía del vendedor de que éste, de forma continua y consistente, ofrecerá sus promesas, basadas tanto explícitamente como implícitamente en aspectos tangibles, umbrales específicos de calidad y beneficios y conveniencia para el consumidor. Para estos autores la marca debe contribuir a la diferenciación del producto cuando el consumidor tenga información asimétrica sobre su calidad y prestaciones, así como a crear mecanismos de lealtad hacia el producto ante la entrada de nuevos competidores en el mercado.

Bajo determinadas situaciones de incertidumbre, el consumidor, tal y como apuntan Swoboda et al. (2016), tiende a buscar más información antes de tomar la decisión de compra, de manera que se minimice así el riesgo, principalmente en los casos de compra de productos que impliquen un significativo o importante desembolso de dinero, es decir, para productos de compra esporádica.

La marca vista como un sistema de identidad es analizada por diversos autores. Kapferer (2004) concibe la marca como una estructura de identidad, compuesta por facetas culturales, de personalidad, de proyección, físicas, reflexivas y de relaciones.

Por su parte, Aaker (1996) apuntaba la importancia del papel de la identidad de marca para desarrollar su posicionamiento. Una marca con una identidad fuerte refuerza el significado que ésta tiene para el consumidor, comunica la esencia de la marca y fortalece una concepción estratégica de la misma. 
Desde un punto de vista de la marca como una imagen en la mente del consumidor, también son diversos los autores que abordan el tema. Autores como Keller (1993) definen la marca como la idea que los consumidores tienen de un producto, siendo la asociación que éstos hacen en su mente.

Teniendo en cuenta este concepto más amplio, Kotler (1992) considera que la marca reside en la mente de los consumidores. Para la correcta construcción de la marca se deberá proceder al posicionamiento de ésta, comunicar el mensaje que se quiere asociar a la marca, presentar sus características y afianzar su valor (Bhimrao M.G., 2008).

Siguiendo con la agrupación de conceptos propuesta por De Chernatony y Dall'Olmo (1998), una corriente de estudios centra su análisis en la marca como un sistema de valores, como ya hicieron Sheth et al. (1991) al considerar que las decisiones de elección de marca están influenciadas por cinco valores de consumo: funcional, social, emocional, espistémico y condicional. Como señalan Franzen y Moriarty (2008) las decisiones de los consumidores vienen influenciadas por valores personales y culturales.

La marca entendida como personalidad reúne un buen grupo de autores que la analizan entendiéndola como una personalidad simbólica que el consumidor valora más allá de sus utilidades funcionales (Goodyear, 1996). A la hora de elegir una marca, el consumidor se fija en cómo la personalidad percibida de la misma se adapta a la personalidad que él intenta proyectar (Zinkhan et al., 1996).

Por su parte, Moore y Reid (2008) consideran que la marca ha ido aportando diferentes características a lo largo del tiempo, tales como estatus, valor añadido, etcétera, hasta el desarrollo del concepto de personalidad de marca.

Aaker (1996) describía la personalidad de marca como una metáfora que puede ayudar al estratega de la marca enriqueciendo su conocimiento de las percepciones de la actitud hacia la marca, contribuyendo a diferenciar la identidad de la misma y ayudando a que los esfuerzos de comunicación contribuyan a crear valor de marca. Basándose en esto, son diversos los estudios que sugieren la influencia de la personalidad de la marca en las 
preferencias del cliente, en su comportamiento y en su experiencia (Rauschnabel et al., 2016; Eisend y Stokburger-Sauer, 2013).

Por su parte, la Asociación Americana de Marketing (2016) define la personalidad de marca como "naturaleza psicológica de una marca en particular como se pretende por sus vendedores, aunque las personas en el mercado puedan verla de otro modo (imagen de marca evocada). Estas dos perspectivas se comparan con las personalidades de los seres humanos individuales: lo que pretenden o desean y lo que ven o creen”.

Otro grupo de definiciones consideran la marca como una relación. La personalidad vista anteriormente, es un requisito previo para que se dé la relación entre el consumidor y la marca, ya que una relación es una extensión lógica de la personalidad de marca y si ésta puede ser personificada, los consumidores no solo la percibirán, sino que también entablarán relaciones con ella (Kapferer, 2004). Como indican Kumar y Mishra (2012) la marca es la expresión de la relación entre el consumidor y el producto.

La marca también es definida desde el punto de vista de valor añadido. Dentro de esta corriente, para Farquhar (1989) ésta es un "nombre, símbolo o diseño que realza el valor de un producto más allá del propósito funcional. Dependiendo del contexto en el que se considere, la marca puede agregar valor a la firma, comercio o consumidor". Vemos como, en la definición aportada por este autor, así como en la conceptualización de Aaker (1991) se contempla la marca desde un punto de vista que no la liga exclusivamente al producto y a sus características, sino que tiene en cuenta la posible aportación de valor más allá de las mismas.

En cuanto al valor añadido, se puede decir que es un concepto que, al igual que el de Valor de Marca, ha ido evolucionando con el tiempo. Así, Wood (1996) señalaba que la manera en que se utiliza este concepto en marketing no es la misma que la utilizada desde el punto de vista contable. Desde el punto de vista del marketing el valor añadido no es cuantificable y se considera como un beneficio aportado al cliente, mientras que desde la perspectiva contable sí que se puede cuantificar y es considerado como algo que devenga beneficios a la organización. Dentro del concepto de valor añadido, la autora apunta que 
hay distintos aspectos o factores, la suma de los cuales componen el valor añadido. Además, parte de la actividad del marketing se basa en la correcta gestión de estos factores, dentro de los cuales hay que destacar la gestión de la marca, lo que conducirá a mejorar el valor añadido, redundando en mayores beneficios para la empresa.

Wood (2000) define la marca como un mecanismo del que disponen las empresas para alcanzar una ventaja competitiva a través de la diferenciación. Los atributos que diferencian a una marca aportan al consumidor satisfacción y beneficios por los cuales están dispuestos a pagar. La ventaja competitiva para las empresas se reflejará en términos de ingresos, beneficios, valor añadido o cuota de mercado.

Para la American Marketing Association (2016) el valor añadido es un concepto económico referido al valor que la empresa añade al coste de sus inputs como resultado de sus actividades, de modo que se refleja en sus outputs (productos y servicios). Además, Kumar y Mishra (2012) señalan que estos valores añadidos son percibidos de diferentes formas en función de los individuos e incluso de un segmento específico.

A la vista de lo expuesto anteriormente, se aprecia como la marca ha evolucionado desde productos sin marca a referencias en las que el nombre se utiliza para su identificación, incluso hacia una personalidad que ofrece atractivos emocionales más allá de los beneficios del propio producto Kumar y Mishra (2012).

Inicialmente, tal y como indica Tuominen (1999) las marcas han servido para diferenciar los productos propios de los de la competencia, representando una determinada consistencia en su calidad y dando protección legal frente a las posibles copias. Ahora bien, más allá de esto, la marca puede tener un poderoso significado simbólico. La marca en si misma puede llevar implícita un status, mejorar la imagen y proyectar o aumentar un determinado estilo de vida, lo que puede conducir a la lealtad del consumidor hacia la marca, impedir la entrada de competidores en el mercado y aportar a sus propietarios la posibilidad de establecer precios mayores y mejores márgenes de beneficios. 
Por su parte, Konecnik, y Ruzzier (2013) en un acercamiento al concepto de marca, consideran que ésta ha sufrido una evolución hacia una entidad compleja que va más allá de su consideración tradicional, basada en las características visuales como factor de diferenciación, para tener en cuenta otros aspectos que consideren las condiciones cambiantes del mercado. De esta forma, a pesar de que los principios relativos a la gestión de marca se hicieron en sus inicios pensando en marcas de productos, un enfoque más moderno deberá tener en cuenta otras categorías como los servicios, organizaciones y destinos. Por tanto, será necesario realizar los ajustes necesarios para que el concepto de marca considere las particularidades de estas categorías.

Tabla 3.1. Evolución del concepto de Marca

\begin{tabular}{|c|c|}
\hline Definición de Marca & Características \\
\hline American Marketing Asociation (1960) & \\
\hline $\begin{array}{l}\text { Un nombre, símbolo o diseño, o una combinación de ellos, } \\
\text { dirigida a identificar los productos o servicios de un vendedor o } \\
\text { grupo de vendedores y a diferenciarlos del resto de competidores. }\end{array}$ & Identificación y diferenciación. \\
\hline $\begin{array}{l}\text { Van Reil y Balmer (1979). } \\
\text { La marca entendida como empresa supone que la identidad } \\
\text { corporativa es vital puesto que otorga una ventaja competitiva a } \\
\text { las organizaciones. }\end{array}$ & $\begin{array}{l}\text { Marca como empresa y ventaja } \\
\text { competitiva. }\end{array}$ \\
\hline $\begin{array}{l}\text { Craimer (1985) } \\
\text { La marca es una declaración legal de propiedad. }\end{array}$ & Instrumento legal. \\
\hline $\begin{array}{l}\text { Bennett, P.D. (1988) } \\
\text { Nombre, término, diseño, símbolo o cualquier otra característica } \\
\text { que identifique el producto o servicio de un vendedor como } \\
\text { distinto o diferente de los de otros vendedores. }\end{array}$ & $\begin{array}{l}\text { Cualquier otra característica } \\
\text { (intangibles). Identificación y } \\
\text { diferenciación. }\end{array}$ \\
\hline $\begin{array}{l}\text { Brown (1992) } \\
\text { La marca es la suma de todas las conexiones mentales que la } \\
\text { gente tiene sobre la misma. }\end{array}$ & $\begin{array}{l}\text { Marca como referente de la } \\
\text { oferta de la empresa. }\end{array}$ \\
\hline
\end{tabular}


Kotler, P. (1992)

Nombre, término, signo, símbolo, diseño o combinación de ellos, dirigidos a identificar los productos y servicios de un vendedor entre un grupo de vendedores y a diferenciarlos de los de la competencia.

Identificación y diferenciación.

Keller (1993)

Idea que los consumidores tienen de un producto, siendo la asociación que éstos hacen en su mente.

Simonson e Itamar (1994)

Marca Registrada como capacidad para proteger una marca en el sentido legal.

Goodyear (1996)

Personalidad simbólica que el consumidor valora más allá de sus utilidades funcionales.

Farquhar (1989)

Nombre, símbolo o diseño que realza el valor de un producto más allá del propósito funcional. Dependiendo del contexto en el que se considere, la marca puede agregar valor a la firma, comercio o consumidor.

Tuominen, P. (1999)

Nombre, término, signo, símbolo, diseño o combinación de ellos que diferencia los productos propios de los de la competencia, representando una determinada consistencia en su calidad y dando protección legal frente a las posibles copias.

Wood, L. (2000)

Mecanismo del que disponen las empresas para alcanzar una ventaja competitiva a través de la diferenciación.

Imagen en la mente.

Marca como instrumento legal.

Marca como personalidad.

Valor añadido.

Diferenciación, consistencia de calidad, protección legal y significado simbólico.

Ventaja competitiva y diferenciación.

Keller (2003)

Los nombres de marcas proporcionan accesos directos en la memoria.

Marca como referente de la oferta de la empresa.

Kapferer (2004)

Estructura de identidad, compuesta por facetas culturales, de

Sistema de identidad. personalidad, de proyección, físicas, reflexivas y de relaciones. 


\section{Kapferer (2004)}

Las marcas son algo más que asociaciones mentales, puesto que las marcas fuertes también tienen una fuerte asociación emocional.

Varadaranjan et al. (2006)

La empresa es conocida por sus marcas.

Asociación mental y asociación emocional.

Marca como empresa

Kotler y Armstrong (2008)

Nombre, un término, un signo, un diseño o una combinación de todos estos elementos, que identifica al fabricante o vendedor de un producto o servicio y que lo diferencia de la competencia.

Bauer et al. (2009)

La marca sirve para reducir el riesgo por parte de los consumidores, ya que estos perciben un riesgo cuando van a adquirir un producto o servicio.

Kumar y Mishra (2012)

La marca es la expresión de la relación entre el consumidor y el producto.

Davcik et al. (2015)

Garantía del vendedor de que éste, de forma continua y consistente, ofrecerá sus promesas, basadas tanto explícitamente como implícitamente en aspectos tangibles, umbrales específicos de calidad y beneficios y conveniencia para el consumidor.

American Marketing Asociation (2016)

Nombre, término, diseño, símbolo, o cualquier otra característica que identifique el bien o servicio de un vendedor y lo diferencie de los demás vendedores de la competencia.
Identificación y diferenciación.

Reducción de riesgo.

Marca como relación.

Garantía de consistencia.

Diferenciación y lealtad.

Cualquier otra característica

(intangibles). Identificación y

diferenciación.

Fuente: elaboración propia

Una vez analizado el concepto de marca y las distintas acepciones que se han venido dando por la literatura, cabe ahora entrar en el concepto de gestión de marca o branding y la importancia del mismo de cara a la creación de valor para la empresa, así como para el comercio minorista. 
La American Marketing Association (2016) indica que la estrategia de branding de una empresa es el intento de desarrollar una reputación de marca fuerte para aumentar el conocimiento de marca y crear un número elevado de impresiones.

Kotler (1992) definió la marca como un nombre, término, signo, símbolo, diseño o combinación de ellos, dirigidos a identificar los productos y servicios de un vendedor entre un grupo de vendedores y a diferenciarlos de los de la competencia. La marca identifica al vendedor o al fabricante, pero si una empresa gestiona la marca únicamente como un nombre, se pierde todo el sentido de la gestión de la marca (branding). El reto para una empresa, consiste en desarrollar un conjunto de significados profundos que se asocien a su marca (Kotler, 1994).

Para Kotler y Keller (2012) el branding consiste en dotar a los productos y servicios del poder que les confiere una marca, con el objetivo de crear diferencias con respecto a otros productos. La gestión de marcas ayuda a crear estructuras mentales que ayudan al consumidor a organizar sus ideas sobre productos y servicios, de manera que éste pueda clarificar su toma de decisiones de compra y que, además, en este proceso, aporte valor a la empresa. Así pues, la marca puede ser una herramienta poderosa para alcanzar la diferenciación, y a su vez, ésta puede significar una importante estrategia competitiva de marketing (Tasci et al., 2007).

La gestión de marca, también conocida como Branding o Brand Management consiste en diseñar y gestionar o dirigir las marcas de una empresa para incrementar su valor neto (Budac y Baltador, 2013), de ahí la importancia que esto puede suponer para el éxito de la empresa en el mercado.

Forero y Duque (2014) señalan como la marca es un activo intangible que las organizaciones deben gestionar para incrementar su valor en el mercado. Además, como se verá en el epígrafe del presente trabajo dedicado al Valor de Marca (Brand Equity), su medición puede basarse en distintas perspectivas, tales como la financiera o la que se centra en el enfoque del cliente desde el punto de vista del marketing. 
En este sentido, Larkin (2013) cuando estudia el impacto de un activo intangible de importancia para la política financiera de la empresa, como es la marca, señala que este tipo de activos juegan un papel importante en su política financiera. Así, si bien hay parte de la literatura que ha asumido que los intangibles aumentan el riesgo de la empresa porque su valor se puede destruir cuando hay dificultades financieras o en situaciones de crisis económicas (Belo et al., 2012; Gourio y Rudanko, 2011), en opinión de estos autores, la percepción de la marca afecta a la política financiera mediante la reducción del riesgo general de la empresa, ya que las fuertes evaluaciones que los consumidores hacen de ésta y la percepción positiva que tienen de sus productos, se traduce en una menor volatilidad del cash flow en el futuro, así como en unos ratios de crédito mayores para empresas potencialmente más volátiles, lo que ayuda a aislarlas en períodos de recesión. De esta manera, los menores riesgos que supone tener una marca fuerte, hacen que aumente la posibilidad de que la empresa pueda hacer frente de mejor manera a sus futuras obligaciones financieras y reduzca fricciones en sus finanzas, permitiéndole tener niveles más altos de endeudamiento y menores colchones en efectivo. La autora también apunta el hecho de que el impacto que puede tener la marca es más fuerte entre las pequeñas empresas.

Así, son diversos los autores que destacan el valor que aporta la marca como activo intangible para las empresas (Morales, 2007), las cuales generan estrategias de marketing enfocadas a la construcción y sostenibilidad de la marca a largo plazo, teniendo en cuenta que entre las funciones de ésta se encuentra el identificar el origen y el fabricante del producto, permitiendo al comprador atribuir responsabilidades al productor o vendedor del bien o servicio (Kotler y Keller, 2016).

Con el correcto desarrollo del conocimiento sobre la gestión de marca y de técnicas para diferenciar bienes y servicios de funcionalidad similar que de otra forma serían difícilmente diferenciados, las organizaciones son capaces de explotar completamente sus recursos y añadir valor a la oferta que presentan al mercado. Así, una organización estará haciendo las cosas correctamente cuando gestione de manera adecuada su cartera de marcas e invierta en ella (Davick et al., 2015) 
En cuanto a cómo se debería gestionar la marca, Tuominen (1999) considera que hay dos aproximaciones principales a la gestión de marcas de productos: por una parte, están las marcas del fabricante y por otra, las marcas blancas, también llamadas marcas del distribuidor.

En lo que hace referencia a las marcas del fabricante, según este autor, intentan dirigirse a un segmento amplio de consumidores que buscan buena calidad con un bajo riesgo de que el producto no sea adecuado. Normalmente las empresas dedican cantidades importantes de dinero a dar a conocer sus marcas y, en ocasiones, colaboran con los minoristas en la realización de sus campañas de comunicación, de forma que se compartan los costes de las mismas.

Por lo que respecta a las marcas del distribuidor, aparecen cuando algún miembro del canal (por ejemplo, un minorista) es capaz de vender productos usando su propio nombre o su propia marca (Burton et al., 1998). Con el paso del tiempo, estas marcas, en muchos casos, han ido evolucionando y son gestionadas de la misma manera y bajo los mismos principios que las marcas de fabricantes. Además, su crecimiento ha dado lugar a que hayan ido adquiriendo cada vez mayor relevancia y poder, aumentando así su control sobre los proveedores.

También es destacable, dentro del marco de la presente tesis, el hecho de que Farquhar (1989) tiene en cuenta la aportación de valor que la marca puede suponer para un comercio. Como se verá más adelante, el comercio detallista deberá cuidar el aspecto de la gestión de su marca, precisamente para obtener un valor que pueda ser importante a la hora de que el consumidor decida dónde va a realizar su compra. Más, teniendo en cuenta que la correcta gestión de estos valores intangibles pueden llevar a la diferenciación con respecto a los competidores, influyendo en las preferencias del consumidor y aumentando el nivel de satisfacción del cliente, lo que a menudo conducirá a una mayor lealtad del mismo (Davcik y Vinhas, 2015).

Siguiendo las prácticas que vienen utilizando desde hace tiempo los fabricantes, las empresas dedicadas al comercio detallista buscan cada vez con mayor intensidad 
estrategias para gestionar sus marcas porque tener una marca fuerte es de extrema importancia para su competitividad (Swoboda et al., 2016).

Al igual que ocurre en otros sectores, la marca tiene un papel importante en el comercio minorista, ya que puede afectar a la percepción que los consumidores tengan de éste y, consecuentemente, a su lealtad (Aliwadi y Keller, 2004). Así pues, vemos la importancia que una correcta gestión de marca del comercio detallista puede suponer, ya que tendrá repercusiones en la manera en la que los consumidores ven al comercio, así como en la lealtad de los mismos hacia un comercio determinado frente a sus competidores. Como veremos en la presente tesis cuando analicemos la lealtad, ésta supone una fuente de ventajas para el comercio detallista, ya que un cliente fiel supone mayor valor a largo plazo, puesto que es menos sensible a los precios, estando dispuesto a pagar un precio superior frente a otros comercios.

Uno de los problemas con los que se encuentra el pequeño comercio detallista es similar al de las marcas pequeñas, puesto que ocupan un porcentaje pequeño dentro de la comunicación. Así, los pequeños comercios hacen muchas menos comunicaciones de marketing, con lo que son más susceptibles de que el consumidor no piense en ellos a la hora de tomar su decisión de dónde comprar (Goodman y Remaud, 2015, Venkatesan et al., 2015).

Llevado al ámbito del comercio detallista la correcta gestión de la marca puede conllevar unos beneficios importantes, ya que, como vemos, permitirá diferenciar a un comercio con respecto a su competencia, siempre que éste haya sido capaz de desarrollar unas ideas y conceptos diferentes y valorados por su público objetivo que permitan a éste posicionarlo frente a la competencia. Como indica Brown (2010), para que una marca tenga éxito, lo primero que necesita es tener un punto de diferencia, si bien para que esta diferencia tenga sentido deberá ser efectivamente ofrecida y comunicada de manera que sea irresistible y memorable y que genera proposiciones claras y únicas.

Si bien en ciertos ámbitos del comercio detallista si se presta esta necesaria atención a la gestión de marca (cadenas de distribución de alimentación y de textil, 
franquicias de múltiples sectores, etcétera) en el comercio tradicional no es tan frecuente la realización de acciones encaminadas al desarrollo de la marca. En este sentido, ya Davis (1995) apuntaba la importancia de las potenciales contribuciones estratégicas y beneficios que una marca puede aportar a la empresa.

Romaniuk y Sharp (2004) señalan que hay que diferenciar la disponibilidad física del punto de venta de su disponibilidad mental, entendida ésta como la propensión a que la marca del comercio se tenga en cuenta en el pensamiento del consumidor en una situación de compra. Así, el hecho de que un comercio minorista tenga una presencia física y esté disponible en el mercado, no significa que el consumidor necesariamente lo visite, ya que para ello tendrá que formar parte del grupo de opciones que éste tenga en su mente.

Vemos, por tanto, como la marca y su adecuada gestión por parte del comercio detallista puede ser un aspecto clave si éste quiere ocupar un lugar en la mente de su público objetivo, de manera que sea tenido en cuenta a la hora de que los consumidores tomen sus decisiones de dónde efectuar sus compras. Esto cobra especial importancia si se tiene en cuenta que, como se ha apuntado anteriormente, bajo determinadas situaciones de incertidumbre, el consumidor, tal y como apuntan Swoboda et al. (2016), tiende a buscar más información antes de tomar la decisión de compra, de manera que se minimice así el riesgo, principalmente en los casos de compra de productos que impliquen un significativo o importante desembolso de dinero, es decir, para productos de compra esporádica.

En este sentido el comercio minorista puede ofrecer al consumidor información que influya en su decisión de compra y que, en última instancia, pueda influir en su lealtad (Allaway et al., 2011). Los consumidores, especialmente los más leales, tienen información sobre el comercio que han ido adquiriendo y almacenando en su memoria como una red de asociaciones interdependientes (Krishnan, 1996). Esto cobra especial importancia si se tiene presente que un consumidor leal supondrá a largo plazo mejoras en la productividad, así como un incremento en los ingresos del negocio (Gwinner et al., 1998; Weinstein y Johnson, 1999). 
A pesar de esto, para sobrevivir en un mercado tan competitivo como el actual, que los consumidores estén satisfechos y sean leales ha dejado de ser suficiente (Carrol y Ahuvia, 2006; Patwardhan y Balasubramanian, 2011). Así, como señalan Delgado et al. (2013), las marcas necesitan de embajadores a los que no solamente les "guste" la marca, sino que sientan una profunda conexión con ella, que la defiendan, la recomienden y, sobretodo, se involucren con ella. En este sentido, en los últimos años ha habido un creciente interés por conocer lo que sienten los consumidores hacia las marcas. Este interés se ha focalizado en el concepto de amor a la marca.

Académicamente el amor a la marca ya se perfila como un concepto capaz de explicar la comunicación boca-oreja y la lealtad (Carroll y Ahuvia, 2006), la disposición a pagar un sobreprecio por la marca (Thomson et al., 2005) y el perdón a las marcas por sus fallos cometidos (Bauer et al., 2009).

Teniendo esto en cuenta el comercio detallista capaz de conseguir una marca reconocida en el mercado, podrá aportar mayor valor a sus clientes. Puesto que los consumidores aprenden de sus experiencias con las propuestas de marketing de las empresas, el punto de venta del comercio detallista se convierte en el lugar adecuado para propiciar dichas experiencias a sus clientes. Así, como veremos más adelante, los detallistas disponen de numerosas herramientas para proporcionar experiencias memorables a sus clientes, tanto manejando factores tangibles como intangibles. Gracias a las nuevas tecnologías esto es posible no sólo en el punto de venta físico, sino también en la venta online, o incluso en ese entorno virtual, sin necesidad de que se produzca la venta, sino tan sólo en la toma de contacto con el cliente a través de Internet. Además, el comercio detallista deberá ser capaz de ofrecer una imagen homogénea al cliente en los distintos canales a través de los cuales interactúe con él, de manera que éste reconozca en todo momento la marca del comercio y no sienta que en distintos canales se le están ofreciendo imágenes del comercio diferentes. De esta manera, se contribuirá a la consecución de una marca para el comercio detallista.

Como se ha visto de las diferentes definiciones de marca aportadas, un aspecto importante a considerar es el que hace referencia a las características intangibles que 
pueden contribuir a que el consumidor "identifique el producto o servicio de un vendedor como distinto o diferente de los de otros vendedores" (Bennett, 1988). Entre ellas, las experiencias y los vínculos emocionales y cognitivos cobran relevancia a la hora de conseguir una marca fuerte (Farquhar, 1989), por lo que van a ser consideradas en la presente tesis, tal y como se expondrá más adelante, en un posible modelo de creación de Valor de Marca para el comercio minorista.

Ante esto, dado el impacto potencial que la marca puede tener en los consumidores, uno de los objetivos generales más importantes para las empresas debería ser el incremento de su Valor de Marca (Castelo et al., 2012). Para ello será necesaria la elección de una estrategia de gestión de marca lo más adecuada posible, que permita a la empresa alcanzar este objetivo.

En este sentido, la correcta gestión de una marca debe centrarse en capitalizar sus valores de manera que estos atributos puedan representar una extensión natural de la percepción general, lo que conducirá a que el Valor de Marca aporte ventajas estratégicas a la empresa (Tsai, 2015; Ventakeasen et al., 2015; Budac y Baltador, 2013). Como se ha comentado anteriormente, el comercio detallista debería intentar identificar sus atributos diferenciales, especialmente aquellos que tengan relevancia entre el segmento del mercado al que quiere llega, para conseguir esas ventajas estratégicas.

La importancia de una correcta gestión de marca se ve en las palabras de Olins (2008) cuando apunta que la marca puede ser uno de los recursos más importantes de la empresa si se crea y se apoya con eficacia. En ocasiones, puede llegar a ser el activo más importante de la organización. Para este autor, la marca entendida como el conjunto de inversión, recurso financiero, recursos humanos, investigación y desarrollo, marketing, tecnologías de la información y otros recursos corporativos, necesita de una autoridad, de unas reglas, así como de una dotación de fondos y de una correcta dirección y gestión, ya que solo de esta manera, el recurso que supone la marca, será tan eficaz como cualquier otro recurso de la empresa. 
Más datos sobre lo mucho que puede aportar una buena gestión de la marca a la empresa los encontramos en el trabajo de Larkin (2013) cuando afirma que la literatura de marketing muestra como una marca fuerte genera consumidores leales que consideran de alto valor los productos de la empresa y desean permanecer con ella a lo largo del tiempo, con lo que las empresas que son capaces de establecer percepciones de marca favorables entre sus clientes, disfrutarán en el futuro de mayor estabilidad en sus beneficios y de menores riesgos.

Así, Muniz y Marchetti (2012) señalan que, gracias a la intensificación de la competencia, los consumidores globales se enfrentan a una creciente disponibilidad de alternativas similares de productos para la satisfacción de sus necesidades y deseos, adquiriendo la marca un importante papel como elemento diferenciador, yendo más allá de sus aspectos racionales y funcionales.

No sólo ocurre esto con los productos, sino también con los comercios detallistas. En este sector también se da una gran variedad de opciones para el consumidor, quien cada vez tiene un más fácil acceso a la información que le permite comparar numerosas opciones, en ocasiones, sin necesidad de desplazarse hasta el punto de venta. Así, esta gran competencia existente, hace imprescindible que el comercio minorista conozca bien cómo es el perfil del público al que quiere dirigirse, cuáles son sus necesidades y cómo se comporta. La marca contribuirá, por su parte, a que ese público reconozca y diferencia a un determinado comercio de su competencia.

La preocupación por la correcta gestión de marca del comercio minorista que en algunos casos como el de algunas franquicias o grandes cadenas de distribución se ve claramente, en el comercio independiente no parece que se tenga en la misma consideración.

A la vista de la importancia que puede tener la realización de una correcta gestión de la marca para la empresa, son distintos los autores que han estudiado y analizado este concepto, si bien, en el ámbito del comercio minorista, como señalan Grewal y Levy (2007) en un artículo en el que recogen parte de las investigaciones realizadas sobre el 
comercio detallista, sólo un pequeño número de artículos que analizan este sector se centran en el branding o gestión de marca del comercio minorista. Los autores inciden en la necesidad de investigar más sobre este tema, a lo cual pretende contribuir, en la medida de lo posible, esta tesis.

Para sacar el máximo partido al valor de la marca de una empresa será necesario utilizar una estrategia adecuada. Para Seo y Jang (2013) una estrategia de marca supone para la empresa tomar la decisión estratégica de construir un Valor de Marca fuerte. De hecho, se ve aquí la estrecha relación existente entre el Valor de Marca y la estrategia de marca, ya que el nivel que alcance la primera será el resultado de cómo la empresa haya llevado a cabo la segunda. Por tanto, la fuerza que pueda tener el Valor de Marca demostrará el éxito de la estrategia, mientras que su debilidad será señal de que la empresa ha cometido errores a la hora de utilizar efectivamente su estrategia de marca.

Para que una estrategia tenga éxito y se cree Valor de Marca, los consumidores tendrán que estar convencidos de que existen diferencias sustanciales entre las marcas en el producto o categoría de productos de que se trate. Estas diferencias en ocasiones se refieren a los atributos o beneficios del producto, mientras que otras veces proceden de aspectos no relacionados con el producto (intangibles), tal y como señalan Kotler y Keller (2012).

En la presente investigación no nos vamos a plantear cómo se gestionan las marcas que comercializa el comercio detallista, bien sean marcas de fabricante o las suyas propias, sino la gestión de la marca del propio comercio. Es por esto que el planteamiento que se hace en los próximos apartados tiene en cuenta el Valor de Marca del comercio minorista y no tanto de los productos que éste comercializa.

Los distintos elementos que componen el Valor de Marca del comercio detallista deberán ser tenidos en cuenta por éste para realizar una correcta gestión de su marca con las ventajas que, como se ha apuntado con anterioridad, le podrá reportar. 
Más allá de los productos que se comercialicen en el punto de venta, el comerciante deberá tener en cuenta que el concepto de compra (shopping) puede aportar tanto valores hedónicos como utilitarios y que la correcta gestión que haga de los mismos contribuirá a la mejora del posicionamiento de su marca (Jones et al., 2006). Así, los valores hedónicos reflejan el valor que el consumidor recibe a través de distintos sentidos, de la fantasía y de los aspectos emotivos de la experiencia de compra, mientras que los valores utilitarios procederán de la adquisición de los productos de manera eficiente y están más relacionados con aspectos no emocionales de la compra (Holbrook y Hirschaman, 1982).

Para Tena (2016) "la dimensión utilitarista representa la parte más racional de la variable motivación" de compra, "recogiendo los aspectos cognitivos y funcionales del comportamiento del consumidor". Así, para Babin et al. (2004) el comportamiento del consumidor utilitarista supone un enfoque racional que implica o se relaciona con una compra que se realiza de manera eficiente, incluso si la realización de la misma no proporciona diversión.

Por otro lado, la compra hedónica supone tener en cuenta los aspectos relacionados con la parte experimental de la compra, entre los que se encuentran la fantasía, la excitación, la estimulación sensorial, el disfrute, el placer y la curiosidad (Scarpi, 2006; Holbrook y Hirschaman, 1982).

En este sentido, el comercio detallista deberá ser capaz de manejar todos estos aspectos para llegar a una correcta gestión de su marca que le haga ser más competitivo en el mercado, prestando especial atención al hecho de que los consumidores ya no buscan únicamente la adquisición de productos y servicios, sino que también desean recibir experiencias en su proceso de compra.

Crear experiencias del cliente memorables y diferenciarse de otros comercios, se ha convertido en un objetivo crucial para muchos detallistas. Los comerciantes pueden mantener relaciones más fuertes con sus clientes si son capaces de ofrecerles experiencias memorables (Verhoef et al., 2009). 
A la vista de todo esto, la creación de marca es importante en el entorno en el que compite el comercio detallista, es decir, en los mercados dirigidos al consumidor final (business to consumer), puesto que la creación de Valor de Marca puede aislar a la empresa contra los ataques de la competencia y mejorar su cuota de mercado (Keller, 2003; Lynch y de Chernatony, 2004). El Valor de Marca se convierte, de esta manera, en una herramienta estratégica importante para los comercios minoristas porque puede conllevar una mejora de los resultados en términos de ventas y de beneficios (Nyadzayo et al., 2011), a pesar de lo cual y aun teniendo en cuenta el aumento de la literatura relativa a la gestión del comercio minorista, se ha prestado poca atención al concepto de Valor de Marca del comercio detallista (Pappu y Quester, 2006).

En este sentido, este trabajo pretende profundizar en estos aspectos, definiendo el Valor de Marca en el ámbito del comercio detallista, contribuyendo así a salvar el vacío existente en este campo, tal y como señalan los citados autores.

\subsection{Perspectivas de análisis del Valor de Marca}

Garnica (2000) y del Rio et al., (2002) nos indican que el término Brand Equity, apareció en la literatura en los años ochenta, siendo su traducción más aproximada Valor de Marca. El concepto cobró interés en el ámbito empresarial, ya que el Valor de Marca está muy relacionado con la lealtad hacia la marca y las extensiones de la misma. Además, las marcas pueden aportar ventajas competitivas que ayuden al éxito de la empresa.

En esa época se produjo la fiebre bursátil quizá más explosiva y despiadada de la historia. En cuestión de semanas, grandes compañías cambiaban de manos, eran tomadas por asalto por compradores hostiles y por especuladores codiciosos, a los que les importaba todo menos las empresas en sí mismas. Para defenderse, los directivos y accionistas de las compañías buscaron tasar, con la mayor precisión posible, el verdadero valor de sus empresas. En la medida que el valor fuera más alto, podría protegerse mejor de ataques externos y movimientos especulativos. Esa contabilidad quedaba truncada 
cuando se llegaba al cálculo del valor de las marcas de la compañía. Había marcas más valiosas que las de la competencia, al margen, e incluso en contraposición, del precio de sus productos en el mercado. Pero lo que no era tan obvio era determinar la fuente de ese valor. A pesar de que se tenía en cuenta que existía una estrecha relación con aspectos como la participación de mercado de la marca, su margen de cobertura o los años que tenía a la venta, también se consideraba que eso no era suficiente.

Finalmente se descubrió que un componente principal del Valor de Marca estaba, precisamente, en la valoración que el consumidor le daba a la marca: qué percepción tenía de ella, por qué la consideraba única y la reconocía, en los tres sentidos de la palabra, es decir que la identificara, que le diera una consideración especial y que le interesara conocerla una y otra vez, es decir, que quisiera adquirirla y consumirla (Garnica, 2000). Bajo esa óptica, las marcas adquirieron un nuevo papel en las estrategias de negocios. Paralelamente, en la literatura de marketing, el tema del Valor de la Marca fue adquiriendo un creciente interés, siendo considerado como una línea de investigación prioritaria por el Marketing Science Institute (del Rio et al., 2002).

Uno de los trabajos pioneros en este ámbito y que goza de un elevado consenso en los estudios de marketing es el trabajo de Aaker (1991), para quien, si bien es cierto que las marcas tienen cada vez más valor, también lo es que hay una opinión bastante extendida que considera que, a pesar de ello, éstas no están siendo gestionadas de la mejor manera posible, poniéndose demasiado énfasis en los resultados a corto plazo, sin tener en cuenta la importancia de una buena gestión de marca y los resultados que de ello se pueden derivar en el largo plazo. El autor define el término Valor de Marca como el conjunto de activos y pasivos vinculados a una marca. Dicho concepto está compuesto por la lealtad a la marca, la notoriedad de marca, las asociaciones de marca y la calidad percibida. Todo ello como vía para conseguir la diferenciación y la consideración especial por parte del consumidor.

Para Aaker (1991) el Valor de Marca se define como el valor que los consumidores asocian a una marca. Este mismo autor indica que normalmente las marcas fuertes aportarán mayores márgenes de beneficios y mejor acceso a los canales de distribución, así 
como una buena plataforma a partir de la cual extender las líneas de productos de la empresa. Aun así, Aaker y Biel (1993) también advierten del peligro que puede suponer una extensión de marca realizada de manera pobre o poco correcta, ya que podría erosionar el Valor de Marca conseguido.

Anteriormente, Leuthesser (1988) ya había definido Brand Equity como "el valor de un producto por encima del que tendría cualquier otro producto idéntico sin el nombre de la marca. En otras palabras, el Valor de Marca representa el grado en que el solo nombre de la marca añade valor a la oferta”.

El trabajo de Aaker (1991) generó gran interés, no sólo en el mundo académico, sino también en el empresarial, porque demostró la posibilidad de tangibilizar, en conceptos y parámetros financieros, atributos intangibles difícilmente cuantificables, puesto que formaban parte del ámbito del comportamiento del consumidor (Fernández, 2002).

Brand Equity o Valor de Marca, puede definirse como la diferencia entre la elección por parte del consumidor de un producto con marca y un producto sin marca, teniendo en cuenta un mismo nivel de características del producto. Se refiere, por tanto, a la comparación de dos productos que son idénticos en todos sus aspectos, excepto en la marca (Yoo et al, 2000).

El consumidor tiene una impresión de lo que una marca determinada transmite y, además, considera que esta impresión es diferente de la que puede transmitir un producto sin marca o con una marca menos reconocida. Así, la diferencia en la elección del consumidor sobre dos productos puede ser avalada midiéndose la intención de compra o la preferencia por la marca, por comparación con un producto sin marca (Castelo et al., 2012).

En la mente del consumidor, tal y como señalan Palmeira y Thomas (2011) si hay dos marcas en la misma categoría de producto deben existir diferencias entre ellas, 
concluyendo en su estudio que las expectativas de calidad para una marca premium son más elevadas cuando el distribuidor comercializa también marcas orientadas al valor.

Partiendo de la evaluación del Valor de Marca que toma la perspectiva propuesta por Aaker (1991) y que es considerada como una de las más apropiadas, Xiucheng y Yan (2000) proponen añadir lo que ellos denominan "factor lealtad" para superar las posibles debilidades del modelo de Aaker (1991), en un intento de superar la dificultad de cuantificar el modelo del Valor de Marca basado en el consumidor, el cual consideran como únicamente cualitativo, y de aportar algunas indicaciones a la función directiva de la empresa.

Por su parte, Keller (1993), centrándose en la perspectiva del cliente, apunta a dos grandes motivaciones para el estudio del Valor de Marca. Por un lado, estarían las consideraciones financieras que intentarían estimar el valor de una marca de la manera más precisa posible con un propósito contable (adquisiciones, fusiones, etcétera). Por otro lado, el autor habla de un segundo grupo de motivaciones centradas en el aspecto estratégico de la empresa y que buscan la mejora de la productividad de la estrategia y acciones de marketing. En una situación en la que aumentan los costes, es mayor la competitividad y menor la demanda de algunos mercados, las empresas buscan mejorar la eficiencia de sus gastos de comercialización.

Así como para Aaker (1991) el Valor de Marca (Brand Equity), tal y como hemos dicho, se compone de cuatro dimensiones: lealtad, calidad percibida, asociaciones y notoriedad, Keller (1993) presenta un modelo conceptual basado en la perspectiva del consumidor individual, definiendo el Valor de Marca basado en el cliente como el efecto diferencial del conocimiento de marca en las respuestas del cliente ante las acciones de marketing de la marca.

Para este autor el conocimiento de marca (brand knowledge) se conceptualiza de acuerdo con un modelo de memoria asociativo en términos de dos componentes: notoriedad de marca e imagen de marca. Así, el Valor de Marca basado en el cliente que 
propone este autor, se dará cuando el consumidor esté familiarizado con la marca y tenga algunas asociaciones favorables, fuertes y únicas de esa marca en su mente.

Además de crear valor para los consumidores, el Valor de Marca también tiene gran importancia en la consecución del éxito comercial de la empresa a largo plazo y en la creación de ventajas competitivas sostenibles en el mercado, por lo que es necesario que ésta tenga un profundo conocimiento de lo que es la marca y que desarrolle un método razonable que le permita evaluar su Valor de Marca (Jia y Zhang, 2013).

El Valor de Marca se refiere a las percepciones de los consumidores más que a cualquier otro indicador objetivo (Lassar et al., 1995). Para estos autores se tiene en cuenta la percepción de una superioridad global de un producto de una marca cuando se compara con un producto de otra u otras marcas. Así, el Valor de Marca lo conciben como el valor añadido con el que la marca dota a un producto. Consideran que el concepto incluye cinco dimensiones perceptuales como son el rendimiento, la imagen social, el valor, la integridad y la unión a la marca.

Por tanto, la percepción que el consumidor realice se convierte en un aspecto clave; y las innovaciones orientadas a él pueden representar armas letales frente a la competencia (Keller, 1993 y 2003).

A pesar de que existe un consenso generalizado de la importancia del Valor de Marca entre los distintos autores y profesionales, todavía no hay uniformidad en cuanto a la aceptación de un modelo de estimación del mismo. La mayor parte de los modelos basados en el consumidor no ofrecen una estimación del valor monetario, mientras que los modelos basados en una perspectiva financiera no suelen considerar las percepciones de los consumidores (Rovedder et al., 2015).

Wood (2000) apunta que a la hora de analizar el concepto de Valor de Marca se han seguido diferentes aproximaciones y significados. Desde un punto de vista financiero o contable se ha conceptuado de forma diferente a la definición adoptada por el marketing. Además, por una parte, se da una concepción en términos de la relación entre el cliente y la 
marca (definiciones centradas en el consumidor) y por otra, tenemos una concepción de marca desde el punto de vista de la propiedad de la misma (definiciones centradas en la empresa).

Así, las técnicas de medición financieras se centran en el valor de la marca para la empresa, mientras que las que se basan en el marketing tienen en cuenta el valor que la marca tiene para los consumidores (Kamakura y Rusell, 1993). Como señalan Del Río et al. (2002), la perspectiva financiera enfatiza el papel de la marca como activo de las empresas con capacidad para afectar a los flujos de caja, el valor de las acciones o el precio de venta en caso de adquisición, absorción o fusión.

Desde una óptica financiera la medición del valor de marca permite asignar un valor a los activos para posteriormente incorporarlos a los estados financieros de la empresa, beneficiando así la operación de la organización, mientras que desde una perspectiva estratégica la medición y el control de la misma permitirá guiar las decisiones del Departamento de Marketing de la empresa en un nivel táctico y estratégico, y evaluar posteriormente la efectividad de las mismas, mejorando así la gestión de la marca (Buil et al., 2013).

Feldwick (1996) realiza una fusión de las diversas concepciones, unificándolas en tres grandes grupos. Por una parte, tendríamos aquellas concepciones que ven el Valor de Marca como un activo separable, susceptible de venta o de ser incluido en el balance de la empresa (Valor de Marca). En segundo lugar, nos encontraríamos con un concepto ligado a la fuerza con que los consumidores están ligados a una marca (Fuerza de la Marca). Y por último, estarían aquellos conceptos relacionados con las asociaciones y creencias que los consumidores tienen sobre una marca (Imagen o Descripción de Marca).

Desde el punto de vista del marketing, cuando se utiliza el término Valor de Marca, se suele hacer referencia a la segunda y tercera de las acepciones apuntadas por Feldwick (1996), es decir, a la descripción de marca y a la fuerza de marca. Para diferenciar estas dos concepciones del aspecto de marca como valoración de un activo, se suele hacer 
referencia a ellas como Valor de Marca desde el punto de vista del consumidor (consumer brand equity).

Este autor trata de desarrollar un argumento más convincente que el de la mejora de la imagen de marca (utilizado hasta ese momento) para justificar el desarrollo de las inversiones que las marcas realizan en marcas comerciales. Se hace referencia, de esta manera, a las ventajas competitivas que a medio y largo plazo pueden obtener las empresas con la realización de este tipo de inversiones.

Para Çifci et al. (2016) el Valor de Marca basado en la perspectiva del consumidor es esencial para obtener el valor del cliente, evaluar los resultados de la marca y aumentar la ventaja competitiva en el mercado (Sun et al., 2014; Zhang et al., 2010).

Un aspecto de vital importancia en la gestión del Valor de Marca es el destacado por Pitta y Katsanis (1995) en el sentido de que éste aumenta la posibilidad de que la marca sea elegida y, además, conduce a la lealtad hacia la marca y sirve para aislarla de algunas amenazas de la competencia.

En la misma línea, Light (1990) resalta la importancia de tener una marca, diciendo que en el futuro será más importante que tener fábricas, ya que ésta será la única manera de tener reconocimiento e influencia sobre el mercado, pues la marca dota al producto de un valor añadido.

Cualquier esfuerzo que la empresa realice en marketing será positivamente relacionado con el Valor de Marca cuando se consiga una respuesta comportamental del consumidor más favorable al producto. Por ello, para crear y gestionar el Valor de Marca, los impactos de las inversiones realizadas en acciones de marketing en todas sus dimensiones y de éstas sobre el Valor de Marca, deberán ser concretados y evaluados (Castelo et al., 2012).

Vemos pues la importancia que van cobrando cada vez más los aspectos intangibles relacionados con las empresas con respecto a aspectos tangibles como pueden ser el mismo 
producto físico, la maquinaria con la que éste se fabrica, las instalaciones, etcétera, ya que el consumidor, cuando adquiere un producto, no tiene en cuenta tanto estos últimos como lo que puede representar una marca y las asociaciones que éstas conllevan. Resulta más difícil para la competencia crear una marca que copiar los productos de la empresa.

El trabajo de Aaker (1992) tenía en cuenta los beneficios que se podían derivar de la correcta gestión del Valor de la Marca, tanto para la empresa como para el consumidor. Esto generó en la literatura dos grandes focos u orientaciones de estudio en función de lo que cada una de ellas tuviese en cuenta: bien un punto de vista más empresarial, centrado en aspectos económicos y financieros, bien un punto de vista que analizase el Valor de Marca por sus efectos sobre el consumidor y su comportamiento.

Partiendo de esto, la literatura sobre el Valor de Marca se ha ido diversificando en función de los aspectos en los que centraban su análisis los distintos autores. Así, a continuación, se presentan las corrientes de análisis que han contado con más aceptación.

Tres perspectivas principales se han adoptado por los diferentes grupos de investigación sobre marca en un intento de comprender el concepto de su valor: la perspectiva financiera, la perspectiva del cliente, y una combinación de estas dos perspectivas (del Rio et al, 2002; Keller, 1993 y 2003; Lee y Back, 2010; Srinivasan, et al., 2005).

Uno de los grandes grupos a considerar en los estudios relativos al análisis del Valor de Marca es el que está basado en la perspectiva financiera. Los autores que toman esta perspectiva intentan estimar de una manera precisa el valor de la marca desde una concepción financiera, como un valor que pueda ser objeto de un asiento contable, como valor a la hora de posibles adquisiciones, fusiones, etcétera

El Valor de Marca basado en la perspectiva financiera explora este concepto desde el punto de vista de los mercados financieros, y considera que hace referencia al flujo de efectivo incremental o al valor agregado adicional que se acumula a un establecimiento o 
cadena de establecimientos por poseer una marca o marcas fuertes, en comparación con una empresa equivalente sin esa fortaleza de marca (Srinivasan, et al., 2005).

Según Stobart (1994) desde una perspectiva financiera, la evaluación de marca deberá partir del análisis de la fuerza de esa marca, ya que ese indicador establecerá la tasa de descuento y de capitalización que sea utilizada sobre los flujos de caja generados por la marca. De esta manera, una marca fuerte otorga una mayor garantía a nivel de estabilidad de los rendimientos futuros de la marca gracias a su reconocimiento.

Dentro de los métodos financieros, Candia y Aguirre (2015) distinguen diferentes tipos en función de la información utilizada para estimar el valor de la marca. Así, diferencian el grupo de métodos que toman como base el valor de mercado de la empresa y su valor en bolsa, del que se basa en el análisis de costes y del que tiene en cuenta el potencial de beneficios futuros.

Tal como señala Corte-Real (2003) una correcta evaluación de la fuerza de una marca requiere de un análisis detallado de su posicionamiento, del mercado en el que actúa, de la competencia, de sus resultados, de sus estrategias futuras y de los riesgos de la marca. La fuerza de marca, por tanto, debe ser vista como una ponderación de diversos factores: liderazgo, identidad de marca, mercado, distribución, tendencias, inversiones y protección de la marca.

Sin embargo, como apuntan Nunes y Haigh (2003) son muchos los modelos de evaluación de marca desde la perspectiva financiera. De entre ellos destacan los basados en costes, los basados en el mercado o en el método de uso de valor económico.

Del Río et al. (2002) señalan que desde la perspectiva financiera se enfatiza el papel de la marca como un activo empresarial que es capaz de afectar a los flujos de caja de la empresa, al valor de sus acciones y/o a su precio de venta (en los supuestos de adquisición, absorción o fusión con otras entidades). Para analizar el Valor de Marca desde esta óptica, se adopta un enfoque económico, en términos de los beneficios adicionales que 
obtiene la empresa por el hecho de comercializar sus productos bajos una determinada marca.

En la medida que la lealtad de los clientes crece, el propietario de la marca puede capitalizar el Valor de la Marca a través de primas en los precios, disminución de la elasticidad de los precios, mayor cuota de mercado, y la expansión de la marca más rápida. Finalmente, las empresas con marcas de éxito se benefician en el mercado financiero mediante la mejora del valor para los accionistas, tal y como apuntan Kerin y Sethuraman (1998), cuando analizan la relación entre el valor monetario de la marca y el valor correspondiente a las acciones de la empresa.

Para Tauber (1988) el valor de una marca es el valor suplementario que alcanza la empresa, por encima del valor de sus activos materiales, debido a la posición que su marca detenta en el mercado y a la posibilidad de extender la misma a otras categorías de productos y/o mercados. Para este autor, el estudio del Valor de Marca cobra relevancia porque el desarrollo de nuevas marcas supone cada vez más costes, lo que conduce a un uso prevalente de extensión de marca y de expansión internacional de la misma.

A su vez, Smith (1991) considera que el valor de una marca es el valor monetario que se deriva del grado en que el nombre de la marca favorece las transacciones o intercambios, actuales y futuros, de la empresa con sus clientes.

Otros autores consideran que las perspectivas financieras adoptan técnicas basadas en el valor de los mercados financieros para estimar el Valor de Marca. Así, Simon y Sullivan (1993) apuntan que la marca es la diferencia entre los flujos de caja obtenidos por un producto con marca y los flujos resultantes en el caso de que ese mismo producto se vendiera sin marca. La técnica de estimación que proponen extrae la valoración del valor de la marca a partir del valor de otros activos de la marca. En primer lugar, esta técnica es válida para asignar desde una aproximación macroeconómica un valor objetivo a las diferentes marcas de una empresa, asociando este valor a los determinantes del Valor de Marca. Además, en segundo lugar, en una aproximación microeconómica detecta los 
posibles cambios en el Valor de Marca en el caso de marcas individuales a través de la medición de la respuesta del Valor de Marca a las decisiones de marketing.

Sin embargo, tal y como indican Candia y Aguirre (2015), los detractores de los métodos financieros señalan que éstos no dan una visión real en cuanto al valor que otorgan los consumidores en sus elecciones y preferencias, puesto que estos métodos no tienen en consideración sus actitudes y conductas.

Entre los diferentes métodos utilizados para calcular el Valor de Marca se encuentra el desarrollado por Interbrand Group, que utiliza un multiplicador subjetivo de los beneficios de la marca basado en los resultados de siete dimensiones: liderazgo, estabilidad, estabilidad del mercado, internacionalización, tendencias, apoyo y protección (Keller, 1993). En este método el valor de una marca determinada se define como el incremento de ingresos obtenidos por los productos que llevan esa marca respecto de los que se obtendrían por los productos si no llevasen esa marca. El proceso de evaluación que propone tiene tres partes diferenciadas: un análisis financiero, un análisis del mercado y un tercer análisis que estudia la fortaleza de la marca basándose en las siete dimensiones apuntadas con anterioridad.

Tomando como base la propuesta de Interbrand, Jia y Ahang (2013) desarrollan un modelo optimizado en el que añaden elementos relativos al consumidor al modelo original, intentando combinar la perspectiva del consumidor con la perspectiva financiera en un intento de calcular el Valor de Marca. Para estos autores, el modelo original tiene el problema de ser excesivamente subjetivo, ya que el índice relativo al efecto de la marca es determinado por un especialista, mientras que en el modelo que ellos proponen, utilizan el método del análisis del componente principal en un intento de alcanzar una mayor objetividad. Así, en el modelo de Interbrand la fortaleza de marca viene determinada únicamente por la fortaleza del mercado, mientras que en el modelo de los citados autores se calcula, además, teniendo también en cuenta el índice de la fortaleza del consumidor.

La segunda de las grandes tendencias dentro del análisis del Valor de Marca es la que tiene en cuenta la perspectiva del cliente, es decir, proponen el análisis del Valor de 
Marca centrado en el cliente. Comúnmente se acepta que esta línea de investigación es la que parte del trabajo de Keller (1993) para quien el análisis del Valor de Marca centrado en el cliente tiene su base en la evaluación de las respuestas que el consumidor tiene frente a un nombre de marca concreto. Este autor presenta un modelo conceptual de Valor de Marca desde la perspectiva de un consumidor individual. En este sentido, define Valor de Marca desde el punto de vista del cliente como el efecto diferencial del conocimiento de marca en las respuestas que el consumidor tiene frente a las acciones de marketing de ésta.

Keller (1993) analiza el valor de marca tomando en consideración los métodos basados más en el marketing que en aspectos financieros. Para el autor, dentro de estos métodos desde la óptica del marketing hay un grupo que denomina directos y que está compuesto por aquellos que tratan de estimar la influencia del valor de marca en la respuesta y comportamiento del consumidor ante las diferentes estrategias de marketing operativo de la empresa. Por su parte, los indirectos se centran en el análisis de las fuentes u orígenes del valor de marca.

En la definición del Valor de Marca que da este autor, hay tres conceptos a destacar: el efecto diferencial, el conocimiento de marca y la respuesta del consumidor al marketing de la misma. El primero de ellos se centra en las diferentes respuestas que puede tener un consumidor frente a las acciones de marketing de una marca, comparándolas con sus respuestas frente a esas mismas acciones, pero en el caso de una marca ficticia o un producto sin marca. El conocimiento de marca se define en términos de la conciencia o la sensibilización e imagen que el consumidor tiene de la marca en términos de las relaciones de asociaciones de marca que realiza. Por último, la respuesta del consumidor al marketing se define en función de las percepciones, preferencias y comportamiento derivados de las acciones del mix de marketing de la marca.

En la aproximación basada en el consumidor, se analiza el Valor de Marca teniendo en cuenta que el poder de la marca radica en lo que los clientes han visto, leído, oído, aprendido, pensado y sentido con respecto a la marca a lo largo del tiempo. De esta manera, el Valor de Marca basado en la perspectiva del cliente es el efecto diferencial que el conocimiento de una marca tiene sobre la respuesta que el consumidor da a las acciones 
de marketing de esa marca (Kotler y Keller, 2012), es decir, estaríamos ante un método directo de cálculo de valor de marca basado en el marketing., en función de la clasificación propuesta por Keller (1993), anteriormente comentada.

Según esta definición, hay tres puntos clave en el Valor de Marca desde esta perspectiva:

- $\quad$ El Valor de Marca surge de las diferencias en la respuesta del consumidor. Por tanto, si no hay diferencias el producto, a pesar de la marca, se verá como una simple mercancía.

- Las diferencias surgirán a partir del conocimiento que el consumidor tenga de la marca (pensamientos, sentimientos, imágenes, experiencias y creencias que asocie a la misma).

- El Valor de Marca se refleja en las percepciones, preferencias y el comportamiento relacionado con los distintos aspectos del marketing de la marca.

Desde esta óptica, Swait et al. (1993) establecieron un método consistente en estimar la percepción de marca para cada consumidor a partir de las respuestas de estos a distintos precios, llegando a definir el precio de igualación o precio hipotético, donde cada marca equilibraría la cuota de mercado en el proceso de compra del consumidor.

En este sentido, para Kotler y Keller (2012) el reto de los profesionales del marketing consiste en asegurarse de que los consumidores tienen las experiencias correctas en su relación con los productos, servicios y programas de marketing de la empresa, de manera que se cree en el consumidor el conocimiento de la marca deseado por la empresa. Por eso la inversión en marketing de la empresa debería considerarse como una inversión dirigida a que el consumidor tenga un mejor conocimiento de la marca.

Así, se considerará que existe un Valor de Marca positivo desde el punto de vista del cliente cuando éste reaccione a un elemento del mix de marketing de la marca más 
favorablemente de lo que lo haría ante el mismo elemento cuando éste fuese atribuido a una versión del producto o servicio con un nombre ficticio o incluso sin nombre. De la misma manera, el Valor de Marca será negativo desde la perspectiva del cliente cuando la reacción sea menos favorable.

Desde esta segunda perspectiva, es decir, desde el punto de vista según el cual el Valor de Marca puede representar una connotación negativa, también hay una corriente de investigación que se ha centrado en los efectos negativos que puede tener un Valor de Marca fuerte en situaciones de crisis. Si bien tradicionalmente se ha estudiado el Valor de Marca desde el punto de vista de los efectos positivos que éste puede aportar a la empresa, hay otra perspectiva de investigación que hace referencia a la perspectiva "amplificadora" del Valor de Marca y entiende que un Valor de Marca fuerte puede suponer, en determinadas situaciones, una amenaza para las empresas (Aaker et al., 2004; Seo y Jang, 2013). Por ejemplo, se puede dar esta circunstancia cuando el cliente percibe que una situación determinada en el servicio que recibe viola las normas de su relación con la empresa (Aggarwal, 2004), cuando siente que el esfuerzo de recuperación es injusto (Grégoire y Fisher, 2008) o cuando tiene tiempo y capacidad suficiente para evaluar un fallo importante (Roehm y Brady, 2007).

Los clientes que sienten una fuerte asociación con una marca, también tienen más posibilidades de emprender acciones ofensivas contra ella cuando ésta comete errores en la satisfacción de sus necesidades. Lo que el consumidor percibe como una "traición" de la empresa, es el concepto que Grégorie y Fisher (2008) utilizan como clave para que se active lo que ellos denominan "el efecto amor se transforma en odio". Los clientes que se sienten defraudados por una marca son más proclives a responder negativamente a las acciones de la marca, jugando aquí un papel amplificador el Valor de Marca, ya que la percepción de "traición" será más intensa entre los clientes que tienen una conciencia alta del valor de esa marca. Así, en situaciones de crisis de la empresa, se generará mayor sentimiento de traición en los clientes con alto Valor de Marca.

Seo y Jang (2013) analizan estos conceptos en el sector de la restauración, concluyendo que ante una situación de crisis (intoxicaciones alimentarias, etcétera) los 
clientes con una mayor percepción del Valor de Marca del restaurante presentan mayor predisposición a reducir sus intenciones de volver a ese restaurante, frente a los clientes con un Valor de Marca más bajo. Esto refleja el papel amplificador del valor de la marca comentado anteriormente, revelando la faceta negativa del Valor de Marca en situaciones de crisis.

De esta manera, entre otras cosas, la importancia de una correcta gestión del Valor de Marca vendrá dada porque la consecución de respuestas positivas por parte del consumidor desembocará en mayores ingresos, disminución de costes y aumento de beneficios para la empresa.

El estudio del Valor de Marca desde esta perspectiva tiene especial importancia en el campo de las estrategias de marketing de cara a aumentar la productividad de las acciones a realizar. El mejor conocimiento del comportamiento del consumidor llevará a unas mejores decisiones estratégicas con respecto al público objetivo definido y al posicionamiento deseado, así como a unas mejores decisiones tácticas relativas a las acciones a realizar con los distintos elementos del mix de marketing de la empresa.

Es por esto que para Keller (1993), quizás el activo más valioso de una empresa para mejorar la productividad de sus acciones de marketing sea el conocimiento que se haya creado de la marca en la mente de los consumidores, gracias a la inversión previa que la empresa haya realizado en sus programas de marketing.

Este autor considera que el Valor de Marca basado en el consumidor se da cuando éste está familiarizado con la marca y tiene asociaciones favorables, fuertes y únicas de dicha marca en su mente.

Valor de Marca hace referencia a que las acciones de marketing de un producto o servicio tienen diferentes resultados en función de la marca que lo ampara o frente a los resultados que se producirían para el mismo producto o servicio si éste no tuviese una marca que lo identificase (Tuominen, 1999). En este sentido, Kamakura y Rusell (1993) tampoco se centran en las características del producto, sino que consideran el Valor de 
Marca independientemente de éstas, ya que para estos autores el valor de una marca es el incremento en la utilidad del consumidor atribuible al nombre de marca, es decir, no relacionado con los atributos del producto.

Hong-bumm et al. (2003) analizan la relación entre los resultados financieros de la industria hotelera con las dimensiones del Valor de Marca basado en la perspectiva del consumidor, entendiendo que éste está constituido por la notoriedad de marca, la lealtad a la misma, la calidad percibida y la imagen de marca, es decir, toman algunas dimensiones de la propuesta de Aaker (1991) como la lealtad, la calidad percibida y la notoriedad de marca, así como también tienen en cuenta la dimensión de la imagen propuesta por Keller (1993). El estudio de Hong-bumm et al. (2003) aporta datos en el sentido de que el Valor de Marca tiene un efecto positivo en los resultados económicos de los hoteles analizados. El resultado implica que las empresas deberían considerar de manera importante la lealtad a la marca, la calidad percibida y la imagen de la marca a la hora de establecer un Valor de Marca definido, desde el punto de vista del consumidor. A pesar de que, en el caso de los hoteles de lujo estudiados, el conocimiento de marca no suponía un factor alto desde la perspectiva del Valor de Marca del consumidor, sí que estaba relacionado de forma significativa con los resultados financieros, al igual que la imagen de marca y la lealtad.

Otras conclusiones relevantes a las que llegan los autores citados es que los hoteles deberían diseñar su marketing mix de manera que su marca se sitúe entre las opciones consideradas por los consumidores para luego entrar en el grupo de marcas con posibilidades de ser elegidas en la compra. Además, la información que se proporcione al consumidor contribuirá a incrementar la notoriedad de la marca y a eliminar otras marcas de su consideración. Para ello, los gestores del hotel también deberían ser conocedores lo que otras marcas suponen para los consumidores, de forma que puedan desarrollar mejores estrategias. Todo ello conllevará un incremento de las ventas.

Teniendo esto en cuenta, podrían trasladarse algunas de las conclusiones de Hongbumm et al. (2003) al entorno del comercio detallista, ya que, como vemos, una correcta gestión de la estrategia de marketing del minorista podría suponer un incremento de su 
notoriedad entre los consumidores, así como también el desarrollo de acciones que lleven a un posicionamiento claro y diferenciado con respecto al de sus competidores.

Parte de la importancia del Valor de Marca radica en el hecho de que éste es uno de los factores más importantes que conducen al valor del cliente, entendido como el valor total del período en que el cliente está con la empresa, para todos los clientes de ésta (Rust et al. 2004). Además, el Valor de Marca hace que el cliente asocie ésta en su memoria y a la hora de realizar sus elecciones de productos o servicios reduzca sus costes de búsqueda de información (Erdem y Swait, 1998).

Por último, las perspectivas del Valor de Marca integradoras o globales, intentan aunar la visión centrada en el cliente y la financiera. Este enfoque ha aparecido para compensar las insuficiencias que puedan existir cuando sólo una de las dos interpretaciones es considerada de manera aislada (Motameni y Shahrokhi, 1998, Kluster et al., 2012).

Como señalan Candia y Aguirre (2015), los detractores de los métodos basados en el marketing alegan que es difícil traducir sus resultados en valores cuantitativos, a la vez que indican que su aplicación requiere del uso de técnicas estadísticas complejas, además de no considerar, en muchos casos, la naturaleza multidimensional del concepto de Valor de Marca.

Este enfoque tiene en cuenta las actitudes y las conductas de todos los agentes susceptibles de interaccionar con la marca: principalmente, la empresa, los consumidores, los distribuidores y los mercados financieros (del Rio et al, 2002). Estas cuatro ópticas o facetas de interpretación del Valor de Marca se encuentran interrelacionadas, ya que el Valor de Marca para la empresa, los distribuidores y los mercados financieros depende del Valor de Marca para el consumidor. De este modo, se defiende una visión amplia de la noción de Valor de Marca que abarque tanto la fortaleza o poder de mercado como el valor financiero de la marca. Estos dos aspectos se pueden considerar como dos dimensiones que se han ido levantando a la vez para interpretar el valor de la marca, de manera que cuando se tienda un puente o enlace entre ellas, se considerará que se ha completado el valor de 
una marca (Ambler y Styles, 1995). Estos autores identifican dos grandes aproximaciones filosóficas para definir la marca. Por un lado, hablan de una aproximación más allá del producto que entiende el branding o gestión de marca como algo añadido al producto y que va más allá del mismo. Aquí, la marca actúa como un identificador. Por otro lado, identifican una aproximación holística que se centra en la marca en sí misma.

Siguiendo en este mismo sentido, Ambler y Styles (1997), cuando analizan la importancia de la marca y su desarrollo frente al desarrollo únicamente de producto, también tienen en cuenta dos acepciones diferentes del concepto de marca. Así, por una parte, entienden que se da la aproximación más tradicional, es decir, aquélla que considera la marca como una adición al producto, sirviendo, principalmente, como identificadora del mismo, mientras que por otra parte habría una visión más amplia del concepto de marca, que va más allá del producto y tiene en cuenta la marca en sí misma. Esta segunda acepción considera que la marca es una suma de todos los elementos del marketing mix, siendo el producto tan sólo uno de sus componentes, junto con el precio, la distribución y la comunicación. La marca sería, según esto, la promesa del conjunto de atributos que alguien compra y que le proporciona satisfacción. Estos atributos provienen de todas las áreas del mix de marketing de la empresa y pueden ser tanto reales como ilusorios, racionales o emocionales y tanto tangibles como intangibles.

Para Farquhar (1989) el valor de la marca es el valor que ésta añade al producto. Su concepción global viene dada por el hecho de que, para él, el valor supone un incremento en los indicadores financieros de la empresa, además de reducir el poder de negociación que los distribuidores tienen frente a ella, mientras que para el consumidor, el Valor de Marca representa una utilidad que no puede ser explicada únicamente por atributos tangibles.

Srivastava y Shocker (1991), en esta línea integradora, entienden que el Valor de Marca abarca tanto la fortaleza de la marca como su valor financiero. La fortaleza de la marca viene dada por las asociaciones y comportamientos de consumidores, distribuidores y directivos de la empresa que permiten la obtención de ventajas competitivas para la misma. Por su parte, el valor financiero tiene en cuenta el aumento de los beneficios y la 
mayor estabilidad de los mismos, conseguida gracias a las acciones tácticas y estratégicas llevadas a cabo por la empresa para aprovechar la fortaleza de la marca.

Las distintas perspectivas utilizadas para estudiar el Valor de Marca, no deben entenderse como contradictorias, sino que, más allá de serlo, presentan diferencias que se basan en la perspectiva adoptada para aproximarse al concepto, así como en el alcance del enfoque seguido dentro de cada una de estas perspectivas. De esta manera, el valor de la marca se puede entender como un concepto global que incluye distintas facetas, y por tanto variables de muy distinta naturaleza, relativas a los principales agentes que interactúan con la misma.

Ante esto, los profesionales del marketing todavía se enfrentan al reto de cómo realizar una estimación del valor de una marca (Rovedder et al. 2015). Como señalaba Keller (1998), hay diversas formas de estimación con diferentes criterios de medida. En consecuencia, las investigaciones en este campo proponen diferentes aproximaciones para calcular el Valor de Marca (Shankar et al., 2008), si bien todavía no se ha llegado a una única propuesta uniformemente aceptada para la valoración de la marca (Raggio y Leone, 2007).

En la tabla 3.2 que se muestra a continuación se recopilan definiciones de Valor de Marca dadas por distintos autores y desde diferentes puntos de vista.

Tabla 3.2. Definiciones del Valor de Marca

\begin{tabular}{l|c}
\hline \multicolumn{1}{c|}{ Definiciones } & $\begin{array}{c}\text { Perspectiva } \\
\text { de análisis }\end{array}$ \\
\hline Leuthesser (1988) & \\
Valor de un producto por encima del que tendría cualquier otro producto idéntico \\
sin el nombre de la marca. El Valor de Marca representa el grado en que el solo \\
nombre de la marca añade valor a la oferta
\end{tabular}




\section{Farquhar (1989)}

Interpreta el valor de la marca desde la perspectiva de la empresa, los miembros del canal de distribución y los consumidores, como el valor que una marca añade al producto. Para la empresa representa un incremento en los flujos de caja o en cualquier otro indicador financiero. Desde la óptica de los distribuidores, el valor de una marca se aprecia en el menor poder negociador que éstos tienen con relación a la empresa propietaria de la misma. Y desde el punto de vista del consumidor equivale a la utilidad no explicada por los atributos tangibles.

\section{Tauber (1989)}

El valor de una marca es el valor suplementario que alcanza la empresa, por encima del valor de sus activos materiales, debido a la posición que su marca detenta en el mercado y a la posibilidad de etender la misma a otras categorías de productos y/o mercados.

\section{Smith (1991)}

El valor de una marca es el valor monetario derivado del grado en que el nombre de la marca favorece las transacciones o intercambios, actuales y futuros, de la empresa con sus clientes.

\section{Srivastava y Shocker (1991)}

El valor de la marca abarca dos dimensiones: la fortaleza de la marca y el valor financiero. La fortaleza de la marca es el conjunto de asociaciones y comportamientos de los consumidores, distribuidores y directivos de la marca que suponen la consecución de ventajas competitivas diferenciables y sostenibles. El valor financiero refleja el incremento de los beneficios actuales y futuros y la Global mayor estabilidad alcanzada en los mismos como consecuencia de las acciones, tácticas y estratégicas, emprendidas por la empresa para aprovechar la fortaleza de la marca. Depende, por tanto, de la consistencia de la marca con los objetivos y recursos de la empresa (entre otros, los restantes productos que ésta comercializa) y las condiciones competitivas del mercado. 
Aaker (1991, 1996)

El valor de una marca está constituido por el conjunto de activos y pasivos que vinculados al nombre y símbolo de la marca aumentan o disminuyen el valor de un producto o servicio para su empresa propietaria y/o a sus consumidores. Tales activos y pasivos pueden ser agrupados en cinco categorías: fidelidad, reconocimiento del nombre, calidad percibida, asociaciones adicionales a la calidad percibida y otros activos relacionados con el comportamiento del mercado.

Simon y Sullivan (1993)

El valor de la marca es la diferencia entre los flujos de caja obtenidos por un producto con marca y los flujos de caja resultantes en el caso de que ese mismo producto se vendiera sin marca.

Kamakura y Rusell (1993)

El valor de una marca es el incremento en la utilidad del consumidor atribuible al nombre de marca, es decir, no relacionado con los atributos del producto.

Financiera

Global

Swait et al. (1993)

estos a distintos precios, llegando a definir el precio de igualación o precio

Cliente

hipotético, donde cada marca equilibraría la cuota de mercado en el proceso de compra del consumidor.

Keller (1993, 1998)

Propone definir el valor de la marca desde el punto de vista del consumidor a fin de comprender cómo se crea y desarrolla este valor. Concretamente, señala que el valor de la marca es el efecto diferencial que ejerce el conocimiento del nombre de marca sobre su respuesta a las acciones de Marketing: el valor positivo (negativo) si la respuesta a nivel de las percepciones, preferencias o comportamiento es más (menos) favorable que la que tendría si el producto se vendiera con un nombre ficticio o sin marca.

Cliente

Cliente 


\section{Stobart (1994)}

Asimila el valor de la marca con la valoración monetaria de los beneficios futuros Financiera que se esperan de la misma.

Ambler (1995, 1997)

Expresa el valor de una marca como la suma ponderada de las relaciones entre la marca y los distintos agentes del mercado susceptibles de aportar a la empresa flujos de caja futuros. Las relaciones se ponderan en función de la importancia relativa de cada agente.

\section{Erdem y Swait (1998)}

Describen el valor de una marca en términos de la función que ésta desempeña como señal de información capaz de reducir al consumidor los costes de búsqueda de información y el riesgo asociado a la compra de un producto.

Yoo et al. (2000)

Valor de Marca, puede definirse como la diferencia entre la elección por parte del consumidor de un producto con marca y un producto sin marca, teniendo en cuenta un mismo nivel de características del producto. Se refiere, por tanto, a la comparación de dos productos que son idénticos en todos sus aspectos, excepto en la marca.

Srinavasan et al. (2005)

El Valor de Marca hace referencia al flujo de efectivo incremental o al valor agregado adicional que se acumula a un establecimiento o cadena de Financiera establecimientos por poseer una marca o marcas fuertes, en comparación con una empresa equivalente sin esa fortaleza de marca

\section{Kotler y Keller (2012)}

Valor de Marca es el efecto diferencial que el conocimiento de una marca tiene sobre la respuesta que el consumidor da a las acciones de marketing de esa marca.

Cliente

Global

Cliente

\section{Cliente}

Financiera

Fuente.: Elaboración propia a partir de Del Río et al. (2002) 
A pesar de los distintos enfoques, en la actualidad se puede concluir que casi todas las conceptualizaciones del Valor de Marca tienen en común que éste incluye el valor añadido al producto por las asociaciones y percepciones que los consumidores hacen de un nombre de marca particular (Chaudhuri, 1995), si bien es destacable la ausencia de una teoría unificada sobre el concepto de Brand Equity que sea aplicable en distintos contextos y para distintas industrias (Davcik et al, 2015).

Teniendo en cuenta que no existe un consenso en la literatura sobre lo que significa exactamente Valor de Marca o brand equity (Pappu y Quester, 2006), de las diferentes clasificaciones y propuestas para definir el Valor de Marca, en el presente trabajo se va a adoptar un enfoque centrado en el cliente que toma como referencia la teoría del Valor de Marca iniciada por Aaker (1991), que puede considerarse como la más aceptada por la literatura, y la de Keller (1993), conocida como Valor de Marca basada en el cliente. El primero de estos autores identifica cuatro dimensiones de este concepto: notoriedad de marca (brand awareness), asociaciones de marca (brand associations), calidad percibida (perceived quality) y lealtad de marca (brand loyalty).

Por su parte, Keller (1993) trata el conocimiento de marca (brand knowledge) definido en términos de dos componentes: notoriedad de marca (brand awareness) e imagen de marca (brand image). La notoriedad de marca se relaciona con el recuerdo y el reconocimiento de la marca por parte de los consumidores, mientras que la imagen hace referencia al conjunto de asociaciones que el consumidor une a la marca en su memoria.

A pesar del debate existente en cuanto a la definición y a las diferentes maneras de medirlo, en general, se da por aceptado en la literatura existente al respecto que el Valor de Marca es el conjunto de utilidades que los consumidores asignan a una marca en comparación con su competencia (de Chernatony y McDonald, 2003). En este sentido, Keller (2003) lo define como un concepto multidimensional y complejo para cuya medición son necesarios diferentes tipos de medidas. 
De Chernatony y McDonald (2003) consideran que, a pesar de la creciente importancia adquirida por el concepto de Valor de Marca en la literatura de marketing, se hace necesario encontrar un instrumento que permita medirlo desde la perspectiva del cliente, puesto que, como se ha apuntado, se trata de un constructo cuya medición es importante por las consecuencias que conlleva.

En la presente tesis, siguiendo a Boo et al (2009) se trabajará a partir de un modelo propuesto en el que se analizará el Valor de Marca basado en el consumidor, en función de las siguientes dimensiones:

- $\quad$ Calidad de Marca (brand quality o perceived quality).

- Valor Percibido (brand value).

- $\quad$ Conocimiento o notoriedad de Marca (brand awareness).

- $\quad$ Imagen de Marca (brand image).

- $\quad$ Lealtad de Marca (brand loyalty).

Estos autores trabajan el Valor de Marca en el ámbito de los destinos turísticos, tomando entre sus referencias el trabajo de Konecnik y Gartner (2007), quienes aplican la perspectiva del Valor de Marca basado en el consumidor, proponiendo cuatro dimensiones para analizar la marca de un destino: notoriedad, imagen, calidad y lealtad. En su estudio encuentran una relación positiva entre estas variables. Si bien llegan a la conclusión de que la imagen es un aspecto central para evaluar la marca y el Valor de Marca de un destino turístico, también apuntan que el resto de dimensiones son también necesarias para un análisis fiable del Valor de Marca basado en el consumidor.

Si bien un destino no puede ser considerado de la misma manera que un producto, dadas, entre otros aspectos, sus características de intangibilidad, el concepto de Valor de 
Marca se puede extender tanto a aspectos tangibles (caso de productos) como intangibles (servicios). Así, Baloglu y McCleary (1999) entienden que los turistas perciben un destino como un producto, evaluando los atributos del mismo a través de procesos tanto cognitivos como afectivos.

Tabla 3.3. Dimensiones del Valor de Marca

\begin{tabular}{|c|c|c|}
\hline Aaker (1991) & Keller (1993) & Boo et al (2008) \\
\hline & $\begin{array}{l}\text { Conocimiento de Marca } \\
\text { (brand knowledge): } \\
\text { - Notoriedad } \\
\text { - Imagen }\end{array}$ & \\
\hline $\begin{array}{ll}\text { Notoriedad (awareness): } \\
\text { - } & \text { Reconocimiento } \\
\text { - } & \text { Recuerdo } \\
\text { - } & \text { Top of Mind } \\
\text { - } & \text { Dominio } \\
\text { - } & \text { Conocimiento } \\
\text { - } & \text { Opinión }\end{array}$ & $\begin{array}{l}\text { Notoriedad (awareness): } \\
\text { - } \quad \text { Reconocimiento } \\
\text { - } \quad \text { Recuerdo }\end{array}$ & Notoriedad (awareness) \\
\hline
\end{tabular}




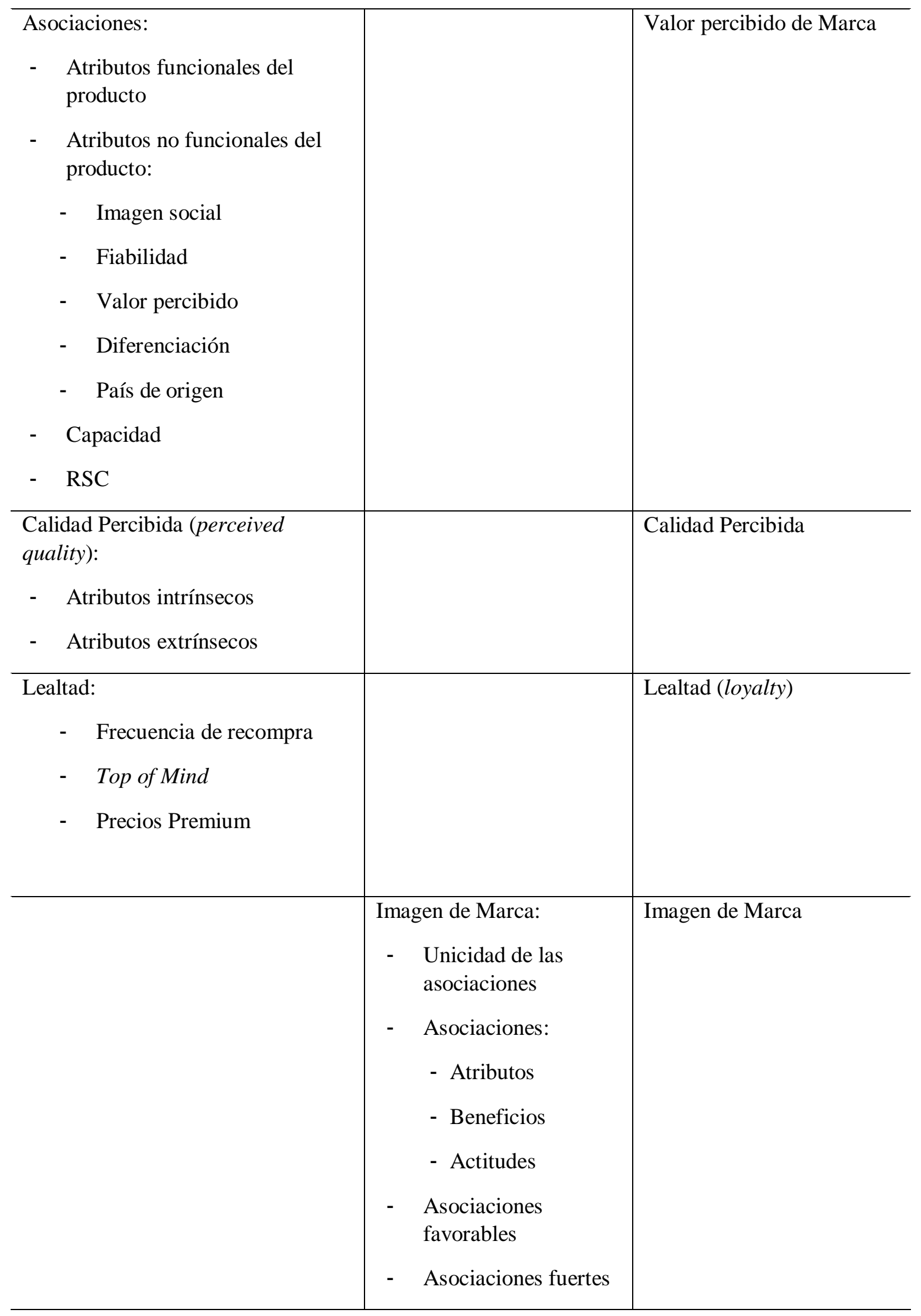


Fuente: Elaboración propia

Para la presente tesis se tendrán en cuenta tres de los cuatro componentes propuestos por Aaker (1991): notoriedad de marca (brand awareness), calidad percibida (perceived quality o brand quality) y lealtad de marca (brand loyalty). Además, se considerará también el valor percibido de marca (brand value o perceived value), que es considerada como parte de las asociaciones de marca por Aaker (1991) y también se tendrá en cuenta la imagen de marca propuesta por Keller (1993).

Por otra parte, además de las dimensiones comentadas del Valor de Marca, la presente tesis plantea la introducción en los modelos propuestos del concepto de experiencia del cliente, ya que, como apuntan distintos autores (Hoolbrok y Hirschmann, 1982; Jones et al., 2006; Verhoef, 2009; Kotler y Keller, 2012; Koniecnik y Ruzzier, 2013) la gestión del Valor de Marca del comercio detallista no puede perder de vista que el cliente moderno no solo busca la adquisición de productos y servicios, sino que también necesita que se le ofrezcan experiencias. Como se desprende de algunos de los trabajos analizados anteriormente, este aspecto puede ser decisivo a la hora de conseguir un posicionamiento claro en la mente del cliente, así como también puede afectar decisivamente a la creación de lealtad en el mismo, con todas las ventajas que ello supone para el minorista.

En este sentido cabe resaltar que la medición del valor que pueda tener una marca no ha sido objeto de estudio y análisis únicamente desde el punto de vista académico, sino que grandes consultoras han desarrollado propuestas para la evaluación periódica de las marcas. Destaca el hecho de que en ellas no se tiene en cuenta únicamente la percepción del consumidor, sino también otras variables.

Así, el modelo Equitrend, propuesto por la consultora norteamericana Total Research Corporation que forma parte de Harris Interactive Inc., propone tres variables de medición como son la notoriedad, la calidad percibida y la satisfacción del usuario. 
Por su parte, ACNielsen ha desarrollado el Índice de Valor de Marca para medir la fortaleza y la salud de la marca, teniendo en cuenta tres variables como son la visibilidad, los valores y la unión en términos de lealtad y vínculo emocional.

Otro modelo a tener en cuenta es el Brand Asset Valuation, elaborado por la consultora Yooung \& Rubicam, el cual analiza cuatro factores para determinar el valor y la salud de una marca: diferenciación, relevancia, estima y conocimiento.

Siguiendo con los modelos desarrollados por consultoras tenemos el BrandZ de la empresa Millward Brown que se establece que la creación de una marca se genera en la transición de etapas secuenciales, considerando que el propósito de una marca es llegar a establecer un vínculo con el cliente mediante la creación de relaciones fuertes con el consumidor, mayor lealtad y más disposición a pagar un alto valor por ella. En este modelo se tiene en cuenta el sello de la marca (mantenimiento de una relación con el consumidor) y el aumento de la lealtad (Forero y Duque, 2014).

Un enfoque que difiere bastante del resto es el que adopta el modelo Lovemarks de Saatchi \& Saatchi, según el cual las marcas se valoran más cuando se siente amor por ellas, por lo que su poder se basa en la relación que éstas puedan construir con el consumidor. Este modelo tiene en cuenta variables como el respeto que el consumidor siente por la marca o incluso el amor por la misma. Una Lovemark se caracteriza por tres componentes: el misterio, la sensualidad y la intimidad, manteniendo una relación con el consumidor basada en el amor, siendo personal y única.

Como se aprecia, son distintas las variables que se contemplan a la hora de establecer el valor de una marca. De hecho, en los modelos planteados por estas consultoras se tiene en consideración aspectos como la satisfacción que la marca proporciona al cliente, el vínculo emocional que se establece con el mismo, la estima, la relación o incluso el amor.

Farquhar (1989) ya apuntaba como para construir una marca con alto valor era necesario fortalecer la relación de ésta con el cliente y para ello un aspecto clave es el 
papel que juegan las experiencias y los vínculos emocionales y cognitivos. Por su parte, Ambler (1997) consideraba que los beneficios psicológicos relacionados con la marca constituían una parte integral de la experiencia de consumo que, a su vez, contribuye a la diferenciación basada en los intangibles.

La importancia de la interacción entre la marca y el consumidor, así como las consecuencias que se derivan de la misma viene destacadas por diversos autores (Aaker, 1991; Keller, 1993; Pappu et al., 2005; Cuneo et al., 2012), por lo que consideramos que la experiencia puede jugar un papel determinante en la percepción de dicha interacción marca-consumidor, influyendo en la calidad de la misma.

En este sentido, Ambler et al. (2002) argumentan que el Valor de Marca representa la mentalidad o la actitud del consumidor con respecto a una marca, incluyendo percepciones, pensamientos, experiencias, imágenes, etcétera.

Una aproximación moderna a la gestión de marca debe incluir una lista de elementos a tener en cuenta que va más allá de las concepciones más tradicionales y que incluye no solo aspectos tangibles relacionados con las características del producto, sino también elementos intangibles, tales como las expectativas de utilidad o la subjetividad del consumidor, centrándose en factores como las actitudes del cliente, la lealtad, las percepciones, etcétera, así como en las inversiones que la organización haga en la marca (Davcik et al., 2015). Así, estos autores consideran que las futuras investigaciones en este campo deberían partir de una concepción más amplia y compleja que considere las necesidades y deseos de los consumidores, así como su comportamiento. Estudios recientes consideran que las marcas son procesos sociales y dinámicos que incluyen múltiples grupos de interés que, a su vez, contribuyen a la co-creación del Valor de Marca (Iglesias et al., 2013).

Tal y como se desprende del trabajo de Keller (1993), el valor desde el punto de vista del consumidor se da cuando éste está familiarizado con la marca y ha desarrollado algún tipo de preferencia y/o fuerte asociación con ella. Tomando esto como punto de partida, Davcik et al. (2015) proponen que las investigaciones futuras tengan en cuenta la 
idea de la implicación emocional del consumidor con la marca y cómo esta implicación se enlaza con la organización y sus productos, los procesos, los códigos de conducta y los términos de unión que son inherentes a la implicación emocional del cliente.

Es por esto que, a la vista de todos estos factores y nuevas perspectivas, se plantea en la presente tesis la inclusión de la experiencia del cliente en su relación con otras variables a la hora de crear Valor de Marca.

El concepto de experiencia se desarrollará más adelante en un epígrafe dedicado exclusivamente a la experiencia del cliente, tanto en el entorno físico de la tienda tradicional como en el entorno virtual, ya que no se puede olvidar que en el actual entorno competitivo, las empresas suelen entrar en contacto con el consumidor a través de distintos canales.

\subsection{Valor de Marca en el comercio detallista}

Una vez analizadas las distintas perspectivas del Valor de Marca y detalladas las dimensiones que se van a plantear para su estudio en la presente tesis, se estudiará en este punto las distintas posibilidades de aplicación del concepto al caso concreto del comercio detallista.

Tal y como apuntan Swoboda et al. (2016), cabe señalar que la literatura, si bien ha dedicado frecuentes estudios a aspectos como los atributos del comercio detallista o incluso a su imagen (Mazursky y Jacoby, 1986; Pan y Zinkhan, 2006), no ha dedicado tanto esfuerzo al estudio del Valor de Marca del comercio detallista (Beristain y Zorrilla, 2011; Yoo et al., 2000).

Pappu y Quester (2006b) se centran en el Valor de Marca del minorista desde una perspectiva basada en el consumidor y, tomando como base el concepto aportado por Aaker (1991), lo definen como "el valor que los consumidores asocian a un minorista, 
reflejado en las dimensiones de: notoriedad del minorista, asociaciones del minorista, calidad percibida del minorista y lealtad hacia el minorista".

Junto a los beneficios que la marca y su valor representan para las empresas, como afirma Camacho (2008), las marcas ofrecen al consumidor una experiencia que va mucho más allá de las funciones básicas del producto.

Este aspecto es importante y se va a considerar en el presente trabajo, ya que el comercio detallista supone un punto de contacto con el cliente en el que se pueden desarrollar las acciones necesarias para ofrecer estas experiencias al cliente. Ante esto, en las siguientes páginas se pretende profundizar en el análisis del Valor de Marca del comercio detallista (retail equity), intentando con ello contribuir a la literatura existente.

Ruiz et al. (2013) consideran el capital de marca de la tienda como un claro elemento diferenciador de la misma. Estos autores también reconocen que, a pesar de la importancia del concepto, es escasa la investigación acerca de su dimensionalidad y de su influencia sobre las intenciones conductuales del consumidor, concluyendo en su estudio que el capital de marca de la tienda tiene una influencia positiva sobre estas intenciones del consumidor.

Como algunos autores señalan, existe la necesidad de una medida del Valor de Marca en el ámbito del pequeño y mediano comercio (Boo et al, 2009; Lee y Back, 2010), puesto que los estudios existentes sobre el tema aplicado concretamente al comercio detallista no son abundantes. Así, este trabajo intentará contribuir a la satisfacción de esta necesidad.

Hay determinados artículos que hacen una aproximación al tema, pero no teniendo en cuenta el Valor de Marca del propio comercio detallista, sino que su análisis se centra en el valor de las marcas comercializadas por él. Así, diferentes estudios comparan la aplicación de este concepto en el caso de marcas propias del comercio detallista frente a las marcas de fabricante (Jara y Cliquet, 2007; Castelo et al., 2012; Cuneo et al., 2012). 
En este sentido, Beristain y Zorrilla, (2011) consideran una evolución similar entre la gestión de las marcas propias del distribuidor y del Valor de Marca del comercio. Las marcas de distribuidor se consideraron en sus inicios como simples productos dirigidos a un público sensible al precio y no como marcas propiamente dichas. Desde esos inicios, su gestión ha evolucionado para centrarse en una consideración más similar a las marcas de fabricante (envases y presentación más cuidada, mayor calidad, búsqueda de una identidad de marca diferenciada, etcétera). Así, pues, vemos como las marcas del distribuidor han ido evolucionando desde su consideración como "marcas blancas", enfocadas a competir por precio, hacia una gestión de las mismas que cada vez las asimila más a las marcas de fabricantes. Esta reorientación y mejora en la gestión y posicionamiento de las marcas del distribuidor ha contribuido a una imagen más cuidada que va más allá de las asociaciones funcionales de la marca para abarcar aspectos relacionados con el comportamiento corporativo del comercio detallista.

Como ejemplo de esta evolución podemos ver la marca de textil Pedro del Hierro que se puede considerar como una marca de distribuidor, ya que únicamente se puede adquirir en los centros comerciales de la cadena española El Corte Inglés. Esta empresa ha desarrollado para esta línea unos productos de calidad, a los que da una buena presentación y para la que invierte importantes cantidades en comunicación (campañas en prensa, televisión, publicidad exterior, contratación de personajes relevantes para protagonizar sus anuncios, etcétera).

A pesar de que la presente tesis no se plantea este análisis, sino que se va a centrar en el Valor de Marca del establecimiento comercial como tal (retail equity) es de destacar el hecho de que la gestión de las marcas del comercio detallista ha sufrido una evolución importante desde sus orígenes que también ha influido en la propia marca del minorista y en la gestión de su Valor de Marca. Como señalan Grewal et al. (1998) las marcas del distribuidor forman parte del surtido completo que ofrece el minorista, con lo que también contribuyen a la formación de la imagen del comercio. Con ello, las marcas del comercio ofrecen una oportunidad para construir la imagen de éste, así como el Valor de Marca del 
mismo y, por tanto, contribuyen también a la generación de lealtad hacia el establecimiento (McGoldrick, 2002).

A la par que las marcas del comercio detallista han evolucionado, también lo ha hecho la propia marca del comercio y la forma de gestionarla. Todos los factores anteriormente citados reflejan un creciente interés en la marca como un arma competitiva de primer orden en el sector minorista. Ejemplo de esta evolución de la gestión de marca lo tenemos con numerosos de comercios detallistas que dan a su marca un papel relevante. Es de destacar el caso de franquicias de diversos sectores que cuidan mucho la gestión de su marca, teniendo en cuenta los valores de la misma y transmitiéndolo a través de todos los puntos de contacto con el consumidor.

Mientras que la perspectiva más tradicional argumentaba que el nombre del comercio en el entorno físico tradicional era menos importante que el nombre de las marcas que en él se comercializaban, en la actualidad el comercio minorista se enfrenta a un entorno competitivo nuevo en el que el nombre del comercio juega un papel importante, especialmente si tenemos en cuenta que muchos comerciantes no sólo actúan en el ámbito físico, sino también en el virtual a través de Internet (Hartman y Spiro, 2005).

Cada vez más el comercio detallista está haciendo considerables esfuerzos para mejorar su gestión de marca para conseguir incrementar el valor de la misma. Con ello se pretende ofrecer al mercado un valor diferencial que estimule la lealtad del cliente (Beristain y Zorrilla, 2011). Como señala Das (2014) la gestión de marca se aplica actualmente al comercio minorista y no sólo a las marcas de los productos como sucedía en el pasado. El minorista es consciente de que una marca del comercio bien conocida atrae a la gente y genera influencias en la intención de compra.

En un entorno económico competitivo de crisis como el que se ha dado en años anteriores, el consumidor ser vuelve más consciente del precio y busca las mejores oportunidades. Ante esta situación el comercio detallista intenta buscar la mejor forma de competir. Para ello utiliza tácticas de precio e intenta presentar propuestas al cliente que le aporten más valor (Grewal et al., 2012). 
A pesar de que la marca se ha convertido en uno de los recursos más importantes para el comercio detallista y de que la gestión de ésta se aprecia cada vez más como clave en la estrategia del minorista moderno, los factores conducentes a la formación del Valor de Marca del comercio detallista y su mecanismo de formación, todavía no están claros (Shen, 2010).

Tal y como destacan Swoboda et al. (2016), entre los primeros autores en estudiar el Valor de Marca en comercios detallistas del sector de la alimentación encontramos los trabajos de Jinfeng y Zhilong (2009), siendo éste el sector que ha recibido mayor atención por parte de la literatura (Swoboda et al., 2014; Allaway et al., 2011; Beristain y Zorrilla, 2011). Por su parte, otro sector dentro del comercio detallista que ha recibido bastante atención por lo que se refiere al Valor de Marca ha sido el de la moda, destacando estudios como los de Liljander et al. (2009) o Arnett et al. (2003).

Si, como señalan Delgado-Ballester et al. (2005), los consumidores son más leales a las marcas con un alto valor, podemos pensar que en el caso del comercio detallista una marca fuerte le reportará ventajas en sus acciones de marketing, lo que se reflejará en sus resultados. Así, se puede considerar que un comercio detallista con un Valor de Marca positivo será el que tenga unas características propias, tenga un alto nivel de reconocimiento de su nombre y una base amplia de clientes leales.

Arnett et al., (2003) se centran en el Valor de Marca del comercio detallista para definirlo como "el conjunto de activos y responsabilidades de la marca, ligados a la marca del establecimiento comercial (por ejemplo, Wal-Mart), su nombre y símbolo, que se suman o se restan por los clientes al valor percibido del comercio".

Desde la perspectiva del Valor de Marca centrada en el cliente, las marcas de establecimientos primero deben crear valor para los clientes garantizándoles un nivel uniforme de calidad (del Rio et al., 2002; Lee y Back, 2010). Desde este punto de vista, se sostiene que la marca generará ventajas competitivas y, por consiguiente, valor para la empresa siempre y cuando aporte valor a un segmento substancial de consumidores. Los trabajos que adoptan esta perspectiva proponen aproximarse al Valor de Marca a través de 
las percepciones (atributos, beneficios y actitudes), las preferencias o los comportamientos de los consumidores hacia la marca. A fin de describir los elementos que ponen de manifiesto el valor de la marca para el consumidor, se han seguido dos enfoques teóricos fundamentados, respectivamente, en el análisis de las asociaciones que el consumidor tiene de la marca (Psicología Cognitiva) y de la utilidad que ésta le reporta como señal de información (Teoría de Señales). Aunque es importante que los propietarios de los pequeños y medianos comercios, para poder reconocer los efectos de una marca en el valor de mercado de un establecimiento, consideren otros beneficios asociados con una marca, tales como la satisfacción del cliente y la lealtad (Ambler et al., 2002). Por lo tanto la perspectiva financiera y la basada en el cliente se encuentran interrelacionadas (Yoo y Donthu, 2001).

Como demuestran los estudios analizados anteriormente los consumidores dan un valor adicional a los productos en función del nombre de la marca que tienen. Este valor añadido proporcionado por la marca al producto es el Valor de Marca (Farquhar, 1989). En el contexto del comercio detallista Keaveney y Hunt (1992) llegaron a la conclusión de que el consumidor se forma una imagen de las tiendas minoristas. De hecho, como señalan Beristain y Zorrilla (2011) la imagen del establecimiento se puede usar por el comerciante para influenciar en el resto de componentes del Valor de Marca del punto de venta, especialmente a través de su dimensión estratégica y comercial.

Sin embargo, a diferencia de la imagen (basada en los atributos del comercio), el Valor de Marca del comercio minorista centrado en la perspectiva del cliente representa información sobre ese comercio en la mente del consumidor que será su conocimiento y asociación del mismo y que permitirán concebirlo como una marca fuerte, atractiva y única (Hartam y Spiro, 2005; Swoboda et al., 2013).

Como resultado de diferentes investigaciones ha surgido en los últimos tiempos el concepto de valor del comercio detallista (retail equity) en la literatura sobre marca (Pappu y Quester, 2006), si bien Keller (1998) ya sugería que, de forma parecida a las marcas, los comercios minoristas también poseían "valor" (equity). De hecho, si tomamos la definición de Keller (1993) del Valor de Marca y la aplicamos al comercio detallista, podríamos decir 
que el valor del comercio es el efecto diferencial del conocimiento del comercio en las acciones de marketing que éste lleve a cabo.

Los detallistas intentan cada vez más conseguir una posición en la mente de los consumidores que sea fuerte, atractiva y única (Aliwadi y Keller, 2004; Verhoef et al., 2007). Aun así, en algunos de ellos se mantiene la idea de que el único secreto para que un comercio tenga éxito es su ubicación, siguiendo con la concepción extendida de que los tres puntos más importantes para que una tienda tenga éxito son: ubicación, ubicación y ubicación. A pesar de que es indudable la importancia que una correcta ubicación puede suponer, como señalan Grewal et al. (2004), el Valor de Marca del comercio detallista determina el valor percibido del local y la imagen del establecimiento. Para estos autores el Valor de Marca del minorista tiene un papel preponderante en el comportamiento del consumidor, lo que cobra especial importancia en un entorno con saturación de comercios y en el que el consumidor puede estar orientado en función del factor de la conveniencia.

Si bien algunos estudios de hace unas décadas indicaban y resaltaban la ubicación como el elemento clave a la hora de explicar la decisión del consumidor en su elección del establecimiento, la literatura más reciente destaca cierta pérdida de relevancia del factor ubicación como decisivo a la hora de elegir el comercio, debido, en parte, al incremento de la movilidad de los consumidores (Swoboda et al., 2013).

En la última década se han realizado diversas aproximaciones para intentar medir el Valor de Marca del comercio minorista, si bien no son abundantes las aportaciones en cuanto a número de estudios realizados al respecto.

Autores como Ailawadi y Keller (2004) consideran, en línea con algunos otros investigadores, que los principios de la gestión de marca pueden ser aplicados a la gestión de marca del comercio detallista (retail branding). En este mismo sentido Yoo y Donthu (2001) ya hicieron una propuesta para extender al comercio detallista los métodos de medición del Valor de Marca. 
Así pues, según Pappu y Quester (2006), podemos extraer de los estudios existentes que una parte de la literatura propone una primera aproximación para medir el valor del comercio detallista consistente en aplicar para la medición del valor de éste los mismos criterios que los utilizados para medir el Valor de Marca desde el punto de vista del consumidor (consumer-based brand equity). Entre los primeros autores en desarrollar esta aplicación están Yoo y Donthu (2001).

Para esta línea de investigación se deberán tener en cuenta tres dimensiones: notoriedad/asociaciones de marca, lealtad y calidad percibida (Pappu y Quester, 2006).

La segunda línea de aproximación a la medición está representada por aquellos autores que consideran la necesidad de desarrollar índices propios para el valor del comercio detallista. Así, cabe destacar entre ellos el trabajo de Arnett et al. (2003) quienes consideran que el valor del comercio detallista es un constructo multidimensional compuesto por: notoriedad del nombre, asociaciones, calidad del servicio y lealtad al establecimiento.

Más concretamente Arnett et al. (2003) parten de la estructura general del Valor de Marca, tomando en cuenta sus cuatro dimensiones. Como particularidad encontramos en su propuesta que, si bien tres de estas dimensiones (lealtad, notoriedad del nombre y calidad del servicio) pueden ser comunes para todo tipo de comercio minorista, la dimensión de las asociaciones del detallista, consideran que debe ajustarse a cada uno de los comercios en concreto, puesto que los consumidores pueden formarse asociaciones únicas con respecto a ciertos minoristas.

Como se puede apreciar, las dos aproximaciones citadas anteriormente para medir el valor del comercio detallista (retail equity) son similares en sus dimensiones comunes, si bien, la diferencia entre ambas se da, más bien, en cómo definen y miden cada una de estas dimensiones.

Así, mientras que autores como Arnett et al. (2003) y Pappu et al. (2005) consideran las dimensiones de notoriedad y de asociación como diferentes para su 
aplicación al comercio detallista (en la misma línea que la propuesta general de Aaker, 1991), la propuesta de Yoo y Donthu (2001) las aplica como una única dimensión para el minorista. La propuesta que realizamos en esta tesis doctoral considera por un lado el concepto de notoriedad propuesto por Aaker (1991), si bien, en cuanto a las asociaciones de marca, teniendo en cuenta los estudios de Boo et al. (2008), se van a analizar a través de la imagen de marca, puesto que se va a incluir esta dimensión siguiendo la propuesta de Keller (1993) que tiene en cuenta el Valor de Marca basado en el cliente.

Además, Arnette et al. (2003) consideran que la calidad del producto y el valor percibido son sub-dimensiones de la dimensión de asociaciones del detallista.

En este sentido, en este trabajo, siguiendo la propuesta citada de Boo et al. (2008), el valor percibido se va a considerar de manera separada, teniendo en cuenta que para Aaker (1991) dentro de las asociaciones de marca se consideran los atributos no funcionales del producto y dentro de éstos cobra relevancia el valor percibido. Para Berry (2000) y Fandos et al. (2006) se hace necesario trabajar el valor percibido cuando se quiere poner en práctica una estrategia de marketing relacional en la empresa, que consista en crear, mantener y desarrollar las relaciones a largo plazo para beneficiarse de la lealtad del cliente. Las organizaciones deben convertirse en proveedoras de valor y lo deben hacer de manera diferente unas de otras, ya que esto les permitirá obtener su diferenciación, mejorar sus resultados y sus perspectivas de futuro (Lapierre, 2000; Callarisa et al., 2002).

Continuando con las diferencias entre ambas aproximaciones a la medición del valor del comercio detallista, por lo que se refiere a la calidad, si bien Arnett et al. (2003) consideran que la calidad del servicio es una dimensión, Yoo y Donthu (2001), siguiendo la propuesta de Aaker (1991) consideran la calidad percibida como una dimensión del constructo de Valor de Marca. Para la presente tesis se seguirá esta última propuesta, ya que la calidad percibida también se tratará como una dimensión diferente al resto que componen el constructo. 
Por último, la dimensión de la lealtad viene definida en ambas tendencias de manera muy similar, en la línea de las adopciones mayoritarias del concepto que se dan en la literatura de marketing.

A modo de conclusión y como aspecto común que se desprende de los estudios más relevantes, se puede considerar que la creación de una marca fuerte ayudará al comercio minorista a ser identificado por los consumidores como algo que aporta valor a los productos, ya que, de lo contrario, si no se consigue ese valor añadido, el precio y la disponibilidad del producto serán los que influyan en mayor medida en la elección de compra. Es por esto que una marca bien construida aportará a la empresa mayor competitividad en el mercado. La marca será, por tanto, una dimensión a tener en cuenta, ya que el consumidor podrá realizar sus decisiones de compra en función de ella, puesto que le estará dando información acerca de la calidad, reputación, consistencia o incluso de la personalidad de la empresa y de sus productos.

Se debe tener presente que los clientes deben ser considerados desde un punto de vista amplio al analizar el Valor de Marca, y deben incluir todos los grupos de interés de las empresas y los destinatarios de las acciones de comunicación de marketing (Lee y Back, 2010).

Como se puede apreciar, la consecución de un método que permita medir lo mejor posible el valor del comercio detallista (retailer equity) cobra gran importancia para que los minoristas puedan gestionar sus negocios de la mejor manera posible en el cada vez más competitivo entorno en el que se están moviendo.

Si bien hay diferentes opciones a la hora de medir el Valor de Marca, la presente tesis intenta aportar un modelo basado en algunas de ellas, pero teniendo en consideración algunas particularidades del comercio detallista, como puede ser la experiencia del cliente en el punto de venta. Además, tampoco se quiere perder de vista la creciente importancia que las nuevas tecnologías de la información y la comunicación están adquiriendo a la hora, no sólo de desarrollar el comercio minorista en el entorno online, sino también desde 
su vertiente como herramientas adecuadas para la creación de experiencias del cliente, tanto en el entorno virtual como en el punto de venta físico.

\subsection{Dimensiones del Valor de Marca}

\subsubsection{Calidad Percibida de Marca}

Teniendo en cuenta las dimensiones del Valor de Marca (brand equity) propuestas por Aaker (1991), en el presente apartado vamos a analizar el papel que juega la calidad percibida de marca en su relación con el resto de dimensiones, teniendo en cuenta la aplicación que se desea hacer al caso del comercio detallista.

Kotler (2000) define calidad como la totalidad de las características y prestaciones de un producto o servicio que hacen que tenga capacidad para satisfacer determinadas necesidades.

La calidad de la marca se ha revelado en diferentes estudios como una de las dimensiones clave del Valor de Marca (Aaker, 1996; Boo et al., 2010; Keller, 2003; Lassar et al., 1995). Los conceptos de calidad de marca y calidad percibida por los clientes se han usado indistintamente y con el mismo significado a la hora de hablar de ellos en los distintos trabajos realizados al respecto (Aaker, 1991; Zeithaml, 1988).

Para Aaker (1996) la calidad percibida desempeña un papel esencial a la hora de medir el Valor de Marca. En los estudios realizados por este autor se llega a la conclusión de que la calidad percibida viene asociada a las primas de precios (price premium), a la elasticidad del precio (price elasticities), a la utilización y uso de la marca (brand usage) y, notablemente, a la rentabilidad de las acciones (stock return). Además, la calidad percibida también está relacionada con otras medidas clave para el Valor de Marca, como pueden ser las variables específicas de los beneficios funcionales. La calidad percibida presenta, como 
añadido, la particularidad de que puede aplicarse a distintas tipologías de productos y servicios.

Por su parte, Zeithaml (1988) ya apuntaba que los conceptos de calidad y valor no se diferencian claramente entre si y tampoco con respecto a otros constructos, tales como el de utilidad, lo que ha llevado a la dificultad de su definición. El concepto abstracto de valor está altamente relacionado y frecuentemente confundido con conceptos como calidad, beneficios e incluso precio. Las señales externas del precio, del nombre de la marca y del nombre del establecimiento influyen en la percepción de la calidad del producto y su valor, así como en el deseo de compra.

Rao y Monroe (1989) llegan a la conclusión de que tanto el precio como la marca tienen un efecto significativo, aunque moderado en la percepción que el comprador tiene sobre la calidad, mientras que el nombre del establecimiento tiene una influencia bastante menor.

Debido a la complejidad de los productos, los consumidores no pueden evaluarlos con una información completa. Es por esto que la calidad viene inferida a partir de determinada información que aporta indicios. El producto está compuesto por una serie de indicios que pueden ser usados para evaluar la calidad, es decir, los indicios son una función de los atributos del producto (Yang, 2012). Este autor apunta que, en base a numerosos estudios, "la calidad percibida de las marcas propias de minoristas (store brands o marca de distribuidor) es el factor más influyente en la evaluación y compra de este tipo de marcas por parte del consumidor. Aun así, la marca del distribuidor es todavía una marca de menor calidad en la mente del consumidor que no puede competir con marcas nacionales (marca de fabricante)". Independientemente del nivel real de la calidad objetiva que tenga la marca del distribuidor, el consumidor da una valoración menor a la calidad de sus productos.

Los indicios o señales de referencia comentados en el párrafo anterior pueden ser intrínsecos o extrínsecos. Los primeros representan atributos del producto cuya alteración supondría un cambio en las propiedades físicas de dicho producto. Por su parte, los 
extrínsecos no son atributos que formen parte del producto físico, sino que comprenden otros como el precio, el nombre de la marca, el nombre del establecimiento, su reputación, país de origen, etcétera

En este sentido, Dodds et al. (1991) apuntan que el precio puede ser tanto un indicador de la cantidad de sacrificio necesaria para comprar un producto como también un indicador del nivel de calidad del mismo. Un precio mayor lleva a una mayor calidad percibida y en consecuencia, a un mayor deseo de compra. Generalmente, los compradores tienen un rango de precios aceptable para una compra determinada, de manera que se abstendrán de comprar ese producto si consideran que el precio es demasiado alto, pero, por el contrario, si es mucho más bajo de lo que consideran aceptable, recelarán de su calidad. Según estos autores, es menos probable que los consumidores confíen en la presencia de una relación precio-calidad para una categoría de producto en concreto, para confiar más en la información familiar que la marca y el nombre del establecimiento aportan para evaluar el valor del producto. Se puede esperar, por tanto, que, para los productos de mayor precio comprados de manera infrecuente, la fuerza de los indicios que aporta el precio pueda disminuir frente a la presencia de otros más conocidos por el consumidor. De cualquier forma, un comprador con poca información sobre el producto, puede usar la información aportada por la marca y el nombre del establecimiento para hacer su valoración de la calidad, confiando menos en las pistas que pueda aportar el precio.

Estos autores muestran en su estudio que la relación entre el precio y la calidad percibida no mejoraba, sino más bien disminuía, frente a los indicios aportados por la marca y el nombre del establecimiento. De esta manera, los resultados de su experimento indican que el tratamiento del precio produce un efecto positivo en las percepciones de un sujeto con respecto a la calidad del producto y un efecto negativo en las percepciones del valor y del deseo de compra. A su vez, una información favorable de la marca y del establecimiento produce efectos positivos en las percepciones del consumidor respecto al valor y la calidad, así como a su intención de compra. 
En esta misma línea, González-Benito y Martos-Partal (2012) analizan el efecto que la sensibilidad al precio y la percepción de calidad tienen en la compra de productos de marca del distribuidor. Esto tiene importancia a la hora de que los comercios establezcan su posicionamiento, ya que "cuanto mayor sea la apuesta del distribuidor por la calidad y el servicio, también en su cartera de marcas de distribuidor, mayor será la importancia de la calidad percibida con respecto a la orientación al precio de los consumidores en la compra de este tipo de marcas".

En función de las características de la clientela, el comercio ajustará su oferta para satisfacer sus necesidades de la forma más adecuada posible. Para Dekimpe et al (2011) estas necesidades se manifiestan en la sensibilidad al precio, el deseo de un determinado surtido, la búsqueda de servicios añadidos, etcétera que en su conjunto determinan la elección del punto de venta.

Así, todas las dimensiones mediante las cuales el minorista plantea su oferta y la adapta a su público objetivo conforman su posicionamiento competitivo (González y Martos, 2012).

Zeithaml (1988) llega a las siguientes conclusiones sobre la calidad percibida:

1. No es lo mismo que la calidad real u objetiva.

2. Supone un nivel de abstracción superior a los atributos específicos de un producto.

3. Es una valoración global que en algunos casos se asemeja a la actitud.

4. Es un juicio hecho habitualmente dentro de un conjunto o categoría evocado por el consumidor.

De esta manera, se puede afirmar que la calidad objetiva es un término que viene usado en la literatura para hacer referencia a una superioridad medible y verificable con respecto a algún criterio ideal predeterminado y que está estrechamente relacionado con 
otros conceptos que describen la superioridad técnica de un producto (tanto desde el punto de vista de sus componentes o ingredientes como del de su proceso de fabricación).

En ese mismo estudio, la autora aborda la definición del concepto de calidad percibida, en términos generales, como superioridad o excelencia. Partiendo de esa base, la calidad percibida viene definida como el juicio del consumidor con respecto a la excelencia o superioridad global de un producto. Pappu y Quester (2006b), partiendo de la definición general de Zeithaml (1988), hacen una aplicación al ámbito minorista y definen la calidad percibida del minorista como "el juicio del consumidor sobre la superioridad o excelencia de un minorista". La calidad percibida se considera por Pappu y Quester (2006b) como un tipo de asociación que justifica la elevación al estatus de dimensión separada del Valor de Marca del minorista.

En el modelo de Valor de Marca basado en el cliente de Keller (2003) se identificaron siete dimensiones de la calidad del producto: el rendimiento, las características, la calidad de sus componentes, la fiabilidad, la durabilidad, la utilidad y el diseño y el estilo. A pesar de la posible confusión conceptual existente, es comúnmente aceptado que valor y calidad son distintos conceptos y que el valor es un concepto de "orden superior", que subsume de la calidad (Oliver, 1997 y 1999).

Entre las siete dimensiones citadas por Keller (2003) el rendimiento de la marca (brand performance) puede ser utilizado para medir la calidad de marca, ya que hace referencia a las distintas maneras en las que una marca puede satisfacer las necesidades funcionales de un consumidor. Por esta razón, Boo et al. (2008) también lo eligen para su modelo que tiene por objeto la medición de la calidad de marca de un destino turístico.

En línea con esto, Michell et al. (2001) hablan, para los mercados industriales, de unos resultados similares, ya que a la hora de determinar los principales factores que contribuyen a crear lealtad hacia la marca identifican como los más importantes la calidad, la fiabilidad y el rendimiento. En su estudio también llegan a la conclusión de que la calidad percibida es una fuerza sobre la que pivota el Valor de Marca. 
En el ámbito comercial, la calidad percibida es un antecedente directo del valor percibido (Oh, 2000; Teas y Laczbiak, 2004). Low y Lamb (2000) señalan que la calidad percibida es fundamental para la teoría de que marcas fuertes aportan valor a las compras de los consumidores. En consecuencia, la calidad tendrá un impacto sobre el valor de la marca de los clientes, sobre su experiencia, su intención de regresar y su disposición a pagar (Berry, 2000).

Para Boo et al., (2009), la calidad de marca influye en la percepción de valor por parte de un cliente y también en su lealtad futura. De la misma manera, Baltas y Argouslidis (2007) indican que la calidad percibida se muestra como el aspecto de mayor prioridad en el proceso de decisión de compra del consumidor.

La innovación y sofisticación en la calidad pueden contribuir al incremento del valor para el cliente. De hecho, una de las fuentes para el éxito del comercio detallista viene dada por su calidad percibida que conduce a una diferenciación del comercio, así como a la creación de lealtad hacia el mismo (Burt y Sparks, 2002; Rondan, 2006). De hecho, como consecuencia de esto, y tal y como apuntan autores como Huang y Huddleston (2009), en la actualidad se está dando una tendencia hacia el aumento de la calidad percibida de la marca del comercio minorista en numerosos países, como consecuencia de su creciente importancia.

La calidad percibida es un constructo cognitivo que valora el resultado en función de las expectativas, mientras que el valor percibido es una evaluación en la que se comparan los beneficios obtenidos con los sacrificios realizados para la adquisición de un producto, así como la influencia ejercida por las emociones (Sánchez et al., 2006). La calidad percibida forma parte del componente positivo del valor funcional. En los modelos de valor la calidad tiene una influencia positiva en el valor percibido (Dodds et al., 1991; Sweeney y Soutar, 2001).

Son diversos los modelos que relacionan la calidad de marca con el valor percibido en estudios sobre diversos sectores. Así, Boo et al (2008) analizan la relación entre ambos 
en el sector del turismo, mientras que Liu et al. (2015) lo hacen aplicándolo al caso de los museos.

Ante estas conclusiones, se pretende ver en el presente trabajo cómo influye, en el ámbito comercial, la calidad percibida de la marca del establecimiento detallista en el valor percibido del mismo. En definitiva, la revisión bibliográfica indica que existe una relación positiva entre la calidad percibida y Valor de Marca y entre calidad de la marca y la lealtad a la marca, por lo que se plantea la siguiente hipótesis:

$H_{1}$ : La calidad percibida de marca afecta positivamente al valor percibido de marca de un establecimiento comercial.

Además de los estudios citados anteriormente en los que se apunta cómo la calidad percibida influye en la lealtad del cliente, Cretu y Brodie (2007) destacan la importancia que para el marketing tiene entender el proceso que crea la percepción de valor de los clientes, ya que ello conduce a su lealtad. Así, concluyen, dentro de un consenso general en la literatura al respecto, que el valor percibido por el cliente determina su lealtad: la imagen de la marca tiene una influencia específica en las percepciones del cliente respecto a la calidad del producto y del servicio, mientras que la reputación tiene influencia en las percepciones del valor y de la lealtad del cliente.

Es importante para las empresas entender cómo los clientes evalúan la calidad y las bases sobre las cuales se hacen leales a una determinada empresa. Como hemos visto, la superioridad de un producto o servicio vendrá dada por las percepciones que tenga el consumidor (Das, 2014). En este sentido, una percepción superior de la calidad no sólo atraerá nuevos clientes, sino que además animará a la repetición de sus compras, consiguiendo lealtad por su parte (Parasuraman et al., 1994). 
Hay numerosas investigaciones sobre la cadena que los efectos psicológicos de la calidad percibida tienen sobre la lealtad del cliente. Así, la calidad percibida tiene una influencia positiva sobre la lealtad del cliente (Johnson et al. 2007) que, a su vez, conduce a beneficios a largo plazo para la empresa (Zeithaml et al, 1996). Por tanto, a pesar de que las inversiones realizadas por las empresas en la calidad del producto tengan un coste significativo en el corto plazo, los beneficios derivados de las mismas vendrán a más largo plazo.

En esta línea, tal y como apuntan Frank et al. (2014), las creencias que se tienen sobre los beneficios de un producto median en la influencia que la calidad percibida tiene en la satisfacción del cliente. Tradicionalmente la literatura viene hablando de tres etapas en la relación calidad percibida - lealtad. De esta forma, la calidad percibida, a través de la satisfacción del cliente, influye en la lealtad de éste. A estas etapas, los autores citados añaden una cuarta, consistente en las creencias que se tienen acerca del producto, teniendo en cuenta tanto las hedónicas como las utilitaristas y que debería ser tenido en cuenta por su influencia sobre la satisfacción del cliente. En este sentido, una vez los consumidores procesan las percepciones sobre la calidad y las convierten en creencias sobre los beneficios de un producto o servicio, sus evaluaciones futuras se basarán en esas creencias previamente procesadas antes que en repetir de nuevo todo el proceso completo de evaluación de la calidad. Así, sabiendo que los efectos de la calidad percibida en los juicios de evaluación están en parte mediatizados por las creencias relativas a los productos, el comercio minorista, que en muchas ocasiones no puede influir en la calidad física de los productos que vende, sí que puede influir en la interpretación que los clientes hacen con respecto a los beneficios de uso de los mismos. De esta forma los esfuerzos que el comercio haga en la comunicación post-compra con el cliente pueden beneficiar en las creencias que éste se forme sobre el producto y en su satisfacción y lealtad a largo plazo.

Esto es especialmente relevante para el comercio detallista, ya que comprender cómo funciona la cadena de efectos psicológicos desde la calidad percibida hasta la lealtad del cliente puede resultar clave para la estrategia minorista. 
Por su parte, los estudios llevados a cabo por Nies y Natter (2012) sobre las decisiones de compra del consumidor, indican que la calidad percibida por los clientes con respecto a las marcas del distribuidor está fuertemente ligada a la lealtad de marca. Así, una evaluación positiva de la calidad puede ser lo suficientemente fuerte como para decidir la elección de la tienda. De hecho, como destacan Frank et al (2014) si bien la calidad percibida afecta a la satisfacción del consumidor, se debe tener en cuenta que una vez éstos han procesado sus percepciones de calidad y las han transformado en creencias sobre los beneficios de usar un producto o servicio determinado, sus evaluaciones se basarán en esas creencias procesadas anteriormente más que en repetir todo el proceso de evaluación de la calidad. Como apuntan Jones et al. (2002) hay una relación directa entre la calidad percibida y las intenciones de recompra, recomendación y resistencia a otras alternativas, que está en el centro del Valor de Marca del comercio detallista.

Frank et al (2014) destacan la importancia de conocer que los efectos de la calidad percibida en los juicios de evaluación están en parte mediatizados por las creencias sobre el producto. Esto puede ser útil para los gestores de los comercios detallistas, ya que, en muchos contextos, el minorista no puede influir en las características físicas después de vender un producto, pero si puede ejercer influencias sobre cómo el consumidor puede interpretar los beneficios reportados del uso de ese producto. Así, los esfuerzos de comunicación post-venta pueden impactar en las creencias sobre los productos y eventualmente en la satisfacción del cliente y en su lealtad a largo plazo después de que la calidad física del producto haya salido del ámbito de actuación del comercio. Es más, saber educar a los consumidores en el uso del producto de una manera efectiva les anima a la creación de valor junto con el comercio, lo que se refleja en su lealtad y, por tanto, en beneficios a largo plazo.

Más allá de la calidad real y objetiva, las decisiones del consumidor se basan en sus percepciones sobre la misma, de manera que la calidad percibida es un poderoso constructo que se encuentra entre los factores más importantes a la hora de la toma de decisiones de los consumidores (Ares et al., 2010). 
Estudios como el de Cai et al. (2015) analizan la influencia directa que la calidad de marca tiene sobre la lealtad a la hora de la formación del Valor de Marca, mientras que Boo et al. (2008) realizan una aplicación a los destinos turísticos. Por su parte, Saleem et al. (2015) apuntan que la calidad percibida influye en la lealtad de marca, haciendo una aplicación al mercado de los refrescos.

Entre los autores que exploran los lazos directos entre la calidad percibida del minorista y la lealtad, destacan Yoo et al. (2000).

Ante las conclusiones expuestas a las que llega la literatura existente al respecto, planteamos la siguiente hipótesis en la que se relaciona la calidad percibida de la marca del comercio detallista con la lealtad hacia el mismo:

H2a: La calidad percibida de marca afecta positivamente a la lealtad de marca de un establecimiento comercial.

De la misma manera que se ha plateado la hipótesis anterior, se desea analizar también la relación que la calidad de marca puede tener con la experiencia del cliente en el modelo planteado, puesto que ésta se ha introducido pensando en las aportaciones de autores como Biedenbach y Marell (2010) que destacan la importancia de la experiencia del cliente a la hora de desarrollar el valor de una marca. Puesto que el comercio detallista (tanto físico como online) supone un punto de contacto importante entre el consumidor y la empresa, se presenta como el marco adecuado para prestar experiencias al cliente. Es en el punto de venta donde convergen el consumidor con el producto y con todo aquello que lo rodea: vendedor, música, colores, etcétera. Se debe tener en cuenta que en las últimas décadas es creciente el interés que los detallistas están prestando a la creación de experiencias del cliente en el punto de venta como una forma de ser más competitivos en el actual entorno de mercado. 
Como señalan Holbrook y Hirschman (1982) las experiencias que aportan placer al consumidor se caracterizan por aportar beneficios, tanto intrínsecos como extrínsecos. Estos últimos se obtienen por la apreciación de una experiencia propia.

En este contexto se plantea la siguiente hipótesis, cuya fundamentación teórica puede verse con mayor profundidad en el punto 4.2.1 de la presente tesis:

H2b: La calidad percibida de marca afecta positivamente a la experiencia del cliente de un establecimiento comercial

En ocasiones la calidad percibida del comercio minorista y las asociaciones del mismo se han visto como una dimensión combinada (Yoo y Donthu, 2001). En este sentido, Keller (1993) destacó que una imagen de marca positiva podía crearse en el consumidor a través de la notoriedad de marca, ya que el autor encontró que cuando los consumidores realizan una buena evaluación de la calidad percibida, también se forman una mejor imagen de la marca. Esto es así porque cuando el consumidor es conocedor de la buena calidad de un producto, se crea una imagen de marca positiva.

Por su parte, Chen y Tseng (2010) concretaron la relación causal entre la notoriedad de marca, la calidad percibida y la imagen en el sector de las aeorlíneas.

En la formulación de la siguiente hipótesis se pretende ver la relación entre la calidad percibida de la marca y su imagen. Puesto que en el modelo de Boo et al. (2008) que es el que se toma como base para la presente tesis no se establece esta relación, se intentará analizar si dicha imagen viene influida por la calidad percibida de la marca del minorista. 
H3: La calidad percibida del establecimiento comercial afecta positivamente a la imagen del mismo

\subsubsection{Valor percibido de marca}

El estudio del concepto de valor percibido ha adquirido una creciente atención como línea de investigación debido principalmente a la importancia que las empresas modernas dan a la creación de valor para sus diferentes públicos objetivos. La creación y transmisión de valor se ha convertido en una ventaja competitiva clave, en entornos caracterizados por la competencia global (Sánchez et al., 2006).

Siguiendo a Tena (2016) el valor percibido por el consumidor es una variable en continua exploración y análisis que está siendo estudiada desde nuevas perspectivas y ámbitos de aplicación.

El entorno cada vez más competitivo en el que se mueven los comercios minoristas hace que éstos se planteen estrategias dirigidas a evitar la pérdida de sus clientes. Woodruff (1997) afirmaba que la generación de valor superior para el cliente sería la fuente de ventaja del s. XXI. En base a esto, la comprensión del concepto de valor percibido de marca y su correcta gestión por parte del comercio detallista cobran relevancia, puesto que, como se ha comentado anteriormente, son múltiples las ventajas de contar con una clientela leal al comercio. En el presente epígrafe se analiza la relación existente entre el Valor de Marca y la lealtad del cliente, para ver si la generación de valor apuntada por Woodruff (1997) tiene efectos sobre la lealtad del cliente.

Como señala Fandos (2010), "las organizaciones empresariales deben convertirse en proveedoras de valor y deben hacerlo de forma diferente unas de otras, puesto que esta habilidad les va a permitir diferenciarse, mejorar sus resultados y aumentar sus posibilidades de supervivencia futura". Si bien el estudio de este autor está centrado en el sector bancario, estas conclusiones pueden ser igualmente válidas para el comercio 
detallista en el sentido de que si éste quiere ocupar un lugar diferente en la mente del consumidor, deberá aportar valor a sus clientes de una forma en que otros comercios no sean capaces de hacerlo.

Como afirmaba Porter (1985) la creación de valor para el cliente es una forma de lograr la ventaja competitiva, proponiendo para ello su modelo conocido como "cadena de valor".

En el contexto de la gestión hotelera, Chang y Ma (2015) llegan a la conclusión de que un hotel puede llegar a desarrollar ventajas basadas en sus recursos creando Valor de Marca de los servicios. Para ello es necesaria la implicación de los directivos y la inversión en capital humano, creando una cultura de los servicios que mejore la calidad de los mismos. Si bien este estudio está centrado en los servicios hoteleros, es cierto que en el comercio detallista también juega un papel importante el servicio que el personal del mismo sea capaz de ofrecer a sus clientes, con lo que, de la misma manera, el comercio minorista podría desarrollar también ventajas creando Valor de Marca a través de los servicios que presta a sus clientes. Además, esto podría hacerlo tanto en el punto de venta físico o tienda tradicional, como en el entorno virtual a través de Internet.

Puesto que el valor percibido juega un papel importante en la decisión de compra del consumidor, así como en sus futuras intenciones de compra, se debe destacar su importancia a la hora de lograr una ventaja competitiva sostenible para los comercios (Eid y El-Gohary, 2015).

El concepto de valor percibido no ha sido definido por los diferentes estudios de manera homogénea, a pesar de que es un constructo de vital importancia en el contexto del marketing de relaciones y del marketing de servicios (Kim et al., 2008; Sánchez et al, 2006; Sweeney y Soutar, 2001).

Tal y como señalan Sánchez et al. (2006), existen distintas perspectivas para analizar el Valor de Marca. Una de ellas entiende el valor percibido como una combinación de dos partes: los beneficios recibidos por el cliente (económicos, sociales y 
relacionales) y los sacrificios hechos por éste (precio, tiempo, esfuerzo, riesgo, inconvenientes) para la adquisición del producto o servicio (Dodds et al., 1991; Bigné et al., 2001; Oh, 2003). En esta línea, Albretch (1994) consideraba el valor como una consecuencia de la calidad percibida por el consumidor en relación con el precio relativo del producto.

Otra más reciente concibe el valor percibido como un constructo multidimensional (Callarisa et al. 2011; Sánchez et al., 2006; Sweeney y Soutar, 2001; Woodruff, 1997), integrado al menos por tres dimensiones, la funcional, la emocional y la social. Aunque en el sector servicios estas dimensiones pueden ampliarse a cinco (incluyendo la dimensión epistémica y la dimensión condicional (Sheth, Newman y Gross, 1991).

El estudio del comportamiento del consumidor presta atención a su componente emocional (Hobrook y Hirschman, 1982). Actualmente está cobrando importancia el punto de vista experiencial frente a la aproximación basada en el procesamiento de la información. Esto es así porque, tal y como apuntaban Havlena y Holbrook (1986), muchos productos tienen significados simbólicos, más allá de sus atributos tangibles, de su calidad percibida o de su precio.

En este sentido el paradigma cognición-afectividad-comportamiento ofrece las bases conceptuales para el punto de vista experiencial. Así, el nivel Cognitivo corresponde a las actividades de procesamiento de la información del consumidor y es el componente racional de las decisiones de consumo. Los procesos cognitivos llevan al conocimiento, significados o creencias que el consumidor desarrolla de sus propias experiencias y almacena en su memoria (Sánchez et al., 2006).

Por su parte la Afectividad o el Afecto implican emociones tales como el amor, odio, disfrute, aburrimiento, ansiedad, orgullo, enfado, disgusto, simpatía, culpabilidad, etcétera (Holbrook y Hirschman, 1982). Como señala Oliver (1997) las respuestas afectivas son los sentimientos que se generan en el consumidor y que pueden ser favorables o desfavorables y, a su vez, variables en intensidad. 
Por último, las experiencias de compra y consumo se dan en el nivel de Comportamiento. Si bien el proceso de aprendizaje tiene su origen en las experiencias de consumo, desde el punto de vista experiencial la satisfacción es un componente importante, pero la corriente de asociaciones que se producen durante el consumo tienen la misma importancia que los aspectos experienciales del comportamiento del consumidor (Holbrook y Hirschman, 1982).

Entre las definiciones que basan el valor percibido en dos aspectos, Lassar et al. (1995) señalan que la elección de una marca por parte del cliente depende del equilibrio percibido entre el precio del producto y su utilidad. Lovelock (1991) consideraba que hay un valor neto para el consumidor que viene dado por la suma de todos los beneficios que éste percibe (valor bruto) a los que habría que restar los costes percibidos por ese mismo consumidor.

En esta misma línea Butz y Godstein (1996) consideran que el valor del cliente viene definido por los lazos emocionales que se establecen entre el consumidor y el productor, una vez el primero ha utilizado un producto o servicio del segundo y ha obtenido de ellos un valor añadido.

Por otra parte, aquellos que consideran el valor percibido como constructo multidimensional, tienen en cuenta las afirmaciones de Aaker (1996) quien dice que éste puede medirse preguntando a los consumidores si la marca les aporta el valor adecuado por el dinero pagado o bien si hay razones para comprar una marca antes que las de los competidores.

Además, el valor percibido es una variable dinámica, puesto que se experimenta antes de la compra, durante la compra, durante su uso y después de éste (Sánchez et al., 2006).

El valor percibido es considerado por la literatura de manera general como un juicio o una valoración que realiza el cliente de la comparación entre los beneficios o utilidad obtenidos de un producto, servicio o relación y los sacrificios o costes percibidos 
(Zeithaml, 1988; Bigné et al., 2000; Teas y Agarwal, 2000), si bien, dadas las divergencias entre el numeroso conjunto de autores que definen el concepto de valor, Woodruff (1997) propone y defiende una definición que incorpora tanto el valor recibido como el esperado, resaltando y diferenciando las percepciones del cliente sobre preferencias y evaluaciones (Fandos, 2010).

Para Monroe (2007) el valor percibido es un intercambio psicológico para el consumidor: el intercambio entre los beneficios y los sacrificios que espera de las transacciones. Es el ratio entre los beneficios o ganancias percibidas y los sacrificios o pérdidas percibidas. Siguiendo con esta misma línea en la concepción del valor percibido, Yoon et al. (2014) entienden que un comprador que esté considerando comprar en un comercio detallista tendrá en cuenta el cálculo del valor que resulta de la relación calidadprecio. De esta manera, los detallistas pueden incrementar las percepciones del consumidor de que está obteniendo valor de diversas maneras: incrementando la calidad del producto y manteniendo el precio, manteniendo la calidad del producto, pero reduciendo su precio o también cambiando tanto calidad como precio. Cuando el cliente se enfrente a un nuevo precio o a una modificación de la calidad, decidirá si la diferencia entre los nuevos precios y calidades y los viejos es lo suficientemente significativa como para apreciar el incremento de valor. Estos autores analizan el valor percibido en su relación con la reputación del comercio detallista, entendiendo que ésta contribuye de manera causal en los juicios y comportamientos del consumidor. En este sentido, Chiu et al. (2014) tienen en cuenta aspectos tangibles e intangibles, junto con la calidad, el servicio y el precio, ya que consideran que el valor percibido por el consumidor refleja los beneficios y costes según su percepción, teniendo en cuenta estos aspectos.

En la Tabla 3.4 se procederá a una recopilación de diferentes definiciones aportadas por la literatura en relación con el concepto de valor percibido, intentando detallar los distintos enfoques sobre el mismo. 
Tabla 3.4. Definiciones de valor percibido por el consumidor

Zeithaml (1988)

El valor es el juicio general que realiza el cliente sobre la utilidad de un producto, basándose en las percepciones de lo que se recibe y lo que se da.

Lovelock (1991)

El valor neto es la suma de todos los beneficios percibidos (valor bruto) menos la suma de todos los costes percibidos.

Gale (1994)

El valor es la calidad percibida de mercado ajustada por el precio relativo del producto.

Butz y Godstein (1996)

Se entiende por valor del cliente los lazos emocionales establecidos entre un cliente y un productor, después de que el cliente haya utilizado un producto o servicio del productor y haya encontrado en el mismo valor añadido.

Woodruff (1997)

El valor del cliente es una preferencia y evaluación percibida de aquellos atributos del producto, atributos de sus resultados y consecuencias que resultan del uso que permiten que el cliente logre sus objetivos en las distintas situaciones de uso.

Bigné et al. (2000)

El valor percibido puede ser considerado como la valoración global que hace el cliente de la utilidad de una relación de intercambio, basada en las percepciones de lo que recibe y lo que da.

Teas y Agarwal (2000)

Las percepciones de valor del consumidor ser basan en la compensación entre los beneficios del producto y el sacrificio monetario. 
Hellier et al. (2003)

Valoración global por parte del cliente del producto o servicio recibido sobre una base de coste/beneficio. Los beneficios buscados por el cliente o consumidor y los gastos de adquisición y utilización del producto o servicio.

Monroe (2007)

Las percepciones de valor de los compradores suponen un intercambio entre la calidad y los beneficios que perciben en relación con los sacrificios percibidos al pagar el precio.

Martín-Ruíz et al. (2008)

El valor percibido procede de la relación entre lo que el sujeto recibe y lo que se da por invertido.

Moliner et al. (2011)

El valor percibido refleja una evaluación perceptiva de un intercambio entre lo que se consigue (resultados y beneficios deseados) y lo que se ha invertido (dinero, tiempo y esfuerzo).

Chiu y Chen. (2014)

Refleja los beneficios y costes según la percepción de los clientes en relación a los productos tangibles e intangibles junto con la combinación de calidad, servicio y precio.

Rasoolimanesh et al. (2016)

El valor percibido por el consumidor describe una opinión, una evaluación mental o un juicio de valor emitido por el consumidor en relación al valor de un producto o servicio que le han sido prestados.

Fuente: elaboración propia a partir de Fandos (2010) y Tena (2016)

En la presente tesis se van a tener en cuenta los trabajos de Aaker (1996), Boo et al. (2009), y Sweeney y Soutar (2001), para el contexto de la marca en el pequeño y mediano comercio. 
El valor percibido por el consumidor es una variable más cognitiva y experiencial, ya que se basa en apreciaciones realizadas por el individuo del rendimiento que ha tenido el producto o servicio comprado (Fandos, 2010). Así, Rasoolimanesh, Dahalan y Jaafar (2016) entienden que el valor percibido por el consumidor es la opinión, la evaluación mental o el juicio de valor que éste emite en relación al valor de un producto o servicio que le han sido prestados.

Si bien en los distintos modelos analizados para el comercio detallista hay estudios que relacionan la experiencia del cliente con la lealtad de marca, son menos los que relacionan el resto de elementos del Valor de Marca con la experiencia. Por este motivo en la presente tesis se plantea el estudio de la relación del Valor de Marca del comercio detallista con la experiencia del cliente.

H4a: El valor percibido de la marca de un establecimiento comercial afecta positivamente a la experiencia del cliente.

Analizando distintos trabajos existentes sobre valor percibido del cliente (Boo et al., 2009; Kimpakorn, N. y Tocquer, 2010; Zeithaml, 1988), podemos indicar que éste tiene un impacto sobre la fidelidad de dicho cliente hacia la marca, y además es la fuerza impulsora que se encuentra detrás de los conceptos de atracción y retención de los clientes y del de proceso de recompra (Oliver, 1997 y 1999; Zeithaml, 1988). En este sentido, se ha determinado la existencia de una relación positiva entre el valor percibido de la marca de un producto y las intenciones futuras de comportamiento, caracterizado como la intención de recompra (Kim et al., 2008; Tsai, 2005; Woodruff, 1997). Otros autores han indicado que el valor percibido del cliente es un factor clave para poder obtener la lealtad del cliente, además de que el valor influye en la lealtad del cliente hacia una determinada marca (Oliver, 1997 y 1999; Camarero et al., 2010; Zeithaml, 1988). Por lo tanto, el valor 
percibido de los clientes aparece en la literatura del marketing como un factor crítico en la gestión de marketing y de la marca (Bailey y Ball, 2006; Ralston, 2003).

Como ya se ha apuntado en el apartado anterior, Cretu y Brodie (2007) concluyen, dentro de un consenso general en la literatura al respecto, que el valor percibido por el cliente determina su lealtad.

Así, vemos que hay una relación positiva entre el valor percibido de una marca y las intenciones de comportamiento futuro caracterizadas como una intención de recompra del producto (Teas y Laczniak, 2004; Tsai, 2005). Además, tal y como indica Oh (2000), el valor percibido por el consumidor está positivamente asociado con el comportamiento futuro de compra, pero también con las intenciones de búsqueda, así como con el deseo de comprar un determinado producto (Sweeney et al., 1999), lo que confirma la opinión de que el valor percibido del cliente juega un importante papel en la creación de lealtad del cliente hacia la marca (Grewal et al., 2004).

Saleem et al. (2015) analizan la relación entre la calidad percibida y la lealtad, encontrando que la primera es una variable muy atractiva para los consumidores. Si una marca logra conseguir una buena percepción de su calidad entre los consumidores, podrá disfrutar de un alto grado de lealtad de los mismos.

A la vista de que parece clara la influencia del valor percibido en la lealtad hacia la marca, se plantea la cuestión para el comercio minorista, entendiendo que el valor percibido que se tiene de un establecimiento detallista afectará a la lealtad del consumidor hacia la marca de ese establecimiento comercial.

Como consecuencia de estos planteamientos se deduce la hipótesis de trabajo que se presenta a continuación: 
H4b: El valor percibido de un establecimiento comercial influye positivamente en la lealtad hacia dicha marca.

\subsubsection{Notoriedad o conocimiento de marca}

La notoriedad de marca hace referencia al hecho de si los consumidores pueden recordar o reconocer una marca o simplemente si conocen o no una marca (Keller, 2003).

La notoriedad de marca contribuye a la creación de valor para la marca, ya que los consumidores unirán el conocimiento de la marca al nombre de la misma, lo que, finalmente constituye Valor de Marca (Aaker, 1991; Keller, 1993).

Para Aaker (1996) la notoriedad de marca es un componente importante del Valor de Marca, si bien, a veces, no suficientemente valorado. La notoriedad puede afectar a las percepciones y a las actitudes hacia la marca, incluso puede conducir a la elección de una determinada marca y a la lealtad hacia la misma. Para este autor hay diferentes niveles de notoriedad:

- Reconocimiento de marca: conocimiento de una determinada marca. Este factor puede ser importante para marcas nuevas o bien para marcas que compitan en un nicho de mercado determinado.

- Recuerdo de marca: marcas de una determinada categoría que están en la mente del consumidor. Tiene importancia sobre todo para marcas con amplio conocimiento por parte del mercado, si bien, las preguntas para determinarlas pueden ser inconvenientes al utilizarlas en una investigación de mercado.

- Top of Mind: la primera marca que aparece en el recuerdo del consumidor. Este aspecto, al igual que el anterior, es importantes para marcas bien conocidas en el mercado. 
- Dominancia de la marca: es la única marca recordada por el consumidor.

- Conocimiento de marca: hace referencia a si el consumidor conoce de qué es la marca, en qué sector actúa.

- Opinión de marca: se da cuando el consumidor tiene formada una opinión sobre una determinada marca.

La capacidad que tenga una marca para estar presente en la mente de un cliente o potencial cliente es un factor estratégico de primer grado en el marketing. La notoriedad de marca consiste en el reconocimiento de marca y su recuerdo (Keller, 1993; Lee y Back, 2007). Las asociaciones de marca son los nodos de información (por ejemplo, los atributos tangibles e intangibles, beneficios y actitudes) vinculados a un nodo de la marca (por ejemplo, una marca o logo), que proporcionan información significativa sobre la marca para los consumidores (Keller, 1993).

Así, Keller (2003) señala que las conceptualizaciones más aceptadas de la estructura de la memoria humana conllevan algún tipo de formulación basado en modelos asociativos. Estos modelos consideran la memoria o el conocimiento como un conjunto de nodos y enlaces, siendo los nodos información almacenada en la memoria, conectada por enlaces que varían en su intensidad o fortaleza. Además, un nodo puede ser una fuente potencial de activación de otros nodos, tanto cuando hay una codificación de información externa, como cuando una información interna es recuperada después de un período largo de tiempo. De esta manera, el autor conceptualiza el hecho de que el consumidor tenga conocimiento de la marca (brand knowledge) en función de los nodos relativos a la marca que tenga en su memoria, a los cuales estarán unidos una variedad de asociaciones.

La notoriedad de la marca vendrá dada por la fuerza de los nodos de la marca y sus trazos en la memoria, como se refleja en la habilidad que tienen los consumidores para identificar una marca aún bajo diferentes condiciones (Rossiter y Percy, 1987). 
Las dimensiones que para Keller (1993) distinguen el conocimiento de marca (brand knowledge) y afectan a la respuesta del consumidor son: la notoriedad de marca (brand awareness), entendido como recuerdo y reconocimiento de la misma, y el favoritismo, fuerza y singularidad de las asociaciones de la marca en la mente del consumidor.

El conocimiento del nombre de la marca hace referencia a la probabilidad de que ese nombre venga a la mente y a la facilidad con que lo haga (Keller, 1993). Así, para el autor, la notoriedad de la marca está compuesta por su reconocimiento (brand recognition) y por su recuerdo (brand recall).

El reconocimiento de marca significa la habilidad del cliente para confirmar exposiciones anteriores a la marca cuando se le presenta la marca como una referencia. Para ello se necesita que el consumidor identifique correctamente la marca como algo que ha visto u oído con anterioridad.

Recuerdo de marca es la habilidad del consumidor para recuperar o recordar la marca como una señal, ante una categoría de producto determinada, ante las necesidades que esa categoría satisface, o ante cualquier otro tipo de prueba. Para ello se necesita que el consumidor genere correctamente la marca a partir de su memoria.

Tanto el recuerdo de marca como su reconocimiento tienen importancia en el sentido de que el consumidor toma decisiones de compra tanto en el punto de venta, como fuera de él. El reconocimiento de marca adquirirá más importancia en la medida en que las decisiones sobre el producto se tomen en el punto de venta (Rossiter y Percy, 1987). Aaker (1996) destaca que el reconocimiento es importante para las nuevas marcas, mientras que el recuerdo cobra importancia en el caso de marcas ya establecidas y bien conocidas en el mercado.

En el caso del comercio detallista la notoriedad vendrá dada por la posibilidad del consumidor de reconocer el nombre del establecimiento y recordarlo, lo que activará 
asociaciones en su memoria que formarán la imagen del comercio detallista (Hartman y Spiro, 2005).

Para Keller (1993) la notoriedad de marca juega un papel importante en la toma de decisiones del consumidor por tres razones:

- Cuando el consumidor piensa en una categoría de producto, es importante que sea capaz de pensar en una marca determinada, dentro del conjunto de posibilidades que se le presenten.

- La notoriedad puede afectar a las decisiones de elección de una marca dentro del conjunto considerado por el consumidor, incluso si no hay otras asociaciones de marca. Así, en las decisiones de compra de baja implicación, un nivel mínimo de notoriedad de la marca puede ser suficiente para realizar la elección, incluso en ausencia de una actitud hacia la marca bien formada (Hoyer y Brown, 1990). Por esta razón, la notoriedad de marca puede llevar a la mejora de los resultados de la empresa en el mercado (Huang y Sarigöllü, 2012). Además, tal y como apuntan Macdonald y Sharp (2000), los consumidores con un conocimiento alto de la marca, también toman sus decisiones más rápido que aquellos para los que la notoriedad no es tan elevada. Jara y Cliquet (2012) llegan a esta conclusión, afirmando que la notoriedad de marca del detallista ejerce una influencia directa y positiva sobre las respuestas del consumidor (elección de la marca detallista e intención de compra) hacia la marca detallista.

- La notoriedad afecta la toma de decisiones del consumidor puesto que le influye en la formación y fortalecimiento de las asociaciones en la imagen de marca. Esto es así porque una condición necesaria para la creación de la imagen de marca es que se establezca un nodo de la marca en la memoria y que la naturaleza del mismo afecte a la facilidad para asociar diferentes informaciones de esa marca en la memoria del consumidor. 
A la vista de las investigaciones analizadas y de las conclusiones a las que llegan distintos autores el concepto de notoriedad de marca puede tener una clara aplicación al ámbito del comercio minorista. Como hemos venido comentando, el presente trabajo no se refiere a las marcas propias de distribuidores, sino a la concepción del valor del comercio detallista en si mismo. En este sentido, la notoriedad de marca vendrá asociada al comercio y no a las marcas que éste pueda comercializar. Así, si un comercio tiene una notoriedad de marca importante, parece lógico pensar que la consecuencia será similar a la apuntada de manera general por Keller (1993) en el sentido de que el consumidor, cuando piense en una categoría de producto determinada, podrá pensar en un comercio detallista determinado frente a la competencia. Además, si tiene en mente un conjunto de establecimientos determinados, la notoriedad hará que se incline por uno de ellos, a pesar de las condiciones similares de todos ellos. Esto puede ser especialmente relevante en el caso de las franquicias. La notoriedad de marca del comercio detallista también influirá en que las asociaciones que el consumidor tenga respecto él sean más fuertes.

Dodds et al (1991) apuntaban que la notoriedad de marca podía afectar positivamente a la calidad percibida por el consumidor, puesto que éste se forma asociaciones entre la calidad del producto y su marca, es decir, una marca notoria puede hacer pensar al cliente que la calidad del producto es superior. Aaker (1991) considera que un consumidor es más receptivo a tener una buena imagen de un producto o de una marca si conoce la marca en cuestión. Una vez el consumidor conoce la marca, tiende a unirle significados en función de sus resultados y de sus características personales.

Hoyer y Brown (1990) destacaban la importancia de la notoriedad de marca y su influencia en la calidad percibida de la misma: "he oído esta marca, por lo que debe ser buena.

En este sentido, Liu et al. (2015) en su análisis del Valor de Marca en el ámbito de los museos apuntan que la notoriedad de la marca influye en la calidad percibida del museo. De manera similar, en la presente tesis se pretende trasladar esto al ámbito del comercio minorista para ver cómo influye la notoriedad de marca del detallista en la calidad percibida del mismo. Se plantea para ello la siguiente hipótesis: 
H5: La notoriedad de marca de un establecimiento comercial afecta positivamente a la calidad percibida de marca del mismo.

Por otra parte, para algunos investigadores la notoriedad de marca es un antecedente directo del Valor de Marca (Brand Equity), es decir, entienden el conocimiento de marca como una dimensión del Valor de Marca que influye directamente en aquel (Berry, 2000; Prasad y Dev, 2000). Otros estudios ponen de manifiesto que la notoriedad de marca, junto con otras dimensiones relacionadas con la marca, puede influir positivamente en la elección de una marca por parte del consumidor en el futuro y en la cuota de mercado de la marca (Srinivasan, Park y Chang 2005).

Para Keller (2003) la notoriedad de marca es un componente del Valor de Marca y un atributo importante de la marca, también de acuerdo con lo considerado por otros autores (Boo et al., 2008; Motameni y Shahrokhi, 1998). En el ámbito de estudio de marca y hoteles, O'Neill y Xiao (2006) nos dicen que el valor de una marca está en las mentes de los clientes y se basa principalmente en la conciencia de marca del cliente, su percepción de la calidad, y su lealtad a la marca, mientras que Liu (2015) relaciona directamente la notoriedad de la marca con el valor percibido de la misma en el sector del turismo.

Por lo tanto, la bibliografía analizada indica que la notoriedad de marca tiene un claro reflejo en el valor percibido por el cliente (Kim et al; 2008; O'Neill y Xiao, 2006) y contribuye a la obtención de resultados positivos para las empresas de la industria hotelera (Kim y Kim, 2005).

Es por esto que se plantea la siguiente hipótesis en la que se pretende estudiar la relación de la notoriedad de marca con el valor percibido de la misma dentro del ámbito del comercio detallista y cómo la primera influye en la segunda. Teniendo en cuenta los 
numerosos estudios que avalan esta hipótesis en diferentes sectores, se pretende realizar una aplicación y verificación para la marca del comercio detallista.

H6: La notoriedad de marca de un establecimiento comercial afecta positivamente al valor percibido de dicha marca.

Siguiendo con el análisis de la notoriedad o conocimiento de marca, vemos como éste guarda también relación con la lealtad de marca. Así, Boo et al. (2008) plantean diferentes modelos para analizar el Valor de Marca en el ámbito del turismo en los que relacionan ambas dimensiones. Por una parte, consideran que la notoriedad de marca influye en la lealtad a través del valor percibido, mientras que, por otra, proponen un modelo alternativo en el que se aprecia la influencia de la notoriedad de marca en la experiencia y de ésta en la lealtad, con lo que nuevamente vemos como la notoriedad influiría en la lealtad, esta vez a través de la experiencia.

Macdonald y Sharp (2000) destacan la importancia de la notoriedad de marca, así como el hecho de que, en sus estudios, los consumidores para los cuales la notoriedad de marca era destacada, mostraban una abrumadora preferencia hacia la marca conocida, a pesar de las posibles diferencias de calidad y precio. Además, los sujetos conocedores de la marca volvían a elegirla en sus elecciones posteriores. Las diferencias de notoriedad resultaron ser una poderosa influencia en la compra repetida de productos de consumo.

Por su parte, en el mercado de los refrescos, Saleem et al. (2015) encuentran una relación positiva entre la notoriedad de marca y la lealtad.

A la vista de estas conclusiones, la hipótesis que se plantea a continuación relaciona la notoriedad de marca con la lealtad en el ámbito del comercio detallista: 
H7a: La notoriedad de marca de un establecimiento comercial afecta positivamente a la lealtad hacia el mismo.

Dentro de la literatura sobre la notoriedad de marca, no son muchos los estudios que analizan su relación con la experiencia del cliente. Para Berry (2000) la experiencia es un factor determinante a la hora de establecer el Valor de Marca (Brand Equity). Como señalan Ambler et al. (2002) hay un énfasis creciente en la aproximación al marketing desde un punto de vista centrado en el consumidor, especialmente en lo que se refiere a maximizar el Valor de Marca a través de la experiencia. El concepto de marca enfatiza los beneficios emocionales para el consumidor a través de las experiencias de compra del cliente (Ambler, 1997).

A pesar de esto, no es abundante la literatura que relaciona la notoriedad de marca con la experiencia del cliente. En esta línea de investigación cabe citar a Boo et al. (2008) cuando plantean que la notoriedad de marca tiene influencia en la experiencia del cliente, en el ámbito del turismo.

Al hilo de estos razonamientos, se plantea la siguiente hipótesis de trabajo:

H7b: La notoriedad de marca de un establecimiento comercial afecta positivamente a la experiencia del cliente con el mismo.

\subsubsection{Imagen de marca}

Se dice de una marca que tiene un Valor de Marca positivo desde el punto de vista del consumidor (customer-based brand equity) cuando éste reacciona más favorablemente ante un producto y su marca de lo que lo haría si no la identificase. Una marca con un 
valor positivo desde el punto de vista del consumidor puede conllevar que éste acepte mejor nuevas extensiones de marca, sea menos sensible a incrementos de los precios y a menores niveles de apoyo publicitario o incluso a que esté dispuesto a buscar la marca en nuevos canales de distribución (Tuominen, 1999).

Para Keller (1993) el Valor de Marca se da cuando el consumidor está familiarizado con ella y tiene asociaciones positivas en su memoria con respecto a la misma. Esto lleva a una respuesta favorable hacia la marca que, a su vez, se traduce en mayores ingresos, menores costes y más beneficios para la empresa. Este autor considera la imagen de marca como las percepciones racionales o emocionales que los consumidores asignan a una marca específica o también el conjunto de percepciones que el consumidor se forma sobre una marca como reflejo de las asociaciones de la misma. Una imagen positiva de marca ayuda a la empresa a establecer su posicionamiento de marca, fortalecer los resultados de la marca en el mercado y protegerla de sus competidores (Aaker, 1996).

Por su parte, Dobni y Zinkhan (1990) definen la imagen de marca como el cuadro o la fotografía de la oferta que el consumidor se forma en la mente y que incluye significados simbólicos que asocia con los atributos específicos del producto o servicio, es decir, la imagen de marca es la representación de la marca en la mente del consumidor que va ligada a una oferta.

Lassar et al. (1995) consideran la imagen de marca como una fuente importante para la creación del Valor de Marca, desarrollando una escala para medir éste último en el que consideran la dimensión de la imagen como imagen social, entendida como la percepción del consumidor de la estima en la que los consumidores de su grupo social tienen a la marca. En este sentido Tsai (2005) considera la imagen de marca como las percepciones del consumidor de aprobación social. La imagen del minorista en la mente del consumidor es la base del Valor de Marca del comercio detallista (Aliwadi y Keller, 2004).

En el ámbito del comercio minorista una de las primeras aportaciones la encontramos en el trabajo de Martineau (1958) en el cual se definía la imagen del 
establecimiento comercial como la forma en la que éste es definido en la mente del comprador, en parte por las cualidades funcionales y en parte por un aura de atributos psicológicos. Más recientemente, Hartman y Spiro (2005), en línea con la concepción dominante en la literatura, definen la imagen del establecimiento comercial como la impresión total representada en la memoria como consecuencia de los atributos percibidos asociados con el comercio, tanto dependientes como independientes, en la memoria del consumidor, que han sido aprendidos de la exposición actual y pasada a diferentes estímulos.

Diversas investigaciones sugieren que la imagen del establecimiento o sus atributos afectan al comportamiento del cliente del comercio (Jinfeng y Zhilong, 2009). A la hora de construir lealtad hacia el comercio detallista, se debe tener en cuenta que el consumidor se ve más influenciado por la gestión del punto de venta que por la comunicación del comercio. Así, cobran especial importancia aspectos como la apariencia de la tienda, la disposición del espacio, la organización de la mercancía, la música o el espíritu de aventura que se pueda asociar a la compra (Dabija y Babut, 2014). A pesar de la importancia que la imagen de marca tiene en la lealtad del cliente, es una variable que no ha recibido mucha atención en la literatura (Nyadzay y Khajehzadeh, 2016; Wang y Yang, 2010).

Teniendo esto en cuenta, los responsables de los establecimientos necesitarán conocer cómo se forma su imagen para posteriormente poder modificarla con la finalidad de atraer a su público objetivo. "La gestión adecuada de la imagen del comercio minorista permitirá influir en la consecución de resultados, tales como el aumento de sus ventas, o la lealtad de sus clientes, que se traducirá en mayor rentabilidad para el comercio", tal y como señalan Moreno et al. (2013).

Por su parte Aaker (1996) relaciona la imagen de marca con el concepto que el consumidor tiene de sí mismo. De hecho, tal y como señalan de Chernatony y Dall'Olmo (1998), cuando las imágenes de marca son fuertes, pueden ser usadas para realzar la autoimagen de una persona. 
La imagen y el valor de las marcas de los comercios minoristas, según Deepra y Chitramani (2013), dependen, en parte, de las marcas de fabricante que comercialicen, así como del valor de las mismas. El comercio detallista puede utilizar las marcas de los fabricantes para generar interés en los consumidores, así como lealtad hacia su establecimiento. Las marcas del fabricante comercializadas por un comercio minorista ayudarán a éste a crear su propia imagen y a posicionarse en el mercado (Ailawadi y Keller, 2004).

En el comercio detallista, las tiendas caracterizan a la empresa a la que pertenecen; el punto de venta es el producto de la empresa detallista (Jara y Cliquet, 2012). Además, la imagen del establecimiento influye en la imagen de marca del minorista (Aliwadi y Keller, 2004; Burt y Sparks, 2002; Grewal et al., 1998).

El conocimiento de marca es un punto clave a la hora de crear Valor de Marca. Siguiendo los estudios de Keller (1993) podemos decir que dicho conocimiento está compuesto por la notoriedad de marca (brand awareness) y por la imagen de marca (brand image).

En cuanto a la notoriedad de marca, en la presente tesis se ha analizado con mayor profundidad en el apartado dedicado concretamente a este componente del Valor de Marca, ya que el concepto propuesto por Keller (1993) está basado en el modelo de Aaker (1991), puesto que para el primero de ellos la notoriedad de marca está formada por el reconocimiento y el recuerdo de la misma. Como decimos, estos dos aspectos son considerados, junto con otros, en la propuesta de Aaker (1991), por lo que remitimos a lo dicho anteriormente.

Sin embargo, consideramos interesante centrarnos en el concepto de imagen de marca, puesto que es una variable importante a la hora de estudiar la marca (Saleem et al, 2015).

Keller (1993) define imagen de marca como las percepciones sobre una marca reflejadas en las asociaciones de marca que el consumidor tiene en su mente. Por su parte 
estas asociaciones son los otros nódulos informacionales ligados al nódulo de la marca en la memoria, que contienen el significado de la marca para el consumidor.

Para el autor, las asociaciones de marca pueden tomar diferentes formas: atributos, beneficios y actitudes. Así, la primera categoría estaría compuesta por los atributos, entendidos como las características descriptivas propias de un producto o servicio (lo que el consumidor piensa que es el producto o servicio y que tiene en cuenta a la hora de su adquisición o consumo). Los atributos pueden, a su vez, estar relacionados con el producto o no estarlo. Los primeros son los que se refieren a las características físicas y a la composición del producto o a los requerimientos del servicio y se definen como los ingredientes que el consumidor ve como necesarios para el funcionamiento del producto o la funcionalidad del servicio. Por su parte, los atributos no relacionados con el producto son los aspectos externos relacionados con su compra o consumo y que son, principalmente, la información sobre el precio, la información transmitida por el envase o por la apariencia, las imágenes de los que usan el producto o servicio y de cómo y en qué ocasiones se usa.

La segunda categoría en las asociaciones de marca vendrá dada por los beneficios, entendidos como el valor personal que el consumidor asigna a los atributos del producto o servicio, es decir, lo que piensan que puede hacer por ellos. Los beneficios pueden ser funcionales (ventajas intrínsecas que normalmente sirven para satisfacer las motivaciones básicas por las que se adquiere el producto o servicio), experienciales (relacionados con lo que se siente al usar el producto o servicio y que satisfacen necesidades experienciales como el placer, la variedad o la estimulación) y simbólicos (que suponen ventajas más extrínsecas del consumo, ya que están relacionados con la aprobación social, la pertenencia a un grupo o la expresión personal).

La tercera categoría tomada en consideración por Keller (1993) se refiere a las actitudes, vistas como las evaluaciones que los consumidores hacen sobre la marca y que cobran especial relevancia por el hecho de que a menudo constituyen la base del comportamiento del consumidor, por ejemplo, en lo que se refiere a la elección de marca. 
Las asociaciones de marca pueden variar en función de que sean evaluadas de manera más o menos favorable, de su fortaleza (que vendrá dada tanto en función de la cantidad como de la calidad de las mismas) y de que sean únicas, es decir, no compartidas con otras marcas.

La imagen de marca de un establecimiento minorista aparece vinculada a diversos estudios que sobre la marca se han desarrollado en el ámbito comercial (Jara y Cliquet, 2012; Papadopoulos y Heslop, 2002). Grewal et al. (1998) definen la imagen del comercio como la suma de percepciones y atributos ligados al mismo, como se reflejan en las asociaciones de la memoria. La calidad de los productos ofrecidos, el surtido de producto, los servicios prestados, facilidades físicas, disposición y ambiente interno son ejemplos que, para estos autores, contribuyen a la formación de la imagen del establecimiento.

A pesar de que el uso de Internet para fortalecer la imagen del comercio y de la marca es importante para cualquier empresa, como apuntan Levenburg et al. (2006), parece que las más pequeñas dan más importancia la utilización de Internet para la búsqueda de información, mientras que apenas lo tienen en cuenta como herramienta que facilita la comunicación con el cliente, proveedores, etcétera.

Este enfoque es relevante ya que la imagen ha jugado un papel trascendental en la medición de la eficacia de las marcas. De esta forma, para autores como Srivastava y Shocker (1991) y Keller (2003), la fortaleza de la marca se apoya en tres aspectos: (1) el grado de conocimiento y en la imagen que el consumidor tiene de la marca. (2) las percepciones acerca de la marca podrían proporcionar a la empresa tres tipos de ventajas comerciales -relativas a la rentabilidad actual, a la estabilidad y al crecimiento potencial de dicha rentabilidad-, las cuales le pueden reportar beneficios económico-financieros, y (3) el desarrollo de actuaciones de marketing dirigidas a vincular la marca con asociaciones fuertes, favorables, únicas y consistentes resulta esencial de cara a crear una imagen de marca positiva.

Cretu y Brodie (2007) señalan la relación positiva que existe entre la imagen de marca y el valor de la misma en la relación de los fabricantes con sus clientes cuando éstos 
son pequeñas empresas, si bien, el efecto de la imagen de marca tiene una influencia más específica en las percepciones de calidad del consumidor.

Otros autores, se expresan en similares términos al afirmar que el valor percibido de un establecimiento comercial viene determinado en parte por la imagen que se tiene del mismo y de su marca (Tsai, 2005).

A partir de lo indicado, podemos establecer la siguiente hipótesis de trabajo:

H8: La imagen de una marca de un establecimiento comercial afecta positivamente al valor percibido de dicha marca.

Por su parte, algunos estudios hacen referencia a la relación entre la imagen de marca del establecimiento y la lealtad del cliente hacia el mismo. Así, Osman (1993) ya planteó que la imagen percibida del establecimiento por parte de los clientes es determinante en la formación de la lealtad de los mismos.

Siguiendo con este análisis, cabe destacar que algunos estudios realizados hasta la fecha determinan que la imagen de marca es un componente fundamental en la formación de la lealtad de marca (Hosany et al., 2006; Jara y Cliquet, 2012). Así, la imagen de marca juega un papel crítico a la hora de ayudar a los clientes a decidir si compran o no una determinada marca $\mathrm{y}$, en consecuencia, influencia también en su comportamiento de recompra (Bian y Moutinho, 2011). También puede servir como una herramienta defensiva de marketing para retener clientes y conducirlos hacia la lealtad, particularmente en el contexto de servicios donde marca y empresa se utilizan en numerosas ocasiones como sinónimos (Berry, 2000; Sweeney y Swait, 2008).

Otros trabajos como el de Cretu y Brodie (2007) han determinado que la imagen de marca ejerce una influencia positiva en la lealtad de los clientes hacia dicha marca. 
Ogba y Zhenzhen (2009) destacan que la imagen de marca influye en la lealtad y que, como hemos visto al hablar de la calidad de marca, ésta influye en la imagen de marca, por lo que la imagen de marca, según estos autores media parcialmente entre la calidad percibida y la lealtad a la marca. Estos resultados también son destacados por Saleem et al. (2015) en su estudio sobre el Valor de Marca en el sector de los refrescos.

De esta manera, algunos estudios como los de Wnag y Yang (2010) muestran que la imagen de marca juega un papel moderador a la hora de explicar el efecto en la lealtad del consumidor y las intenciones de compra, particularmente en las empresas de servicios (Lai et al., 2009).

La relación directa entre la imagen de marca y la lealtad se analiza en estudios como Boo et al. (2008) para el sector turístico, Seric et al. (2014) aplicado al caso de los hoteles, Liu et al. (2015) en el caso de los museos o como se ha comentado, Saleem et al. (2015) en su estudio relativo al mercado de los refrescos.

Vemos pues como son numerosos los estudios en los que se relaciona la imagen de marca con la lealtad hacia la misma. Por tanto, se espera que la imagen de marca y la lealtad de marca se encuentren relacionados entre sí en el caso del comercio detallista, tal y como se plantea en la siguiente hipótesis de trabajo:

H9a: La imagen de marca de un establecimiento comercial afecta positivamente a la lealtad hacia dicha marca.

Si bien son diversos los estudios que analizan la relación entre la imagen de marca y la lealtad, es más bien escasa la literatura que intenta ver la relación existente entre la imagen de marca y la experiencia del cliente. 
En el caso del comercio detallista, como hemos visto, la imagen de marca, siguiendo la definición más amplia de Keller (1993) serían las percepciones racionales o emocionales que los consumidores asignan a la marca de un comercio específico. Por au parte, Dobni y Zinkhan (1990) definen la imagen de marca como el cuadro o la fotografía de la oferta que el consumidor se forma en la mente y que incluye significados simbólicos que asocia con los atributos específicos del producto o servicio.

También se han tenido en cuenta las diversas influencias que ejerce la imagen en la formación del Valor de Marca del comercio minorista. Ahora bien, yendo más allá de estas relaciones, el presente trabajo se plantea la influencia que la imagen del comercio puede tener sobre la experiencia que el cliente puede tener con respecto a la marca del mismo. Entendemos de las definiciones anteriores que, a la hora de valorar la experiencia, el cliente puede verse influenciado, entre otros aspectos, por la imagen que tenga del comercio. Así, ante una nueva experiencia del cliente en relación con el minorista, se trataría de ver si la imagen que el consumidor tiene de éste influye de alguna forma en la valoración de la experiencia vivida. Para ello, consideramos la siguiente hipótesis de trabajo:

H9b: La imagen de marca de un establecimiento comercial afecta positivamente a la experiencia del cliente con el mismo.

\subsubsection{Lealtad de marca}

En este apartado se pretende analizar la lealtad de marca como dimensión del Valor de Marca, además de hacer una aplicación al sector del comercio minorista. Frente a la lealtad, el Valor de Marca es un concepto más amplio que comprende tanto la imagen de marca como la familiaridad con la misma. Por su parte, la lealtad se ha concebido tradicionalmente por la literatura como un constructo de comportamiento relacionado con 
las intenciones de repetición de compras. Por contraste, el Valor de Marca supone la disposición favorable hacia la marca que no necesariamente tiene porqué resultar en un comportamiento de compra (Nam et al., 2011).

Conseguir clientes leales a la marca se ha demostrado que es vital para conseguir la rentabilidad y supervivencia de las empresas. Los clientes leales generalmente tienen una intención de pago mayor y una menor sensibilidad al precio en comparación con otros clientes (Jorgensen et al., 2016). Además, desde hace décadas ya se apunta el hecho de que conseguir nuevos clientes bastante más caro que retener a uno existente (Mellens et al., 1996). Por otra parte, los clientes leales pueden mejorar la calidad, así como la productividad del servicio ofrecido por el comercio minorista, ya que ofrecen información sobre las necesidades y preferencias de los consumidores (Sonderlund, 2004).

La lealtad a la marca por parte de los clientes es el elemento fundamental que persigue el Valor de Marca (Aaker, 1991). Lassar et al. (1995) señalaron que "el Valor de Marca se debe a la mayor confianza que los consumidores depositan en una marca en lugar de hacerlo en las marcas de sus competidores. Esta confianza se traduce en la lealtad de los consumidores y su disposición a pagar un precio superior por la marca".

La capacidad de crear lealtad de los clientes es un objetivo importante de la gestión de la marca. Para Keller (2003) conseguir la lealtad de marca es la principal fuente de generar valor a una marca desde la perspectiva del cliente. El desarrollo experimentado por el marketing en las últimas décadas ha propiciado a su vez que el concepto de lealtad haya evolucionado, con una conceptualización y operacionalización del constructo más profunda y rica (Caruana, 2004).

Lógicamente esto cobra especial importancia en el caso del comercio detallista. En el actual entorno competitivo, cada vez más el consumidor tiene innumerables opciones a las que acudir. No sólo dispone de numerosas posibilidades a la hora de elegir un comercio minorista en el que realizar sus compras de manera presencial, sino que, además, también puede dirigirse a Internet y decidir si las compras de ese mismo producto las hace en el entorno virtual. 
Si bien en principio Cunningham (1956) consideraba la lealtad como la proporción de compras que realiza una familia de una determinada marca, comprada con mayor frecuencia, respecto del total gastado, autores más recientes como Chancy (2001) entienden que la lealtad por parte del consumidor presenta unos niveles de decadencia a pesar de los esfuerzos que las empresas realizan con sus programas de fidelización. Esto es así porque los consumidores mantienen cierta tendencia a dividir sus compras entre varias marcas dentro de una misma categoría de producto (Cooil et al., 2007).

Frente a esta problemática a la que se tienen que enfrentar las marcas, cabe destacar, desde el punto de vista del comercio minorista, el concepto de "lealtad hacia el establecimiento principal", que tiene en cuenta el porcentaje de gasto que el cliente realiza en su establecimiento preferido (East et al., 1995; Terblanche y Boshoff, 2006; Cooil et al., 2007). En esta misma línea diversos autores definen la lealtad del consumidor como el porcentaje de gasto que éste realiza en una marca específica o en un determinado establecimiento (Pritchard et al., 1999; Liang y Wang, 2005).

La consecución de lealtad del cliente hacia el establecimiento comercial es de extremo interés para el comerciante, dado que los altos costes necesarios para conseguir un nuevo cliente son difíciles de amortizar si no hay repetición de las compras por su parte (Wallace et al., 2004). Además, con el rápido crecimiento de las nuevas tecnologías de la información y la comunicación y la aparición del comercio electrónico, se han visto reducidos para el consumidor los costes de cambio de proveedor, con lo que cada día es más difícil para el comercio poder retenerlos (Srinivasan et al., 2002). En este entorno, el esfuerzo por construir la lealtad del cliente se convierte en una estrategia defensiva de vital importancia para los minoristas (Das, 2014), puesto que para autores como Gremler y Brown (1996) la lealtad consiste en el grado en que el cliente manifiesta un comportamiento de repetición de compra de un proveedor determinado y tiene, además, una predisposición hacia ese proveedor, teniéndolo a él únicamente en cuenta cuando le surge la necesidad de consumir sus servicios.

Odin et al. (2001) consideran que la recompra de la misma marca puede darse como resultado de una lealtad reflexiva, como resultado de un compromiso o actitud 
favorable hacia la marca, o también puede ser consecuencia de una inercia de compra, es decir, una repetición de compra de la misma marca sin un motivo real para esta elección. Según esto, Jorgensen et al. (2016) entienden que en el caso de que la inercia haga que un individuo vuelva a comprar la misma marca, el comportamiento de compra no sería de lealtad a la marca, sino simplemente repetición de compra.

Ante esta situación el comercio detallista con presencia física no solo compite por conseguir y mantener clientes fieles con otros comercios de su entorno geográfico, sino que se encuentra con la necesidad de conseguir la lealtad del cliente también frente a la competencia minorista online. En el presente apartado se pretende analizar la dimensión de la lealtad dentro del Valor de Marca y su importancia y aplicación al sector minorista, puesto que se considera de vital importancia para conseguir la competitividad del comercio detallista. Si éste es capaz de conseguir clientes leales conseguirá también incrementar sus beneficios en el sentido de que un cliente fiel supone menos coste que el necesario para conseguir uno nuevo. Además, el cliente leal al comercio es menos sensible al precio, consume más que aquel que no lo es y es más tolerable ante posibles errores o situaciones de disgusto, tal y como se desprende de algunos estudios que se analizan en el presente apartado.

A pesar de la importancia que puede conllevar la lealtad para el comercio minorista, es más bien escasa la literatura existente al respecto hasta la fecha (Das, 2014). La presente tesis pretende, entre otros objetivos, contribuir a mejorar el conocimiento de esta dimensión del Valor de Marca en su aplicación al comercio detallista.

Para diferenciar su oferta de la de su competencia, construir lealtad del cliente y desarrollar ventajas competitivas sostenibles, Grewal y Levy (2007) indican que los minoristas pueden ofrecer un servicio excelente a sus clientes. Una opción puede consistir en prestar un servicio personalizado, otra es proporcionar esa excelencia a través de la innovación en tecnologías en el punto de venta (como, por ejemplo, los kioscos interactivos) y en el entorno multicanal se pueden ofrecer servicios de chats o conversaciones instantáneas a través de Internet con personal del comercio, modelos virtuales que ayuden al consumidor a ver cómo le quedaría el producto en su cuerpo, etc. 
Aaker (1991 y 1996) define la lealtad a la marca como el apego de un cliente a una marca. En general, podemos decir que la lealtad de marca ha sido considerada una actitud o comportamiento (Odin et al., 2001). Así, autores como Rauyruen y Miller (2007) definen la lealtad del consumidor como un concepto formado por una dimensión actitudinal y otra comportamental.

Según apunta Fandós (2010), la lealtad actitudinal se basa en el nivel de afecto psicológico y de actitud favorable hacia un proveedor, en preferencias manifiestas, en un compromiso por parte del consumidor o en intenciones de recompra, mientras que la lealtad comportamental se define en términos de recompras al mismo proveedor observadas durante un periodo determinado de tiempo (Rundle-Thiele y Mackay, 2001).

Sin embargo, en términos de medición, una revisión de la literatura pone de manifiesto la falta de claridad sobre la naturaleza conceptual de la lealtad a la marca. Esto ha dado lugar al uso de una variedad de herramientas de medición que han producido resultados inconsistentes (Odin et al., 2001). El Valor de Marca se crea, en gran parte, por la lealtad de marca; por lo que esta dimensión representa para muchos autores el pilar esencial del valor de una marca (Baloglu, 2002; Boo et al., 2009; Yoo et al., 2000; Mohd et al., 2007).

En el estudio de la lealtad en el comercio detallista Arnett et al. (2003) destacan que para desarrollar una medida de la lealtad hacia el punto de venta se deberá considerar el número de veces que una persona compra en un comercio determinado, el número de veces que compra en otros comercios y la disponibilidad de esa persona para recomendar el establecimiento a otras personas.

La lealtad viene a menudo definida como un compromiso profundo y sostenido de comprar repetidamente en el futuro un producto o servicio preferido, causando así la compra repetitiva de una marca, a pesar de influencias situacionales o de los esfuerzos de marketing realizados para que haya un comportamiento de cambio de marca en el consumidor (Oliver, 1999). El concepto de lealtad se divide en cuatro fases, según este autor: cognitiva, afectiva, conativa y acción. Para conseguir clientes leales las marcas 
deberían intentar asegurarse de que los atributos de la marca tienen un alto nivel de prestaciones que además perdura en el tiempo. Si no, es posible que los clientes decidan cambiarse a otras marcas. Si una marca es capaz de ofrecer buenas prestaciones a lo largo del tiempo, los consumidores entrarán en la fase afectiva de la lealtad. Les empezará a gustar la marca por esas altas prestaciones continuadas que les ofrece. A partir de aquí, debido a la percepción de afecto hacia la marca de manera repetida, se entra en la fase conativa en la cual desarrollan una sensación de obligatoriedad de recompra de la misma marca. Por último, en la fase de acción se destaca el deseo de actuar y de superar los obstáculos que puedan ir en contra de esa intención de recompra. Vemos como, por tanto, la construcción de lealtad hacia el comercio detallista es un proceso a largo plazo.

Comprender este proceso es importante en el caso del comercio detallista, ya que permitiría a sus gestores destacar e incidir en los atributos considerados como más importantes por el consumidor, para, partiendo de esa base, desarrollar el gusto por la marca y llevar a cabo las acciones necesarias para generar la acción del consumidor, es decir, el deseo de compra en un establecimiento determinado.

Tabla 3.5. Definiciones de lealtad de marca del consumidor

\section{Cunningham (1956)}

La lealtad de marca viene dada por la proporción de compras de una determinada marca que realiza una familia, comparada con mayor frecuencia, respecto del total gastado.

Jacoby y Kynner (1973)

La lealtad de marca es intencionada, con una respuesta comportamental, expresada a lo largo del tiempo, a partir de un proceso de decisión respecto de una o más marcas del conjunto de marcas posibles y que es resultado de un proceso psicológico.

East et al. (1995)

La lealtad del consumidor está relacionada con la proporción de gasto realizado por dicho consumidor en una marca específica o en un determinado establecimiento. 
Gremler y Brown (1996)

La lealtad hacia un servicio es el grado en que un cliente manifiesta un comportamiento de repetición de compra de un proveedor concreto, posee una disposición actitudinal positiva hacia dicho proveedor y sólo considera a éste cuando le surge la necesidad de utilizar dicho servicio.

Oliver (1999)

La lealtad supone un compromiso de recompra de un producto o servicio preferido que causará repetición de compra de la misma marca, si bien las influencias del entorno y los esfuerzos de marketing de las empresas tienen el potencial de provocar un cambio.

East et al. (2000)

La lealtad del consumidor se puede describir como una predisposición positiva hacia una marca o un establecimiento.

Wallace et al. (2004)

La lealtad del consumidor hacia un establecimiento es una respuesta comportamental intencionada, expresada a lo largo del tiempo, a partir de un proceso de decisión respecto de un establecimiento concreto del conjunto de establecimientos posibles y que es resultado de un proceso de evaluación y decisión que desemboca en un compromiso hacia el establecimiento.

Liang y Wang (2005)

Definen la lealtad del consumidor como el porcentaje de gasto que éste realiza en una marca específica o en un determinado establecimiento

Rauyruen y Millar (2006)

La lealtad es un concepto formado por una dimensión actitudinal (nivel de afecto psicológico y de actitud favorable hacia un proveedor) y otra comportamental (disposición de los clientes de volver a comprar al mismo proveedor y de mantener una relación con el mismo).

Liu et al. (2011)

La lealtad es considerada como relación a largo plazo beneficiosa para los proveedores de servicios, pues se centra en establecer una relación con los clientes dinámica y duradera. 
Swoboda et al. (2013)

La lealtad hacia un comercio se define como la intención y la disposición para la recompra en una tienda en particular, al mismo tiempo que se identifican conductas de recomendación del comercio.

Castaldo et al. (2015)

El grado en que un cliente habitual muestra intención de compra con su proveedor, posee una disposición de actitud positiva hacia el mismo y acude a él en cada ocasión que surge la necesidad.

Fuente: Elaboración propia a partir de Fandos (2010)

Vista la importancia que la lealtad puede llegar a tener en la gestión del comercio detallista, nos planteamos a continuación qué papel juega la experiencia en su relación con la lealtad hacia el comercio detallista, puesto que, como se ha venido indicando a lo largo de la presente tesis, cada vez más está extendida entre las empresas de todos los sectores la preocupación por ofrecer a sus clientes experiencias memorables, más allá de la adquisición de productos y servicios.

La influencia de la experiencia del cliente sobre la lealtad del mismo hacia el comercio detallista se analiza con mayor profundidad en el punto 4.2.5 de la presente tesis, si bien a continuación se destacan algunos puntos a tener en cuenta para el planteamiento de la hipótesis de trabajo.

En la línea de investigación que incide en el papel que ejerce la experiencia del cliente sobre la lealtad, Iglesias et al. (2011) encontraron que el efecto de la experiencia de marca en la lealtad hacia la misma estaba mediatizado por la obligación afectiva. Por su parte Brakus et al. (2009) destacan los efectos positivos que la experiencia de marca tiene sobre la lealtad del cliente, mientras que Nysveen et al. (2013) llegan a la conclusión de que las experiencias relacionales son importantes predictores de la satisfacción del cliente y de su lealtad de marca. 
En el ámbito del comercio, el creciente número de alternativas de productos y establecimientos comerciales, así como la competencia por incrementar la cuota de mercado, requiere que los gestores de los establecimientos se preocupen por la lealtad hacia su marca (Huusik, 2011). La importancia de la lealtad de marca en el comercio la ponen de manifiesto estudios como el de Brakus et al. (2009), para quienes el valor percibido del cliente es consecuencia de las experiencias globales relacionadas con la marca, y representan importantes impulsores de la lealtad de los clientes, que pueden verse afectadas sustancialmente por los correspondientes niveles de compromiso con el cliente.

Las experiencias anteriores que un cliente haya tenido en su relación con un comercio detallista, serán determinantes en la lealtad que éste tenga hacia el mismo, tal y como ya determinó en su momento Osman (1993).

La siguiente tesis que se plantea relaciona la experiencia del cliente con la lealtad de éste hacia un comercio detallista, tomando como base para su formulación los estudios citados anteriormente:

H10: La experiencia del cliente afecta positivamente a la lealtad hacia el establecimiento comercial

Una vez visto el papel de la experiencia sobre la lealtad, nos planteamos analizar la influencia de la lealtad de marca sobre el Valor de Marca en el comercio detallista (retail equity).

La influencia que ejerce la lealtad sobre el Valor de Marca (brand equity) ha sido extensamente desarrollada por la literatura desde un punto de vista amplio, en el sentido de que la lealtad es considerada como factor clave a la hora de generar Valor de Marca. Ya 
Aaker (1991) destacaba en su planteamiento el papel de la lealtad como dimensión clave para la creación de Valor de Marca.

La lealtad hacia el minorista es, para Arnett et al. (2003), un componente importante del capital de marca de la tienda, puesto que reduce la vulnerabilidad del minorista ante las acciones de su competencia (Aaker, 1991). Para Yoo et al. (2000) el valor del comercio (retailer equity) está compuesto por cuatro dimensiones: lealtad al comercio, notoriedad, calidad del servicio y asociaciones.

Rondan (2004) en un estudio donde analiza la importancia que tiene el precio así como la lealtad a la marca en la elección de compra en productos de uso frecuente, nos dice que los consumidores que son fieles a una marca o establecimiento consumen más que aquellos que no lo son. Shani, Rivera y Hara (2009) determinan que los clientes que acuden de manera repetitiva a un determinado evento cultural gastan más dinero en general, recomiendan el evento a otras personas, permanecen más tiempo y visitan más lugares a lo largo de la duración de dicho evento. Para otros autores (Burt y Sparks, 2002; Corstjens y Lal, 2000; Halstead y Ward, 1995; Richardson, 1997; Rondán et al., 2006) una de las fuentes de éxito de la marca comercial es la calidad percibida que conduce a crear diferenciación, que puede llevar a la lealtad. A su vez, la lealtad de marca indica una actitud positiva de los clientes, lo que lleva a la generación de un boca-oído positivo, el cual aumenta la fiabilidad de la marca y disminuye el riesgo percibido del cliente (Bowen y Chen, 2001; Brakus et al., 2009).

La influencia de la lealtad sobre el Valor de Marca ha sido analizada por la literatura en diversos estudios a lo largo de las últimas décadas. Partiendo de las definiciones iniciales de Aaker (1991), para quien una de las dimensiones clave del Valor de Marca viene dada por la lealtad, autores como Cai et al. (2015) siguen contemplando esta misma línea de estudio. Por su parte, otros como Boo et al. (2008) ven la influencia que la lealtad tiene sobre el Valor de Marca en el caso de los hoteles, mientras que también hay otros estudios que profundizan en esta relación aplicándola al comercio minorista (Musekiwa et al., 2013; Ruiz et al., 2013; Shen, 2010). 
En definitiva, a la vista de dichos estudios, podemos pensar que existe una relación positiva entre la lealtad hacia el establecimiento comercial y el Valor de Marca del mismo. Por ello, se plantea la hipótesis de trabajo:

H11: La lealtad de marca afecta positivamente al Valor de Marca (brand equity) del establecimiento comercial.

El último aspecto a analizar dentro de este apartado de la tesis dedicado a la lealtad de marca del comercio minorista es la influencia que ésta puede jugar en la percepción de las experiencias del cliente con el comercio detallista.

Para Shankar et al. (2003) un cliente leal es más receptivo a considerar la experiencia con su proveedor de servicios más satisfactoria que un cliente no leal. En base a esto, y teniendo en cuenta que el comercio detallista tiene un amplio componente de servicio al cliente, podemos considerar que aquellos clientes que sean fieles a un determinado minorista, tendrán una mejor predisposición a la hora de valorar las experiencias del cliente que dicho comercio pueda proponerle.

Según la teoría de las uniones de familiaridad (Rindfleisch e Inman, 1998), la lealtad de un individuo hacia un proveedor de servicios puede influir en su grado de satisfacción con el servicio. Según esta teoría, el cliente leal puede estar más satisfecho con el servicio que un cliente no leal, debido a varios factores: la mera exposición al servicio, la información disponible sobre el servicio y que éste sea socialmente más deseable.

Por tanto, un cliente leal a un determinado comercio podrá estar más expuesto a los servicios propuestos por éste, podrá tener más información acumulada sobre ese comercio y podrá formarse unas expectativas en función de otros usuarios que pueda conocer. De esta manera, este cliente fiel podría tener una disposición más favorable hacia los servicios 
prestados por el comercio detallista y estar más satisfecho con las experiencias que éste le proponga.

Para Shankar et al. (2003), si un cliente leal tiene una experiencia negativa con su proveedor y está insatisfecho con él, puede plantearse el cambio. Ahora bien, a la vez, también se planteará algunas pérdidas que podría conllevar ese cambio de proveedor, tales como pérdidas emocionales, pérdidas relacionadas con programas de recompensas o incluso el tener que enfrentarse a una nueva situación poco familiar para él. En comparación con un cliente que no sea leal, las pérdidas percibidas serán mayores.

En el comercio detallista situaciones como la descrita también pueden darse: ante una posible insatisfacción del cliente pueden plantearse opciones de cambio de comercio por parte de éste. Sin embargo, junto a la posibilidad de cambio, el cliente leal se planteará unas determinadas pérdidas e inconvenientes que serán percibidas como mayores de lo que se podría percibir por parte de un cliente no leal. Es por esto que, siguiendo el planteamiento de Zeithaml et al., 1993), un cliente leal tendrá una zona de tolerancia más amplia y experimentará mayores niveles de satisfacción que un cliente no leal. Por tanto, cuanto mayor sea el grado de lealtad del cliente hacia el comercio, mayor será el nivel de satisfacción con respecto al servicio y a su experiencia general con el minorista.

Siguiendo con los análisis anteriores, en la presente tesis se pretende analizar la influencia que la lealtad de marca del comercio minorista tiene sobre la experiencia del cliente en su relación con aquel. Se quiere analizar si los clientes leales a un comercio determinado perciben las experiencias que éste les propone de manera diferente a cómo son vistas por clientes que no tengan esa lealtad. Para ello se plantea la siguiente hipótesis:

\section{H12: La lealtad de marca hacia el establecimiento comercial afecta positivamente} a la experiencia del cliente. 



\section{4 - LA EXPERIENCIA DE COMPRA DEL \\ CLIENTE}





\section{LA EXPERIENCIA DE COMPRA DEL CLIENTE}

\subsection{Concepto de experiencia de compra del cliente}

La gestión de la experiencia del cliente se ha convertido, en los últimos años, amparada por la llegada de las nuevas tecnologías de la información, en un factor clave de éxito de las empresas. A partir de las aportaciones que Holbrook y Hirschman realizaron en la década de los ochenta del siglo pasado, que fueron pioneros en introducir la interesante e influyente idea de que el comportamiento del consumidor tenía una dimensión experiencial (Holbrook y Hirschman 1982, Hirschman y Holbrook, 1982) y por lo tanto, esa nueva perspectiva experiencial apareció como una alternativa a la visión hegemónica del procesamiento de la información para comprender el comportamiento del consumidor, muchos nuevos autores se han venido incorporando a esta nueva perspectiva sobre la necesidad de seguir investigando en conocer con mayor profundidad cómo influyen las experiencias de los clientes en su comportamiento de compra, principalmente en los mercados de servicios o en la venta (Tynan y McKechnie. 2009). Desde esta perspectiva, y siguiendo aportaciones como las de Wong (2013), los productos son tangibles, los servicios intangibles, y sólo las experiencias son memorables, perduran en el tiempo, y ayudan a conseguir la lealtad del cliente.

También este cambio ha afectado a la sociedad de consumo, de tal manera que la democratización de las nuevas tecnologías ha cambiado la forma en cómo se comportan los consumidores en el punto de venta, o incluso en su comportamiento en la red. En concreto, los consumidores utilizan sus visitas a los comercios no solo para comprar, sino también con el propósito de disfrutar y entretenerse, evaluando el servicio en términos de cuánto placer o diversión han recibido (Srivastava y Kaul, 2016).

Schmidt (2006) considera que las experiencias son sucesos privados que se producen como respuesta a una estimulación. Además, apunta que normalmente parten de 
la observación directa y/o de la participación en sucesos y que se producen como resultado de encontrar, pasar o vivir determinadas situaciones por medio de estímulos que se provocan en los sentidos, en este caso que se conectan a la empresa u organización y la marca con la forma de vida del cliente en un contexto social más amplio.

Para Kotler et al. (2010) el Marketing ha ido evolucionando desde lo que denominan Marketing 1.0 (centrado en el producto), hacia el Marketing 2.0, que nace en la era actual de las tecnologías de la información y en el cual el valor del producto viene definido por el cliente y hacia el Marketing 3.0 o marketing basado en los valores que tiene en cuenta al consumidor desde un amplio punto de vista como ser humano y que considera que el consumidor busca soluciones a sus necesidades y también a sus deseos de que el mundo sea un lugar mejor. Para estos autores, las empresas en la era del Marketing 3.0 se diferencian gracias a sus valores, lo cual es especialmente importante en épocas turbulentas y de crisis.

En este contexto, tal y como se apuntaba en el punto 2.4 de la presente tesis, aparece el consumidor 3.0 que usa las nuevas tecnologías para buscar información, ofrecer opiniones, explicar experiencias, hacer compras y hablar de la marca. En un entorno omnicanal los diferentes canales se usan de forma indiferente durante el proceso de búsqueda y compra y es difícil, sino virtualmente imposible, para los detallistas, controlar su uso (Neslin et al., 2014).

Caridad et al. (2105), apuntan que habitualmente se ha partido de la premisa de que el elemento motivacional para adquirir bienes y servicios es la calidad versus el precio. Actualmente, las propiedades y beneficios de lo ofertado, pese a ser necesarios, ya no son suficientes para incentivar la compra, pues la calidad y la innovación en éstos se sobreentiende. En consecuencia, hay necesidad de ofrecer productos atractivos o satisfactorios y que además tengan un valor adicional basado en aspectos emocionales y vivenciales, adquiriendo aquí importancia el Marketing Experiencial.

En el actual entorno competitivo las empresas se ven obligadas a realzar sus ofertas y ofrecer otras cada vez mejores para satisfacer la búsqueda de experiencias de sus 
clientes. El comercio detallista no es ajeno a esta situación y por ello aspira a ofrecer a sus clientes grandes experiencias en todos los canales en los que con ellos interactúa; para ello debe dedicar tiempo y recursos a desarrollar estrategias que aseguren que el consumidor tenga experiencias positivas tanto en su establecimiento físico como en el virtual.

Babin et al. (1994) señalaban la relevancia de la experiencia del cliente en el contexto del comercio detallista y apuntaban que la evaluación que un cliente hace de un comercio detallista no solo se ve influenciada por la calidad funcional, sino también por la "calidad emocional inducida" que el consumidor atribuye al comercio.

Los detallistas reconocen que la mejora del conocimiento del consumidor puede ayudar a mejorar su lealtad y los resultados del comercio. Ante la creciente oferta de servicios, pueden aparecer nuevas fuentes de diferenciación y ventajas si la empresa es capaz de centrarse en la gestión de las experiencias del cliente. Recientemente los directivos han tomado conocimiento de la creciente importancia de la necesidad de crear valor para sus clientes bajo la forma de las experiencias. Para competir con efectividad, las empresas deben centrarse en las experiencias de compra de los consumidores (Srivastava, 2016).

La atención prestada por los detallistas a la creación de experiencias en el punto de venta ha crecido en las últimas décadas, debido a un entorno cada vez más competitivo. Según los estudios de Bäckström y Johansson (2006) los comerciantes consideran que el mercado demanda una orientación hacia las experiencias, ya que los consumidores se centran en la parte emocional de las compras. Así mismo, también creen que el entorno y el ambiente del punto de venta juegan un papel clave a la hora de que una empresa tenga éxito en su orientación hacia las experiencias del cliente.

En este sentido, según el estudio de Forrester (2016), un tercio de las empresas B2C (de venta al consumidor) cambiarán su estructura de negocio para estar más cerca del consumidor y poder competir eficazmente en base a las experiencias. 
Entre otros autores, Berry et al. (2002) realzan la importancia y la necesidad de investigar el papel de la experiencia del cliente. Addis y Holbrook (2001) entienden que el marketing experiencial se centra en la búsqueda de una nueva fuente de ventaja competitiva basada en la implicación emocional de los clientes y en la creación de experiencias ligadas al producto. De esta forma, Caridad et al. (2015) consideran que el marketing experiencial proporciona inspiración para la promoción de bienes y servicios, entendiéndose que ésta está orientada a efectuar la comunicación entre la empresa y su audiencia objetiva.

En este sentido, Wong (2013) indica que la mayor parte de los estudios que hacen referencia a la experiencia del cliente son más bien conceptuales, mientras que los que presentan una orientación más práctica se circunscriben a aspectos muy concretos del concepto o de su aplicación.

Además, la literatura existente que tiene en cuenta la experiencia en el comercio detallista se ha venido centrando sobre todo en los aspectos de la atmósfera del establecimiento, tales como la música, el color, perfumes, etc. Sin embargo, cada vez más los detallistas prestan especial atención a la creación de experiencias memorables que atraigan al consumidor tanto a nivel físico como psicológico. Por ello las experiencias en el punto de venta detallista tienen diversas facetas (Healy et al, 2007).

Esto lleva a considerar la experiencia del cliente desde un punto de vista amplio, es decir, desde una perspectiva holística. Tal y como apuntan Verhoef et al. (2009) la creación de experiencias del cliente superiores parece ser uno de los objetivos principales en el ámbito del comercio detallista moderno, cobrando especial importancia la gestión de la experiencia del cliente, incluso incorporando este concepto en la misión de la empresa. De hecho, autores como Abratt y Kleyn (2012) van más allá cuando afirman que gestionar la experiencia de la marca corporativa de la empresa como una fuente de diferenciación podrá aportar una ventaja competitiva debido a su habilidad para crear diferenciación de marca a largo plazo. 
Además, son diversas las investigaciones que han analizado los distintos factores que influyen en la decisión de elección de un punto de venta por parte del consumidor a la hora de realizar sus compras (Goodman y Remaud, 2015). Así, Morschett et al. (2005) agrupan estos factores según hagan referencia a la calidad, a la variedad, proximidad, precio, servicio y experiencia en el punto de venta.

En la presente tesis se pretende analizar el papel que juega la experiencia del cliente en la formación del Valor de Marca (brand equity) del comercio detallista. Como se desprende de los diferentes estudios que se citan a lo largo del presente trabajo, la experiencia del cliente ha sido analizada desde diversos puntos de vista, principalmente en su relación con la creación de lealtad del cliente hacia la marca. Si bien la literatura que analiza esta relación es amplia a niveles de marca en general, su aplicación al ámbito del comercio detallista es mucho más reducida.

Veremos como muchos de los autores que se citan a continuación estudian el impacto de la experiencia del cliente en la formación del Valor de Marca y, en algunos casos, en los distintos componentes de la misma.

En nuestro caso planteamos un primer modelo en el que la experiencia del cliente antecede a la lealtad de marca del comercio detallista, viéndose afectada a su vez por los distintos componentes del Valor de Marca, así como también un segundo modelo en el que la experiencia del cliente se ve afectada por los componentes del Valor de Marca, siendo un antecedente directo de la misma en el comercio detallista. Para ello, como se ha venido indicando, se ha partido del modelo de Valor de Marca de Boo et al. (2008), quienes a su vez han tenido en cuenta los componentes propuestos por Aaker (1991) y Keller (1993). Además, a la hora de plantear la influencia de la experiencia del cliente en su relación con el Valor de Marca, se han considerado las aportaciones de Berry (2000).

El concepto de experiencia ha sido desarrollado por diferentes estudios y desde diferentes perspectivas durante las últimas décadas. Se suele considerar el trabajo de Holbrook y Hirschman (1982) como el punto de partida de muchos de estos estudios. Estos autores comenzaron a hablar del consumo desde un punto de vista experiencial. Así, 
analizaron la evolución del comportamiento del consumidor desde un punto de vista racional a otro que ponía mayor énfasis en aspectos aparentemente irracionales de las necesidades de compra. De esta forma, empiezan a hablar del consumo como un flujo de fantasías, sentimientos y diversión el cual definieron como punto de vista experiencial. En su modelo de comportamiento del consumidor recogían una serie de aspectos o inputs, tanto del entorno del consumidor como internos, tomando una perspectiva más amplia en la que tenían cabida aspectos del consumo relacionados con el placer, la estética del consumo, los significados simbólicos, la creatividad, las emociones, etc. considerando que el más tradicional enfoque basado en el proceso de la información por parte del consumidor, podría verse enriquecido con la adición de una perspectiva experiencial del proceso de compra.

Tal y como señala Tena (2016) en las últimas décadas la motivación de compra del consumidor examina la experiencia de compra desde perspectivas tanto utilitaristas como hedónicas (Babin et al., 1994; Bardhi y Arnould, 2005), estudiándose la motivación como un constructo de dos dimensiones, una racional y otra emocional.

Así, desde un punto de vista utilitarista las compras se comparan con la realización de una tarea, siendo su valor representado por el éxito o la finalización de la misma, tal y como destacan Holbrook y Hirschman (1982), considerando además estos autores que el individuo es, en este sentido, un solucionador de problemas.

Por otra parte, en la literatura nos encontramos con el estudio de la experiencia de compra desde una perspectiva emocional: la motivación hedónica de compra (Bardhi y Arnould, 2005). El consumo hedónico está relacionado con lo multisensorial, la fantasía y los aspectos emotivos de la compra (Holbrook y Hirschaman, 1982; Kang y Park-Poaps, 2010), siendo el objetivo de la compra en este caso la experimentación de diversión, fantasía y estimulación sensorial, más allá de la consecución eficiente y rápida de la meta (Babin et al., 1994).

Para Holbrook y Hirschman (1982) el comportamiento de la gente en general y de los consumidores en particular es el complejo resultado de la interacción de numerosas 
facetas entre el organismo y el entorno. Se trata de un proceso dinámico en el cual ni los problemas directos ni los componentes relacionados con la experiencia, pueden ser ignorados. Desde su punto de vista el constructo de la experiencia tiene en cuenta las dimensiones de actividades, emociones y sensaciones, propuestas para complementar el acercamiento cognitivo de la perspectiva del procesamiento de la información. Explícitamente estos autores relacionan la experiencia con las dimensiones de consumo simbólicas, hedónicas y estéticas.

Para Shaw (2007) la experiencia del consumidor es una mezcla del rendimiento físico de una organización, los sentidos que se estimulan y las emociones evocadas, cada uno medido intuitivamente frente a las expectativas del consumidor en todos los momentos de contacto con la empresa.

Burgos (2007) define el Marketing Experiencial como aquel que busca incentivar tanto a individuos como a grupos de equipos participantes en programas de incentivos o fidelización para disfrutar actividades únicas, considerando que la exclusividad de vivir estas experiencias les da un valor agregado para el público objetivo que se quiere motivar.

Por su parte, Lenderman y Sánchez (2008) hacen referencia al Marketing Experiencial como una estrategia que intenta dar vida intencionalmente a la promesa que hace la marca a los consumidores por medio de experiencias organizadas que tienen lugar antes de la compra, durante el proceso de compra y en las posibles interacciones posteriores.

Grundey (2008) considera que en el ámbito del comportamiento del consumidor una experiencia es, sobre todo, un hecho personal, a menudo con un importante significado emocional, basado en la interacción con estímulos producidos por los productos y servicios consumidos.

Tal y como apuntan Nysveen et al (2013) el concepto ha sido analizado desde distintos puntos de vista, tales como la experiencia de consumo, experiencia de servicio, experiencia de compra, experiencia de producto, experiencia del cliente o experiencia de 
marca. Para estos autores la experiencia del cliente puede considerarse como uno de los puntos de vista que abarca con mayor amplitud el contexto de experiencia, junto con la experiencia de marca, ya que esta última tiene en cuenta que no sólo los clientes, sino también aquellos que no lo son, pueden tener experiencias con una marca.

En este sentido Grewal et al (2009) consideran que la experiencia del cliente tiene en cuenta todos los puntos de contacto entre el consumidor y la empresa, el producto o el servicio, mientras que Meyer y Schwager (2007), en esta misma línea, consideran que la experiencia del cliente supone una respuesta interna y subjetiva que las personas tienen ante cualquier contacto directo o indirecto con la empresa. El contacto directo suele producirse en el transcurso de la compra, uso y servicio, siendo normalmente iniciado por el consumidor, mientras que el contacto indirecto se da normalmente en los contactos empresa-consumidor que no han estado planificados de antemano: recomendaciones personales, publicidad, relaciones públicas, noticias, etc.

En la misma línea, Srivastava y Kaul (2016) indican que es importante entender que el proceso de creación de experiencias para el consumidor por parte del comercio detallista está compuesto a partir de los diferentes puntos de contacto del consumidor con el comercio a lo largo del proceso de intercambio.

La experiencia se produce cuando los consumidores buscan productos, cuando los compran y reciben un servicio y cuando los consumen (Holbrook, 2000), de manera que, para Brakus et al (2009) hay una experiencia de producto que se da cuando el consumidor interactúa con el producto, es decir, durante su búsqueda, cuando lo examina y cuando lo evalúa, una experiencia de compra y de servicio que se produce cuando el cliente interactúa con el entorno físico del establecimiento, su personal y sus políticas y prácticas comerciales y, también, una experiencia de consumo que es multidimensional y que incluye aspectos hedónicos como los sentimientos, fantasía o diversión. En resumen, se puede decir, según estos autores que las experiencias surgen en una variedad de marcos, ya que si bien la mayor parte se dan directamente cuando el consumidor realiza la compra, adquiere y consume el producto, también pueden surgir de manera indirecta, como sería el caso de exposición del consumidor a las comunicaciones de marketing de una empresa. 
Para Tena (2016) "el componente hedónico o emocional de las compras es visto como una experiencia positiva donde los consumidores pueden disfrutar y sentirse satisfechos con una experiencia relacionada con la actividad comercial, independientemente de si finalmente se realiza la transacción comercial o no".

Sin embargo, el consumidor actual no siempre compra sus productos únicamente en base a los valores o principios que aporta el producto y su marca determinada, sino que los valores propugnados por la compañía (Valor de Marca Corporativo) juegan un papel importante en la toma de decisiones del consumidor y en su proceso de compra (Klaus, 2013). Teniendo en cuenta que el valor de la marca corporativa representa la promesa de la organización y su credibilidad, no son pocos los consumidores que antes de realizar sus compras se preocupan por conocer cómo es la empresa que comercializa esos productos, cuáles son sus principios, cómo se comporta o qué nivel de transparencia e integridad presenta.

Tal y como señala Tena (2016) en las últimas décadas la motivación de compra del consumidor examina la experiencia de compra desde perspectivas tanto utilitaristas como hedónicas (Babin et al., 1994; Bardhi y Arnould, 2005), estudiándose la motivación como un constructo de dos dimensiones, una racional y otra emocional.

Así, desde un punto de vista utilitarista las compras se comparan con la realización de una tarea, siendo su valor representado por el éxito o la finalización de la misma, tal y como ya habían destacado Holbrook y Hirschman (1982) quienes, además, consideran que el individuo es, en este sentido, un solucionador de problemas.

Por otra parte, en la literatura nos encontramos con el estudio de la experiencia de compra desde una perspectiva emocional o motivación hedónica de compra (Bardhi y Arnould, 2005). El consumo hedónico está relacionado con lo multisensorial, la fantasía y los aspectos emotivos de la compra (Holbrook y Hirschaman, 1982; Kang y Park-Poaps, 2010), siendo el objetivo de la compra en este caso la experimentación de diversión, fantasía y estimulación sensorial, más allá de la consecución eficiente y rápida de la meta (Babin et al., 1994).Sin embargo, el consumidor actual no siempre compra sus productos 
únicamente en base a los valores o principios que aporta el producto y su marca determinada, sino que los valores propugnados por la compañía (Valor de Marca Corporativo) juegan un papel importante en la toma de decisiones del consumidor y en su proceso de compra (Klaus, 2013). Teniendo en cuenta que el valor de la marca corporativa representa la promesa de la organización y su credibilidad, no son pocos los consumidores que antes de realizar sus compras se preocupan por conocer cómo es la empresa que comercializa esos productos, cuáles son sus principios, cómo se comporta o qué nivel de transparencia e integridad presenta.

Tynan y Mckechnie (2009) realizaron una revisión de la literatura sobre el marketing de experiencias desde la teoría de "código abierto" de la lógica de ServicioDominante (S-D) presentada por primera vez por Vargo y Lusch (2004) quienes también enfatizaban sobre la importancia de las experiencias en marketing. Desde dicha perspectiva, estos autores concluyeron en su trabajo que este enfoque requiere trabajar con clientes y miembros de una extensa red de creación de valor como socios, durante mucho tiempo para co-crear fuentes de valor complejo y no simplemente ofrecerles una oferta. Co-crear valor con el cliente requiere altos niveles de confianza, compartir riesgos y tomar decisiones conjuntamente. El marketing de experiencias bajo la lógica S-D requiere un enfoque totalmente diferente, en términos de trabajar con el cliente como socio para configurar la oferta, incluyendo una amplia gama de generar valor a través de fuentes sensoriales, emocionales, funcionales / utilitarias, relacionales, sociales, informativas, nuevas y utópicas.

Las diferentes definiciones consideran que la experiencia del cliente está formada por el conjunto de interacciones del consumidor con alguna parte de la empresa. Para ello tienen en cuenta las aportaciones de Pine y Gilmore (1999) relativas a la Economía de la Experiencia como una forma de aportar valor tanto para el cliente como para la empresa. En su libro estos autores presentan las experiencias como un nuevo tipo de oferta económica que ellos denominan el progreso del valor económico y que consideran que emerge como un paso posterior a la oferta de mercancías, bienes y servicios. Se considera así el consumo como una experiencia holística que tiene en cuenta a la persona como un 
todo en diferentes niveles y en todas sus diferentes interacciones con la empresa o con su oferta. Para Pine y Gilmore (1999) cuando un cliente compra un servicio adquiere un conjunto de actividades intangibles personalizadas para el individuo. Sin embargo, cuando el cliente compra una experiencia paga por pasar su tiempo disfrutando de una serie de eventos memorables que un negocio organiza para atraerle de una manera personal.

Como podemos observar y deducir del conjunto de aportaciones anteriores, la experiencia del cliente tiene en cuenta numerosos aspectos de la relación de éste con el comercio, por lo que vamos a considerarla en el presente trabajo, ya que abarca el contexto de este concepto desde un punto de vista más amplio que el que puedan aportar otros similares como pueden ser la experiencia de compra, la experiencia de servicio o la experiencia de producto.

En esta misma línea, posteriormente Gilmore y Pine (2002) apuntan que los negocios tienen que ir más allá de los bienes y servicios para crear experiencias memorables para cada uno de sus clientes. En la economía de la experiencia las empresas deben crear este tipo de experiencia si quieren generar mayor valor económico, no pudiendo limitarse a ofrecer simplemente productos y servicios. En este sentido, cabe destacar el título de su artículo, ya que es muy significativo "Por qué vender servicios no es suficiente".

En las últimas décadas se observa como se está dando una evolución de una economía basada en los servicios a una economía basad en las experiencias. Esto supone que los clientes ya no sólo buscan beneficios, Valor de Marca o relaciones, sino también una experiencia que les enganche y que les ayude a diferenciar a las distintas empresas que compiten en el mercado.

Además, las nuevas tecnologías y unos consumidores más sofisticados y exigentes hacen que los servicios que antes se consideraban como un factor distintivo para la empresa, se vean ahora como una mercancía más, ya que, en el actual entorno competitivo, ofrecer productos de calidad y servicios es algo que ya espera de antemano el consumidor. Por tanto, difícilmente pueden ser considerados como una ventaja competitiva para quien 
los ofrece. En esta coyuntura, las empresas que quieran conseguir una ventaja competitiva no podrán limitarse a ofrecer productos y servicios, por muy buenos que estos sean en relación a su calidad, sino que deberán intentar ofrecer a sus clientes "algo más" que puede venir dado de la mano de la creación de experiencias del cliente.

Gracias a las tecnologías de la información y la comunicación, los consumidores actuales se juntan en sus propias comunidades, contribuyen a la co-creación de sus propios productos y experiencias y únicamente van más allá de sus comunidades si encuentran algo con características admirables, si bien, una vez encuentran algo de este tipo, se convierten en "evangelizadores" del mismo (Kotler et al., 2010).

Gilmore y Pine (2002) apuntan que los negocios tienen que ir más allá de los bienes y servicios para crear experiencias memorables para cada uno de sus clientes. En la economía de la experiencia las empresas deben crear este tipo de experiencia si quieren generar mayor valor económico, no pudiendo limitarse a ofrecer simplemente productos y servicios. En este sentido, cabe destacar el título de su artículo, ya que es muy significativo al respecto: "por qué vender servicios no es suficiente".

Para Blázquez (2014) los consumidores actuales están inmersos en la búsqueda de experiencias en sus procesos de compra, de acuerdo con el paradigma de la economía de las experiencias, antes comentada.

En esta línea de investigación, Schmitt (1999) ya hablaba de la aparición del marketing experiencial como consecuencia de la creciente utilización de las tecnologías de la información que permiten el contacto inmediato entre la gente y las empresas en cualquier momento, de la supremacía de la marca y de la ubicuidad de las comunicaciones y el entretenimiento que hacen que las empresas presten especial atención a ambas para ofrecerlas a sus clientes. El autor consideraba estos tres fenómenos como las tres primeras señales de una nueva aproximación al concepto general de marketing. Así, frente a una concepción más tradicional, el marketing experiencial presenta cuatro características destacadas: 
- Se centra en las experiencias del cliente, ya que éstas proporcionan valores sensoriales, emocionales, cognitivos, de comportamiento y de relación que sustituyen a los valores funcionales.

- Se centra en el consumo como una experiencia holística y más amplia desde el punto de vista del contexto sociocultural.

- Los consumidores son animales racionales y emocionales que guían sus decisiones no sólo desde un punto de vista racional, sino que también actúan en función de fantasías, sentimientos y diversión.

- Los métodos y herramientas del marketing experiencial son eclécticos, no siendo únicamente altamente analíticos y cuantitativos, sino también más intuitivos y cualitativos.

Schmitt $(1999,2006)$ propone una serie de módulos estratégicos para la gestión de las experiencias enfocada a la creación de diferentes tipos de experiencias del cliente. Estos módulos que se deben considerar a la hora de gestionar el Marketing Experiencial incluyen las experiencias sensoriales (sense o sentidos), las afectivas (feel o sentimientos), las experiencias creativas cognitivas (think o pensar), las físicas, de comportamiento y de estilo de vida (act o actuar) y las experiencias de identidad social que son resultado de la relación con un grupo de referencia o cultura (relate o relación), teniendo cada uno de estos módulos sus propios objetivos, así como su propia estructura interna y sus principios.

En este sentido, Hormigo (2002) señala que la experiencia sensorial se refiere a cómo el individuo reacciona ante un estímulo, en el ofrecimiento de bienes y servicios, ratificando que en la compra y en el consumo participan los cinco sentidos.

Caridad et al (2015) indican que este tipo de experiencias se pueden crear a través de la vista, el oído, el tacto, el gusto y el olfato, siendo así que el marketing, en este ámbito, tendría como objetivo la gestión de la comunicación impactando en los cinco sentidos del consumidor con el fin de influir sobre su comportamiento de compra. 
Por lo que se refiere a los sentimientos Moral y Fernández (2012) indican que éstos son bloques de información integrada que sintetizan datos de experiencias pasadas, de deseos y proyectos del propio sistema de valores y de la realidad. Desde el punto de vista del marketing se busca apelar a los sentimientos a fin de crear experiencias afectivas vinculadas a un producto.

El tercer aspecto que señala Schmitt (2006) para la gestión de las experiencias está relacionado con los pensamientos. Así, para este autor, el pensamiento transforma una representación específica de información en formas y significados nuevos y diferentes, lo que permite responder preguntas, resolver problemas y alcanzar metas.

En cuanto a las actuaciones, tal y como indican Kotler y Armstrong (2009), el marketing busca enriquecer la vida de los consumidores ampliando sus experiencias físicas, mostrándoles formas alternativas de hacer las cosas y persiguiendo impactar en sus estilos de vida.

Por último, de los diferentes aspectos apuntados por Schmitt (2006), en cuanto a las relaciones, las experiencias persiguen ir más allá de los aspectos individuales y privados del individuo, teniendo en cuenta sus interacciones con otras personas o culturas. Alet (2007) señala que para lograr una experiencia positiva con base en las relaciones, debe estar centrada en el cumplimiento de la oferta del producto y su valor agregado, que han sido adaptadas al consumidor de acuerdo con sus características, necesidades y expectativas.

Schmitt (2009) concluye que el objetivo del marketing debe ser la integración de las cinco experiencias para crear una única experiencia holística.

Por su parte, Ojiako y Maguire (2009) analizan la experiencia del cliente como una estrategia de negocio. Para estos autores la experiencia surge de la síntesis de varios conceptos. En primer lugar, hablan de un cambio en los paradigmas de las ideas del cliente y su percepción con respecto a los servicios que reciben. En segundo lugar, consideran como factor importante el marketing de relaciones y el énfasis en que éstas perduren en el 
largo plazo. Otro concepto a tener en cuenta como previo al de experiencia del cliente es el de su ciclo de vida, ya que si la calidad del servicio es gestionada correctamente puede influir positivamente en las interacciones empresa-cliente y en la duración de la relación entre ambos. En cuarto lugar, consideran los autores las teorías sobre la estructura del servicio que van desde el nacimiento de la relación entre las partes hasta su madurez. Otro aspecto que influye en este concepto es la psicología de gasto del cliente, ya que asocia la forma en la que los consumidores gastan su dinero con aspectos de desarrollo de la psicología humana. Por último, también consideran importante el hecho de que es posible aplicar disciplinas científicas, de gestión y de ingeniería a tareas que la organización desarrolla en la relación con sus clientes.

Tomando como punto de partida los aspectos citados en el párrafo anterior, Ojiako y Maguire (2009) definen la experiencia del cliente como "una articulación de la interacción personal, experiencias, memorias y oportunidades que una organización ofrece a sus consumidores actuales y potenciales y que excede sustancialmente a sus expectativas en un grado en el que una relación duradera se establece entre el cliente y el proveedor del servicio. Habitualmente dichas experiencias pueden ser evaluadas desde diferentes perspectivas, incluyendo productos, servicios, cuidado, funcionalidad, utilidad y facilidad de uso, confianza, publicidad y envase".

En el ámbito de las experiencias del cliente son de destacar las aportaciones de Gentile et al (2007), quienes hablan del marketing experiencial en relación con los elementos intangibles unidos al valor emocional percibido por los clientes, llegando a una definición de la experiencia del cliente que tiene en cuenta la evolución del concepto de relación entre la empresa y el cliente. Así, teniendo en cuenta esto, consideran que la experiencia del cliente se forma a partir de las interacciones entre un cliente y un producto, una empresa o parte de su organización que provocan una reacción. Esta experiencia es personal y supone la implicación del cliente a diferentes niveles (racional, emocional, sensorial y espiritual). La evaluación que el cliente hace depende de la comparación entre sus expectativas y los estímulos resultantes de la interacción con la empresa y su oferta, en correspondencia con los diferentes momentos de contacto entre ambos. 
Dichos autores llegan a la conclusión de que una parte relevante del valor propuesto a los clientes y que a su vez es reconocido como tal por ellos, está ligada a las características experienciales: independientemente del contexto en el que se encuentren, los clientes quieren vivir experiencias de consumo positivas. Si la empresa es capaz de que su cliente viva una experiencia positiva podrá promover la creación de lazos emocionales entre sus marcas y sus clientes, lo que resultará en un fortalecimiento de la lealtad de los mismos. Según este mismo estudio, esto no significa que el cliente no de importancia a las funcionalidades del producto, entendidas en algunos casos como un estándar requerido y en otros como factores que permiten alcanzar una experiencia óptima. Es más, las conclusiones de Gentile et al (2007) indican que el valor funcional o utilitario alcanza en muchas ocasiones una valoración tan alta como los valores experienciales, siendo por esto importante que la empresa sea capaz de alcanzar una oferta que aporte un equilibrio adecuado entre el valor utilitario y el experiencial.

En parecidos términos se expresan Verhoef et al. (2009), quienes describen la experiencia como algo que conlleva respuestas cognitivas, afectivas, sociales y físicas hacia el comercio detallista. Estos autores, siguiendo con la línea iniciada por Schmitt (1999) identifican como componentes de la experiencia del cliente el aspecto sensorial, el aspecto emocional, el aspecto cognitivo, el aspecto pragmático, el estilo de vida y el componente relacional. El componente pragmático hace referencia al uso del producto a lo largo de todo su ciclo de vida, mientras que el componente del estilo de vida se refiere a los valores y creencias de las personas como consecuencia de su comportamiento.

Por tanto, siguiendo esta corriente de análisis vemos que en la experiencia del cliente se puede distinguir el aspecto físico del de los valores, habiendo, además, una dimensión sensorial. También hay un componente pragmático que tiene en cuenta los aspectos relacionales de la persona.

Como se deduce de todo lo expuesto anteriormente, el concepto que estamos tratando va más allá del producto o del servicio ofrecido por la empresa. Es por esto que éstas deberían hacer un esfuerzo por identificar los componentes que forman parte del proceso por el cual se consigue ofrecer experiencias a los clientes, de manera que éstas 
estén realmente en la línea de lo que el consumidor espera y necesita. El tradicional enfoque del marketing hacia el producto pudo ser válido hace unas décadas, pero parece claro que para generar valor al cliente las empresas deben ser capaces de ofrecerle algo que vaya más allá de las características funcionales del producto, para llegar a una propuesta que tenga también en cuenta los beneficios emocionales que éste pueda necesitar, es decir, una experiencia en el sentido amplio que se viene apuntando en los párrafos anteriores.

Siguiendo con el trabajo de Verhoef et al (2009), estos autores profundizan en el análisis de la experiencia del cliente en el comercio detallista reconociendo la importancia que cobran aspectos como las experiencias anteriores que haya podido tener el cliente, el entorno del establecimiento, así como las marcas propias. En este sentido, definen el concepto desde un punto de vista holístico que debe tener en cuenta no solo el aspecto cognitivo del consumidor, sino también el afectivo, el emocional, el social y las respuestas físicas hacia el comercio detallista. De esta manera, para estos autores, la experiencia viene dada no solo por factores que el detallista puede controlar (tales como el servicio, la atmósfera del establecimiento, el surtido o el precio), sino también por otros que quedan fuera de su control (influencia de otras personas, propósito de la compra, etc.). Teniendo esto en cuenta, el análisis del constructo de experiencia del cliente desde un punto de vista holístico de estos autores (respuestas cognitivas, afectivas, emocionales, sociales y físicas) es coincidente con las dimensiones del concepto de experiencia de marca propuesto por Brakus et al. (2009), excepto en la dimensión relacional propuesta por este último.

Así, la experiencia del cliente no puede ser considerada como un hecho puntual o como un único contacto del consumidor con la empresa, sino que debe incluir toda la relación entre ambas partes: desde el contacto inicial hasta la fase de post-compra y evaluación del producto. En este sentido, Naylor et al. (2008) se centran en el análisis de las comunicaciones con el cliente y los diferentes efectos que pueden provocar los anuncios en función de su tipología. Así, la publicidad con mensajes de carácter más transformacional emocional (aquella que pone énfasis en las experiencias que se obtendrán con el consumo del producto o servicio) es más efectiva para comunicar y resaltar beneficios de carácter más subjetivo y basados en emociones, destacando más en concreto 
que este tipo de publicidad resulta particularmente efectiva para las empresas minoristas de servicios. Según los autores los individuos expuestos a mensajes publicitarios transformacionales reportaron una mejor experiencia del cliente que aquellos que recibieron comunicaciones de carácter más racional o informativo. Además, la comunicación emocional funciona con mayor efectividad en aquellos consumidores que previamente no han tenido la oportunidad de establecer expectativas.

Este concepto de experiencia no como un único contacto puntual, sino más bien como un flujo, es también considerado por Meyer y Schwager (2007) quienes señalan que dicho flujo está compuesto por los distintos puntos de contacto del cliente con la empresa. Además, no todos los puntos de contacto tendrán el mismo valor en la generación de experiencia del cliente, ya que, por ejemplo, cuando lo que se ofrece es principalmente un servicio, las interacciones del cliente con el personal que lo presta cobrarán mayor relevancia. Es por esto que las empresas, incluidos los comercios detallistas, deben preocuparse por conocer cómo es el esquema del flujo de la experiencia para sus clientes, sabiendo cuáles pueden ser los puntos de contacto más importantes, puesto que en cada uno de ellos la diferencia entre las expectativas del cliente y la experiencia que se le proporciona determinará el que disfrute con lo que ha recibido o que no sea así y la experiencia resulte negativa o menos satisfactoria de lo esperado.

Meyer y Schwager (2007) apuntan que la experiencia que se ofrece al cliente no será mejorable hasta que se convierta en una prioridad para la empresa y esto se vea reflejado en sus procesos de trabajo, en sus sistemas y en su estructura. Una vez la empresa es consciente de la importancia de la experiencia, cada función de la misma tendrá un papel determinado. Así, el departamento de marketing tendrá que captar los gustos y estándares de cada segmento al que se dirige, desarrollando luego políticas de comunicación a medida para ellos, las operaciones de servicio deberán estar pensadas para cada punto de contacto con el cliente y el desarrollo de producto no deberá limitarse a las características del mismo, sino que deberá diseñar experiencias después de observar cómo usan los clientes sus productos y servicios. 
Gentile el al. (2007) llegan a la conclusión de que una parte relevante del valor propuesto a los clientes y que a su vez es reconocido como tal por ellos, está ligada a las características experienciales: independientemente del contexto en el que se encuentren, los clientes quieren vivir experiencias de consumo positivas. Si la empresa es capaz de que su cliente viva una experiencia positiva podrá promover la creación de lazos emocionales entre sus marcas y sus clientes, lo que resultará en un fortalecimiento de la lealtad de los mismos. Según este mismo estudio, esto no significa que el cliente no de importancia a las funcionalidades del producto, entendidas en algunos casos como un estándar requerido y en otros como factores que permiten alcanzar una experiencia óptima. Es más, las conclusiones de Gentile et al (2007) indican que el valor funcional o utilitario alcanza en muchas ocasiones una valoración tan alta como los valores experienciales, siendo por esto importante que la empresa sea capaz de alcanzar una oferta que aporte un equilibrio adecuado entre el valor utilitario y el experiencial.

Por su parte, Biedenbach y Marell (2010) señalan que la prueba del producto es una herramienta importante en la formación de creencias y actitudes sobre la marca y que cuando éstas provienen de una experiencia directa son más fuertes y son mejores predictores del comportamiento del cliente que aquéllas que se generan a partir de experiencias indirectas, tales como la publicidad.

Verhoef et al (2009) profundizan en el análisis de la experiencia del cliente en el comercio detallista reconociendo la importancia que cobran aspectos como las experiencias anteriores que haya podido tener el cliente, el entorno del establecimiento, así como las marcas propias. En este sentido, definen el concepto desde un punto de vista holístico que debe tener en cuenta no solo el aspecto cognitivo del consumidor, sino también el afectivo, el emocional, el social y las respuestas físicas hacia el comercio detallista. De esta manera, para estos autores, la experiencia viene dada no solo por factores que el detallista puede controlar (tales como el servicio, la atmósfera del establecimiento, el surtido o el precio), sino también por otros que quedan fuera de su control (influencia de otras personas, propósito de la compra, etc.). Teniendo esto en cuenta, el análisis del constructo de experiencia del cliente desde un punto de vista 
holístico de estos autores (respuestas cognitivas, afectivas, emocionales, sociales y físicas) es coincidente con las dimensiones del concepto de experiencia de marca propuesto por Brakus et al. (2009), excepto en la dimensión relacional propuesta por este último.

Bäckström y Johansson (2006) señalan que la experiencia del cliente en el punto de venta detallista está influenciada por factores que hacen referencia al propio detallista y por factores que hacen referencia al consumidor.

Entre los factores relativos al detallista encontramos el personal de la tienda (ya que muchas de las experiencias se crean a través de la interacción del personal con el cliente: su habilidad para prestar consejos adecuados, para hacer sugerencias adaptadas al consumidor o incluso para gestionar correctamente las posibles quejas y reclamaciones), los elementos relacionados con el servicio aunque no directamente éste (horarios de apertura y cierre, adaptabilidad del servicio y de las soluciones que puedan proponer o incluso una zona de cafetería en algunos casos), los precios (que influyen positivamente en la experiencia del cliente cuando se considera que son buenos), la selección de producto (una adecuada selección puede crear experiencias positivas en el punto de venta, mientras que la falta de determinados productos conllevará reacciones negativas), el diseño (las tiendas renovadas y actualizadas atraen más la atención en función de su diseño), la exposición de los productos (facilitando el acceso a los productos ofrecidos la visita del cliente al establecimiento será más fácil y esto contribuirá a la creación de experiencias positivas), la organización espacial del punto de venta (cuando el cliente puede encontrar fácilmente el producto, cuando la planificación de la tienda parece lógica y cuando el punto de venta está correctamente señalizado, resulta más fácil orientarse y, por tanto, se está contribuyendo a la experiencia positiva) y por último, la atmósfera del establecimiento (iluminación, colores, etc.).

En cuanto a los factores relativos al cliente que afectan a la experiencia en el comercio detallista, estos autores citan los aspectos sociales (presencia e interacción con otras personas en la tienda), la tarea por la que el cliente está en el punto de venta (por ejemplo, comprar un regalo, un determinado producto, etc.), el tiempo (principalmente para aquellos compradores que tienen poco tiempo para realizar una determinada compra) 
y el estado o humor en el que se encuentra el consumidor (un cliente con un estado de ánimo positivo tiende a evaluar las experiencias de manera más positiva que otro con un estado negativo).

Lemke et al. (2011) proponen el concepto de calidad de la experiencia del cliente que definen como el juicio percibido sobre la excelencia o superioridad de la experiencia del cliente. Definen la experiencia del cliente como la respuesta subjetiva de éste al encuentro holístico, tanto directo como indirecto, con la empresa, pero no necesariamente limitándolo a las comunicaciones, el servicio o el consumo. Además, tienen en cuenta que cada cliente puede perseguir unos objetivos distintos y que éstos determinan la relevancia relativa que pueden tener tanto el producto como las características del comercio detallista, de forma que el consumidor perciba lo que es importante para él (Puccinelli et al., 2009). Así, la evaluación de la experiencia real por parte del cliente dependerá de la experiencia que deseaba en función de sus objetivos. A partir de aquí, Lemke et al. (2011) elaboran su definición de calidad de la experiencia del cliente.

Vemos, por tanto, que estamos ante un concepto que no puede considerarse únicamente como un hecho puntual en la relación cliente-empresa, sino que se deriva de toda la serie de interacciones entre ambas partes. Además, también se deberá tener en cuenta que cada cliente presenta unas características y persigue unos objetivos distintos en su relación con la empresa, por lo que su valoración de la experiencia que pueda vivir con un comercio detallista dependerá, entre otras cosas, de estas circunstancias. La evaluación de la experiencia se hará, por tanto, en función de las expectativas que se haya formado cada consumidor, así como de los estímulos que resulten de la interacción entre éste y la empresa y la oferta que ésta haga en cada contacto con el cliente.

Es por esto que el comercio detallista deberá tener en cuenta todas las operaciones que entran a formar parte de ese proceso durante el cual el cliente obtendrá esas experiencias. Tal y como apuntan Carù y Cova (2006), la experiencia requiere del apoyo de la empresa a lo largo de todo el proceso. Para ello deberá centrarse en algunos elementos del servicio que pueden resultar de gran importancia, tales como la actuación 
del personal, ya que será éste, en muchas ocasiones, quien guie al consumidor dubitativo de manera que pueda alcanzar una experiencia satisfactoria en su relación con el comercio.

Para comprender la relación entre el comercio detallista y la experiencia del cliente debemos tener en cuenta que el consumidor adquiere los productos y servicios con algún objetivo, es decir, los consumidores compran en función de diversas razones. Con independencia de estas razones u objetivos se establece, como hemos visto anteriormente, una progresión en la experiencia, ya que se trata de un proceso y no únicamente de un hecho puntual en la relación entre el cliente y la empresa. Hay, además, una percepción del entorno del comercio detallista por parte del consumidor y un determinado nivel de satisfacción con la experiencia. El comercio detallista debe ser consciente de que un mismo entorno puede producir diferentes resultados y sentimientos en función de los objetivos de cada cliente.

Esto es particularmente importante en las empresas que ofrecen servicios, como puede ser el caso de la restauración. Walter el al. (2010) analizan las experiencias en este sector y destacan que los clientes de un restaurante interactúan continuamente con los empleados del comercio, pero también con otros clientes. En este segundo caso el restaurante tiene poco control sobre la experiencia. Los distintos tipos de interacción pueden destruir o contribuir a la experiencia del cliente.

Así, por ejemplo, un establecimiento con mucha gente puede ser estimulante para un consumidor que busque entretenimiento, mientras que eso mismo puede dar una impresión de mal servicio a otro consumidor que esté buscando un producto determinado para satisfacer de manera inmediata una necesidad. Además, los objetivos de un consumidor también pueden variar en función del momento de compra, tal y como indican Puccinelli et al. (2009). Estos autores llegan a la conclusión de que los objetivos del consumidor influyen en la manera en la que éste percibe el entorno del punto de venta y sus elementos individuales, así como su comportamiento de compra y su satisfacción con la experiencia vivida. 
Para Blázquez (2014) la experiencia del consumidor cobra especial relevancia en el comercio detallista. Así, el desarrollo de experiencias de compra excelentes tiene una influencia directa en las respuestas de los consumidores, generando mayor lealtad (Manning y Dorsey, 2008) y determina la cantidad que el consumidor está dispuesto a pagar por un producto (Pine y Gilmore, 2011).

Debemos tener en cuenta que el punto de venta del comercio detallista es el lugar en el cual el cliente entra en contacto, no solo con el producto, sino también con todo aquello que lo rodea: personal de ventas que puede prestar su servicio, música, temperatura, colores, iluminación, etc. Es por ello que consideramos en esta tesis la importancia que para el comercio detallista puede tener la capacidad tanto de crear experiencias para el cliente, como de gestionarlas. Todo ello puede conducir al incremento de su competitividad frente a aquellos comercios que no sean capaces de proporcionar las experiencias adecuadas a su público objetivo.

El entorno físico es importante para las experiencias del cliente, ya que la mayoría de los servicios se prestan en un entorno en el que el cliente está presente durante todo o parte del proceso de creación del servicio (Walter et al, 2010).

En el caso de la experiencia del cliente en el punto de venta se deben tener en cuenta tanto variables personales como variables situacionales que pueden afectar a ésta. La literatura al respecto hace referencia a los valores del consumidor. Así, según Holbrook y Hirschman (1982) las experiencias placenteras en el punto de venta a menudo reflejan diferentes tipos de valores hedónicos y se caracterizan por satisfacción intrínseca, libertad percibida o entretenimiento. Para estos autores el valor experiencial ofrece beneficios tanto intrínsecos como extrínsecos. Más concretamente, en el contexto del comercio detallista los beneficios extrínsecos se derivan de los viajes a la tienda que son de naturaleza utilitaria y, por tanto, consecuencia de que el comprador logre realizar determinadas tareas. Por su parte, el valor intrínseco se obtiene por la apreciación de una experiencia propia. 
En cuanto a las variables situacionales que influyen en este concepto, aplicado al punto de venta, proceden de su entorno psicológico y sus dimensiones generales son: atmósfera del establecimiento, diseño y dimensión social.

Así, para Kotler (1973) la primera de ellas, es decir, la atmósfera, hace referencia a los factores en el entorno del establecimiento que pueden ser diseñados o manipulados para crear determinadas respuestas emocionales y de comportamiento en el consumidor. Incidiendo en esta dimensión Hoffman y Turley (2002) señalan que la atmósfera está compuesta tanto por elementos tangibles (edificio, pavimentos utilizados, decoración, etc.) como intangibles (colores, música, temperatura, etc.) que componen las experiencias del servicio. En este sentido, Bäckström y Johansson ((2006) señalan que una atmósfera positiva de la tienda es crucial para poder ofrecer no sólo productos y servicios, sino también experiencias al cliente.

Por lo que hace referencia al diseño del establecimiento normalmente se entienden los elementos tangibles presentes en el interior del mismo (estilo, decoración, arquitectura, etc.), tal y como indican Bäckström y Johansson (2006).

La última dimensión psicológica, la dimensión social, consiste en las interacciones (físicas, emocionales, etc.) que los consumidores tienen con otros miembros de la sociedad Bäckström y Johansson (2006).

Por último, y de acuerdo a lo indicado por autores como Verhoef et al (2009) o Kim et al (2011) que consideran que la experiencia del cliente no ha sido analizada en profundidad desde una perspectiva teórica, habiendo sido tratada normalmente dentro de los estudios sobre la calidad del servicio y la satisfacción, este trabajo pretende contribuir, entre otras cosas, al conocimiento de la experiencia del cliente en el ámbito del comercio detallista y en su relación con el Valor de Marca del mismo.

A continuación, y a modo de resumen, en la Tabla 4.1 aparecen recopiladas algunas de definiciones de experiencia del cliente y de marketing experiencial aportadas por la literatura analizada en este capítulo. 
Tabla 4.1. Definiciones de experiencia del cliente

Holbrook y Hirschman (1982)

El consumo desde un punto de vista experiencial está constituido por un flujo de fantasías, sentimientos y diversión. Estos autores relacionan la experiencia con las dimensiones de consumo simbólicas, hedónicas y estéticas.

Babin et al. (1994)

El consumo hedónico está relacionado con lo multisensorial, la fantasía y los aspectos emotivos de la compra, siendo el objetivo de ésta, en este caso, la experimentación de diversión, fantasía y estimulación sensorial, más allá de la consecución eficiente y rápida de la meta.

Addis y Holbrook (2001)

El marketing experiencial se centra en la búsqueda de una nueva fuente de ventaja competitiva basada en la implicación emocional de los clientes y en la creación de experiencias ligadas al producto.

Schmidt (2006)

Las experiencias son sucesos privados que se producen como respuesta a una estimulación. Parten de la observación directa y/o de la participación en sucesos y se producen como resultado de encontrar, pasar o vivir determinadas situaciones por medio de estímulos que se provocan en los sentidos, que conectan a la empresa u organización y la marca con la forma de vida del cliente en un contexto social más amplio.

Shaw (2007)

La experiencia del consumidor es una mezcla del rendimiento físico de una organización, los sentidos que se estimulan y las emociones evocadas, cada uno medido intuitivamente frente a las expectativas del consumidor en todos los momentos de contacto con la empresa. 
Burgos (2007)

Define el Marketing Experiencial como aquel que busca incentivar tanto a individuos como a grupos de equipos participantes en programas de incentivos o fidelización para disfrutar actividades únicas, considerando que la exclusividad de vivir estas experiencias les da un valor agregado para el público objetivo que se quiere motivar.

Meyer y Schwager (2007)

La experiencia del cliente supone una respuesta interna y subjetiva que las personas tienen ante cualquier contacto directo o indirecto con la empresa.

Gentile et al (2007)

Consideran que la experiencia del cliente se forma a partir de las interacciones entre un cliente y un producto, una empresa o parte de su organización que provocan una reacción. Esta experiencia es personal y supone la implicación del cliente a diferentes niveles (racional, emocional, sensorial y espiritual). La evaluación que el cliente hace depende de la comparación entre sus expectativas y los estímulos resultantes de la interacción con la empresa y su oferta, en correspondencia con los diferentes momentos de contacto entre ambos.

Lenderman y Sánchez (2008)

El Marketing Experiencial es visto como una estrategia que intenta dar vida intencionalmente a la promesa que hace la marca a los consumidores por medio de experiencias organizadas que tienen lugar antes de la compra, durante el proceso de compra y en las posibles interacciones posteriores.

Grundey (2008)

En el ámbito del comportamiento del consumidor una experiencia es, sobre todo, un hecho personal, a menudo con un importante significado emocional, basado en la interacción con estímulos producidos por los productos y servicios consumidos. 
Verhoef et al. (2009)

Describen la experiencia como algo que conlleva respuestas cognitivas, afectivas, sociales y físicas hacia el comercio detallista. La experiencia viene dada no solo por factores que el detallista puede controlar (tales como el servicio, la atmósfera del establecimiento, el surtido o el precio), sino también por otros que quedan fuera de su control (influencia de otras personas, propósito de la compra, etc.).

Ojiako y Maguire (2009)

Experiencia del cliente como una articulación de la interacción personal, experiencias, memorias y oportunidades que una organización ofrece a sus consumidores actuales y potenciales y que excede sustancialmente a sus expectativas en un grado en el que una relación duradera se establece entre el cliente y el proveedor del servicio. Habitualmente dichas experiencias pueden ser evaluadas desde diferentes perspectivas, incluyendo productos, servicios, cuidado, funcionalidad, utilidad y facilidad de uso, confianza, publicidad y envase.

Lemke et al. (2011)

Definen la experiencia del cliente como la respuesta subjetiva de éste al encuentro holístico, tanto directo como indirecto, con la empresa, pero no necesariamente limitándolo a las comunicaciones, el servicio o el consumo.

Nysveen et al (2013)

La experiencia del cliente puede considerarse como uno de los puntos de vista que abarca con mayor amplitud el contexto de experiencia, junto con la experiencia de marca, ya que esta última tiene en cuenta que no sólo los clientes, sino también aquellos que no lo son, pueden tener experiencias con una marca.

Caridad et al. (2015)

El marketing experiencial proporciona inspiración para la promoción de bienes y servicios, entendiéndose que ésta está orientada a efectuar la comunicación entre la empresa y su audiencia objetiva.

Fuente: elaboración propia 


\subsection{La experiencia del cliente y el Valor de Marca del comercio detallista}

El Valor de Marca (brand equity) crea valor tanto para la empresa como para el cliente, así como también incrementa la elección de marca por parte de éste y su disponibilidad a pagar mejores precios (Aaker, 1991). Desde la perspectiva del cliente, el Valor de Marca se da cuando los consumidores están familiarizados y tienen en su mente una asociación favorable de una determinada marca. El papel que juega el Valor de Marca es mayor cuando los consumidores conectan emocionalmente con la marca y cuando hay un intercambio de experiencias. Las marcas con un valor alto pueden alcanzar un mayor nivel de reconocimiento e incluso de precio y, en consecuencia, el valor percibido de marca se considera como un antecedente de los comportamientos de lealtad del cliente (Brakus et al., 2009).

Una experiencia de compra agradable fortalece la relación entre el consumidor y el detallista (Spena et al., 2012), reforzando la conexión emocional con la marca (Healy et al., 2007) y se asocia a un incremento con la actividad de compra (Kim et al., 2007).

En la presente tesis vamos a considerar la experiencia del cliente en relación con la creación de Valor de Marca, ya que es un factor importante en la conversión de los atributos del producto en Valor de Marca, como indican, entre otros autores, Sheng y Teo (2012) quienes ofrecen evidencias de que la experiencia del cliente media en la relación entre los atributos del producto y el Valor de Marca, en su estudio que analiza estos conceptos en el ámbito de los dispositivos móviles.

Tradicionalmente la experiencia del cliente se ha venido situando entre los atributos del producto y el Valor de Marca. Además, la interacción se ve como un factor clave que determina la naturaleza de la experiencia del cliente. Se puede decir, por tanto, que los atributos del producto afectan al Valor de Marca a través de su efecto en la experiencia del cliente.

Así pues, en este trabajo se van a considerar las experiencias del cliente dentro de un posible modelo de Valor de Marca (Brand Equity) que las tenga en cuenta como 
aspecto intangible que puede contribuir a la creación de dicho valor para el comercio minorista, ya que es en el contacto que éste va a tener con el consumidor donde se pueden producir, en mayor medida, dichas experiencias. En este sentido Farquhar (1989) plantea un modelo teórico para construir una marca con alto valor, basado en tres etapas: introducción, elaboración y fortificación. Así, si bien en la primera de estas etapas el autor considera que se debe tener en cuenta principalmente la imagen de la marca o su personalidad y en la segunda etapa las actitudes o relaciones marca-consumidor, en la última de estas etapas, es decir, en la fortificación de la marca, este autor considera que las variables básicas a tener en cuenta son las experiencias y los vínculos emocionales y cognitivos entre la empresa y el consumidor.

En el segundo de los modelos que planteamos en nuestro trabajo, la experiencia del cliente se ve afectada por los distintos componentes del Valor de Marca y es un antecedente directo del Valor de Marca (brand equity) del comercio minorista.

Fung y King (2010) analizan la importancia de la experiencia en la creación del Valor de Marca. Para ello se basan en modelos tradicionales como el de Aaker (1991). Ahora bien, Fung y King (2010) consideran que el modelo de este autor está muy enfocado a empresas fabricantes de productos, pasando por alto la importancia que pueda tener la experiencia a la hora de construir marcas de éxito en el sector de los servicios.

Teniendo en cuenta la experiencia en su relación con el Valor de Marca, Berry (2000) desarrolla un modelo para analizar el Valor de Marca de los servicios en el que adopta un punto de vista desde la perspectiva del cliente. Debido a las características particulares de los servicios (intangibilidad, inseparables, heterogéneos y perecederos) la noción de gestión de marca puede resultar incluso más importante que en el caso de los productos físicos. Para Berry (2000) una marca fuerte en el sector de los servicios supone para el cliente no solo una promesa de futura satisfacción, sino también un incremento de la confianza asociada a la compra "invisible", permitiéndole visualizar y comprender un bien intangible. 
Este autor analiza el impacto indirecto que la experiencia tiene en el Valor de Marca, mediante un modelo que evalúa ésta última a través de dos dimensiones tales como el conocimiento de marca y las asociaciones de marca, estando la experiencia del cliente, relacionada con las asociaciones de marca que a su vez tienen una influencia directa sobre el Valor de Marca.

Lógicamente, cuando hablamos de servicios, cobran especial importancia las actividades internas en cuanto a creación de marca, ya que habrá que reforzar el comportamiento de marca de los empleados que vayan a prestar los diferentes servicios, así como también habrá que gestionar estos de manera adecuada, puesto que serán un punto crucial en el contacto con el cliente.

Basándose en la literatura previa, Jara y Cliquet (2012) definen el Valor de Marca minorista en términos similares a los elementos que se pueden utilizar en cualquier marca de fabricante, si bien añadiendo el componente del servicio asociado, la dimensión corporativa del comercio detallista y su personalidad. Además, para estos autores el Valor de Marca minorista incluye específicamente los beneficios provenientes de la experiencia, relacionados con el servicio que se presta en el punto de venta, la personalidad del comercio minorista y sus valores y símbolos.

El éxito del comercio detallista se basa en combinar las marcas de los fabricantes que va a comercializar con la naturaleza de empresa de servicios que le caracteriza. Los diferentes aspectos del punto de venta, tales como el color, el olor, la música o la cantidad de gente pueden influir en las percepciones del cliente relativas al ambiente del comercio (Musekiwa et al., (2013). Esto ayuda a los consumidores a decidir si visitan o no el establecimiento, el tiempo que quieren pasar en él y cuánto dinero quieren gastar (Grewal et al., 2003).

Tal y como indican Biedenbach y Marell (2010) los escasos artículos que relacionan los conceptos de experiencia del cliente y de estrategia de marca, apuntan que el primero tiene especial relevancia para el desarrollo del Valor de Marca, es decir, destacan la importancia de la experiencia del cliente a la hora de desarrollar el valor de una marca. 
Estos mismos autores indican que es más bien poca la literatura relativa al impacto que la experiencia tiene sobre el Valor de Marca, destacando la necesidad de profundizar en esta materia. En este sentido, la presente tesis pretende ahondar en los estudios realizados sobre la relación existente entre la experiencia del cliente y el Valor de Marca (brand equity) del comercio detallista, intentando contribuir, en la medida de lo posible, a cubrir la carencia existente en este campo.

Biedenbach y Marell (2010) concluyen en su estudio que las relaciones entre la experiencia del cliente y el Valor de Marca son significativas, ya que la primera afecta positivamente a todos los componentes de la segunda, en mayor o menor medida, destacando, además, la importancia que tiene la interacción del consumidor y el proveedor del servicio.

Teniendo en cuenta las particulares características de los servicios, De Chernatony et al (2006) destacan la importancia que tienen las relaciones entre los empleados de la empresa y los clientes de ésta a la hora de crear experiencias que aumenten el Valor de Marca (brand equity) de la misma.

Esto cobra particular relevancia en el ámbito del comercio detallista $\mathrm{y}$, especialmente en el de carácter más tradicional, ya que es evidente la relación directa entre el personal del mismo y el cliente durante el proceso de compra. De la mayor o menor calidad de esta relación pueden derivarse consecuencias tanto positivas como negativas a la hora de la creación de la experiencia del cliente.

En el campo de la gestión hotelera diversos estudios como el de Xu y Chan (2010) concluyen en la importancia de la experiencia del cliente, ya que el Valor de Marca (brand equity) se consigue en aquellos clientes cuya necesidad de obtener experiencias positivas se ha visto satisfecha.

Wong (2013) señala que, puesto que la satisfacción del cliente contribuye al Valor de Marca, tanto la experiencia del servicio como la relación entre la empresa y el cliente jugarán un papel indirecto en la formación del Valor de Marca. 
Puesto que el punto de venta del comercio detallista supone un contacto directo con el cliente y es susceptible de crear experiencias, uno de los aspectos que se quiere analizar en la presente tesis es en qué medida la experiencia del cliente influye en la formación del Valor de Marca del comercio detallista. Vemos como la literatura existente relaciona la influencia de la experiencia sobre el Valor de Marca a nivel general, si bien son escasos los estudios que lo hacen centrándose en el comercio detallista. Ante esto, nos planteamos la siguiente hipótesis que tiene en cuenta la relación entre la experiencia del cliente y el Valor de Marca dentro del ámbito del comercio detallista.

H13: La experiencia del cliente afecta positivamente al Valor de Marca (brand equity) del establecimiento comercial.

Las experiencias ricas y productivas se convierten en una disposición favorable hacia la marca, medida por el Valor de Marca basado en el cliente. Biedenbach y Marell (2010) analizan el impacto de la experiencia del cliente en la formación del Valor de Marca, llegando a la conclusión de que la experiencia del cliente tiene un efecto positivo en sus cuatro dimensiones: conocimiento de marca, asociaciones de marca, calidad de marca y lealtad a la marca.

Más concretamente, estos autores llegan a la conclusión de que la experiencia del cliente tiene un efecto directo más fuerte en la dimensión de las asociaciones de marca, mientras que, en el otro extremo, es decir, donde su efecto es menor, es en la calidad percibida. En ese mismo estudio apuntan que la experiencia del cliente tiene un efecto positivo directo sobre la lealtad.

A la vista de esto, el comercio detallista debe ser consciente de la importancia que las experiencias positivas tienen sobre la lealtad de sus clientes y, por tanto, de la posibilidad de aumentar sus beneficios gracias a ello. 
Las experiencias derivadas de la prueba del producto son para Sheng y Teo (2012) una herramienta poderosa para la formación de creencias y actitudes con respecto a la marca. Las creencias originadas de experiencias directas son más fuertes y se sostienen con mayor confianza que las generadas por experiencias indirectas como puede ser la publicidad. Además, son también mejores indicadores del comportamiento del consumidor con respecto a la marca.

Por su parte, autores como Bennett et al (2005) señalan el impacto directo que la experiencia del cliente tiene sobre la lealtad de marca.

Para Berry y Carbone (2007) la evaluación que los clientes hacen de un servicio descansa tanto en aspectos racionales como emocionales que se encuentran dentro de la experiencia como un todo. Dentro de los aspectos emocionales cabe destacar que hay características tanto mecánicas (procedentes de objetos inanimados y de aspectos físicos asociados al servicio), como humanas (derivadas del comportamiento y aspecto de las personas que proveen el servicio). Así, las organizaciones deben gestionar estos aspectos de la experiencia del cliente, de forma que evoquen actitudes que conlleven a la creación de lealtad.

Vemos, por tanto, como la creación de experiencias positivas lleva a la lealtad del cliente en la prestación de servicios. En este sentido, como se ha apuntado en diversos capítulos de la presente tesis, el comercio detallista tradicional puede optar, entre otras cosas por la diferenciación como estrategia para sobrevivir en un entorno competitivo. Para ello, muchos comercios detallistas intentan ofrecer a sus clientes sensaciones emocionales a través del diseño del entorno del punto de venta.

Tal y como señalan Carù y Cova (2003), si bien puede hablarse de experiencias memorables, no es menos cierto que las experiencias suelen tener lugar de manera más ordinaria en los eventos de cada día, ya que la mayor parte de la actividad de compra de los consumidores suele darse en el contexto de la vida diaria, si bien, son pocos los estudios que se centran en el análisis de las experiencias que tienen lugar en los comercios detallistas ordinarios. En esta misma línea, Pecoraro y Uusitalo (2014) profundizan en la 
amplia variedad de experiencias diferentes que se pueden encontrar en el entorno del día a día de los comercios detallistas tradicionales. Más allá de las tiendas más emblemáticas de algunas marcas (flagship stores), se centran en las características de los comercios detallistas convencionales y las experiencias que éstos proporcionan, llegando a la conclusión de que, en vez de ser simplemente receptores pasivos, los consumidores interpretan activamente y dan sentido a sus experiencias cotidianas en el comercio detallista, interactuando con los elementos del entorno visual, material, espacial y social del establecimiento.

Puesto que la experiencia es una fuente personal de información, jugará un papel importante, principalmente a la hora de reducir el riesgo percibido por el cliente. Es por ello que planteamos aquí el estudio de la influencia que la experiencia puede ejercer sobre la lealtad que un cliente tenga hacia un establecimiento comercial detallista a la hora de realizar sus compras, ya que, como se ha apuntado, la lealtad se forma a través de las interacciones y experiencias del cliente a lo largo de todo el proceso de relación con la empresa. La consecución de unos mayores índices de lealtad entre sus clientes supondrá también la mejora de la rentabilidad del comercio, puesto que un cliente fiel se encuentra con una mayor disponibilidad a probar nuevos productos, puede ser más comprensivo con posibles errores producidos en el proceso de venta, tiene una mejor actitud respecto a sus intenciones de compra y, por supuesto, si tiene un alto nivel de satisfacción, será una herramienta de comunicación de cara a otras personas. Además, los costes de conseguir clientes nuevos son mucho más altos que los de retener a los ya existentes. Por el contrario, los clientes también aprenden de sus experiencias negativas, por lo que éstas conducirán a un posible deterioro de las relaciones y consecuentemente a una reducción de las compras.

En el comercio detallista los consumidores habitualmente suelen visitar distintas tiendas. Así, será importante conocer porqué varían a la hora de decidir cómo reparten sus compras entre las diversas tiendas y cómo éstas pueden conseguir una mayor cuota de las compras de los consumidores. Dos maneras importantes te influenciar estas decisiones y aumentar así el porcentaje que el cliente destine a un comercio será a través de la gestión de las experiencias del cliente y de la lealtad (Srivastava y Kaul, 2016). Para estos autores, 
el gasto que un cliente hace en un comercio determinado es consecuencia de la lealtad. Los estudios conducidos por estos autores determinan que la experiencia del cliente tiene influencia tanto en la lealtad actitudinal como en la de comportamiento y que la lealtad actitudinal está mejor explicada por la experiencia del cliente.

Verhoef et al (2009), como hemos visto, profundizan en el análisis de la experiencia del cliente en el comercio detallista reconociendo la importancia que cobran aspectos como las experiencias anteriores que haya podido tener el cliente, el entorno del establecimiento, así como las marcas propias. Definen la experiencia desde un punto de vista holístico que considera el aspecto cognitivo del consumidor, el afectivo, el emocional, el social y las respuestas físicas hacia el comercio detallista. Teniendo esto en cuenta, el análisis del constructo de experiencia del cliente desde un punto de vista holístico de estos autores (respuestas cognitivas, afectivas, emocionales, sociales y físicas) es coincidente con las dimensiones del concepto de experiencia de marca propuesto por Brakus et al. (2009), excepto en la dimensión relacional propuesta por este último.

Al igual que ocurre con la experiencia del cliente, este último autor revela los efectos positivos que la experiencia de marca tiene sobre la personalidad y la satisfacción con la marca, así como sobre la lealtad de marca.

Puesto que las experiencias aportan valor al cliente, cuanto más fuertes sean éstas, mayor será su satisfacción. Es de suponer que los consumidores querrán repetir aquellas experiencias positivas que les hayan producido satisfacción con lo que podemos pensar que las experiencias también influyen positivamente en la lealtad.

Crosby y Johnson (2007) indican que la gestión de la experiencia del cliente es el ingrediente más importante a la hora de construir la lealtad del mismo. En esta línea, Kim et al. (2008) desarrollaron una escala para medir experiencias memorables y confirmaron que éstas tenían efectos positivos en las futuras intenciones comportamentales. Además, señalaban que las experiencias memorables son más propensas a influir el comportamiento futuro de las personas. 
Por su parte, Yeng y Mat (2013) afirman que, mientras la calidad del servicio y de los productos, la atmósfera del establecimiento y las actividades de promoción tienen influencia en la lealtad cognitiva/actitudinal, la satisfacción, los programas de fidelización y el valor de marca del comercio, afectan directamente a la lealtad afectiva.

Tomando en consideración los estudios y conclusiones expuestos en los párrafos anteriores, se puede proceder a realizar la siguiente hipótesis:

H10: La experiencia del cliente afecta positivamente a la lealtad del mismo hacia el establecimiento comercial.

Los estudios existentes hasta la fecha hacen referencia, en su mayor parte, a la relación entre la experiencia del cliente y la lealtad del mismo, centrándose en cómo la primera afecta a la segunda.

Sin embargo, es escasa la literatura que intenta ver cómo la lealtad puede afectar a la experiencia del cliente. En este sentido cabría plantearse qué efecto tiene el que un cliente sea leal a un establecimiento comercial sobre la valoración de las experiencias que dicho comercio pueda proponer a los consumidores. Es decir, si bien hemos visto como parte de la literatura existente analiza la influencia de las experiencias del cliente sobre su lealtad, también podemos preguntarnos cómo la lealtad puede afectar a la percepción que un cliente tiene con respecto a una nueva experiencia propuesta por el comercio. Es por ello que en la presente tesis nos planteamos también el análisis de esta relación, es decir, en función de la lealtad, cómo se ve afectada la experiencia del cliente en su relación con el establecimiento detallista.

Las expectativas del cliente con respecto a la experiencia se forman, en parte, con base a sus experiencias previas con esa empresa. Tal y como señalan Meyer y Schwager 
(2007) los clientes comparan instintivamente cada nueva experiencia, positiva o negativa, con otras previas y las juzgan en consecuencia. Las expectativas también vienen condicionadas por las distintas situaciones del mercado, la competencia y la situación personal del propio cliente.

Así, puesto que vemos como el cliente juzga cada nueva experiencia que tiene con la marca, aunque no sea la primera, y que en su valoración también juegan un papel sus condiciones particulares, se plantea la siguiente hipótesis, puesto que el que exista lealtad hacia un establecimiento por parte de un cliente podría ser una característica que influya en su percepción a la hora de valorar nuevas experiencias con el comercio detallista.

Si, como se viene apuntando por la literatura, la lealtad del cliente supone que éste sea más permisivo con posibles errores cometidos por la empresa en la relación entre ambos, así como que incluso esté dispuesto a pagar algo más, se trata de analizar si el hecho de que el cliente sea leal a un determinado comercio detallista puede tener efectos sobre su experiencia de cliente.

Por tanto, se plantea la siguiente hipótesis:

H12: La lealtad hacia el establecimiento comercial afecta positivamente a la experiencia del cliente.

\subsection{La experiencia del cliente y las tecnologías de la información y comunicación}

En el ámbito del comercio detallista es importante la creación de experiencias para el cliente. Parece claro que en los comercios físicos esta experiencia puede lograrse a través de acciones que afecten a los diversos sentidos de la persona. 
Nicholson's et al. (2002) establecen que cuando el consumidor busca artículos hedónicos, definidos por los autores como 'premios' prefiere la tienda física, debido a que el entorno físico refuerza el estado de ánimo a través de las oportunidades de interacción social, evaluación de producto y estimulación sensorial. Visitar la tienda física puede ser considerado como un modo de evasión y una forma de autoindulgencia (Bäckström y Johansson, 2006). Sin embargo, las últimas investigaciones muestran que la compra de ropa a través de Internet también es percibida como una actividad que proporciona valor hedónico y disfrute (Clifford, 2012).

Tal y como señalan Marín y Gil-Saura (2016) los frentes más importantes de la innovación tecnológica en las relaciones con el consumidor final son las tecnologías de pago y envío, precios dinámicos, los sistemas de pago electrónicos y móviles, venta a distancia, y tecnologías de autoservicio (SST), tales como las máquinas expendedoras y quioscos multimedia.

Según estos autores, desde una perspectiva relacional, "las innovaciones en los canales de comercialización pueden suceder en varios frentes, que no necesariamente representan una innovación en sí mismos, pero a través de las cuales las empresas pueden adoptar soluciones innovadoras, asociadas a la gestión de la relación con los clientes y que incluyen aspectos vinculados con, por ejemplo, los planes de lealtad, Trade Marketing, procesos de compra, Responsabilidad Social Corporativa, iniciativas de atención al cliente, etcétera."

Ahora bien, cuando hablamos de comercio en Internet se deben puntualizar algunos aspectos, ya que algunas acciones que pueden influir en determinados sentidos, tales como pueden el tacto o el olfato que pueden ser importantes para algunas categorías de producto, es difícil que se puedan dar en el entorno online. Cuando hablamos de Internet podemos decir que los recursos visuales pueden ser útiles para evaluar aspectos tales como el tamaño de los productos, la forma, etc. Sin embargo, otros sentidos como el tacto o el olfato serán menos participativos a la hora de poder evaluar los productos en este entorno. De esta manera, los clientes pueden percibir una falta de experiencias sensoriales en 
Internet desde un punto de vista holístico que les puede disuadir a la hora de utilizar este medio.

Así, Internet puede presentar determinadas ventajas para el comercio detallista y también para sus clientes, pero también presenta un reto importante a la hora de crear experiencias sensoriales completas para estos últimos.

Citrin et al (2003) analizaban el papel que juega la necesidad de evaluar los productos mediante el tacto, destacando la importancia que esto puede tener a la hora de que el consumidor elija un canal u otro. Esto varía en función de la categoría de producto (por ejemplo, textil), así como del perfil de consumidor. Los autores destacaban que aquellos comercios que tienen presencia tanto online como física pueden tener ventajas en la creación de experiencia del cliente, por lo que la ausencia de un establecimiento comercial físico en favor de tener presencia únicamente en Internet puede hacerles perder la posibilidad de ofrecer a sus clientes experiencias multisensoriales que pueden serles valiosas a la hora de evaluar un producto. En el caso de que se comercialicen productos altamente experienciales, se debería dar al consumidor la oportunidad de "experimentarlos", bien a través de pruebas de producto, bien en el comercio físico tradicional.

Blázquez (2014) señala como la industria de la moda ha sido más lenta que otras en la adopción del comercio electrónico debido principalmente a la dificultad de trasladar la experiencia del punto de venta al entorno online. Esto es así porque la ropa se considera como una categoría de producto que conlleva alta implicación para el consumidor, ya que está relacionada con el ego personal y es un producto que precisa ser visto, tocado, sentido y probado para su correcta evaluación. Las tiendas detallistas proporcionan al instante tanto la prueba del producto y su compra, como la experiencia del servicio.

Incluso con los avances de la tecnología existe todavía una desventaja para la venta de indumentaria a través del canal online, puesto que los consumidores no pueden probarse físicamente las prendas antes de tomar su decisión de compra, tal y como sucedería en un comercio físico tradicional. En este último el cliente puede comprobar en ese mismo 
instante las características del producto y ver cómo le queda una vez puesto. Lógicamente, esto no sucede con la compra en entornos virtuales, dada la limitación que ya se ha apuntado relativa a los sentidos como el tacto o incluso el olfato, que quedan apartados cuando hablamos de compras en Internet. Por tanto, si se compara con la compra en un establecimiento físico, el consumidor percibe en el entorno virtual mayores riesgos derivados de las preocupaciones por la privacidad, incertidumbre relativa al plazo de entrega o el relativo a la imposibilidad de inspeccionar el producto antes de la compra, puesto que la información táctil relativa al producto y a su entorno es un elemento importante en la experiencia del cliente en un punto de venta físico.

Para intentar reducir esta desventaja, algunos comercios detallistas online proporcionan a los clientes en sus páginas web herramientas interactivas, tales como la posibilidad de ampliar las imágenes del producto, verlo desde cualquier ángulo posible, simular combinaciones de distintos productos, etc. Así, las llamadas "tecnologías de interactividad de imagen" permiten la creación y manipulación de las imágenes del producto y del entorno para estimular las experiencias del cliente. Entre estas tecnologías destacan los modelos virtuales en tres dimensiones que reflejan la apariencia de la indumentaria y de sus posibles combinaciones en cuerpos tridimensionales. Algunos comercios detallistas, tales como H\&M, Speedo, Levi Strauss Singature o Sears utilizan modelos virtuales en 3D. Estas tecnologías permiten al cliente experimentar con la apariencia, con lo que se intenta capturar la parte experiencial que supone la posibilidad de probarse el producto antes de adquirirlo (Lee et al., 2010).

Vemos pues la importancia de una página web bien diseñada y estructurada, que proporcione las herramientas necesarias para reducir el hueco que existe entre la experiencia del cliente en un entorno físico y en uno virtual.

El diseño de la presencia online del comercio detallista tiene una importancia significativa en las ventas del mismo. Por ello las empresas están continuamente innovando en el diseño de sus páginas web para conseguir ventajas competitivas y para proporcionar al cliente experiencias mejoradas, creando una atmósfera virtual que le permita disfrutar de su contacto con la empresa (Eroglu et al., 2003). 
Los comerciantes detallistas online experimentan con la utilización de diseños en tres dimensiones para sus páginas web, intentando replicar la atmósfera de compra de los comercios con presencia física. Estas webs en 3D permiten al cliente moverse a través de una tienda tridimensional de una manera similar a la que se hace con algunos juegos para ordenadores y también le permite seleccionar y ver los productos en un modo que imita la compra en un comercio físico (Visinescu et al., 2015).

Del estudio llevado a cabo por Lee et al. (2010) se desprende que las características de las "tecnologías de interactividad de imagen" aumentan la sensación de disfrute de la compra, reducen las percepciones de riesgo asociadas con la compra online y mejoran la actitud del consumidor hacia el comercio detallista que las utiliza en Internet. Un nivel elevado de estas tecnologías supone una influencia positiva sobre los aspectos afectivos de la experiencia. Además, también destacan que la posibilidad de experimentar con la apariencia influye significativamente en la experiencia de compra online de indumentaria.

Las tecnologías de la información y la comunicación deben tenerse en cuenta tanto en el comercio detallista físico más tradicional como por lo que al entorno virtual se refieren. Por una parte, cuando hablamos del punto de venta físico, las nuevas tecnologías pueden contribuir a alcanzar las expectativas de los clientes mejorando sus experiencias en el mismo. Así, tecnologías que faciliten la realización del pedido en la tienda, pantallas que muestren el producto y que lo hagan más accesible, etc. ayudarán a facilitar una mejor experiencia del cliente. Por otra parte, han permitido el desarrollo del entorno virtual de una manera impensable hace sólo unas décadas.

Además, las nuevas tecnologías cobran especial importancia a la hora de crear una experiencia del cliente que integre el canal físico con el canal online. La evolución de estas tecnologías permite que la relación del cliente con el comercio a través de diferentes canales pueda presentarse de manera homogénea, pudiendo, por ejemplo, hacer parte de su proceso de compra en el entorno virtual, pero optando por recoger el producto en el punto de venta físico. 
Estas tecnologías redefinen la experiencia del cliente, si bien el comerciante no debe perder de vista que la tecnología que aporta valor al consumidor es únicamente la que es relevante para él (Blázquez, 2014). Así, si bien, como señalan Ruiz et al. (2013) las tecnologías de la información y la comunicación pueden suponer mejoras en el servicio y ahorro de tiempo, también es cierto que existen segmentos de consumidores que consideran la tecnología del proveedor de servicios como fuente de insatisfacción. Como indican Piotrowicz y Cuthberson (2014), la tecnología debe solucionar problemas a los consumidores, por lo que el comerciante no debería implementarla sólo por el hecho de tenerla en el punto de venta, sino que debería hacerlo para alcanzar objetivos determinados. Además, en ocasiones, la tecnología en el punto de venta debería ser invisible para el consumidor y debería probarse con antelación para asegurarse de que no va a causar problemas que puedan implicar una mala imagen de cara al cliente. En cualquier caso, la tecnología de la tienda debería ser complementaría y no sustitutiva del personal de la tienda.

Bäckström y Johansson (2006) analizan la experiencia del cliente en el punto de venta y comparan la perspectiva que tienen los comerciantes y los consumidores. Parece claro que hay una creciente demanda de experiencias por parte del consumidor y que, por tanto, es crucial para el detallista centrarse en proporcionárselas. Ahora bien, tal y como se desprende de su estudio, en ocasiones los detallistas intentan proporcionar experiencias a sus clientes a través de soluciones tecnológicas avanzadas, mientras que muchas veces el consumidor considera como importantes cosas básicas tales como el trato del personal, la disposición y distribución del local, etc. a la hora de crear experiencias partiendo de pequeños detalles. La diferencia entre las apreciaciones de los comercios y de los consumidores no significan necesariamente que éstos no aprecien el tipo de experiencias que los detallistas intentan proporcionarles, sino más bien que hay aspectos básicos y fundamentales que deben ser considerados por los comerciantes antes de intentar avanzar hacia experiencias más complejas.

Así pues, a la vista de los resultados de diferentes estudios, a la hora de plantearse la creación de experiencias para sus clientes, el comercio detallista debe tener claro que 
hay determinados aspectos básicos, que podríamos denominar valores tradicionales, que debe ser capaz de satisfacer correctamente antes de intentar ofrecer otro tipo de experiencias más complejas o avanzadas. Lógicamente, éstas serán apreciadas por los consumidores, pero siempre y cuando las básicas les sean satisfechas.

En este sentido, las investigaciones de Nah et al. (2011) sobre el efecto que la dimensión utilizada en la página web tiene sobre el Valor de Marca (Brand Equity) y la intención de uso, reflejan que un entorno virtual en tres dimensiones tiene efectos, tanto positivos como negativos. Por una parte, los positivos se atribuyen a sensaciones como la telepresencia y el hecho de disfrutar de la compra, mientras que, por otra parte, los efectos negativos vienen explicados por la distracción que el entorno supone para la persona. Visinescu et al (2015) señalan que el entorno 3D puede tener efectos negativos directos en la sensación sobre la facilidad de uso e indirectos en la utilidad percibida por el cliente y en su intención de compra.

Hamzah et al (2014) también identifican sentimientos positivos y negativos en la dimensión de las experiencias emocionales de los consumidores cuando navegan por páginas web. Así, los sentimientos favorables vienen dados por la felicidad que representa la transacción o la confianza con el sitio web, mientas que los sentimientos menos favorables se dan por la frustración, la preocupación o la decepción.

Tal como indican Piotrowicz y Cuthbertson (2014) las tecnologías de la información y comunicación están adquiriendo cada vez más protagonismo dentro del punto de venta físico. Así, herramientas como pantallas interactivas, realidad aumentada o probadores virtuales, al igual que otras que puedan ser utilizadas por los empleados, como las tabletas, deberían utilizarse para generar una completa interacción enfocada hacia la creación de experiencias para el cliente y no simplemente quedares como simples instrumentos dispersos por el punto de venta.

Como señala Pantano (2014) el consumidor cada vez más demanda innovaciones en el punto de venta, ya que desean vivir experiencias que le llenen cuando hacen su compra. Esperan encontrar tanto elementos de entretenimiento como herramientas que 
mejoren la calidad de la experiencia de compra. Los últimos avances en la tecnología hacen que aumente la posibilidad de tener éxito innovando en el punto de venta. La integración de la realidad virtual y aumentada, así como las redes sociales y las tecnologías móviles son un área a desarrollar para captar la atención del cliente e influir en su decisión de compra, incluso en el mismo punto de venta.

Por tanto, si bien las tecnologías vemos que son indispensables para la creación de experiencias, tanto en los entornos físicos como en los virtuales, no debemos perder de vista que el comercio detallista debe centrarse en ofrecer a su cliente tan solo aquellas tecnologías que le vayan a suponer un aporte de valor en su relación con la empresa, ya que, como hemos visto, un exceso en su utilización, o más bien, el uso de tecnologías excesivamente complejas o que no aporten valor, puede suponer una desventaja o un impedimento a la hora de realizar la compra, antes que una ventaja en la intención de compra. Se puede concluir, de esta manera, que el comercio detallista virtual debe tener cierta cautela a la hora de introducir nuevas tecnologías en su entorno online, debiendo estar éstas dirigidas a facilitar la navegación en la página web y a contribuir a la generación de experiencias positivas buscadas por el consumidor.

Las nuevas tecnologías de la información y comunicación son la base de la creación de experiencias en el entorno virtual. Hemos visto cómo pueden contribuir en gran medida a la creación de experiencias en el comercio físico, pero no podemos olvidar que son totalmente necesarias a la hora de trasladarlas al ámbito online. Tal y como señalan Menon y Khan (2002) la importancia de la atmósfera del comercio detallista se da también en el entorno virtual y la página Web del establecimiento puede utilizarla de manera similar a la tienda física tradicional, ya que las tecnologías actuales permiten trasladar variables tales como el color, la música o la iluminación.

Para Eroglu et al. (2003) los aspectos relativos a la atmósfera influyen en las respuestas del consumidor durante sus visitas a la página Web, pudiendo incrementar el nivel de placer que éste sienta. De esta forma, la atmósfera de la tienda online puede marcar la diferencia con respecto a la competencia. Su efecto en la actitud del consumidor, 
en su satisfacción e incluso en su comportamiento, sin embargo, no es directo, sino que es el resultado de las emociones por él experimentadas.

Vemos pues como la presencia de las nuevas tecnologías desdibuja los límites entre las experiencias del entorno físico y el virtual, contribuyendo con su correcta utilización a homogeneizarlas, de forma que el comerciante pueda hacer que el consumidor sienta en todo momento que está interactuando únicamente con un único interlocutor, independientemente de que su contacto con él se produzca a través de canales diferentes.

Esto cobra especial importancia en un entorno tecnológico como el actual en el cual el consumidor ha ido adquiriendo cada vez más poder en el sentido de que cada vez tiene mayor facilidad para acceder a distintas fuentes de información. El acceso a la misma puede hacer que tenga más facilidad para comparar productos y servicios, con lo cual sus expectativas con respecto a los mismos son mayores que hace unos años.

Además, la facilidad de uso de las nuevas tecnologías contribuye a que el consumidor pueda elegir diferentes canales a la hora de entrar en contacto con la empresa. Este es un punto importante que el comercio detallista debe tener en cuenta, ya que, según Lu y Rucker (2006) los consumidores que utilizan más de un canal para realizar sus compras gastan de media más dinero, compran más frecuentemente y tienen, por tanto, un mayor valor en su ciclo de vida para la empresa, que aquellos que utilizan únicamente el canal tradicional. En su estudio sobre la compra de indumentaria a través de distintos canales (tienda, catálogo e Internet) destacan las ventajas de los detallistas que utilizan varios canales sobre los que utilizan solamente uno. Puesto que existen diferencias a favor de los primeros, es importante comprender cómo se comportan los consumidores en los distintos canales. Así, las experiencias positivas con relación a innovaciones, facilitará el que un cliente que habitualmente compra en un canal más tradicional como puede ser una tienda, dé el paso hacia un canal más innovador como puede ser Internet.

Ahora bien, no se debe perder de vista que esta tipología de cliente "multicanal", también espera más de sus experiencias de compra, ya que su comportamiento de compra 
es más exploratorio y tienen un proceso de búsqueda más variado que los consumidores que utilizan un único canal, tal y como señalan Kumar y Venkatesan (2005).

Como hemos visto con anterioridad, el cliente que utiliza varios canales para realizar su proceso de compra, tiene una perspectiva más holística de su experiencia y entiende que éstos tienen que estar integrados, no pudiendo dar la sensación de que los distintos canales que el comercio pueda poner a su disposición funcionan de manera aislada o con independencia uno de otro. Esto último no contribuiría a proporcionar una buena experiencia del cliente.

Puesto que el consumidor cambia de un canal a otro durante el proceso de compra, la experiencia que se le proporcione deberá ser consistente entre estos canales, aunque la realidad muestra que muchos detallistas que gestionan bien los canales de manera individual, fallan cuando intentan ofrecer una experiencia integrada en los distintos canales (Khan, 2007)

En este sentido, lo mismo se puede decir de las distintas redes sociales en Internet, tales como Facebook o Twitter en las cuales se inicia muchas veces el proceso de compra, ya que el consumidor acude a ellas para buscar información e incluso consejo.

En general, tal y como indica Scarpi (2012) las experiencias positivas previas que un consumidor haya tenido en Internet contribuirán a crear una actitud positiva hacia este canal y serán un predictor importante de la compra online, ya que la navegación virtual incrementa la probabilidad de realizar compras en Internet.

Si el comercio detallista es capaz de ofrecer al consumidor buenas experiencias en el entorno virtual, esto afectará positivamente su comportamiento de compra online. Internet se ha convertido en un mercado global y en una fuente de información primaria, con lo que ha ganado importancia, ya que influencia la forma en que se comportan tanto las empresas como los consumidores en este medio. Por tanto, se deben plantear nuevas estrategias y prácticas por parte del comercio detallista para hacer frente a este entorno 
nuevo que cada día supone unos mayores niveles de interactividad y que está más centrado en el concepto de comunidad que en el de empresa (Hamzah et al., 2014).

Cuanto mayor sea la experiencia del cliente comprando online mayor será el efecto positivo en la actividad de compra, puesto que el consumidor adquiere más confianza en el uso de Internet y percibe menos riesgo en la compra a través de distintos canales (San Martin et al., 2009).

Según Blázquez (2014) el comportamiento de compra multicanal incluso en el sector de la moda es una realidad y la gente interactúa en ellos de diferentes maneras, buscando y comparando información sobre productos y marcas, llegando incluso en el caso del público femenino a buscar algo más experiencial con la búsqueda de inspiración en blogs y redes sociales.

Ahora bien, según Lu y Rucker (2006), los consumidores que ven la compra en la tienda como una actividad recreativa compran en Internet con menos frecuencia y gastan menos en este canal que aquéllos que no consideran que la compra en la tienda sea una actividad recreativa.

A la vista de esto, el comercio detallista debe tener en cuenta la importancia de las nuevas tecnologías, no solo por lo que se refiere al canal virtual, sino también por su utilización en el punto de venta físico.

Las nuevas tecnologías de la información aplicadas en el punto de venta pueden ayudar a proporcionar al cliente mayor placer, interacción con el producto e incluso ayudar a una mejor ubicación y disposición de los productos en la tienda de forma que aumente el nivel de la experiencia que se quiere ofrecer al cliente. Para Choi et al. (2015) esta experiencia vendrá dada por la suma de todas las interacciones del consumidor con el detallista, empezando incluso antes de que éste entre en el establecimiento y acabando bastante después de que lo haya dejado. 
De esta manera, antes de que el consumidor vaya a realizar su compra puede optar por buscar información a través de páginas web de distintas empresas, foros de consumidores, Redes Sociales online, etcétera, entrando aquí en juego una posible aplicación de las tecnologías de la información y comunicación que el detallista deberá ser capaz de manejar correctamente, ya que de ello dependerá la correcta presentación de su empresa ante su público objetivo en el entorno virtual. Además, si la experiencia en esta primera etapa es satisfactoria, el consumidor podrá optar por acudir al punto de venta físico del detallista.

En una segunda fase, la experiencia del cliente vendrá dada por su interacción con el detallista en el mismo punto de venta. Durante la compra el consumidor esperará tener una experiencia proactiva, informativa y placentera de su interacción con el producto y su entorno, incluidos los vendedores. En este momento, determinadas tecnologías en el punto de venta pueden contribuir a la mejora de la satisfacción del cliente: pantallas interactivas con información y recomendaciones sobre el producto, probadores virtuales, terminales que permitan hacer el pedido para recogerlo en caja en ese mismo instante o con posterioridad, etcétera.

Así, por ejemplo, son varios los autores que analizan el efecto que los displays o pantallas digitales instaladas en el punto de venta pueden tener sobre el consumidor. Dennis et al. (2013) señalan que estos dispositivos aumentan el aspecto hedónico de la compra y las experiencias afectivas, fortaleciendo el proceso de la experiencia en su conjunto. En esta misma línea, Dennis et al. (2014) indican que las pantallas digitales aumentan la información utilitaria, evocando experiencias intelectuales y fortaleciendo el proceso de compra.

Este aspecto es importante, ya que el comercio detallista a través de Internet presenta algunas limitaciones que pueden salvarse gracias a la presencia de un punto de venta físico. Como apuntan Citrin et al. (2003), la Red reduce la oportunidad de realizar ventas sensoriales. Así, los consumidores con una alta necesidad de contacto táctil con el producto a la hora de realizar su decisión de compra, serán menos proclives a comprar online. Debido a la imposibilidad de utilizar el sentido del tacto para evaluar el producto, la 
publicidad en Internet (al igual que ocurre con la televisión), se centra en aspectos verbales $\mathrm{y}$ visuales.

A pesar de esto, la posición de los consumidores y de los detallistas con respecto a las tecnologías de la información y la comunicación, no siempre son coincidentes. Así, del estudio de Pantano y Viassone (2014) se confirma que hay una difusión limitada de nuevas tecnologías aplicadas al punto de venta en contraste con el creciente interés mostrado por los clientes con respecto a la introducción en la tienda de innovaciones basadas en las nuevas tecnologías. A pesar de que los comerciantes son conscientes de dicho interés, la investigación de estos autores destaca como su experiencia es escasa y que sólo una minoría de los comercios estudiados adoptan tecnologías avanzadas, en parte, debido a sus dimensiones (la mayor parte de los que no las adoptaban sólo tenían uno o dos puntos de venta), a los costes y a la complejidad de su aplicación, lo que no les permitía alcanzar las ventajas de estas innovaciones en términos de economías de escala.

Por último, tras la visita a la tienda, un canal online interactivo puede ayudar con información y consejos sobre el producto, actualizaciones sobre el mismo, foros y comunidades de usuarios, etcétera.

Vemos, por tanto, como durante toda la relación del consumidor con el comercio detallista, la utilización de las nuevas tecnologías puede ser un factor clave a la hora de mejorar su satisfacción, lo que puede conducir a un aumento de sus compras y a su mayor lealtad hacia el comercio.

Desde el punto de vista del cliente, una correcta integración de los canales puede ser clave para potenciar la experiencia en la tienda online del comercio detallista, permitiendo a éste ofrecer al consumidor lo que desee en cada fase del proceso de compra (Herhausen et al., 2015). En el sector detallista, crear intención de recompra en el cliente, lo que refleja lealtad, representa un objetivo de la dirección de la empresa (Parasuraman et al., 2005). 
Como se ha apuntado en el apartado 2.4 de la presente tesis, nos encontramos ante un consumidor omnicanal, que espera tener una experiencia a través de los distintos canales durante su viaje de compra que no presente fisuras (Yurova et al., 2016), siempre teniendo en cuenta que la evolución de los medios interactivos ha hecho que el proceso de venta al consumidor sea más complejo (Crittenden et al., 2010; Medrano et al. 2016).

Court et al. (2009) de la consultora McKinsey\&Company, cuando hablan del viaje de decisión del consumidor (The Consumer Decision Journey), resaltan que, en la actualidad, dos terceras partes de la fase de evaluación de productos que realiza el consumidor proceden de actividades de marketing promovidas por él mismo, tales como visitas a Internet, recomendaciones de amigos y familiares, etcétera y tan solo un tercio tiene como origen las acciones desarrolladas por las empresas. En este contexto, si bien el marketing tradicional sigue siendo importante, los autores recomiendan que los comercios realicen movimientos más agresivos, aprendiendo a influenciar al consumidor en los distintos puntos de contacto que tiene con él (Internet, redes sociales, etcétera).

Así, señalan Parise et al. (2016) que la experiencia del consumidor viene determinada por un complejo mix de puntos de contacto con la marca y cómo el detallista es capaz de atraer al usuario proporcionándole experiencias, contenido inmediato, personalizado y emocional que determinará el éxito de la relación comercial. Las actuales tecnologías digitales (vídeo conferencia, aplicaciones móviles, realidad aumentada, etcétera) proporcionan un entorno altamente personalizado e "inmersivo" que permite la interactividad y un rico intercambio de información entre la marca y el consumidor.

Los clientes desean más que únicamente la producción, entrega y consumo de productos y servicios; buscan experiencias únicas y memorables que acompañen a la entrega de productos y prestación de servicios (Pine y Gilmore, 199). El consumidor espera niveles más altos de servicio por parte del detallista a lo largo de su viaje de compra. De esta manera, prácticamente el 50\% de los consumidores online de Estados Unidos abandonan su compra si no consiguen respuestas rápidas a sus preguntas (Legget et al., 2013). 
Con el desarrollo de las nuevas tecnologías los consumidores están, cada vez más, convirtiéndose en compradores multicanal, usando diversos canales (tiendas físicas, websites, plataformas sociales y aplicaciones móviles) para llegar a una única transacción. Así, se estima que el $86 \%$ de los compradores globales y el $65 \%$ de los consumidores estadounidenses visitan al menos dos canales para hacer sus compras (McPartlin y Dugal, 2012). Además, los compradores online gastan más (Maxwell, 2013) y son más rentables (Graeber, 2013) cuando utilizan múltiples canales.

El crecimiento de páginas web, revistas online, redes sociales y aplicaciones móviles permite a los consumidores conocer mejor los productos y servicios que el propio vendedor (Stein y Ramaseshan, 2016).

Los consumidores tienen experiencias cada vez que entran en contacto con el producto, el servicio, la marca o la organización a través de múltiples canales y en diversos momentos (Pantano y Milena, 2015). Estos momentos de la verdad entre el consumidor y la empresa se conocen como puntos de contacto. El viaje que el consumidor realiza para conseguir alguna tarea en el proceso de compra (búsqueda de información, compra, etcétera) está formado por estos puntos de contacto (Stein y Ramaseshan, 2016). Así, la experiencia del cliente se desarrolla a través de todos los puntos de contacto durante el proceso de prestación del servicio (Jüttner et al., 2013).

De los estudios analizados se desprenden diferentes consecuencias, ya que parece claro que el consumidor que utiliza distintos canales a la hora de entrar en contacto con el detallista, es propenso a realizar más compras, así como a gastar más dinero.

El reto para el comercio detallista está, entre otros, en conseguir que el consumidor interactúe con él a través de distintos canales, para lo cual deberá poner éstos a su disposición. Sin embargo, esto no debe hacerse de cualquier manera, sino que se debe conseguir que el cliente, independientemente del canal a través del cual entre en contacto con el detallista, tenga la sensación de que está relacionándose con un único comercio, es decir, debe percibir homogeneidad y unidad entre los distintos canales que pueda llegar a utilizar. 
No solo esto, sino que además se debe tener conciencia de la importancia que puede suponer el proporcionar al consumidor experiencias, tanto en el nivel tradicional o físico como en el entorno virtual. Jugarán aquí un papel importante las nuevas tecnologías de la información y comunicación, puesto que proporcionan las herramientas adecuadas para la consecución de este objetivo.

De esta manera, podemos concluir que el concepto de experiencia del cliente se ha convertido en una estrategia decisiva para el comercio minorista que tiene que hacer frente a una fuerte competencia (Andajani, 2015).

\subsection{Modelos propuestos}

En este apartado de la tesis se presenta, en la Figura X y X.1 los modelos teóricos que se tomarán como base para realizar el estudio. En ambas quedan recogidas las diferentes hipótesis que se han ido planteando hasta este punto.

Teniendo en cuenta el modelo de Boo et al. (2009) se planteará el análisis del Valor de Marca del comercio minorista, tomando como variables la calidad percibida, el valor percibido, la notoriedad de marca, la imagen y la lealtad. Se tendrán en cuenta, por tanto, tres de los cuatro componentes propuestos por Aaker (1991) como son la notoriedad, la calidad percibida y la lealtad de marca. Además, se considerará también el valor percibido de marca (brand value o perceived value), que es considerada como parte de las asociaciones de marca por Aaker (1991) y también se tendrá en cuenta la imagen de marca propuesta por Keller (1993).

Por otra parte, además de las dimensiones comentadas del Valor de Marca, la presente tesis plantea la introducción en los modelos propuestos del concepto de experiencia del cliente, ya que, como apuntan distintos autores (Hoolbrok y Hirschmann, 1982; Jones et al., 2006; Verhoef, 2009; Kotler y Keller, 2012; Koniecnik y Ruzzier, 2013) la gestión del Valor de Marca del comercio detallista no puede perder de vista que el 
cliente moderno no solo busca la adquisición de productos y servicios, sino que también necesita que se le ofrezcan experiencias.

Así pues, en el primero de los modelos planteados la experiencia de compra del consumidor se tendrá en cuenta de manera previa a la lealtad del consumidor hacia el comercio detallista, mientras que en el segundo modelo será a la inversa, es decir, la lealtad se considerará como antecedente de la experiencia. 
Figura 4.1. Modelo I

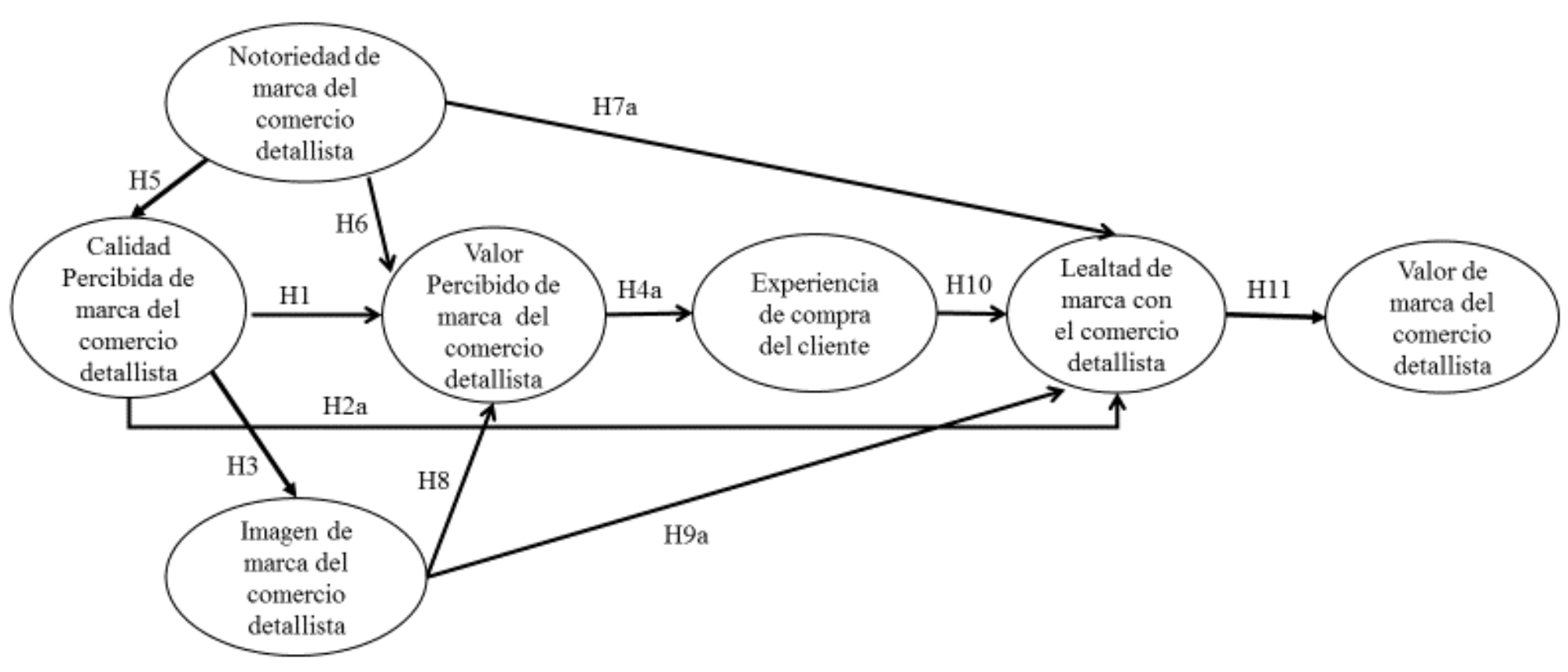


Figura 4.2. Modelo II

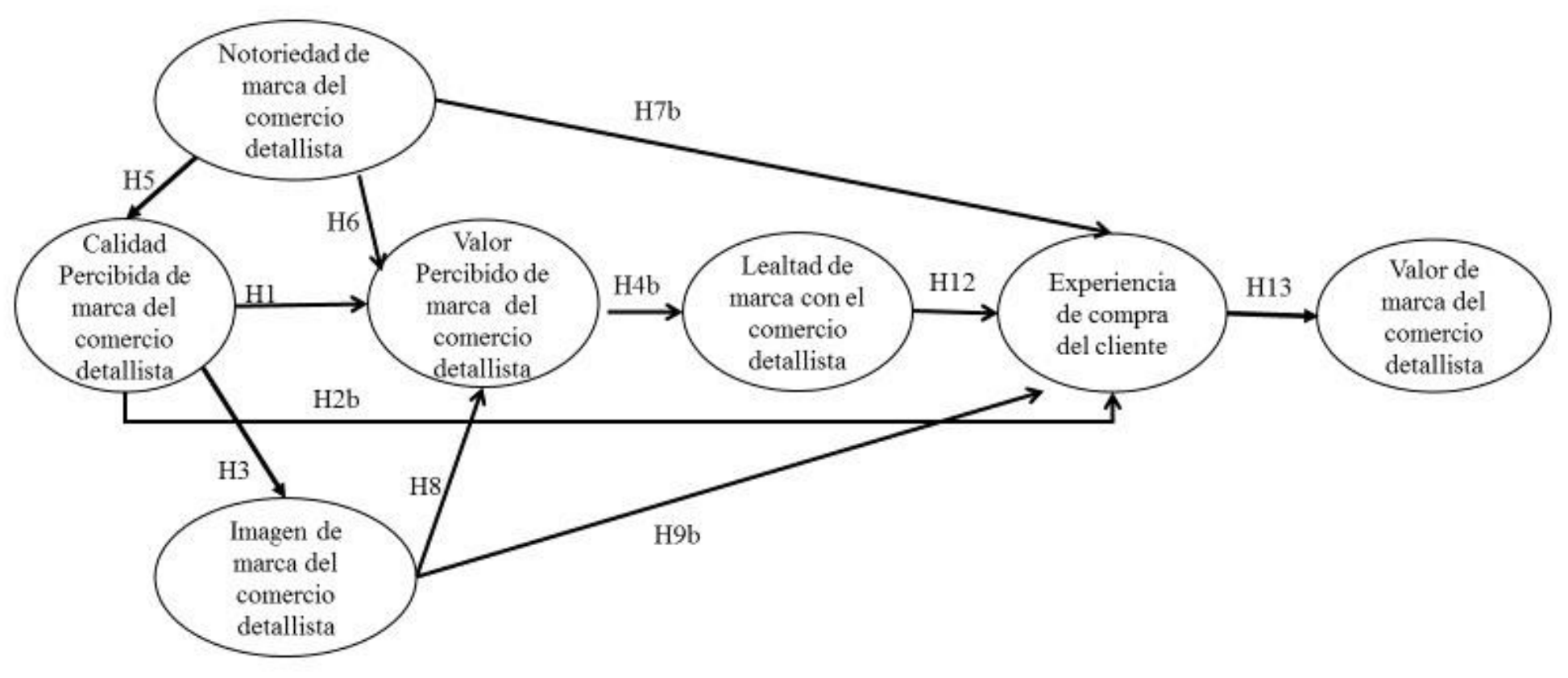





\section{5 - METODOLOGÍA}





\section{METODOLOGÍA}

\subsection{Diseño de la investigación}

En primer lugar, por lo que se refiere a la población objeto de estudio, ésta está formada por hombres y mujeres mayores de 18 años que realizaron compras en comercios detallistas durante los meses de marzo y abril de 2016 en la Comunidad Valenciana, principalmente en las provincias de Castellón y Valencia.

En cuanto a las entrevistas realizadas, en total se hicieron 623 válidas, lo que supone un error muestral del $\pm 4 \%$ (para $\mathrm{p}=\mathrm{q}=0,5$ y un nivel de confianza del 95,5\%), mediante cuestionario estructurado con preguntas cerradas y escala de respuesta tipo Likert de 5 puntos.

Tabla 5.1. Ficha técnica de la investigación

\begin{tabular}{|l|l|}
\hline \multicolumn{2}{|c|}{ Ficha técnica } \\
\hline Universo: & $\begin{array}{l}\text { Clientes de comercios detallistas de diversos sectores, } \\
\text { mayores de } 18 \text { años }\end{array}$ \\
\hline $\begin{array}{l}\text { Método de recogida de la } \\
\text { información: }\end{array}$ & Entrevista personal mediante cuestionario estructurado \\
\hline Ámbito de estudio: & Comercio minorista \\
\hline Tamaño de la muestra: & 623 encuestas válidas \\
\hline Procedimiento de muestreo: & Aleatorio simple \\
\hline Error muestral: & $\pm 4 \%$ (para p=q=0,5 y un nivel de confianza del 95,5\%) \\
\hline Cuestionario: & Estructurado con preguntas cerradas (escala Likert 1-5) \\
\hline Fecha del trabajo de campo: & Marzo y abril de 2016 \\
\hline
\end{tabular}




\subsection{Medición de las variables}

Para la recogida de información necesaria para la elaboración del presente trabajo se realizó un cuestionario estructurado en el que cabe diferenciar tres bloques. Uno de ellos hace referencia a los datos y características de los entrevistados (sexo, edad, estudios, residencia) y frecuencia de compra en el establecimiento. Otro bloque recoge la información relativa al comercio, tal como el nombre y la tipología (pertenencia a cadena o comercio independiente). Por último, se encuentran las preguntas dirigidas a obtener información relacionada con las variables de estudio: notoriedad de marca del comercio, valor percibido, calidad percibida, imagen de marca del establecimiento, lealtad de marca, Valor de marca y experiencia de compra del cliente. Así mismo, en este bloque se incluye un apartado en el que se recoge información sobre las tecnologías de la información, puesto que su relación con la creación de experiencias de compra puede ser objeto de estudio en futuras investigaciones.

En este punto se tratarán con detalle los aspectos relativos a la medición de las variables utilizadas, mientras que la descripción de la muestra se analizará en el apartado 6.1.1 de la presente tesis.

Para medir las variables se ha utilizado una escala cerrada de tipo Likert con 5 posibilidades de respuesta, en la que 1 se corresponde con totalmente en desacuerdo y 5 con totalmente de acuerdo. Estas escalas vienen validadas por trabajos anteriores, tal y como se detalla en los siguientes puntos y se adaptan a las necesidades para la obtención de la información para llevar a cabo la investigación.

En octubre de 2015 se realizó un pretest del cuestionario a 84 personas (47 mujeres y 37 hombres) de la provincia de Valencia con el que se buscaba analizar si las preguntas estaban correctamente formuladas. A la vista de los resultados, se vio que el cuestionario resultaba excesivamente largo, por lo que se decidió reducir el número de ítems utilizado 
para cada variable, eliminando aquellos que presentaban mayor similitud y que los entrevistados veían como prácticamente iguales.

Además, en cuanto a las características del comercio, se añadió la pregunta relativa a si éste formaba parte de una cadena o era un comercio independiente.

Con respecto al cuestionario, cabe decir que en el mismo se hace referencia al Comercio X, si bien los entrevistadores tenían instrucciones de sustituir esto por el nombre del comercio concreto del que acababa de salir la persona entrevistada.

\subsubsection{Calidad de marca del comercio detallista}

Para la medición de la variable de Calidad de Marca se recurrió a diversos autores. En la tabla 5.2 se muestran los diversos ítems que se tuvieron en cuenta a la hora de considerar esta variable.

Tabla 5.2. Calidad de Marca

Ítems

\begin{tabular}{ll}
\hline Ítems & Fuentes \\
\hline
\end{tabular}

Shen (2010), adaptado de:

El comercio X ofrece productos de calidad

Arnett et al. (2003)

Pappu y Quester (2006)

El servicio del comercio $\mathrm{X}$ es de lo mejor que hay

El comercio $\mathrm{X}$ es mejor que otros similares

El comercio $\mathrm{X}$ tiene equipamiento moderno

El comercio $\mathrm{X}$ ofrece productos de confianza
White et al. (2013)

Sweeney y Soutar (2001)
Musekiwa et al. (2013)

Jinfeng y Zhilong (2009) 
Al igual que se hizo con el resto de variables y dado que se observó que el cuestionario resultaba demasiado largo a la hora de llevarlo a la práctica, en un principio se partió del análisis de un número más elevado de ítems propuestos por diversos autores. Posteriormente se procedió a depurar las cuestiones a realizar para la variable calidad de marca, dejando tan solo cinco ítems.

Así, en primer lugar, se tuvieron en cuenta las propuestas de Yoo et al. (2000) quienes desarrollaron siete ítems basados en el trabajo de Dodd's et al. (1991), si bien éstas venían desarrolladas en el contexto del producto. También se estudiaron los trabajos de Biedenbach y Marell (2009) relativos a la relación existente entre la experiencia del cliente y la calidad de marca, si bien éstos más centrados en los servicios.

Tal y como señalan Ruíz et al. (2013), son pocos los estudios relativos al concepto de capital de marca en el ámbito del comercio minorista. A pesar de ello, autores como Arnett et al. (2003), Pappu y Quester (2006), quienes adaptan la propuesta de Yoo et al. (2000) al comercio detallista, o Shen (2010), centran sus trabajos en el valor de marca de la tienda.

Así, Pappu y Quester (2006) aplican el modelo del valor de marca basado en el consumidor al campo del valor de marca del comercio detallista, aplicando las dimensiones de notoriedad del comercio minorista, asociaciones, calidad percibida y lealtad hacia éste.

Por su parte, Shen (2010) mide la calidad de marca del comercio detallista usando escalas adaptadas de Arnett et al. (2003) y Pappu y Quester (2006). En esta línea, White et al. (2013) señalan que muchos estudios proponen la investigación del valor de marca desde el punto de vista de los productos físicos, pero estos autores lo aplican al ámbito minorista, puesto que consideran que es escasa la investigación en este campo.

Sweeney y Soutar (2001), tomando como base las investigaciones de Aaker (1991) desarrollan una escala de medición del valor percibido que denominan PERVAL que tiene 
entre sus dimensiones el valor percibido y la calidad percibida del producto. Estos autores desarrollan su estudio aplicándolo al ámbito del comercio minorista.

Musekiwa et al. (2013) centran su trabajo en el valor de marca del comercio minorista, desarrollando ítems para la medición de las distintas dimensiones del mismo, tomando como base para la medición de la calidad de marca del detallista el trabajo de Aaker (1996), mientras que Jinfeng y Zhilong (2009), tal y como señalan Ruiz et al. (2013), optan por adaptar al comercio minorista "las medidas multidimensionales del capital de marca desarrolladas en contextos de producto".

Así pues, los ítems elegidos para la medición de esta variable se han considerado dada su adecuación al comercio detallista, tal y como se ha apuntado en párrafos anteriores.

\subsubsection{Valor Percibido de marca del comercio detallista}

Para la medición de la variable relativa al valor percibido de marca del comercio detallista, se han elegido seis ítems, basándose en distintos autores. Los enunciados de las preguntas que forman parte del cuestionario se reflejan en la tabla 5.3.

Al igual que en el caso de la calidad de marca del comercio detallista, en la medición de esta variable se descartaron una serie de ítems como algunos de Shen (2010) o Noya y Gölbasi (2014) por ser muy similares a los que se presentan en la tabla 5.2, ya que incluirlos habría supuesto un cuestionario excesivamente largo, así como demasiada reiteración con preguntas muy similares desde el punto de vista de los entrevistados. 
Tabla 5.3. Valor Percibido de Marca

\section{Ítems}

\begin{tabular}{ll}
\hline Ítems & Fuentes \\
\hline
\end{tabular}

Fandós (2010) adpatado de:

El personal tiene conocimiento de los productos y servicios ofrecidos

Suelo recibir un servicio rápido y ágil

En general me siento a gusto con el comercio $\mathrm{X}$

La relación calidad precio del comercio X es buena

La reläion calidad precio del comercio X es buena

Comprar en el comercio X es una buena opción
PERVAL, Sweene y Soutar (2001)

GLOVAL, Moliner et al. (2005)

Fandós et al. (2006)

Sánchez et al. (2006)

Ruíz et al. (2013), adaptado de:

Sweeney y Soutar (2001)

Adaptado de:

Oh (2000)

Del Río et al. (2001)

Sweeny y Soutar (2001)

Yoo y Donthu (2001)

Arnett et al. (2003)

Keller (2003)

Adaptado de:

Gallarza et al. (2015)

Cronin et al. (2000)

Para la medición de la profesionalidad (valor funcional) del personal del comercio, así como el valor funcional y emocional del detallista se han utilizado los ítems propuestos por Fandós (2010), quien, a su vez parte de los estudios de diversos autores (Seeney y Soutar (2001), Moliner et al. (2005), Fandós et al. (2006) y Sánchez et al. (2006)).

El ítem relativo a la relación calidad precio del comercio lo proponen Ruíz et al. (2013) tomando como partida el estudio de Sweeney y Soutar (2001) en el que analizan el valor percibido en el ámbito del comercio minorista. 
También se ha recurrido a autores como Oh (2000), Yoo y Donthu (2001) o Boo et al. (2008) a la hora de seleccionar ítems para la medición del valor percibido de marca del establecimiento comercial. También se ha considerado el trabajo de Arnett et al. (2003) en el que se desarrolla un índice de medición del capital de marca para el detallista, tomando como base a Aaker (1991) y a Yoo et al. (2000).

Por otra parte, se ha tenido en cuenta el valor percibido en un sentido amplio, adaptando un ítem de Gallarza et al. (2015), utilizado para el sector hotelero, basado, a su vez en el estudio de Cronin et al. (2000) sobre el sector servicios.

\subsubsection{Notoriedad de marca del comercio detallista}

Para medir la notoriedad de marca del comercio detallista se utilizan nuevamente seis ítems de diversos autores, adaptados al sector minorista. Así, en la tabla 5.4 se recogen tanto los ítems que se incluyeron en el cuestionario, como las fuentes utilizadas para su redacción.

Tabla 5.4. Notoriedad de Marca

\begin{tabular}{ll}
\hline \multicolumn{1}{c}{ Ítems } & \multicolumn{1}{c}{ Fuentes } \\
\hline Puedo identificar el comercio X entre otros comercios & Shen (2010), adaptado de: \\
$\begin{array}{l}\text { Algunas características del comercio X me vienen a la } \\
\text { mente rápidamente }\end{array}$ & Arnette et al. (2003) \\
\hline & Pappu y Quester (2006) \\
Puedo recordar fácilmente el logotipo del comercio X & Adaptado de: \\
& Yoo et al. (2000) \\
& Biedenbach y Marell (2009) \\
& Ding y Tseng (2015) \\
\hline
\end{tabular}


Adaptado de:

Yoo y Donthu (2001)

El comercio X es muy conocido

Arnett et al. (2003)

Pappu y Quester (2006)

Boo et al. (2008)

Cuando pienso en comprar, el comercio $\mathrm{X}$ me viene a la mente

Musekiwa et al. (2013)

Conozco las promociones del comercio $\mathrm{X}$

Como se puede observar, nuevamente se acude a las investigaciones de Shen (2010) sobre el valor de marca del comercio detallista, si bien, en esta ocasión, en lo que se refieren a la notoriedad de marca del mismo, que al igual que sucedía en la variable de calidad de marca, toman como base las escalas de Arnett et al. (2003) y Pappu y Quester (2006). Otros autores que también han utilizado estos ítems en sus estudios son Jinfeng y Zhilong (2009) y Das (2014), aplicándolos al ámbito del comercio detallista.

En lo que se refiere al recuerdo de la marca, se utiliza un ítem, presente en los trabajos de Yoo et al. (2000), Biedenbach y Marell (2009) y Ding y Tseng (2015), en este caso adaptado al comercio detallista, ya que el primero de ellos viene referido a la notoriedad de marca de manera general, el segundo al comercio entre empresas, mientras que el último de ellos versa sobre detallistas de alimentación.

Para los últimos ítems utilizados para medir esta variable se vuelve a recurrir a autores como Pappu y Quester (2006) y Musekiwa et al. (2013), cuyos estudios analizan la notoriedad de marca en el ámbito del comercio minorista. 


\subsubsection{Imagen de marca del comercio detallista}

La medición de la variable relativa a la imagen de marca del comercio minorista se ha efectuado presentando a los encuestados los seis ítems que se muestran en la tabla 5.5.

Tabla 5.5. Imagen de Marca

\begin{tabular}{l|l}
\hline \multicolumn{1}{c|}{ Ítem } & \multicolumn{1}{c}{ Fuentes } \\
\hline El comercio X es frecuentado por gente parecida a mí & Yoo et al. (2000) \\
\hline La imagen del comercio X es coherente con mi propia imagen & $\begin{array}{l}\text { Adaptado de: } \\
\text { Lassar et al. (1995) } \\
\text { Boo et al. (2008) }\end{array}$ \\
\hline Me gusta el comercio X & $\begin{array}{l}\text { Pappu y Quester (2006), } \\
\text { adaptado de: } \\
\text { Aaker (1991) } \\
\text { Koo (2003) }\end{array}$ \\
\hline El comercio X tiene personalidad & $\begin{array}{l}\text { Buil et al. (2013), } \\
\text { adaptado de: } \\
\text { Lasse et al. (1995) } \\
\text { Aaker (1996) } \\
\text { Netemayer et al. (2004) } \\
\text { Pappu et al. (2005) }\end{array}$ \\
\hline Comprar en el comercio X causa buena impresión en la gente & $\begin{array}{l}\text { Adaptado de: } \\
\text { Sweeney y Soutar (2001) }\end{array}$ \\
\hline La imagen general del comercio X es muy positiva & García et al. (2012) \\
\hline
\end{tabular}

La selección de ítems para la medición de la variable referente a la imagen del comercio detallista se hizo a partir de diversos autores tales como Yoo et al (2000), Shen 
(2010), Calvo y Lang (2015), Musekiwa et al. (2013), etc., si bien, a la hora de elegir los seis ítems definitivos se consideró la similitud entre algunos de ellos o el hecho de que los enunciados de las preguntas fuesen prácticamente iguales.

Cabe destacar el trabajo de Pappu y Quester (2006), quienes, basándose en estudios anteriores de Aaker (1991), Yoo et al. (2000), Koo (2003) o Arnett et al. (2003), hacen una aplicación al comercio minorista de los distintos ítems para medir esta variable que se habían utilizado previamente en otros ámbitos, tales como destinos turísticos, hoteles, marcas, etc.

\subsubsection{Lealtad de marca del comercio detallista}

Si bien son numerosos los trabajos dedicados a la lealtad de marca y a su medición, son menos los que aplican esta variable al ámbito específico del comercio minorista. Para la elección de los ítems definitivos que se presentaron en el cuestionario, se tuvieron presentes los trabajos de Pappu y Quester (2006) y de Ruiz et al. (2013), ya que están centrados específicamente en la aplicación de la lealtad al comercio detallista.

Si bien los ítems definitivos son los que se muestran en la tabla 5.6, previamente también se analizaron las propuestas de autores como Beatty y Kahle (1998), Gremler et al. (2001), Baloglou (2002), Keller (2003) o Boo et al. (2008). Al igual que en las variables estudiadas anteriormente en el presente capítulo, hubo que optar por una selección de seis ítems a incluir en el cuestionario para evitar que éste tuviese una longitud excesiva a la hora de presentarlo a los encuestados. 
Tabla 5.6. Lealtad de Marca

\begin{tabular}{|c|c|}
\hline Ítems & Fuentes \\
\hline A la hora de comprar, el comercio X es mi primera opción & Aaker (1991) \\
\hline \multirow[t]{2}{*}{ No voy a otros comercios si lo que busco está en el comercio X } & Yoo et al. (2000) \\
\hline & Pappu y Quester (2006) \\
\hline \multirow{3}{*}{$\begin{array}{l}\text { Intentaré seguir comprando en el comercio } \mathrm{X} \\
\text { Animaré a mis parientes y amigos a comprar en el comercio X }\end{array}$} & Adaptado de: \\
\hline & Oliver (1996) \\
\hline & Fandos (2010) \\
\hline \multirow{4}{*}{ Aún con productos similares, prefiero el comercio $\mathrm{X}$} & Yoo et al. (2000) \\
\hline & Arnette et al. (2003) \\
\hline & Ruíz et al. (2013) \\
\hline & Ding y Tseng (2015) \\
\hline $\begin{array}{l}\text { En el futuro compraré más en el comercio X que en cualquier } \\
\text { otro }\end{array}$ & Swoboda et al. (2013) \\
\hline
\end{tabular}

\subsubsection{Experiencia del cliente}

A la hora de analizar la experiencia del cliente, como se puede apreciar en la tabla 5.7 que contiene los ítems seleccionados para tal fin, se ha recurrido a algunos autores coincidentes con los de las variables anteriores, pero se han analizado también estudios de nuevos autores, dado que no es tan abundante la literatura que une la experiencia con el valor de marca. 
Tabla 5.7. Experiencia del cliente

\begin{tabular}{ll}
\hline \multicolumn{1}{c}{ Ítem } & \multicolumn{1}{c}{ Fuentes } \\
\hline El comercio X no llama la atención de mis sentidos & Adaptado de: \\
El comercio X estimula mi curiosidad y creatividad & Brakus et al. (2009) \\
\hline El comercio X intenta estimular mis sentidos & Adaptado de: \\
\hline Disfruto comprando en el comercio X & Ding y Tseng (2015) \\
\hline Los entornos estimulantes me animan a comprar & Sweeney y Soutar (2001) \\
$\begin{array}{l}\text { La interacción con el producto o servicio hace la compra más } \\
\text { interesante }\end{array}$ & Kim et al. (2011) \\
\hline
\end{tabular}

En primer lugar, cabe apuntar que el trabajo de Brakus et al. (2009), si bien no se centra en el comercio detallista, sí que relaciona la experiencia de marca con la lealtad, midiendo cómo la primera afecta a la segunda.

Por su parte, Ding y Tseng (2015) analizan la experiencia de marca y su relación con el valor de marca y la lealtad, teniendo en cuenta, entre otros, los estudios de Brakus et al. (2009).

El trabajo de Sweeney y Soutar (2001) se centra en el desarrollo de una escala para medir el valor percibido del consumidor en el ámbito del comercio detallista, mientras que Kim et al. (2011) desarrollan un índice para la medición de la experiencia del cliente.

\subsubsection{Valor de Marca (Brand Equity) del comercio detallista}

Para la medición del valor de marca se eligieron los cinco ítems que se recogen en la tabla 5.8, después de analizar propuestas de diversos autores (Arnett et al. (2003), Pappu y Quester (2006), Shen (2010), etc.) 
Tabla 5.8. Valor de marca

\begin{tabular}{lc}
\hline \multicolumn{1}{c}{ Ítem } & \multicolumn{1}{c}{ Fuentes } \\
\hline Prefiero el comercio X aunque haya otro con similares características & Ruíz et al. (2013) \\
\hline Tengo una actitud más favorable hacia el comercio X que hacia otros & Ryan et al. (2013) \\
\hline El comercio X me resulta atractivo & Dabija y Babut (2014) \\
\hline El comercio X es una marca fuerte & Swoboda et al. (2013) \\
\hline El comercio X es visualmente atractivo & Nam et al. (2011) \\
\hline
\end{tabular}

Para medir esta variable se han utilizado ítems de Ruíz et al. (2013), ya que sus estudios se centran en el comercio detallista, tomando como base, entre otros autores a Shen (2010).

Ryan et al. (2015) centran sus estudios en el valor de marca del comercio detallista con presencia multicanal, con lo que se aportan una serie de ítems adaptados para el ámbito minorista.

Dabija y Babut (2014), por su parte, aportan ítems en su estudio dirigido a construir lealtad hacia el comercio minorista a través de la gestión del punto de venta y de la comunicación.

Swoboda et al. (2013), basándose en las propuestas de Verhoef et al. (2007), hacen una adaptación para la medición del valor de marca del comercio en el ámbito de la competencia local.

\subsubsection{Tecnologías de la Información y la Comunicación}

Se incluyó en el cuestionario un bloque con siete ítems enfocado a analizar la opinión de los encuestados sobre las tecnologías de la información y la comunicación. Dichos ítems se recogen en la tabla 5.9 que se muestra a continuación. 
Tabla 5.9. Tecnologías de la Información y la Comunicación

\begin{tabular}{|c|c|}
\hline Ítem & Fuentes \\
\hline Prefiero realizar mis compras en Internet & Emrich et al. (2015) \\
\hline $\begin{array}{l}\text { Comprar en Internet es fiable } \\
\text { Comprar en Internet es una de mis actividades de ocio preferidas }\end{array}$ & Lu y Rucker (2006) \\
\hline Comprar en Internet puede hacer difícil la elección del producto & Lee et al. (2010) \\
\hline $\begin{array}{l}\text { Cuando compro online las condiciones del entorno de Internet hacen } \\
\text { más lento el proceso de decisión }\end{array}$ & \multirow{3}{*}{ Maity y Dass (2014) } \\
\hline $\begin{array}{l}\text { La experiencia de tomar decisiones en el comercio físico es muy } \\
\text { similar a la del comercio online }\end{array}$ & \\
\hline $\begin{array}{l}\text { Intento buscar información y tomar decisiones de compra en un } \\
\text { entorno online }\end{array}$ & \\
\hline
\end{tabular}

La pregunta sobre las preferencias de compra en Internet se ha tomado del estudio realizado por Emrich et al. (2015) sobre los beneficios de la integración multicanal y el papel moderador del tipo de comercio minorista. Se trata de una adaptación del ítem utilizado por Shim et al. (2001).

Por su parte, los ítems sobre la fiabilidad de la compra en Internet y de su consideración como actividad de ocio proceden del trabajo de Lu y Rucker (2006) relativo a las diferencias sobre la compra a través de un único canal o de varios canales.

Lee et al. (2010) hacen una propuesta de diferentes ítems para medir la experiencia, tanto cognitiva como afectiva, de la compra online. De estos autores se ha tomado el ítem relativo a la dificultad de elección del producto cuando se compra en Internet.

El resto de ítems se han tomado de Maity y Dass (2014) y fueron planteados en su trabajo sobre las decisiones de compra y las diferencias existentes en función de que ésta 
se realice en medios tradicionales o modernos: comercio electrónico, comercio a través de dispositivos móviles o comercio en el punto de venta físico.

Como se ha ido viendo a lo largo del presente capítulo, para el diseño final del cuestionario se partió de un número elevado de ítems que fue depurándose a fin de que el número de preguntas no fuese excesivo y la duración de la entrevista a los encuestados fuera correcta.

Las preguntas se estructuraron por bloques y a raíz del pretest que se realizó, se replantearon las que presentaban problemas de comprensión o se sustituyeron por las de los autores que resultaban de más fácil comprensión para los entrevistados.

En el cuestionario definitivo aparece en primer lugar un bloque de preguntas dirigido a conocer las características del entrevistado: sexo, edad, estudios y residencia. Luego se introdujeron las preguntas relativas al comercio: pertenencia a una cadena o comercio independiente, así como la frecuencia de compra del entrevistado en el comercio sobre el que versaba el cuestionario.

Los bloques siguientes recogen los ítems relativos a las distintas variables presentes en el estudio: notoriedad, valor percibido, calidad, imagen de marca, experiencia de compra, lealtad y valor de marca.

Por último, se incluye en el cuestionario un bloque relativo a las tecnologías de la información y la comunicación por su relación a la hora de ayudar a la creación de experiencias de compra para el cliente. 



\section{6 - ANÁLISIS}





\section{ANÁLISIS}

Para la exposición de los resultados de la investigación se van a presentar dos partes, centrándose la primera de ellas en el análisis descriptivo, mientras que la última parte del presente capítulo se dedicará a contrastar las hipótesis planteadas a lo largo de esta tesis, siguiendo las consideraciones de Anderson y Gerbing (1998) relativas a la orientación en dos etapas.

\subsection{Análisis descriptivo}

Por un lado, en la primera parte de este punto se analizará el perfil de la muestra que dio respuesta a los cuestionarios (descripción de la muestra), mientras que en la segunda parte se procederá al análisis de los valores de las variables que se han tenido en cuenta para la realización del estudio:

- Calidad de marca del comercio minorista

- Valor percibido de marca del comercio minorista

- Notoriedad de marca del comercio minorista

- Imagen de marca del comercio minorista

- Lealtad de marca del comercio minorista

- Experiencia de compra del cliente

- Valor de marca (brand equity) del comercio minorista 
- Tecnologías de la información y la comunicación

De esta manera se da continuidad a la estructura general de la tesis, analizando las variables propuestas a lo largo de la misma.

\subsubsection{Descripción de la muestra}

Como se ha señalado, para la presente tesis se realizaron un total de 623 entrevistas válidas, durante los meses de marzo y abril de 2016.

Del total de las encuestas realizadas, un $41,3 \%$ corresponden a hombres, mientras que el $58,7 \%$ a mujeres. Si bien estos porcentajes se aproximan bastante a la distribución de la población por sexos en la Comunidad Valenciana (49\% hombres y $51 \%$ mujeres), durante la realización del trabajo de campo se vio que mayoritariamente eran las mujeres las que acudían a realizar las distintas compras en los establecimientos comerciales.

En el cuestionario se contemplan seis grupos de edad: de 18 a 24 años, de 25 a 34 años, de 35 a 44 años, de 45 a 54 años, de 55 a 64 años y de 65 años o más.

Tabla 6.1. Distribución de la muestra por edad

\begin{tabular}{|c|c|c|}
\hline Edad & Encuestados & Porcentaje \\
\hline $18-24$ & 208 & 33,4 \\
$25-34$ & 122 & 19,6 \\
$35-44$ & 103 & 16,5 \\
$45-54$ & 96 & 15,4 \\
$55-64$ & 67 & 10,8 \\
65 o más & 27 & 4,3 \\
\hline
\end{tabular}


Si bien la distribución por edades se intentó que fuese lo más próxima posible a la que presenta la población de la Comunidad Valenciana, cabe decir que el porcentaje de personas entrevistadas mayores de 65 años es bastante inferior al de la Comunidad, mientras que el rango de entrevistados comprendidos entre los 18 y 24 años es superior al de la misma.

Por otra parte, por lo que se refiere al nivel de estudios de los encuestados, cabe destacar que el 43,8\% declaró tener estudios universitarios, seguido este grupo por el de personas con estudios secundarios $(32,1 \%)$, quedando algo más reducidos los grupos formados por personas con estudios primarios $(14,4 \%)$ y de máster o superiores $(9,6 \%)$.

No se aprecian apenas diferencias entre los países de residencia de los encuestados, ya que prácticamente el $99 \%$ de los mismos declaró ser residente en España y tan solo el $1 \%$ restante en el extranjero. Ahora bien, por lo que respecta a sus provincias de residencia, hay que señalar que la mayor parte de las entrevistas se realizó a personas que tenían su residencia en la provincia de Castellón $(60,8 \%)$, seguidos por el grupo de personas residentes en la provincia de Valencia (36\%) y en menor medida Alicante $(1,9 \%)$, teniendo fijada su residencia el resto de entrevistados en otras provincias.

En cuanto al lugar de realización de las encuestas, las entrevistas se hicieron a la salida de los entrevistados de los comercios sobre los que se les iba a preguntar. De esta manera, los encuestados tenían reciente la experiencia de la visita al comercio minorista que acababan de visitar.

En la tabla 6.2 se muestran los comercios, ordenados de mayor a menor según el número de entrevistas realizadas a la salida de cada uno de ellos.

Tabla 6.2. Comercios sobre los que se realizaron las entrevistas

\begin{tabular}{|l|c|c|}
\hline Comercio & Frecuencia & Porcentaje \\
\hline Zara & 77 & 12,4 \\
\hline
\end{tabular}




\begin{tabular}{|c|c|c|}
\hline Comercio & Frecuencia & Porcentaje \\
\hline Mercadona & 70 & 11,2 \\
\hline El Corte Inglés & 35 & 5,6 \\
\hline Primark & 34 & 5,5 \\
\hline Consum & 34 & 5,4 \\
\hline Pull \& Bear & 27 & 4,4 \\
\hline Stradivarius & 20 & 3,2 \\
\hline Media Markt & 17 & 2,9 \\
\hline Carrefour & 17 & 2,7 \\
\hline Sprinter & 17 & 2,7 \\
\hline Springfield & 11 & 1,8 \\
\hline C\&A & 8 & 1,4 \\
\hline Mango & 9 & 1,4 \\
\hline Decathlon & 8 & 1,3 \\
\hline Druni & 6 & 1,0 \\
\hline Cortefiel & 5 & 0,9 \\
\hline Aldi & 5 & 0,8 \\
\hline Bershka & 5 & 0,8 \\
\hline Blanco & 5 & 0,8 \\
\hline Desigual & 5 & 0,8 \\
\hline Inside & 5 & 0,8 \\
\hline Massimo Dutti & 5 & 0,8 \\
\hline Alcampo & 10 & 0,6 \\
\hline Benetton & 4 & 0,6 \\
\hline Game & 3 & 0,6 \\
\hline Austria 36 & 3 & 0,5 \\
\hline Dia & 3 & 0,5 \\
\hline Double Agent & 3 & 0,5 \\
\hline Estanco & 3 & 0,5 \\
\hline
\end{tabular}




\begin{tabular}{|c|c|c|}
\hline Comercio & Frecuencia & Porcentaje \\
\hline Festa & 3 & 0,5 \\
\hline Lidl & 3 & 0,5 \\
\hline Nike & 3 & 0,5 \\
\hline Pixal & 3 & 0,5 \\
\hline Punto Roma & 3 & 0,5 \\
\hline Shana & 3 & 0,5 \\
\hline Tino González & 3 & 0,5 \\
\hline Belros & 2 & 0,4 \\
\hline Bonarea & 2 & 0,4 \\
\hline Calzedonia & 2 & 0,4 \\
\hline $\mathrm{H} \& \mathrm{M}$ & 8 & 0,4 \\
\hline Herbolario Navarro & 2 & 0,4 \\
\hline Jack \& Jones & 2 & 0,4 \\
\hline Mar y Paz & 2 & 0,4 \\
\hline New Yorker & 2 & 0,4 \\
\hline Oysho & 2 & 0,4 \\
\hline Alcapone & 2 & 0,3 \\
\hline Ikea & 2 & 0,3 \\
\hline Natura & 2 & 0,3 \\
\hline Okeysi & 2 & 0,3 \\
\hline Panadería Barrio & 2 & 0,3 \\
\hline Plácido Gómez & 2 & 0,3 \\
\hline Salsa & 2 & 0,3 \\
\hline Supermercados Mendoza & 2 & 0,3 \\
\hline Abanna 5 & 1 & 0,2 \\
\hline Adidas & 1 & 0,2 \\
\hline $\mathrm{AK}$ & 1 & 0,2 \\
\hline AMC & 1 & 0,2 \\
\hline
\end{tabular}




\begin{tabular}{|l|c|c|}
\hline Comercio & Frecuencia & Porcentaje \\
\hline Amichi & 1 & 0,2 \\
Base esport & 1 & 0,2 \\
Bimba \& Lola & 1 & 0,2 \\
Black & 1 & 0,2 \\
Bobolí & 1 & 0,2 \\
Botticelli & 1 & 0,2 \\
Boutique Bárbara & 1 & 0,2 \\
Bricodepot & 1 & 0,2 \\
Ca Ferran & 1 & 0,2 \\
Cafetería Granier & 1 & 0,2 \\
Canem & 1 & 0,2 \\
Carnicería & 1 & 0,2 \\
Carnicería J. Cremades & 1 & 0,2 \\
Carolina Herrera & 1 & 0,2 \\
Casa Viva & 1 & 0,2 \\
Celio & 1 & 0,2 \\
Centro Bonsai & 1 & 0,2 \\
ChipSpain & 1 & 0,2 \\
Ciclos AB & 1 & 0,2 \\
Claire's & 1 & 0,2 \\
Elogy & 1 & 0,2 \\
Esport & 1 & 0,2 \\
Esport Natura & 1 & 0,2 \\
Ferreteria La Cadena & 1 & 0,2 \\
Feuvert & 1 & 1 \\
Floristería Rosa & 1 & 0,2 \\
Floristería Roser & 1 & 1 \\
\hline
\end{tabular}




\begin{tabular}{|c|c|c|}
\hline Comercio & Frecuencia & Porcentaje \\
\hline Frutas Company & 1 & 0,2 \\
\hline Frutería & 1 & 0,2 \\
\hline Frutería Conchita & 1 & 0,2 \\
\hline Frutería de barrio & 1 & 0,2 \\
\hline Ganso & 1 & 0,2 \\
\hline Gourmet El Corte Inglés & 1 & 0,2 \\
\hline Greenwich & 1 & 0,2 \\
\hline Hawkers Co. & 1 & 0,2 \\
\hline Herboristería Ruzafa & 1 & 0,2 \\
\hline Hermanos Adsuara & 1 & 0,2 \\
\hline Hilfiguer & 1 & 0,2 \\
\hline Horno Juan & 1 & 0,2 \\
\hline Horno Pascual & 1 & 0,2 \\
\hline Imaginarium & 1 & 0,2 \\
\hline Indian & 1 & 0,2 \\
\hline Intimissimi & 1 & 0,2 \\
\hline Ives Rocher & 1 & 0,2 \\
\hline KIABI & 1 & 0,2 \\
\hline La Ferretería & 1 & 0,2 \\
\hline La Jaca & 1 & 0,2 \\
\hline Leroy Merlin & 1 & 0,2 \\
\hline Levi's & 1 & 0,2 \\
\hline Maribel & 1 & 0,2 \\
\hline Mercería Celia & 1 & 0,2 \\
\hline Mercería M. Gozalbo & 1 & 0,2 \\
\hline Muebles Castor & 1 & 0,2 \\
\hline Multi Opticas & 1 & 0,2 \\
\hline Musical Center & 1 & 0,2 \\
\hline
\end{tabular}




\begin{tabular}{|c|c|c|}
\hline Comercio & Frecuencia & Porcentaje \\
\hline Natur House & 1 & 0,2 \\
\hline Opencor & 1 & 0,2 \\
\hline Optica Chaques & 1 & 0,2 \\
\hline Optica Universitaria & 1 & 0,2 \\
\hline Pablo Ochoa & 1 & 0,2 \\
\hline Paco Martínez & 1 & 0,2 \\
\hline Panadería Adzaneta & 1 & 0,2 \\
\hline Panadería El Pilar & 1 & 0,2 \\
\hline Panadería La Vilavella & 1 & 0,2 \\
\hline Panaria & 1 & 0,2 \\
\hline Papeleria El Trenet & 1 & 0,2 \\
\hline Paquetería Casa Concheta & 1 & 0,2 \\
\hline Parfois & 1 & 0,2 \\
\hline Perfumarte & 1 & 0,2 \\
\hline Perfumería Zaragoza & 1 & 0,2 \\
\hline Pinturas Montó & 1 & 0,2 \\
\hline Pollos Planes & 1 & 0,2 \\
\hline Prieto & 1 & 0,2 \\
\hline Primichi & 1 & 0,2 \\
\hline Quiosco Veronica & 1 & 0,2 \\
\hline Rafael Abad Bicicletas & 1 & 0,2 \\
\hline Regalos Agora & 1 & 0,2 \\
\hline Salamandra & 1 & 0,2 \\
\hline Saxo & 1 & 0,2 \\
\hline Shopping & 1 & 0,2 \\
\hline Signe & 1 & 0,2 \\
\hline Solo Pesca & 1 & 0,2 \\
\hline Solo Porteros & 1 & 0,2 \\
\hline
\end{tabular}




\begin{tabular}{|l|c|c|}
\hline Comercio & Frecuencia & Porcentaje \\
\hline Soloptical & 1 & 0,2 \\
Sparky & 1 & 0,2 \\
Sport Zone & 1 & 0,2 \\
Supercor & 1 & 0,2 \\
Tabacos & 1 & 0,2 \\
Tere II & 1 & 0,2 \\
Tetería Yabar & 1 & 0,2 \\
Tienda Hípica & 1 & 0,2 \\
Tienda Villarreal CF & 1 & 0,2 \\
Tiger & 1 & 0,2 \\
Toni H & 1 & 0,2 \\
Toys'R'us & 1 & 0,2 \\
Ulanka & 1 & 0,2 \\
Ultramarinos & 1 & 0,2 \\
Vip's & 1 & 0,2 \\
Yoigo & 1 & 0,2 \\
Zapatero & 1 & 0,2 \\
Zara Home & 1 & 1 \\
\hline
\end{tabular}

A grandes rasgos y agrupando los comercios en función de sus principales tipologías se puede observar que la mayor parte de entrevistas se realizó sobre una diversidad de tipologías (72,9\%), si bien es destacable que algo más del 19\% de entrevistas fue realizado a personas que habían realizado su compra en algún supermercado. Hay que apuntar en este sentido que, de manera individual, el mayor número de entrevistas se realizó a personas que acababan de visitar un establecimiento de la cadena textil Zara $(12,4 \%)$, seguido por los supermercados de la enseña Mercadona, con un $11,2 \%$ de entrevistas. 
Tabla 6.3. Comercios en función de su tipología

\begin{tabular}{|l|c|c|}
\hline Tipología de Comercio & Frecuencia & Porcentaje \\
\hline Hipermercado & 27 & 3,3 \\
Supermercado & 119 & 19,1 \\
Tiendas de alimentación & 24 & 4,7 \\
Resto & 453 & 72,9 \\
\hline
\end{tabular}

Por otra parte, teniendo en cuenta el formato comercial de los establecimientos minoristas utilizados para la realización de las entrevistas, cabe decir que el $85,6 \%$ de los mismos pertenecía a una cadena, mientras que el 14,4\% restante estaba compuesto por comercios independientes.

Por último, también se preguntó dentro de este primer bloque de preguntas, sobre la frecuencia de compra en el establecimiento correspondiente. En la tabla 6.4 se muestran los resultados obtenidos.

Tabla 6.4. Frecuencia de compra

\begin{tabular}{|l|c|c|}
\hline Frecuencia de compra & Frecuencia & Porcentaje \\
\hline Diariamente & 31 & 5,0 \\
Semanalmente & 127 & 20,4 \\
Al menos 2 veces al mes & 93 & 14,9 \\
Mensualmente & 118 & 18,9 \\
Cada 2 ó 3 meses & 146 & 23,4 \\
2 veces al año & 79 & 12,7 \\
Anualmente & 29 & 4,7 \\
\hline
\end{tabular}

Como puede apreciarse en los datos de la tabla anterior, el 23,4\% de los entrevistados dijo comprar cada 2 o 3 meses en el comercio del cual acababa de salir. Las compras diarias en el establecimiento son las que tienen un menor porcentaje, junto con las 
compras anuales, ya que ambas frecuencias están prácticamente muy cerca del 5\%. Por otro lado, también es destacable el hecho de que las compras semanales en el establecimiento tienen bastante peso, ya que suponen más del $20 \%$ de los casos entrevistados.

\subsubsection{Análisis de los valores medios de las variables}

En este apartado de la presente tesis se pretende presentar los principales resultados obtenidos con respecto a las valoraciones medias resultantes de las respuestas de los encuestados a las preguntas del cuestionario.

Se presentarán en los distintos sub-apartados de este punto las medias aritméticas de las respuestas, obtenidas, tal y como se ha indicado anteriormente, sobre una escala Likert del 1 al 5, siendo 1 totalmente en desacuerdo y 5 totalmente de acuerdo.

Las preguntas se realizaron sobre la notoriedad y relevancia de marca del establecimiento comercial, el valor percibido de la marca del mismo, la calidad percibida, la imagen de marca del comercio, la experiencia de compra del cliente con el establecimiento del que acababa de salir al ser entrevistado, la lealtad de marca y el valor de la marca (brand equity) del comercio detallista.

\subsubsection{Calidad de Marca}

Con respecto a la calidad percibida de marca del comercio detallista, se presentan en la tabla 6.5 los valores medios de los ítems que se utilizaron para su medición. Con respecto a los mismos cabe destacar, en primer lugar, que en general, la percepción de los entrevistados sobre la calidad de los comercios de los que salían es alta, ya que en todos los casos se da una puntuación superior a 3 en una escala de 1 a 5. 
Ahora bien, también es destacable el hecho de que, a pesar de que las valoraciones medias pueden considerarse como positivas, no hay ningún aspecto que destaque por obtener una valoración sobresaliente. Así, el aspecto mejor valorado por los entrevistados, es el que hace referencia a la confianza de los productos ofrecidos por los comercios, habiendo obtenido una puntuación que roza el 4 de media (3,99 sobre 5). En segundo lugar, en orden de valoración, aparece el ítem que hace referencia a la calidad de los productos ofrecidos por el comercio.

En cuanto al aspecto peor valorado dentro de la calidad percibida de marca del establecimiento aparece el ítem que compara el comercio en concreto con otros y que lo califica como "de lo mejor que hay" (3,45 sobre 5), aunque algo mejor es la valoración del comercio con respecto a que sea "mejor que otros similares", ya que obtiene una valoración de 3,67 puntos.

Tabla 6.5. Descriptivos de calidad de marca

\begin{tabular}{|c|l|c|c|}
\hline $\mathbf{N}^{\mathbf{0}}$ & $\begin{array}{l}\text { Calidad percibida de marca del establecimiento } \\
\text { comercial }\end{array}$ & Media & $\begin{array}{c}\text { Desviación } \\
\text { estándar }\end{array}$ \\
\hline 1 & El comercio X ofrece productos de calidad & 3,95 & 0,97 \\
\hline 2 & El servicio del comercio X es de lo mejor que hay & 3,45 & 0,99 \\
\hline 3 & El comercio X es mejor que otros similares & 3,67 & 0,95 \\
\hline 4 & El comercio X tiene equipamiento moderno & 3,81 & 0,99 \\
\hline 5 & El comercio X ofrece productos de confianza & 3,99 & 0,90 \\
\hline
\end{tabular}

\subsubsection{Valor Percibido de Marca}

En la tabla 6.7 se recogen los resultados de los descriptivos relacionados con el valor percibido de la marca del comercio detallista. Los resultados, al igual que ocurría con la variable de la calidad de marca, son positivos, ya que todos superan el 3 sobre 5, si bien, 
a diferencia de aquella, en el caso del valor percibido son tres los ítems cuya valoración está por encima de los 4 puntos.

El aspecto mejor valorado es el que califica la experiencia de compra en el comercio como positiva, con un 4,24 de media. Se trata de un ítem utilizado por Gallarza et al. (2015) y por Cronin et al. (2000) para la medición del valor percibido desde un punto de vista general. En segundo lugar, como segundo ítem mejor valorado está el referente a la opción de compra: “comprar en el comercio X es una buena opción”, que obtiene una puntuación media de 4,12 sobre 5 , aunque seguido muy de cerca por "en general me siento a gusto con el comercio X" que obtiene una puntuación muy similar al anterior $(4,11)$. Este último es un ítem centrado en la medición del valor emocional.

Por la parte baja en cuanto a las valoraciones tenemos un ítem relacionado con el valor funcional del comercio, como es el que hace referencia a la rapidez del servicio $(3,87)$ y el que se refiere a la relación calidad precio del comercio $(3,88)$.

En un término medio por lo que se refiere a esta variable, está el ítem que hace referencia al valor funcional del personal del establecimiento: "el personal tiene conocimiento de los productos y servicios ofrecidos", con una puntuación de 3,99 sobre 5 .

Tabla 6.6. Descriptivos valor percibido de marca

\begin{tabular}{|c|l|c|c|}
\hline $\mathbf{N}^{\mathbf{0}}$ & $\begin{array}{l}\text { Valor percibido de marca del establecimiento } \\
\text { comercial }\end{array}$ & Media & $\begin{array}{c}\text { Desviación } \\
\text { estándar }\end{array}$ \\
\hline 1 & $\begin{array}{l}\text { El personal tiene conocimiento de los productos y } \\
\text { servicios ofrecidos }\end{array}$ & 3,99 & 0,91 \\
\hline 2 & Suelo recibir un servicio rápido y ágil & 3,87 & 0,96 \\
\hline 3 & En general me siento a gusto con el comercio X & 4,11 & 0,87 \\
\hline 4 & La relación calidad precio del comercio X es buena & 3,88 & 0,91 \\
\hline 5 & Comprar en el comercio X es una buena opción & 4,12 & 0,78 \\
\hline 6 & $\begin{array}{l}\text { En general, la experiencia de compra en el comercio X } \\
\text { ha sido positiva }\end{array}$ & 4,24 & 0,77 \\
\hline
\end{tabular}




\subsubsection{Notoriedad de Marca}

Dentro de los ítems propuestos para la valoración de la notoriedad de marca del establecimiento comercial, recogidos en la tabla 6.8 destaca el que indica que el comercio es muy conocido con una puntuación media de 4,35 sobre 5 puntos, si bien, le sigue en orden de importancia y con una valoración similar $(4,32)$ el ítem "puedo identificar el comercio entre otros comercios". También reciben una puntuación superior al 4 la pregunta referida al recuerdo del logotipo del comercio $(4,18)$ y la que se refiere al recuerdo de las características del comercio $(4,03)$.

Si bien la notoriedad y los ítems relacionadas con ella han obtenido valoraciones medias elevadas, también cabe destacar que la pregunta relativa al conocimiento del cliente de las promociones del comercio, obtiene prácticamente la peor puntuación de todo el cuestionario (3,03 puntos sobre 5).

Tabla 6.7. Descriptivos notoriedad de marca

\begin{tabular}{|c|l|c|c|}
\hline $\mathbf{N}^{\mathbf{0}}$ & Notoriedad de marca del establecimiento comercial & Media & $\begin{array}{c}\text { Desviación } \\
\text { estándar }\end{array}$ \\
\hline 1 & Puedo identificar el comercio X entre otros comercios & 4,32 & 0,91 \\
\hline 2 & $\begin{array}{l}\text { Algunas características del comercio X me vienen a la } \\
\text { mente rápidamente }\end{array}$ & 4,03 & 0,99 \\
\hline 3 & Puedo recordar fácilmente el logotipo del comercio X & 4,18 & 1,12 \\
\hline 4 & El comercio X es muy conocido & 4,35 & 0,94 \\
\hline 5 & $\begin{array}{l}\text { Cuando pienso en comprar, el comercio X me viene a } \\
\text { la mente }\end{array}$ & 3,87 & 1,14 \\
\hline 6 & Conozco las promociones del comercio X & 3,03 & 1,37 \\
\hline
\end{tabular}




\subsubsection{Imagen de Marca}

Los seis ítems utilizados para medir las valoraciones de la imagen de marca se recogen en la tabla 6.9. En general, son todos positivos, si bien no reciben una valoración tan alta como los utilizados para medir la notoriedad de marca, tal y como se ha visto en el apartado anterior.

Así, por la parte alta de las valoraciones destaca la que indica "me gusta el comercio X", siendo, con un 4,16 sobre 5 la única que supera los 4 puntos de valoración media. El resto, a pesar de estar todos por encima de los 3, 5 puntos de valoración, no llega en ningún caso a una valoración de 4 puntos. Prácticamente rozando esta valoración está tanto la pregunta relativa a la similitud con el entrevistado de la gente que frecuenta el comercio $(3,98)$, como la cuestión relativa a la imagen general del comercio, con un 3,95 sobre 5 puntos.

Obtiene la puntuación más baja la pregunta que hace referencia a la buena impresión que causa sobre la gente el comprar en el comercio $X$, obteniendo tan solo una valoración media de 3,66 puntos.

Tabla 6.8. Descriptivos Imagen de Marca

\begin{tabular}{|c|l|c|c|}
\hline $\mathbf{N}^{\mathbf{0}}$ & Imagen de marca del establecimiento comercial & Media & $\begin{array}{c}\text { Desviación } \\
\text { estándar }\end{array}$ \\
\hline 1 & El comercio X es frecuentado por gente parecida a mí & 3,98 & 1,01 \\
\hline 2 & $\begin{array}{l}\text { La imagen del comercio X es coherente con mi propia } \\
\text { imagen }\end{array}$ & 3,73 & 1,01 \\
\hline 3 & Me gusta el comercio X & 4,16 & 0,85 \\
\hline 4 & El comercio X tiene personalidad & 3,84 & 1,01 \\
\hline 5 & $\begin{array}{l}\text { Comprar en el comercio X causa buena impresión en } \\
\text { la gente }\end{array}$ & 3,66 & 1,02 \\
\hline 6 & La imagen general del comercio X es muy positiva & 3,95 & 0,93 \\
\hline
\end{tabular}




\subsubsection{Lealtad de Marca}

Para la valoración de la lealtad de marca por parte de los clientes se han utilizado 5 ítems, recogidos en la tabla 6.9.

Destaca que las valoraciones medias realizadas por los entrevistados con respecto a esta variable de la lealtad hacia el comercio, no es de las más destacadas en comparación con el resto de variables. Así, ninguna de las valoraciones alcanza la puntuación de 4 sobre 5 puntos. Es más, tan solo, el ítem "intentaré seguir comprando en el comercio X", con un 3,77 de valoración, supera los 3,50 puntos. Esta pregunta está relacionada con la lealtad conativa y es, por tanto, la respuesta que mejor valoración ha obtenido por parte de los encuestados, por lo que se refiere a la lealtad de marca con el establecimiento minorista.

Los ítems relacionados con el comercio como primera opción de compra $(3,52)$, el que indica que "no voy a otros comercios si lo que busco está en el comercio X" $(3,50)$ o el relativo a animar a otras a personas a comprar en ese comercio $(3,40)$, también relacionado con la lealtad conativa, se mueven en niveles de puntuación similares.

La puntuación más baja, tan solo de 3,30 puntos sobre 5, es para el ítem que se refiere a las intenciones futuras de compra del consumidor.

Así pues, como se ha señalado, a pesar de que todos los apartados relativos a la lealtad superan la puntuación de 6 , en general, no se pueden considerar como bien valorados en el sentido que no destaca ninguno, ya que no se alcanza en ningún caso los 4 puntos sobre 5, tal y como sí que sucede en la valoración del resto de variables. 
Tabla 6.9. Descriptivos Lealtad de Marca

\begin{tabular}{|c|l|c|c|}
\hline $\mathbf{N}^{\mathbf{0}}$ & Lealtad de marca con el establecimiento comercial & Media & $\begin{array}{c}\text { Desviación } \\
\text { estándar }\end{array}$ \\
\hline 1 & $\begin{array}{l}\text { A la hora de comprar, el comercio X es mi primera } \\
\text { opción }\end{array}$ & 3,52 & 1,23 \\
\hline 2 & $\begin{array}{l}\text { No voy a otros comercios si lo que busco está en el } \\
\text { comercio X }\end{array}$ & 3,50 & 1,29 \\
\hline 3 & Intentaré seguir comprando en el comercio X & 3,77 & 1,05 \\
\hline 4 & $\begin{array}{l}\text { Animaré a mis parientes y amigos a comprar en el } \\
\text { comercio X }\end{array}$ & 3,40 & 1,16 \\
\hline 5 & $\begin{array}{l}\text { En el futuro compraré más en el comercio X que en } \\
\text { cualquier otro }\end{array}$ & 1,19 \\
\hline
\end{tabular}

\subsubsection{Experiencia de compra del cliente}

Las valoraciones medias de los aspectos relacionados con la experiencia del cliente se recogen en la tabla 6.10, en la que se presentan los cinco ítems elegidos para el cuestionario relativos a esta variable. De manera similar a lo que ocurría en el caso de la lealtad, aquí, si bien sí que hay una valoración superior al 4 como es la relativa a la organización del comercio, con un 4,20 sobre 5, el resto de ítems, a pesar de estar valorados con una puntuación superior a 3, no alcanza el 4 de media. Este aspecto que obtiene la puntuación más elevada dentro de esta variable, tiene en cuenta la accesibilidad del comercio como parte de la experiencia de compra.

El segundo ítem mejor valorado, con una puntuación de 3,71 se refiere a la interacción del producto y su posibilidad de hacer la compra más interesante. Este ítem, junto con el que indica que "los entornos estimulantes me animan a comprar", (que obtiene una valoración similar, con 3,66 puntos), hacen referencia al ambiente como factor a valorar en la experiencia de compra. 
Puntuación similar a los dos anteriores es la obtenida por "disfruto comprando en el comercio X", con 3,67 puntos de valoración media. Este ítem refleja la parte de las emociones hedónicas dentro de la experiencia de compra.

El aspecto con una valoración más baja de los ítems que hacen referencia a la experiencia de compra es el que indica que "el comercio $\mathrm{X}$ estimula mi curiosidad y creatividad", ya que tan solo obtiene una media de 3,18 puntos sobre 5 posibles.

Tabla 6.10. Descriptivos Experiencia de Compra

\begin{tabular}{|c|l|c|c|}
\hline $\mathbf{N}^{\mathbf{o}}$ & Experiencia de compra & Media & $\begin{array}{c}\text { Desviación } \\
\text { estándar }\end{array}$ \\
\hline 1 & El comercio X llama la atención de mis sentidos & 3,46 & 1,06 \\
\hline 2 & $\begin{array}{l}\text { El comercio X estimula mi curiosidad y } \\
\text { creatividad }\end{array}$ & 3,18 & 1,11 \\
\hline 3 & El comercio X intenta estimular mis sentidos & 3,25 & 1,11 \\
\hline 4 & Disfruto comprando en el comercio X & 3,67 & 1,07 \\
\hline 5 & Los entornos estimulantes me animan a comprar & 3,66 & 1,59 \\
\hline 6 & $\begin{array}{l}\text { La interacción con el producto o servicio hace la } \\
\text { compra más interesante }\end{array}$ & 3,71 & 1,04 \\
\hline 7 & $\begin{array}{l}\text { El comercio debe estar bien organizado para } \\
\text { encontrar lo que quiero }\end{array}$ & 4,20 & 0,98 \\
\hline
\end{tabular}

\subsubsection{Valor de marca (Brand Equity)}

La medición del valor de marca se ha realizado a través de los cinco ítems que se pueden ver en la tabla 6.11. En este caso, al igual que ocurría en las variables relacionadas con la calidad percibida y la lealtad hacia el comercio minorista, a pesar de que todas las puntuaciones superan la valoración media de 3 puntos, no hay ningún ítem que alcance los 4 puntos sobre 5 . 
En el aspecto más positivo cabe mencionar el ítem relativo a la fortaleza del comercio, ya que consigue una media de puntuación de 3,89 puntos, siendo así, el mejor considerado entre los relativos al valor de marca. Este aspecto viene seguido de "el comercio X es visualmente atractivo", que cuenta con una valoración media de 3,72 puntos. El ítem referente al atractivo general del comercio está próximo al del atractivo visual, ya que obtiene 3,69 puntos de media.

Dentro del valor de marca, los aspectos que obtienen peores resultados medios son "prefiero el comercio X aunque haya otros con similares características" con una puntuación de 3,47, siendo así el peor valorado, y el ítem que hace referencia a tener una actitud más favorable hacia el comercio sobre el que se preguntaba que hacia otros comercios, con 3,52 puntos de valoración.

Tabla 6.11. Descriptivos Valor de Marca

\begin{tabular}{|c|l|c|c|}
\hline $\mathbf{N}^{\mathbf{0}}$ & $\begin{array}{l}\text { Valor de marca (brand equity) del establecimiento } \\
\text { comercial }\end{array}$ & Media & $\begin{array}{c}\text { Desviación } \\
\text { estándar }\end{array}$ \\
\hline 1 & $\begin{array}{l}\text { Prefiero el comercio X aunque haya otro con similares } \\
\text { características }\end{array}$ & 3,47 & 1,97 \\
\hline 2 & $\begin{array}{l}\text { Tengo una actitud más favorable hacia el comercio X } \\
\text { que hacia otros }\end{array}$ & 3,52 & 1,11 \\
\hline 3 & El comercio X me resulta atractivo & 3,69 & 1,02 \\
\hline 4 & El comercio X es una marca fuerte & 3,89 & 1,10 \\
\hline 5 & El comercio X es visualmente atractivo & 3,72 & 1,07 \\
\hline
\end{tabular}

\subsubsection{Tecnologías de la Información y la Comunicación}

Para analizar el aspecto relativo a las tecnologías de la información y la comunicación en la presente investigación, se han planteado siete ítems. Cabe destacar el hecho de que, en general, los ítems relacionados con este apartado son los que peor 
puntuación han obtenido de todos los planteados en el cuestionario. Así, se aprecia como ninguno de ellos alcanza el 4 de puntuación media, pero, además, tan solo un ítem de los siete por los que se preguntaba supera el 3 sobre 5.

De esta manera, el aspecto mejor valorado (3,17 puntos sobre 5) es el que indica que la compra en Internet puede hacer difícil la elección del producto. Como puede apreciarse, no se trata de una puntuación alta en sí misma y tampoco si la comparamos con el resto de ítems planteados en el cuestionario. Esto indica que, en general, los entrevistados aprecian que la compra online puede dificultar la toma de decisiones con respecto a qué comprar.

El segundo aspecto en función de la valoración media es el que indica que "cuando compro online las condiciones del entorno de Internet hacen más lento el proceso de decisión". Este ítem obtiene una puntuación de 2,96 puntos, es decir, al no ser muy elevada significa que los encuestados, en general, no consideran que Internet haga más lento el proceso de decisión de compra.

Por otra parte, las respuestas nos indican que los entrevistados en el trabajo de campo no consideran que comprar en Internet sea fiable, ya que la valoración a esta respuesta ha sido de 2,91 puntos, es decir, relativamente bajo si se compara con otras puntuaciones resultantes de las encuestas, a pesar de ser la respuesta con la tercera mejor valoración dentro del apartado de las tecnologías de la información y la comunicación. Además, también se puede apreciar como la toma de decisiones de compra en el entorno online no presenta una puntuación media elevada, ya que no alcanza el 3, quedándose en 2,84 puntos de valoración.

Idéntica puntuación obtienen el ítem que mide la preferencia por hacer compras en Internet y el que indica que "la experiencia de tomar decisiones en el comercio físico es muy similar a la del comercio online", ya que ambos tienen una puntuación de 2,17. Así, por una parte, esto indica que no hay una preferencia generalizada por realizar las compras en Internet y por otra que la experiencia con la toma de decisiones de compra difiere del comercio físico al comercio online. 
Por último, el aspecto peor valorado sin llegar a los 2 puntos, es el que se refiere a la compra en Internet como actividad de ocio. Este ítem ha tenido una valoración de 1,98 puntos, siendo la peor, no solo por lo que se refiere a las tecnologías de la información y la comunicación, sino de todo el cuestionario en general. Esto da a entender que los compradores no consideran la compra en Internet como una de sus actividades de ocio preferidas.

Tabla 6.12. Descriptivos Tecnologías de la Información y Comunicación

\begin{tabular}{|l|c|c|}
\hline Tecnologías de la Información y la Comunicación & Media & $\begin{array}{c}\text { Desviación } \\
\text { estándar }\end{array}$ \\
\hline Prefiero realizar mis compras en Internet & 2,17 & 1,28 \\
\hline Comprar en Internet es fiable & 2,91 & 1,31 \\
\hline $\begin{array}{l}\text { Comprar en Internet es una de mis actividades de ocio } \\
\text { preferidas }\end{array}$ & 1,98 & 1,16 \\
\hline $\begin{array}{l}\text { Comprar en Internet puede hacer difícil la elección del } \\
\text { producto }\end{array}$ & 3,17 & 1,35 \\
\hline $\begin{array}{l}\text { Cuando compro online las condiciones del entorno de } \\
\text { Internet hacen más lento el proceso de decisión }\end{array}$ & 2,96 & 1,28 \\
\hline $\begin{array}{l}\text { La experiencia de tomar decisiones en el comercio } \\
\text { físico es muy similar a la del comercio online }\end{array}$ & 2,17 & 1,16 \\
\hline $\begin{array}{l}\text { Intento buscar información y tomar decisiones de } \\
\text { compra en un entorno online }\end{array}$ & 2,84 & 1,43 \\
\hline
\end{tabular}

\subsection{Dimensionalidad, fiabilidad y validez de las escalas de medida}

En el presente apartado se pretenden probar las diferentes hipótesis del modelo teórico planteadas en la parte empírica expuesta en la primera parte de la tesis. Para ello se tomará como base el enfoque de dos etapas de Anderson y Gerbing (1988). 
En la primera parte de este apartado se fundamentarán los componentes del modelo conceptual, determinando la calidad de las escalas utilizadas. Se realizará un análisis factorial confirmatorio con todas las escalas utilizadas, determinando su validez divergente y convergente, así como su dimensionalidad y fiabilidad.

En un segundo momento se contrastarán las relaciones causales de los modelos propuestos en la tesis.

Así pues, teniendo en cuenta la primera fase de Anderson y Gerbing (1988), se procede a continuación a la realización del análisis factorial confirmatorio a fin de determinar la validez convergente y la discriminante, así como la fiabilidad de las escalas.

En el análisis factorial confirmatorio, se aprecia en la tabla 6.14 que se deben eliminar algunos ítems que inicialmente se incluyeron en el cuestionario.

Así, por lo que se refiere a la escala que mide la Notoriedad de marca del comercio detallista, hay tres ítems que no se van a considerar. En primer lugar, el ítem "puedo identificar el comercio X entre otros comercios”, con una carga factorial de 0,55, así como el ítem "cuando pienso en comprar, el comercio X me viene a la mente" $(0,56)$ y también "conozco las promociones del comercio X", con la carga factorial más baja de la Notoriedad, ya que únicamente es de 0,39. Además, en el caso de la Notoriedad, como se apunta en la tabla 6.15, la varianza extraída promedio (AVE), presenta unos valores inferiores a 0,50 .

En cuanto al Valor percibido del establecimiento comercial, el ítem "el personal tiene conocimiento de los productos y servicios ofrecidos" tiene una carga factorial de 0,49, mientras que también presenta un valor de 0,59 el ítem "suelo recibir un servicio rápido y ágil’". Hay que añadir que la varianza extraída promedio del Valor percibido es de 0,46 . 
Con referencia a la Calidad percibida tan solo hay que descartar el ítem "el comercio X tiene equipamiento moderno", con una carga factorial de 0,42 , teniendo también en cuenta que el valor AVE es de 0,48.

De la variable relativa a la Imagen de marca del comercio detallista, se descartarán dos ítems, como son "el comercio X es frecuentado por gente parecida a mí" y "la imagen del comercio X es coherente con mi propia imagen”, con unas cargas factoriales de 0,49 el primero de ellos y 0,59 el segundo y con una varianza extraída de 0,44.

En la variable Experiencia nos encontramos con dos ítems cuyas cargas factoriales no son suficientes y que, además, hay un valor de varianza extraída promedio de 0,40. Estos ítems son: "la interacción con el producto o servicio hace la compra más interesante", con una carga factorial de 0,56 y "el comercio debe estar bien organizado para encontrar lo que quiero" $(0,24)$.

Por otro lado, cabe destacar el hecho de que en la escala de la variable de Lealtad de marca del comercio detallista se van a considerar todos los ítems planteados de inicio, ya que todos ellos tienen unas cargas factoriales superiores a 0,60 , presentando, además, un valor de la varianza extraída promedio (AVE) de 0,57.

Por último, en cuanto al Valor de marca del comercio detallista, de los cinco ítems planteados inicialmente se considerarán únicamente tres, ya que los relativos a "prefiero el comercio X aunque haya otro con similares características" y "el comercio X es una marca fuerte" presentan unas cargas factoriales de 0,42 y 0,40 respectivamente, siendo la varianza extraída promedio del Valor de marca de 0,37. 
Tabla 6.13. Análisis de escalas de medida (I)

\begin{tabular}{|c|c|c|c|}
\hline & Factores e ítems & $\begin{array}{c}\text { Cargas } \\
\text { factoriales }\end{array}$ & $\mathbf{T}$ \\
\hline & toriedad de marca del establecimiento comercial & & \\
\hline 1 & Puedo identificar el comercio $\mathrm{X}$ entre otros comercios & $0,55 *$ & 6,32 \\
\hline 2 & $\begin{array}{l}\text { Algunas características del comercio X me vienen a la mente } \\
\text { rápidamente }\end{array}$ & 0,77 & 6,94 \\
\hline 3 & Puedo recordar fácilmente el logotipo del comercio X & 0,71 & 6,76 \\
\hline 4 & El comercio $\mathrm{X}$ es muy conocido & 0,68 & 6,43 \\
\hline 5 & Cuando pienso en comprar, el comercio $\mathrm{X}$ me viene a la mente & $0,56^{*}$ & 6,76 \\
\hline 6 & Conozco las promociones del comercio $\mathrm{X}$ & $0,39 *$ & 5,78 \\
\hline & lor percibido de marca del establecimiento comercial & & \\
\hline 1 & El personal tiene conocimiento de los productos y servicios ofrecidos & $0,49 *$ & 12,65 \\
\hline 2 & Suelo recibir un servicio rápido y ágil & $0,59 *$ & 17,39 \\
\hline 3 & En general me siento a gusto con el comercio $\mathrm{X}$ & 0,74 & 26,74 \\
\hline 4 & La relación calidad precio del comercio X es buena & 0,68 & 16,07 \\
\hline 5 & Comprar en el comercio X es una buena opción & 0,79 & 29,03 \\
\hline 6 & $\begin{array}{l}\text { En general, la experiencia de compra en el comercio X ha sido } \\
\text { positiva }\end{array}$ & 0,75 & 23,28 \\
\hline & lidad percibida de marca del establecimiento comercial & & \\
\hline 1 & El comercio X ofrece productos de calidad & 0,72 & 5,93 \\
\hline 2 & El servicio del comercio $\mathrm{X}$ es de lo mejor que hay & 0,75 & 5,83 \\
\hline 3 & El comercio X es mejor que otros similares & 0,72 & 5,68 \\
\hline 4 & El comercio $\mathrm{X}$ tiene equipamiento moderno & $0,42 *$ & 5,12 \\
\hline 5 & El comercio X ofrece productos de confianza & 0,78 & 5,94 \\
\hline & agen de marca del establecimiento comercial & & \\
\hline 1 & El comercio X es frecuentado por gente parecida a mí & $0,49 *$ & 10,93 \\
\hline
\end{tabular}




\begin{tabular}{|c|c|c|c|}
\hline 2 & La imagen del comercio $\mathrm{X}$ es coherente con mi propia imagen & $0,59 *$ & 14,24 \\
\hline 3 & Me gusta el comercio $X$ & 0,72 & 14,39 \\
\hline 4 & El comercio X tiene personalidad & 0,70 & 15,70 \\
\hline 5 & Comprar en el comercio $\mathrm{X}$ causa buena impresión en la gente & 0,70 & 14,49 \\
\hline 6 & La imagen general del comercio $X$ es muy positiva & 0,74 & 15,68 \\
\hline \multicolumn{4}{|c|}{ Experiencia de compra } \\
\hline 1 & El comercio X llama la atención de mis sentidos & 0,77 & 4,36 \\
\hline 2 & El comercio X estimula mi curiosidad y creatividad & 0,79 & 4,43 \\
\hline 3 & El comercio $\mathrm{X}$ intenta estimular mis sentidos & 0,76 & 4,48 \\
\hline 4 & Disfruto comprando en el comercio $\mathrm{X}$ & 0,68 & 4,37 \\
\hline 5 & Los entornos estimulantes me animan a comprar & $0,40 *$ & 4,19 \\
\hline 6 & $\begin{array}{l}\text { La interacción con el producto o servicio hace la compra más } \\
\text { interesante }\end{array}$ & $0,56^{*}$ & 4,20 \\
\hline 7 & El comercio debe estar bien organizado para encontrar lo que quiero & $0,24 *$ & 3,35 \\
\hline \multicolumn{4}{|c|}{ Lealtad de marca con el establecimiento comercial } \\
\hline 1 & A la hora de comprar, el comercio $\mathrm{X}$ es mi primera opción & 0,78 & 9,35 \\
\hline 2 & No voy a otros comercios si lo que busco está en el comercio X & 0,74 & 9,49 \\
\hline 3 & Intentaré seguir comprando en el comercio $\mathrm{X}$ & 0,84 & 9,65 \\
\hline 4 & Animaré a mis parientes y amigos a comprar en el comercio $X$ & 0,66 & 9,02 \\
\hline 5 & En el futuro compraré más en el comercio X que en cualquier otro & 0,75 & 9,24 \\
\hline \multicolumn{4}{|c|}{ Valor de marca (brand equity) del establecimiento comercial } \\
\hline 1 & Prefiero el comercio $\mathrm{X}$ aunque haya otro con similares características & $0,42 *$ & 5,27 \\
\hline 2 & Tengo una actitud más favorable hacia el comercio X que hacia otros & 0,73 & 4,93 \\
\hline 3 & El comercio $\mathrm{X}$ me resulta atractivo & 0,73 & 4,94 \\
\hline 4 & El comercio $\mathrm{X}$ es una marca fuerte & $0,40 *$ & 4,61 \\
\hline
\end{tabular}




\begin{tabular}{|l|l|c|c|}
\hline 5 & El comercio X es visualmente atractivo & 0,68 & 4,91 \\
\hline
\end{tabular}

* Este ítem se elimina de la escala.

Así pues, a la vista de la tabla 6.13, se han eliminado los ítems que se han especificado previamente, por ser sus cargar factoriales inferiores a 0,6 (Bagozzi, 1980; Bagozzi y Yi, 1988; Hair, Black, Babin, Anderson y Tatham, 2006) y la varianza extraída promedio (AVE), inferior a 0,5, siguiendo con las premisas de Fornell y Larcker (1981).

Se recogen en la tabla 6.14 los resultados obtenidos con respecto a la fiabilidad compuesta y a la varianza extraída promedio para las distintas variables consideradas en el estudio.

Tabla 6.14. Análisis de escalas de medida (II)

\begin{tabular}{|l|c|c|}
\hline & $\begin{array}{c}\text { Fiabilidad } \\
\text { compuesta (IFC) }\end{array}$ & $\begin{array}{c}\text { Varianza extraída } \\
\text { promedio (AVE) }\end{array}$ \\
\hline Notoriedad de marca del establecimiento comercial & 0,78 & 0,39 \\
\hline Valor percibido de marca del establecimiento comercial & 0,84 & 0,46 \\
\hline Calidad percibida de marca del establecimiento comercial & 0,81 & 0,48 \\
\hline Imagen de marca del establecimiento comercial & 0,82 & 0,44 \\
\hline Experiencia de compra & 0,81 & 0,40 \\
\hline Lealtad de marca con el establecimiento comercial & 0,87 & 0,57 \\
\hline Valor de marca (brand equity) del establecimiento comercial & 0,74 & 0,37 \\
\hline
\end{tabular}

Después de eliminar los ítems antes comentados de las diferentes escalas, el modelo resultante cumple los requisitos de dimensionalidad, fiabilidad y validez, siendo un 
modelo ajustado., ya que la probabilidad asociada al chi-cuadrado es de 0,08330, superior, por tanto, a 0,05 .

Como se ha apuntado anteriormente, las cargas factoriales superan en todos los casos el 0,6 (Bagozzi, 1980; Bagozzi y Yi, 1988; Hair, Black, Babin, Anderson y Tatham, 2006) mientras que la varianza extraída promedio (AVE), no supera en ningún caso 0,5 (Fornell y Larcker, 1981).

Además, las diferentes variables muestran siempre una fiabilidad compuesta superior a 0,6 (Bagozzi y Yi, 1988).

Una vez depuradas las diferentes escalas, se muestran en la tabla 16.6 los ítems que permanecen en cada una de ellas para las diferentes variables analizadas. Como se puede apreciar, todos los ítems elegidos para las distintas escalas tienen una carga factorial superior a 0,60 y su valor T está por encima de 1,96 en todos los casos.

Así, por lo que respecta a la Notoriedad de marca del establecimiento comercial, son tres los ítems a tener en cuenta. De ellos, el que presenta una carga factorial más alta es el que hace referencia a las características del comercio recordadas por el entrevistado $(0,78)$, seguido del ítem relativo a la facilidad de recuerdo del logotipo $(0,74)$, quedando con una carga factorial de 0,70 el ítem "el comercio X es muy conocido".

Por su parte, en la escala utilizada para el Valor percibido hay cuatro ítems que van a ser considerados. El primero de ellos por su mayor carga factorial es "comprar en el comercio X es una buena opción” con 0,81 . A continuación está el ítem relativo a tener una experiencia de compra positiva en el comercio $(0,76)$, seguido de "en general me siento a gusto con el comercio X”, con una carga factorial de 0,71 . El ítem con una menor carga factorial es el relativo a la relación calidad precio, ya que solo obtiene 0,69.

La Calidad percibida tendrá en cuenta cuatro ítems, siendo el de la confianza de los productos ofrecidos el que mayor carga factorial presenta $(0,77)$. A continuación, con una carga factorial de 0,75 tenemos el ítem que pregunta sobre el servicio ofrecido por el 
comercio, mientras que los dos aspectos con menos carga factorial son "el comercio X ofrece productos de calidad" y "el comercio X es mejor que otros similares", con unas cargas de 0,74 y 0,72 respectivamente.

Son también cuatro ítems los que miden la Imagen de marca del establecimiento comercial. Son dos de ellos los que comparten una carga factorial más baja de 0,69: "me gusta el comercio X" y "el comercio X tiene personalidad". Por la otra parte, el ítem con una carga factorial más elevada $(0,77)$ es "la imagen general del comercio X es muy positiva", seguido con una carga factorial de 0,70 por el ítem "comprar en el comercio $\mathrm{X}$ causa una buena impresión a la gente".

La quinta variable tenida en cuenta es la que hace referencia a la Experiencia de compra. En este caso se han eliminado tres ítems de los siete planteados en un inicio. Así, el que presenta una mayor carga factorial $(0,81)$ es "el comercio X estimula mi curiosidad y creatividad". Por orden de mayor a menor carga factorial se encuentran los siguientes ítems: "el comercio X llama la atención de mis sentidos" $(0,78)$, "el comercio X intenta estimular mis sentidos" $(0,76)$ y, en último lugar, "disfruto comprando en el comercio X", con una carga factorial de 0,66 .

En el caso de la Lealtad de marca con el establecimiento comercial, nos encontramos con la única variable en la que se han mantenido los cinco ítems propuestos de inicio, es decir, no ha habido que descartar ninguno de ellos. El de mayor carga factorial, con 0,83 es "intentaré seguir comprando en el comercio X". A continuación, el ítem relativo al comercio como primera opción de compra obtiene una carga factorial de 0,78. El tercer ítem con mejor carga factorial es "en el futuro compraré más en el comercio X que en cualquier otro" $(0,75)$. Por último, aparece el ítem "no voy a otros comercios si lo que busco está en el comercio X" $(0,74)$ y "animaré a mis parientes y amigos a comprar en el comercio X" $(0,67)$.

En último lugar, a la hora de hablar del Valor de marca del establecimiento comercial, se han eliminado dos ítems, quedando, por orden de importancia en base a su carga factorial, los siguientes: "tengo una actitud más favorable hacia el comercio X que 
hacia otros" $(0,73)$, "el comercio X me resulta atractivo" $(0,72)$ y "el comercio X es visualmente atractivo" $(0,70)$.

Tabla 6.15. Análisis de escalas de medida (III)

\begin{tabular}{|c|c|c|}
\hline Factores e ítems (tras depuración) & $\begin{array}{l}\text { Cargas } \\
\text { factoriales }\end{array}$ & $\mathbf{T}$ \\
\hline \multicolumn{3}{|l|}{ Notoriedad de marca del establecimiento comercial } \\
\hline Algunas características del comercio $\mathrm{X}$ me vienen a la mente rápidamente & 0,78 & 5,13 \\
\hline Puedo recordar fácilmente el logotipo del comercio $\mathrm{X}$ & 0,74 & 6,42 \\
\hline El comercio $\mathrm{X}$ es muy conocido & 0,70 & 6,04 \\
\hline \multicolumn{3}{|l|}{ Valor percibido de marca del establecimiento comercial } \\
\hline En general me siento a gusto con el comercio $\mathrm{X}$ & 0,71 & 4,91 \\
\hline La relación calidad precio del comercio $\mathrm{X}$ es buena & 0,69 & 4,79 \\
\hline Comprar en el comercio $\mathrm{X}$ es una buena opción & 0,81 & 4,96 \\
\hline En general, la experiencia de compra en el comercio $\mathrm{X}$ ha sido positiva & 0,76 & 4,94 \\
\hline \multicolumn{3}{|l|}{ Calidad percibida de marca del establecimiento comercial } \\
\hline El comercio X ofrece productos de calidad & 0,74 & 20,66 \\
\hline El servicio del comercio $\mathrm{X}$ es de lo mejor que hay & 0,75 & 21,60 \\
\hline El comercio X es mejor que otros similares & 0,72 & 19,08 \\
\hline El comercio $X$ ofrece productos de confianza & 0,77 & 21,77 \\
\hline \multicolumn{3}{|l|}{ Imagen de marca del establecimiento comercial } \\
\hline Me gusta el comercio $X$ & 0,69 & 9,04 \\
\hline El comercio $\mathrm{X}$ tiene personalidad & 0,69 & 9,39 \\
\hline Comprar en el comercio X causa buena impresión en la gente & 0,70 & 9,58 \\
\hline
\end{tabular}




\begin{tabular}{|l|c|c|}
\hline La imagen general del comercio X es muy positiva & 0,77 & 9,49 \\
\hline Experiencia de compra & 0,78 & 22,51 \\
\hline El comercio X llama la atención de mis sentidos & 0,81 & 20,67 \\
\hline El comercio X estimula mi curiosidad y creatividad & 0,76 & 14,36 \\
\hline El comercio X intenta estimular mis sentidos & 0,66 & 19,72 \\
\hline Disfruto comprando en el comercio X & & \\
\hline Lealtad de marca con el establecimiento comercial & 0,78 & 13,11 \\
\hline A la hora de comprar, el comercio X es mi primera opción & 0,74 & 13,20 \\
\hline No voy a otros comercios si lo que busco está en el comercio X & 0,83 & 13,11 \\
\hline Intentaré seguir comprando en el comercio X & 0,67 & 11,80 \\
\hline Animaré a mis parientes y amigos a comprar en el comercio X & 0,75 & 13,16 \\
\hline En el futuro compraré más en el comercio X que en cualquier otro & 0,73 & 8,47 \\
\hline Valor de marca (brand equity) del establecimiento comercial & 0,70 & 7,55 \\
\hline Tengo una actitud más favorable hacia el comercio X que hacia otros & & \\
\hline El comercio X me resulta atractivo & & \\
\hline El comercio X es visualmente atractivo & & \\
\hline \multicolumn{1}{|c|}{ Ajuste del modelo } & 0,$995 ; \mathrm{NNFI}=0,994$ \\
\hline
\end{tabular}

Una vez depurados los ítems, se recogen en la tabla 6.16 los resultados obtenidos con respecto a la fiabilidad compuesta y a la varianza extraída promedio para las distintas variables consideradas en el estudio, en base a los ítems definitivos seleccionados. 
Tabla 6.16. Análisis de escalas de medida (IV)

\begin{tabular}{|l|c|c|}
\hline & $\begin{array}{c}\text { Fiabilidad } \\
\text { compuesta } \\
\text { (IFC) }\end{array}$ & $\begin{array}{c}\text { Varianza } \\
\text { extraída } \\
\text { promedio } \\
\text { (AVE) }\end{array}$ \\
\hline Notoriedad de marca del establecimiento comercial & 0,78 & 0,55 \\
\hline Valor percibido de marca del establecimiento comercial & 0,83 & 0,55 \\
\hline Calidad percibida de marca del establecimiento comercial & 0,84 & 0,56 \\
\hline Imagen de marca del establecimiento comercial & 0,81 & 0,51 \\
\hline Experiencia de compra & 0,84 & 0,57 \\
\hline Lealtad de marca con el establecimiento comercial & 0,87 & 0,57 \\
\hline Valor de marca (brand equity) del establecimiento comercial & 0,76 & 0,51 \\
\hline
\end{tabular}

A continuación, en la tabla 6.17 se recogen los resultados relativos a la validez discriminante de los constructos que forman parte del modelo, evaluado a través de la varianza extraída promedio (AVE), según Fornell y Larcker (1981). Se debe tener en cuenta que un constructo deberá compartir más varianza con sus indicadores que con el resto de otros constructos incluidos en el modelo, lo que se dará cuando la raíz cuadrada de la varianza extraída promedio entre cada par de factores, sea superior a la correlación estimada entre esos factores. Se aprecia en la siguiente tabla como se dan estas condiciones, por lo que se puede ratificar su validez discriminante. 
Tabla 6.17. Análisis de escalas de medida (V)

\begin{tabular}{|c|c|c|c|c|c|c|c|}
\hline & Notoriedad & Valor percibido & Calidad percibida & Imagen & Experiencia & Lealtad & Valor de marca \\
\hline Notoriedad & $\mathbf{0 , 7 4}$ & & & & & & \\
\hline Valor percibido & 0,43 & $\mathbf{0 , 7 4}$ & & & & & \\
\hline Calidad percibida & 0,31 & 0,62 & $\mathbf{0 , 7 5}$ & & & \\
\hline Imagen & 0,47 & 0,57 & 0,68 & $\mathbf{0 , 7 1}$ & & \\
\hline Experiencia & 0,30 & 0,49 & 0,51 & 0,67 & $\mathbf{0 , 7 5}$ & \\
\hline Lealtad & 0,24 & 0,57 & 0,63 & 0,63 & 0,57 & $\mathbf{0 , 7 6}$ \\
\hline Valor de marca & 0,46 & 0,64 & 0,64 & 0,62 & 0,62 \\
\hline
\end{tabular}




\subsection{Análisis del modelo estructural}

Habiéndose estimado el modelo de medición en el apartado anterior y en función del enfoque de Anderson y Gerbing (1988) de dos etapas, se continuará en el presente epígrafe con la estimación del modelo estructural, mediante el análisis path con variables latentes (Jöreskog y Sörbom, 1996), utilizado para contrastar las hipótesis teóricas planteadas en la primera parte de la presente tesis.

El ajuste del modelo I es adecuado puesto que la probabilidad asociada al chicuadrado es 0,07432 , siendo, por tanto, superior a 0,05 .

Se recogen a continuación en la figura 6.1 los resultados del modelo estructural. 
Figura 6.1. Contraste Modelo I

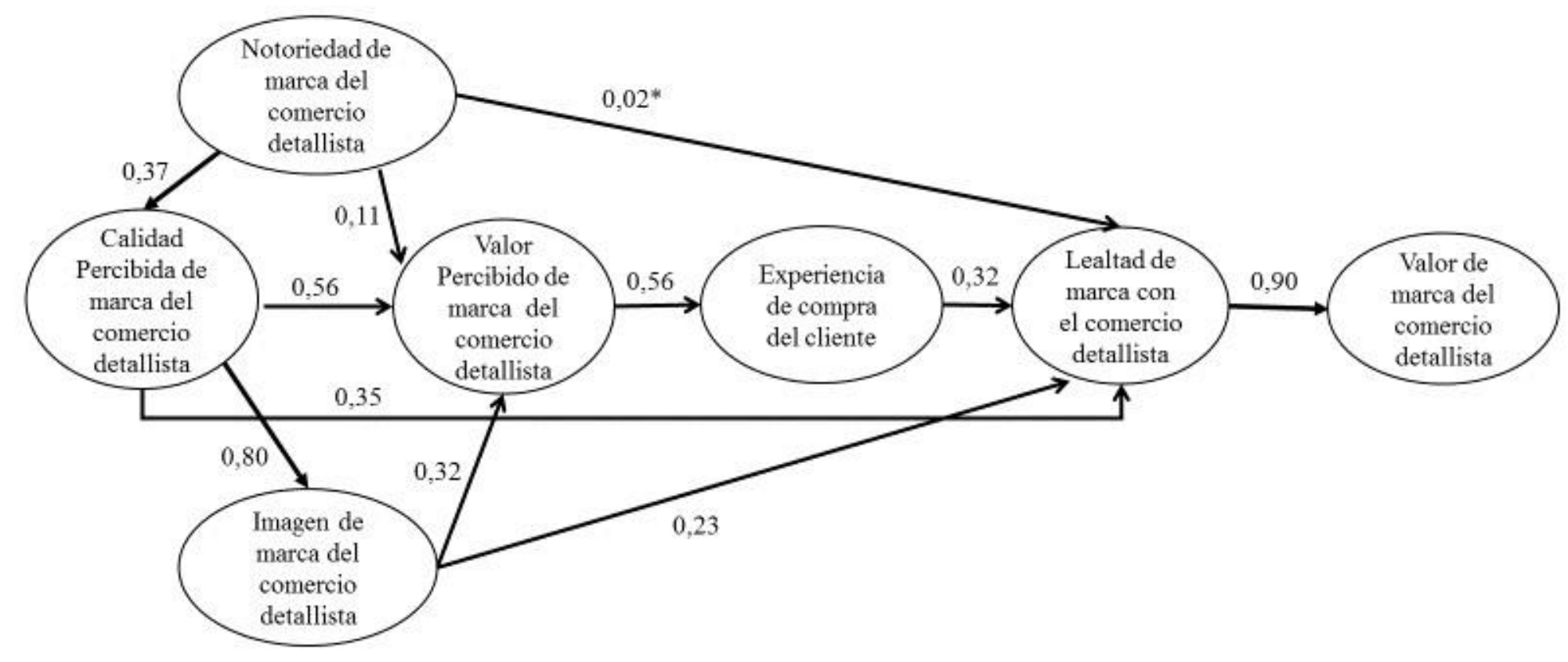

*Relaciones causales no significativas $(\mathrm{T}<1,96)$.

Ajuste del modelo: Chi-cuadrado=341,3643; gl=305; $\mathrm{P}=0,07432 ; \mathrm{RMSEA}=0,015 ; \mathrm{CFI}=0,994 ; \mathrm{NNFI}=0,993$ 
En los apartados que se presentan a continuación se analizarán los efectos de las variables que conforman este modelo.

\subsubsection{Calidad percibida de marca y Valor percibido de marca del establecimiento comercial}

La primera hipótesis planteada en la presente tesis relaciona la influencia de la calidad percibida de marca del comercio detallista sobre el valor percibido de marca del mismo.

A la vista de los resultados, la calidad percibida de marca del establecimiento comercial ejerce un efecto significativo y positivo sobre el valor percibido de marca del comercio detallista, tomando un valor de 0,56. Esto ratifica que la primera de las hipótesis planteadas en el presente trabajo sí que se cumple para el comercio detallista, en la línea de lo que ocurre en otros sectores, tal y como apuntaban los estudios de Sweeney y Soutar (2001) cuando hablan de la marca en general o Boo et al. (2008) y Liu et al. (2005) en sus aplicaciones a diversos sectores.

Esto es importante en el sentido de que, tal y como apuntan Burt y Sparks (2002) y Rondan (2006), una de los factores de éxito del comercio minorista radica en su calidad percibida, ya que ésta conduce a su diferenciación. Como señalan Low y Lamb (2000), la calidad percibida es fundamental para la teoría de que marcas fuertes aportan valor a las compras de los consumidores.

Así, se puede decir que existe una tendencia hacia el aumento de la calidad percibida de la marca del comercio minorista en numerosos países, debido a su cada vez mayor importancia (Huang y Huddleston, 2009). 


\subsubsection{Calidad percibida de marca y Lealtad de marca del establecimiento comercial}

La segunda relación planteada en las hipótesis de trabajo analiza la influencia que la calidad percibida de marca del establecimiento detallista tiene sobre la lealtad del cliente hacia el mismo.

Ya en 1994 Parasuraman et al. apuntaban que una percepción superior de calidad de una marca animaba a la repetición de compras de la misma. Por su parte, Johnson et al. (2007) señalan que la calidad percibida que el consumidor tiene con respecto a una marca ejerce una influencia positiva sobre su lealtad hacia ella.

En lo que respecta al comercio detallista, Nies y Natter (2012) señalan que la calidad percibida por los clientes con respecto a las marcas del distribuidor está muy unida a la lealtad hacia estas marcas. Así, si la evaluación realizada por el cliente es positiva, podrá incluso tener la fuerza suficiente como para decidir la elección de la tienda. Como señalan Ares et al. (2010), la calidad percibida se encuentra entre los factores más importantes en la toma de decisiones por parte del consumidor.

Los efectos de la calidad percibida de marca del comercio detallista sobre la lealtad del consumidor hacia el mismo toman un valor de 0,35 , con lo cual se cumple la segunda hipótesis de trabajo planteada en el estudio, ratificándose así en el ámbito de marca del comercio minorista los planteamientos que autores como Yoo et al. (2000), Saleem et al. (2015) o Cai et al. (2015) apuntan en distintos sectores.

\subsubsection{Calidad percibida de marca e Imagen de marca del establecimiento comercial}

La tercera de las hipótesis planteadas es la que relaciona la calidad percibida de marca del establecimiento comercial con su imagen. A la vista de los resultados podemos confirmar que en el ámbito del comercio detallista la calidad percibida de su marca por 
parte del consumidor ejerce una influencia positiva sobre la imagen de marca del establecimiento, puesto que ofrece un valor de 0,80. Es esta la segunda de las relaciones más fuertes de las que resultan en el modelo planteado en primer lugar.

Este resultado viene a confirmar que para el ámbito del comercio detallista también se cumple el hecho ya observado en otros sectores por Keller (1993) y Chen y Tseng (2010), en el sentido de que cuando los consumidores realizan una buena evaluación de la calidad percibida, también se forman una mejor imagen de la marca, ya que el consumidor que es conocedor de la buena calidad de un producto, se forma una mejor imagen de la marca.

\subsubsection{Valor percibido de marca y experiencia de compra del cliente}

Tal y como señala Tena (2016) el valor percibido por el consumidor es una variable en continua exploración y análisis que está siendo estudiada desde nuevas perspectivas y ámbitos de aplicación.

El valor percibido por el consumidor es una variable cognitiva y experiencial, ya que se basa en apreciaciones realizadas por el individuo del rendimiento que ha tenido el producto o servicio comprado (Fandos, 2010).

Si bien hay estudios que relacionan la experiencia del cliente con la lealtad, tal y como hemos visto en el punto 3 de la tesis, son menos los que relacionan el resto de variables que conforman el Valor de Marca con la experiencia. En este sentido, el primero de los modelos propuestos en esta tesis relaciona el valor percibido de la marca del establecimiento comercial con la experiencia de compra que el consumidor pueda tener en el mismo. 
Los resultados de la investigación señalan una influencia importante del valor percibido de la marca sobre la experiencia de compra del cliente $(0,56)$, situándose la misma como la cuarta más fuerte de las analizadas en el modelo.

\subsubsection{Notoriedad de marca y Calidad percibida de marca del establecimiento comercial}

La capacidad que tenga una marca para estar presente en la mente de un cliente o potencial cliente es un factor estratégico de primer grado en el marketing (Keller, 1993; Lee y Back, 2007). Aplicado al ámbito del comercio detallista, la notoriedad vendrá dada, según Hartman y Spiro (2005), por la capacidad del consumidor de reconocer y recordar el nombre del establecimiento.

En ámbitos distintos al del comercio detallista autores como Liu et al. (2015) en su análisis del Valor de marca señalan que la notoriedad influye en la calidad percibida. Esto se ve reflejado también para el caso del establecimiento comercial, ya que en la hipótesis planteada se obtiene un valor de 0,37 que nos indica que la notoriedad de marca del establecimiento afecta de manera positiva a la calidad percibida del mismo.

\subsubsection{Notoriedad de marca y Valor percibido de marca del establecimiento comercial}

En la sexta hipótesis de la tesis se analiza la influencia que la notoriedad de marca del comercio detallista ejerce sobre el valor percibido de marca del mismo.

En función de los resultados obtenidos cabe señalar que la notoriedad influye sobre el valor percibido de marca del establecimiento comercial $(0,11)$, si bien es la segunda relación que menor puntuación obtiene en el primer modelo, siendo la última de ellas la 
que relaciona la notoriedad con la lealtad de marca del establecimiento comercial, tal y como se verá en a continuación.

Así, la relación obtenida en esta hipótesis sexta ratifica que la notoriedad de marca tiene un claro reflejo en el valor percibido por el cliente (Kim et al; 2008; O’Neill y Xiao, 2006), si bien no es tan fuerte su influencia como el resto de las analizadas en el modelo.

\subsubsection{Notoriedad de marca y Lealtad de marca del establecimiento comercial}

Como se ha adelantado en el punto anterior, en lo que se refiere a la notoriedad de marca del comercio detallista, los resultados obtenidos indican que la influencia que ésta ejerce sobre la lealtad de marca no es significativa $(0,02)$, con lo que no se cumple la hipótesis H7a.

Este resultado en el ámbito del comercio minorista difiere de los obtenidos en los estudios de Macdonald y Sharp (2000) y de Saleem et al. (2015), el primero de ellos relativo a productos de consumo y el segundo, más concretamente, al ámbito de los refrescos.

\subsubsection{Imagen de marca y Valor percibido de marca del establecimiento comercial}

Como señalan diversos autores (Nyadzay y Khajehzadeh, 2016; Wang y Yang, 2010), a pesar de la importancia que la imagen de marca tiene en la lealtad del cliente, es una variable que no ha recibido mucha atención en la literatura. Como señalan Moreno et al. (2013), "la gestión adecuada de la imagen del comercio minorista permitirá influir en la consecución de resultados, tales como el aumento de sus ventas, o la lealtad de sus clientes, que se traducirá en mayor rentabilidad para el comercio". 
Los resultados del presente análisis muestran como, en el caso del comercio detallista, la imagen de marca del mismo ejerce una influencia positiva en el valor percibido del comercio.

Esto es importante, puesto que, como indican Deepra y Chitramani (2013), la imagen y el valor percibido de las marcas de los comercios minoristas dependerán, en parte, de las marcas que comercialicen, así como del valor de las mismas.

\subsubsection{Imagen de marca y Lealtad de marca del establecimiento comercial}

Osman (1993) ya planteó que la imagen percibida del establecimiento por parte de los clientes es determinante en la formación de la lealtad de los mismos. Estudios más recientes determinan que la imagen de marca es un componente fundamental en la formación de la lealtad de marca (Hosany et al., 2006; Jara y Cliquet, 2012). Así, la imagen de marca juega un papel crítico a la hora de ayudar a los clientes a decidir si compran o no una determinada marca $y$, en consecuencia, influencia también en su comportamiento de recompra (Bian y Moutinho, 2011).

En esta línea, aplicando los conceptos al ámbito minorista, los resultados obtenidos indican que la imagen de marca del establecimiento comercial afecta positivamente a la lealtad de marca del consumidor hacia el detallista $(0,23)$, quedando así confirmada la hipótesis de trabajo H9a.

\subsubsection{Experiencia de compra y Lealtad de marca del establecimiento comercial}

Como se apuntó en el punto 3 de este trabajo, cuando se habla de comercio detallista, el creciente número de alternativas de productos y establecimientos comerciales, así como la competencia por incrementar la cuota de mercado, requiere que los gestores de 
los establecimientos se preocupen por la lealtad hacia su marca (Huusik, 2011). En este sentido, se destacaban como determinantes a la hora de establecer la lealtad, las experiencias anteriores que el consumidor hubiese tenido en su relación con el comercio con el comercio detallista.

En general, los trabajos que estudian el Valor de Marca no suelen tener en cuenta la experiencia como variable que pueda contribuir a su formación. Ahora bien, los consumidores utilizan sus visitas a los comercios no solo para comprar, sino también con el propósito de disfrutar y entretenerse, evaluando el servicio en términos de cuánto placer o diversión han recibido (Srivastava y Kaul, 2016).

Actualmente, las propiedades y beneficios de lo ofertado, pese a ser necesarios, ya no son suficientes para incentivar la compra, pues la calidad y la innovación en éstos se sobreentiende. En consecuencia, hay necesidad de ofrecer productos atractivos o satisfactorios y que además tengan un valor adicional basado en aspectos emocionales y vivenciales (Caridad et al., 2015).

En la presente tesis se analiza el papel que juega la experiencia del cliente en la formación del Valor de Marca (brand equity) del comercio detallista. Farquhar (1989) planteaba un modelo teórico para construir una marca con alto valor, basado en tres etapas: introducción, elaboración y fortificación. Así, en la última de estas etapas, es decir, en la fortificación de la marca, este autor considera que las variables básicas a tener en cuenta son las experiencias y los vínculos emocionales y cognitivos entre la empresa y el consumidor.

Como se desprende de los diferentes estudios que se analizado en la parte teórica del presente trabajo, la experiencia del cliente ha sido analizada desde diversos puntos de vista, principalmente en su relación con la creación de lealtad del cliente hacia la marca. $\mathrm{Si}$ bien la literatura que analiza esta relación es amplia a niveles de marca en general, su aplicación al ámbito del comercio detallista es mucho más reducida. 
El resultado de la hipótesis planteada entre estas dos variables es positivo $(0,32)$, con lo que realmente la experiencia que el consumidor haya tenido en un comercio afectará positivamente a la lealtad que pueda tener hacia el mismo. Se ratifica, por tanto, la importancia que puede tener para los gestores comerciales el ofrecimiento de experiencias de compra adecuadas a las características y necesidades de sus clientes.

\subsubsection{Lealtad de marca y Valor de marca del establecimiento comercial}

Por último, se plantea en el modelo la relación entre la lealtad hacia la marca del comercio detallista y el Valor de Marca del mismo. Desde Aakker (1991) hasta estudios más recientes (Cai et al., 2015), consideran que la lealtad de marca es una de las dimensiones clave del Valor de Marca.

Teniendo esto en cuenta, a la vista de dichos estudios, podemos pensar que existe una relación positiva entre la lealtad hacia el establecimiento comercial y el Valor de Marca del mismo, tal y como se plantea en la hipótesis H11 de esta tesis.

La relación positiva queda confirmada, puesto que el valor obtenido es de 0,90, siendo el más alto de todas las relaciones establecidas en el modelo. Así pues, se puede decir que la lealtad de marca tiene un efecto positivo en la creación de Valor de Marca del comercio detallista.

Tras haber comentado en los apartados anteriores las relaciones causales entre las variables que conforman las distintas hipótesis de trabajo, en la tabla 6.18 se resumen y se muestra el resultado del modelo estructural. 
Tabla 6.18. Relaciones causales y contrastes de hipótesis modelo I

\begin{tabular}{lccc}
\hline \multicolumn{1}{c}{ Relaciones causales } & $\begin{array}{c}\text { Valor } \\
\text { relación }\end{array}$ & T & Hipótesis \\
\hline Calidad Percibida $\rightarrow$ Valor Percibido & 0,56 & 6,20 & H1 $\square$ \\
\hline Calidad Percibida $\rightarrow$ Lealtad & 0,35 & 3,77 & H2a $\square$ \\
\hline Calidad Percibida $\rightarrow$ Imagen de marca & 0,80 & 11,94 & H3 $\square$ \\
\hline Valor Percibido $\rightarrow$ Experiencia del cliente & 0,56 & 10,93 & H4a $\square$ \\
\hline Notoriedad $\rightarrow$ Calidad Percibida & 0,37 & 7,06 & H5 $\square$ \\
\hline Notoriedad $\rightarrow$ Valor Percibido & 0,11 & 2,36 & H6 $\square$ \\
\hline Notoriedad $\rightarrow$ Lealtad & 0,02 & $0,49 *$ & H7a $\square$ \\
\hline Imagen de marca $\rightarrow$ Valor Percibido & 0,32 & 3,97 & H8 $\square$ \\
\hline Imagen de marca $\rightarrow$ Lealtad & 0,23 & 2,78 & H9a $\square$ \\
\hline Experiencia del cliente $\rightarrow$ Lealtad & 0,32 & 7,05 & H10 $\square$ \\
\hline Lealtad $\rightarrow$ Valor de marca & 0,90 & 18,88 & H11 $\square$ \\
\hline
\end{tabular}

*Relaciones causales no significativas $(\mathrm{T}<1,96)$.

\subsubsection{Modelo alternativo}

El modelo alternativo se propone como una variación al anterior en cuanto a la experiencia se refiere. Como se ha indicado en diversos puntos de la presente tesis, a la hora de estudiar el Valor de Marca, los trabajos sobre este concepto no han tenido en cuenta la variable de la experiencia.

Para competir con efectividad, las empresas deben centrarse en las experiencias de compra de los consumidores (Srivastava, 2016). Además, Srivastava y Kaul (2016) indican que es importante entender que el proceso de creación de experiencias para el consumidor 
por parte del comercio detallista está compuesto a partir de los diferentes puntos de contacto del consumidor con el comercio a lo largo del proceso de intercambio.

Los resultados obtenidos en el primero de los modelos propuestos están en la línea de los trabajos de diversos autores, tales como Manning y Dorsey, (2008), para quienes el desarrollo de experiencias de compra excelentes tiene una influencia directa en las respuestas de los consumidores, generando mayor lealtad.

En el modelo alternativo se propone la influencia de la lealtad de marca del comercio detallista sobre la experiencia del cliente. El resultado es muy similar al del primer modelo, ya que, en aquel, la experiencia en su influencia sobre la lealtad tenía un valor de 0,32 que coincide con la influencia que la lealtad tiene sobre la experiencia, que es lo que se propone en el modelo alternativo.

Ahora bien, así como en el primer modelo propuesto, la notoriedad de marca del comercio detallista no tenía significación en su relación sobre la lealtad de marca del minorista $(0,02)$, en el modelo alternativo la notoriedad de marca no tiene significación con respecto a la experiencia del cliente $(0,01)$, pero tampoco la tiene la calidad percibida de marca del comercio con respecto a la experiencia de compra del cliente en el mismo $(0,01)$.

Por otra parte, cuando se considera la lealtad de marca hacia el comercio como antecedente de la experiencia de compra (como sucede en el modelo alternativo), la influencia de esta última sobre el Valor de Marca del comercio es algo más baja $(0,85)$ que la influencia que tiene la lealtad sobre el Valor de Marca cuando se considera la experiencia de compra de manera previa a la lealtad hacia el establecimiento, tal y como se plantea en el primero de los modelos.

Esto se une al hecho de que el primer modelo propuesto presenta un ajuste adecuado, ya que la probabilidad asociada al chi-cuadrado es de 0,07435, superior, por tanto, a 0,05, cosa que no ocurre con el modelo alternativo.

En la figura 6.2 se recogen los resultados del modelo alternativo planteado en la tesis. 
Figura 6.2. Contraste modelo II

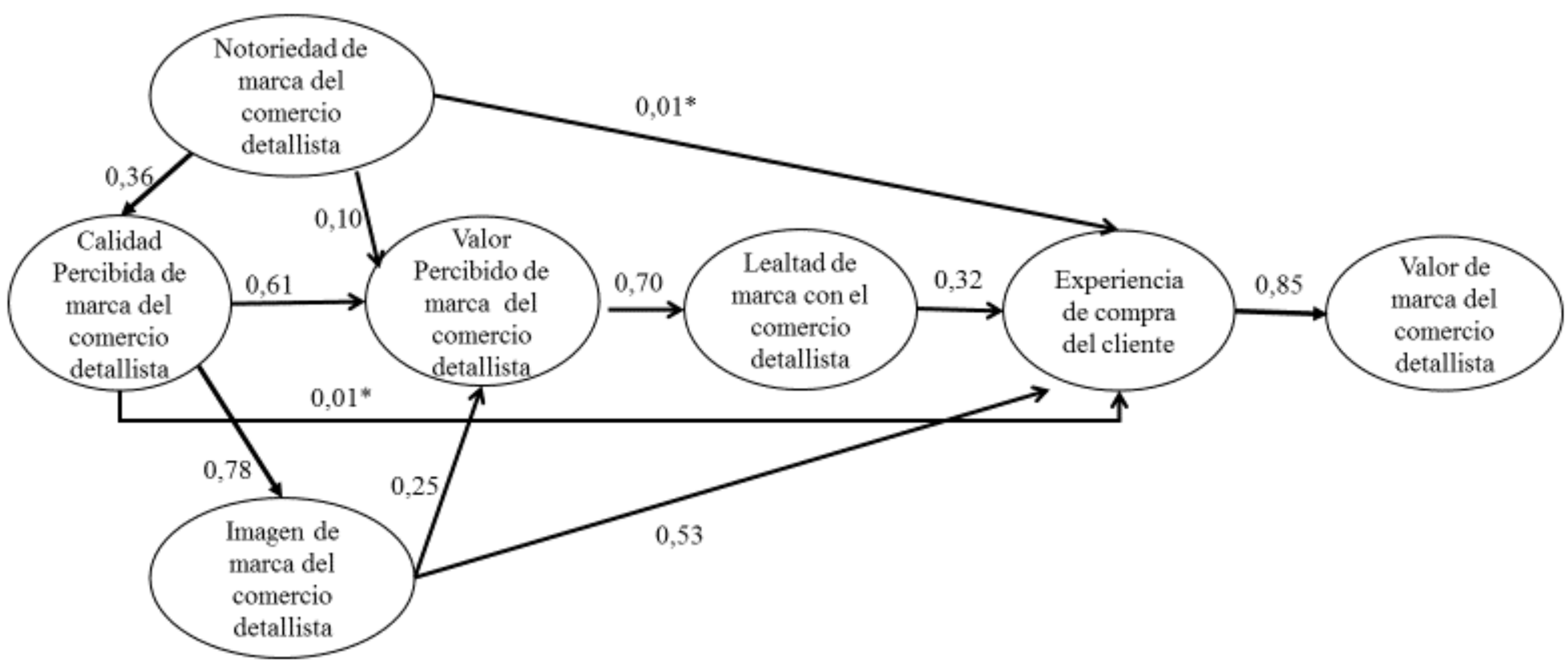

*Relaciones causales no significativas $(\mathrm{T}<1,96)$.

Ajuste del modelo: Chi-cuadrado=682.9447; $\mathrm{gl}=305 ; \mathrm{P}=0,00000 ; \mathrm{RMSEA}=0,045 ; \mathrm{GFI}=0,944 ; \mathrm{AGFI}=0,935$ 
Se resumen en la tabla 6.19 las relaciones causales entre las variables contempladas en el modelo alternativo.

Tabla 6.19. Relaciones causales y contrastes de hipótesis modelo II

\begin{tabular}{llll}
\hline \multicolumn{1}{c}{ Relaciones Causales } & $\begin{array}{c}\text { Valor } \\
\text { relación }\end{array}$ & T & Hipótesis \\
\hline Calidad Percibida $\rightarrow$ Valor Percibido & 0,61 & 6,85 & H1 $\square$ \\
\hline Calidad Percibida $\rightarrow$ Experiencia del cliente & 0,01 & $0,11^{*}$ & H2b ■ \\
\hline Calidad Percibida $\rightarrow$ Imagen de marca & 0,78 & 11,65 & H3 $\square$ \\
\hline Valor Percibido $\rightarrow$ Lealtad & 0,70 & 13,95 & H4b $\square$ \\
\hline Notoriedad $\rightarrow$ Calidad Percibida & 0,36 & 7,05 & H5 $\square$ \\
\hline Notoriedad $\rightarrow$ Valor Percibido & 0,10 & 2,10 & H6 $\square$ \\
\hline Notoriedad $\rightarrow$ Experiencia del cliente & 0,01 & $0,11^{*}$ & H7b $\boldsymbol{~}$ \\
\hline Imagen de marca $\rightarrow$ Valor Percibido & 0,25 & 3,35 & H8 $\square$ \\
\hline Imagen de marca $\rightarrow$ Experiencia del cliente & 0,53 & 8,28 & H9b $\square$ \\
\hline Lealtad $\rightarrow$ Experiencia del cliente & 0,32 & 6,53 & H12 $\square$ \\
\hline Experiencia del cliente $\rightarrow$ Valor de marca & 0,85 & 16,64 & H13 $\square$ \\
\hline
\end{tabular}

*Relaciones causales no significativas $(\mathrm{T}<1,96)$. 


\section{7 - CONCLUSIONES, LIMITACIONES Y FUTURAS LÍNEAS DE INVESTIGACIÓN}





\section{CONCLUSIONES, LIMITACIONES Y FUTURAS LÍNEAS DE INVESTIGACIÓN}

Se procederá a exponer en este capítulo las principales aportaciones con las que la presente tesis pretende contribuir a la literatura sobre el Valor de Marca del comercio detallista, tanto por lo que se refiere al aspecto teórico como al empírico.

Se estructurará esta parte del trabajo en tres bloques, estando el primero de ellos dirigido a exponer las conclusiones generales que se derivan del estudio realizado, mientras que el segundo de ellos hará referencia a la aplicación que puede derivarse para el gestor del comercio detallista, estando el tercero enfocado a describir las limitaciones encontradas a lo largo del trabajo, así como a mostrar las principales líneas de investigación que se pretenden llevar a cabo en el futuro, tomando como base la tesis.

\subsection{Conclusiones}

En un entorno en el que cada vez son más los competidores y en el que el consumidor tiene más fácil acceso a la información, se hace necesario para el comercio minorista tener una estrategia lo suficientemente clara y adecuada que le permita sobrevivir.

La presente tesis se planteó como punto de partida el estudio del Valor de Marca del comercio detallista, ya que, como señalan Swoboda et al. (2016), la literatura, si bien ha dedicado frecuentes estudios a aspectos como los atributos del comercio detallista o incluso a su imagen (Mazursky y Jacoby, 1986; Pan y Zinkhan, 2006), no ha dedicado tanto esfuerzo al estudio del Valor de Marca del comercio detallista (Beristain y Zorrilla, 2011; Yoo et al., 2000). 
Ruiz et al. (2013) consideran el capital de marca de la tienda como un claro elemento diferenciador de la misma. Estos autores también reconocen que, a pesar de la importancia del concepto, es escasa la investigación acerca de su dimensionalidad y de su influencia sobre las intenciones conductuales del consumidor.

Por otra parte, también se ha tenido en cuenta la experiencia de compra del consumidor, ya que ésta, como se apuntó en el desarrollo teórico, no ha sido considerada con amplitud por la literatura relativa al Valor de Marca. En este sentido, Ambler et al. (2002) argumentan que el Valor de Marca representa la mentalidad o la actitud del consumidor con respecto a una marca, incluyendo percepciones, pensamientos, experiencias, imágenes, etcétera.

Así, se ha analizado a lo largo de esta tesis la situación actual del comercio detallista, teniendo en cuenta las diversas tipologías y las tendencias observadas en su desarrollo. En este punto, cobran especial importancia las tecnologías de la información y comunicación, ya que son un aspecto importante a la hora de diseñar los distintos canales y puntos de contacto del comercio detallista con el consumidor. No solo esto, sino que, además, estas tecnologías permitirán el desarrollo de mayores y mejores experiencias de compra para el cliente, no solo en el espacio físico de venta, sino también en el medio online.

Dentro del comercio minorista se encuentran englobados diferentes formatos que van desde las grandes corporaciones globales que actúan en prácticamente todo el mundo hasta las más pequeñas y tradicionales tiendas de barrios, desde grandes hipermercados en centros comerciales hasta tiendas más reducidas ubicadas en el centro de las ciudades, pasando por el modelo de tiendas franquiciadas, etcétera. Se da, por tanto, una diversidad muy amplia en la que los actores participantes deben ser capaces de encontrar su sitio en el mercado para poder competir con garantías de éxito.

La venta al detalle o venta al por menor (retailing) comprende, según Armstrong et al. (2011), todas las actividades de venta de productos y servicios directamente al consumidor final para su uso personal. Esto origina distintas controversias, como, por 
ejemplo, el continuo debate sobre si los grandes distribuidores acabarán con el pequeño comercio o incluso si esto supondrá la decadencia de los centros de las ciudades en los que se suelen ubicar estos pequeños minoristas (Fernie et al., 2003).

Además, la aparición de las nuevas tecnologías de la información y la comunicación ha supuesto un importante cambio en la comercialización de productos y servicios. Todo esto, como es lógico, ha afectado de manera notable al comercio detallista, y más especialmente al de carácter más tradicional (Ramakrishnan, 2010; Praharsi et al., 2014).

Como señalan Juaneda-Ayensa et al. (2016) las nuevas tecnologías han transformado el entorno competitivo del comercio minorista, ya que continuamente están emergiendo nuevos canales, haciendo que el consumidor cambie sus hábitos y su comportamiento de compra. De esta manera, la evolución de los medios interactivos hace que el proceso de compra sea más complejo (Crittenden et al., 2010; Medrano et al. 2016; Anderl et al, 2016b).

La incorporación del canal móvil, tabletas, redes sociales y la integración de estos nuevos canales y dispositivos en el comercio minorista, tanto online como offline, ha supuesto profundos cambios en el comportamiento del consumidor (Verhoef et al., 2015).

La aparición de los escaparates y probadores virtuales, terminales interactivos en el punto de venta, menús dinámicos de información o terminales que permitan hacer el pedido para recogerlo en ese mismo instante o con posterioridad, así como códigos QR (Quick Response) que a través de los dispositivos móviles de los usuarios permiten la interacción de la tienda con ellos (Fundación Telefónica, 2016) o innovaciones como las gafas que permiten la visión en tres dimensiones o las impresoras 3D todavía llevan más allá la evolución del entorno minorista (Piotrowicz y Cuthbertson, 2014).

Como se observa, las nuevas tecnologías contribuyen al desarrollo de nuevas experiencias de compra para el consumidor, tanto en Internet como en el propio punto de 
venta físico. Es por ello que se ha dedicado un apartado del trabajo al análisis de estas tecnologías y de su impacto sobre el comercio detallista y sobre la evolución del mismo.

En el entorno actual se pueden encontrar empresas que únicamente tienen presencia física, otras únicamente operando en Internet, otras que combinan la presencia física con el canal online, etcétera, hasta las últimas tendencias que hablan no ya de empresas multicanal, sino de empresas omnicanal, es decir, presentes en todos los canales disponibles (Massimo et al, 2013; Herhausen et al., 2015; Verhoeff et al., 2015).

Herhausen et al. (2015) apuntan que la integración de canales ayuda a una mayor percepción de la calidad del servicio prestado en el medio online; la integración es un factor que puede contribuir a mejorar las percepciones del cliente y a aceptar mayores precios en distintos canales.

Cao y Li (2015) confirman que las empresas capaces de coordinar de mejor manera los diferentes canales mejorarán la confianza del consumidor, incrementarán su lealtad y su ratio de conversión y crearán más oportunidades para hacer venta cruzada.

Por lo que hace referencia al incremento de la lealtad del consumidor, la multiplicidad implica que el comercio puede ofrecer más servicios que aporten valor a sus clientes, lo que mejora su percepción, actitud, satisfacción y lealtad hacia la empresa (Berry et al., 2010). Con esto, tal y como indican Avery et al. (2012) los consumidores recompensan al detallista comprando más y concentrando sus compras en él.

En el ámbito de estudio de la presente tesis, es decir, el comercio detallista, la correcta gestión de la marca puede conllevar unos beneficios importantes, puesto que ayudará a diferenciar a un comercio con respecto a su competencia. Si bien en ciertos ámbitos del comercio detallista sí que es está prestando esta necesaria atención a la gestión de marca (cadenas de distribución de alimentación y de textil, franquicias de múltiples sectores, etcétera) en el comercio tradicional no es tan frecuente la realización de acciones encaminadas al desarrollo de la marca. 
Ante esto, dado el impacto potencial que la marca puede tener en los consumidores, uno de los objetivos generales más importantes para las empresas debería ser el incremento de su Valor de Marca (Castelo et al., 2012).

En el ámbito del comercio minorista, como señalan Grewal y Levy (2007) sólo un pequeño número de artículos que analizan este sector se centran en el branding o gestión de marca del comercio minorista.

En este sentido, el comercio detallista deberá ser capaz de manejar todos estos aspectos para llegar a una correcta gestión de su marca que le haga ser más competitivo en el mercado, prestando especial atención al hecho de que los consumidores ya no buscan únicamente la adquisición de productos y servicios, sino que también desean recibir experiencias en su proceso de compra.

La importancia de la interacción entre la marca y el consumidor, así como las consecuencias que se derivan de la misma viene destacadas por diversos autores (Aaker, 1991; Keller, 1993; Pappu et al., 2005; Cuneo et al., 2012), por lo que consideramos que la experiencia puede jugar un papel determinante en la percepción de dicha interacción marca-consumidor, influyendo en la calidad de la misma.

Crear experiencias del cliente memorables y diferenciarse de otros comercios, se ha convertido en un objetivo crucial para muchos detallistas. Los comerciantes pueden mantener relaciones más fuertes con sus clientes si son capaces de ofrecerles experiencias memorables (Verhoef et al., 2009).

Para la presente tesis se tendrán en cuenta tres de los cuatro componentes propuestos por Aaker (1991): notoriedad de marca (brand awareness), calidad percibida (perceived quality o brand quality) y lealtad de marca (brand loyalty). Además, se considerará también el valor percibido de marca (brand value o perceived value), que es considerada como parte de las asociaciones de marca por Aaker (1991) y también se tendrá en cuenta la imagen de marca propuesta por Keller (1993). 
Por otra parte, además de las dimensiones comentadas del Valor de Marca, la presente tesis plantea la introducción en los modelos propuestos del concepto de experiencia del cliente, ya que, como apuntan distintos autores (Hoolbrok y Hirschmann, 1982; Jones et al., 2006; Verhoef, 2009; Kotler y Keller, 2012; Koniecnik y Ruzzier, 2013) la gestión del Valor de Marca del comercio detallista no puede perder de vista que el cliente moderno no solo busca la adquisición de productos y servicios, sino que también necesita que se le ofrezcan experiencias. Como se desprende de algunos de los trabajos analizados anteriormente, este aspecto puede ser decisivo a la hora de conseguir un posicionamiento claro en la mente del cliente, así como también puede afectar decisivamente a la creación de lealtad en el mismo, con todas las ventajas que ello supone para el minorista.

Es por esto que, a la vista de todos estos factores y nuevas perspectivas, se plantea en la presente tesis la inclusión de la experiencia del cliente en su relación con otras variables a la hora de crear Valor de Marca.

El comercio detallista supone un punto de contacto con el cliente en el que se pueden desarrollar las acciones necesarias para ofrecer estas experiencias al cliente. Ante esto, en las siguientes páginas se pretende profundizar en el análisis del Valor de Marca del comercio detallista (retail equity), intentando con ello contribuir a la literatura existente.

Como algunos autores señalan, existe la necesidad de una medida del Valor de Marca en el ámbito del pequeño y mediano comercio (Boo et al, 2009; Lee y Back, 2010), puesto que los estudios existentes sobre el tema aplicado concretamente al comercio detallista no son abundantes. Así, este trabajo intentará contribuir a la satisfacción de esta necesidad.

Hay determinados artículos que hacen una aproximación al tema, pero no teniendo en cuenta el Valor de Marca del propio comercio detallista, sino que su análisis se centra en el valor de las marcas comercializadas por él. Así, diferentes estudios comparan la aplicación de este concepto en el caso de marcas propias del comercio detallista frente a las marcas de fabricante (Jara y Cliquet, 2007; Castelo et al., 2012; Cuneo et al., 2012). 
Según Pappu y Quester (2006), podemos extraer de los estudios existentes que una parte de la literatura propone una primera aproximación para medir el valor del comercio detallista consistente en aplicar para la medición del valor de éste los mismos criterios que los utilizados para medir el Valor de Marca desde el punto de vista del consumidor (consumer-based brand equity). Para esta línea de investigación se deberán tener en cuenta tres dimensiones: notoriedad/asociaciones de marca, lealtad y calidad percibida.

Si bien hay diferentes opciones a la hora de medir el Valor de Marca, la presente tesis intenta aportar un modelo basado en algunas de ellas, pero teniendo en consideración algunas particularidades del comercio detallista, como puede ser la experiencia del cliente en el punto de venta. Además, tampoco se quiere perder de vista la creciente importancia que las nuevas tecnologías de la información y la comunicación están adquiriendo a la hora, no sólo de desarrollar el comercio minorista en el entorno online, sino también desde su vertiente como herramientas adecuadas para la creación de experiencias del cliente, tanto en el entorno virtual como en el punto de venta físico.

Tras el planteamiento teórico de la cuestión, se ha procedido a un análisis de los datos obtenidos en el trabajo de campo. Así, a continuación, se destacan algunos datos relevantes relacionados con el mismo.

La calidad percibida de la marca se ha revelado en diferentes estudios como una de las dimensiones clave del Valor de Marca (Aaker, 1996; Boo et al., 2010; Keller, 2003; Lassar et al., 1995).

En el ámbito comercial, para Oh, 2000; Teas y Laczbiak, 2004, la calidad percibida es un antecedente directo del valor percibido. Así, del análisis de los resultados obtenidos en el trabajo de campo, se observa como esto se cumple en la primera de las hipótesis planteadas, ejerciendo la calidad percibida de marca del comercio minorista una influencia positiva sobre el valor percibido de marca del mismo.

Además, para Boo et al., (2009), la calidad percibida de marca influye en la percepción de valor por parte de un cliente y también en su lealtad futura. En el ámbito del 
comercio detallista, a la vista de los resultados obtenidos, esto es así también para el caso de la lealtad del consumidor hacia el establecimiento comercial, pudiéndose afirmar que ésta viene positivamente influenciada por la calidad que aquel percibe con respecto a la marca del comercio.

Por otra parte, Berry (2000) señalaba que la calidad tendrá un impacto sobre el valor de la marca de los clientes, sobre su experiencia, su intención de regresar y su disposición a pagar. En base a esto, se analizaba también la relación que la calidad percibida de marca puede tener con la experiencia del cliente en el modelo alternativo planteado, puesto que ésta se ha introducido pensando en las aportaciones de autores como Biedenbach y Marell (2010) que destacan la importancia de la experiencia del cliente a la hora de desarrollar el valor de una marca.

Si bien, como hemos visto, la calidad percibida sí que afecta positivamente al valor percibido de marca del establecimiento detallista y a la lealtad, los resultados no indican lo mismo con respecto a la experiencia. En el modelo alternativo planteado en la presente tesis, se contempla una hipótesis que relaciona calidad percibida de marca del establecimiento comercial con experiencia, pero los resultados indican que la influencia de la primera sobre la segunda no es significativa.

De esta forma, podemos concluir que las aportaciones de Boo et al., (2009) para la marca en general, según las cuales la calidad de marca influye en la percepción de valor por parte de un cliente y también en su lealtad futura, también se cumplen en el caso del comercio minorista, no ocurriendo lo mismo en el caso de la experiencia del cliente.

Puesto que en el modelo de Boo et al. (2008) que es el que se toma como base para la presente tesis no se establece la relación entre calidad percibida e imagen, se pretendía analizar si dicha imagen viene influida por la calidad percibida de la marca del minorista. Cabe señalas que los resultados muestran como la calidad percibida del establecimiento tiene una relación positiva con la imagen de marca del mismo, confirmando así, para el comercio minorista, los trabajos de Keller (1993) quien destacaba que una imagen de marca positiva podía crearse en el consumidor en base a que, cuando los consumidores 
realizan una buena evaluación de la calidad percibida, también se forman una mejor imagen de la marca.

En cuanto a las relaciones del valor percibido de marca, se plantearon en un primer modelo con respecto a la experiencia de compra, mientras que en el segundo eran con respecto a la lealtad del cliente.

Cretu y Brodie (2007) destacan la importancia que para el marketing tiene entender el proceso que crea la percepción de valor de los clientes, ya que ello conduce a su lealtad. Así, concluyen, dentro de un consenso general en la literatura al respecto, que el valor percibido por el cliente determina su lealtad (Boo et al., 2009; Kimpakorn, N. y Tocquer, 2010; Zeithaml, 1988). Así, del análisis realizado en la presente tesis, se puede confirmar que el valor percibido de marca del comercio detallista afecta positivamente, tanto a la experiencia del cliente con el mismo, como a la lealtad.

Por su parte, la notoriedad de marca contribuye a la creación de valor para la marca, ya que los consumidores unirán el conocimiento de la marca al nombre de la misma, lo que, finalmente constituye Valor de Marca (Aaker, 1991; Keller, 1993). Autores como Liu et al. (2015) en su análisis del Valor de Marca en el ámbito de los museos apuntan que la notoriedad de la marca influye en la calidad percibida. Esto queda refrendado también para el comercio detallista, puesto que los resultados apuntan que la notoriedad de marca del comercio ejerce una influencia positiva sobre la calidad percibida de la misma.

Además, también se confirma para el comercio detallista lo apuntado por la bibliografía analizada que indica que la notoriedad de marca tiene un claro reflejo en el valor percibido por el cliente (Kim et al; 2008; O’Neill y Xiao, 2006), puesto que se ha verificado en el presente trabajo que la notoriedad de marca del establecimiento influye positivamente en el valor percibido de su marca.

Se ha querido analizar en la presente tesis la relación existente entre la notoriedad de marca del comercio detallista y la lealtad hacia el mismo, puesto que en otros ámbitos 
diversos autores como Saleem et al. (2015) han encontrado una relación positiva entre la notoriedad de marca y la lealtad. Sin embargo, a la vista de los resultados, no podemos confirmar esta influencia en el ámbito de la marca del comercio detallista, puesto que no ha resultado significativa.

Como se apuntó en la parte empírica del presente trabajo, dentro de la literatura sobre la notoriedad de marca, no son muchos los estudios que analizan su relación con la experiencia del cliente. Para Berry (2000) la experiencia es un factor determinante a la hora de establecer el Valor de Marca (Brand Equity), mientras que Ambler et al. (2002) destacan que hay un énfasis creciente en la aproximación al marketing desde un punto de vista centrado en el consumidor, especialmente en lo que se refiere a maximizar el Valor de Marca a través de la experiencia. A pesar de esto, no es abundante la literatura que relaciona la notoriedad de marca con la experiencia del cliente. En esta línea de investigación cabe citar a Boo et al. (2008) cuando plantean que la notoriedad de marca tiene influencia en la experiencia del cliente, en el ámbito del turismo.

En base a esto, también se planteó en el modelo alternativo de la presente tesis la influencia de la notoriedad sobre la experiencia de compra del consumidor, obteniendo unos resultados similares a los resultantes con la lealtad, es decir, no es significativa la relación entre ambas.

Por lo que se refiere al análisis de la imagen de marca del establecimiento comercial, son varias las investigaciones indican que la imagen del establecimiento o sus atributos afectan al comportamiento del cliente del comercio (Jinfeng y Zhilong, 2009). A pesar de la importancia que la imagen de marca tiene en la lealtad del cliente, es una variable que no ha recibido mucha atención en la literatura (Nyadzay y Khajehzadeh, 2016; Wang y Yang, 2010). Algunos estudios realizados hasta la fecha determinan que la imagen de marca es un componente fundamental en la formación de la lealtad de marca (Hosany et al., 2006; Jara y Cliquet, 2012).

Ante esta situación, se planteó en el modelo de estudio la relación entre la imagen de marca del comercio detallista y la lealtad hacia el mismo, llegándose a la conclusión de 
que la primera ejerce una influencia positiva sobre la segunda. Es más, en el modelo alternativo se planteó también la relación de la imagen con respecto a la experiencia de compra, resultando que la imagen de marca del establecimiento comercial también ejerce una influencia positiva sobre la experiencia de compra en el mismo.

Con respecto a la imagen de marca del establecimiento minorista, también se planteó su influencia sobre el valor percibido del mismo. Como señala Tsai (2005), el valor percibido de un establecimiento comercial viene determinado en parte por la imagen que se tiene del mismo y de su marca (Tsai, 2005). Así, se analizó también esta relación en el modelo propuesto, obteniéndose como resultado que, efectivamente, la imagen de marca del minorista ejerce una influencia positiva sobre el valor percibido de marca del mismo.

Como se vio en la parte empírica de la tesis, la consecución de lealtad del cliente hacia el establecimiento comercial es de extremo interés para el comerciante, dado que los altos costes necesarios para conseguir un nuevo cliente son difíciles de amortizar si no hay repetición de las compras por su parte (Wallace et al., 2004). A pesar de la importancia que puede conllevar la lealtad para el comercio minorista, es más bien escasa la literatura existente al respecto hasta la fecha (Das, 2014).

En los modelos propuestos se analiza la relación existente entre la lealtad de marca del cliente del comercio y la experiencia de compra, así como la influencia de estas variables sobre el Valor de Marca del detallista.

Las experiencias anteriores que un cliente haya tenido en su relación con la marca, serán determinantes en la lealtad que éste tenga hacia la misma, tal y como ya determinó en su momento Osman (1993). Para Blázquez (2014) la experiencia del consumidor cobra especial relevancia en el comercio detallista. Así, el desarrollo de experiencias de compra excelentes tiene una influencia directa en las respuestas de los consumidores, generando mayor lealtad (Manning y Dorsey, 2008). Crosby y Johnson (2007) indican que la gestión de la experiencia del cliente es el ingrediente más importante a la hora de construir la lealtad del mismo. En esta línea, Kim et al. (2008) desarrollaron una escala para medir 
experiencias y confirmaron que éstas tenían efectos positivos en las futuras intenciones comportamentales.

Los estudios existentes hasta la fecha hacen referencia, en su mayor parte, a la relación entre la experiencia del cliente y la lealtad del mismo, centrándose en cómo la primera afecta a la segunda.

Sin embargo, es escasa la literatura que intenta ver cómo la lealtad puede afectar a la experiencia del cliente. En este sentido cabría plantearse qué efecto tiene el que un cliente sea leal a un establecimiento comercial sobre la valoración de las experiencias que dicho comercio pueda proponer a los consumidores.

Para Shankar et al. (2003) un cliente leal es más receptivo a considerar la experiencia con su proveedor de servicios más satisfactoria que un cliente no leal.

En base a esto, y teniendo en cuenta que el comercio detallista tiene un amplio componente de servicio al cliente, como hipótesis de trabajo que aquellos clientes que sean fieles a un determinado minorista, tendrán una mejor predisposición a la hora de valorar las experiencias del cliente que dicho comercio pueda proponerle.

Tras analizar los datos obtenidos, podemos confirmar que las propuestas comentadas en los párrafos anteriores también se cumplen en el caso del comercio detallista. Así, la experiencia del cliente tiene una influencia positiva sobre la lealtad, así como, según el segundo de los modelos propuestos, la lealtad también influye positivamente en la experiencia de compra del cliente.

En último lugar, cabe plantear, tal y como señaló Berry (2000), la influencia de la experiencia del cliente en su relación con el Valor de Marca. En este sentido Biedenbach y Marell (2010) apuntan la escasez de artículos que relacionan los conceptos de experiencia del cliente y de estrategia de marca, indicando que el primero tiene especial relevancia para el desarrollo del Valor de Marca, es decir, destacan la importancia de la experiencia del cliente a la hora de desarrollar el valor de una marca. Estos mismos autores indican que es 
más bien poca la literatura relativa al impacto que la experiencia tiene sobre el Valor de Marca, destacando la necesidad de profundizar en esta materia.

Pues bien, profundizando en esta línea de trabajo, se ha llegado a la conclusión de que tanto la lealtad del cliente como la experiencia de compra ejercen una influencia positiva en el Valor de Marca del comercio detallista.

A la vista de las conclusiones expuestas, podemos afirmar que la experiencia juega un papel importante a la hora de generar Valor de Marca para el comercio detallista. Es por esto que, para la correcta dirección de la empresa dedicada a la venta minorista será necesario que sus gestores tengan presente la importancia que las nuevas tecnologías suponen a la hora de estar presente en diversos canales, siempre teniendo en cuenta que éstas, además, son una herramienta adecuada para ofrecer experiencias de compra al consumidor, que permitirán, a su vez, la diferenciación del establecimiento con respecto a su competencia, de manera que se aumente así el Valor de Marca del comercio detallista.

\subsection{Implicaciones para la gestión}

La tesis presenta un marco global sobre la formación del Valor de Marca del comercio minorista, teniendo en cuenta la experiencia de compra que se puede ofrecer al cliente del mismo. Por una parte, si bien los trabajos sobre Valor de Marca son abundantes en la literatura, son bastantes menos los que se centran en su aplicación al ámbito del comercio minorista. Por otra parte, el hecho de incluir la experiencia de compra puede aportar algunos puntos de mejora para los directivos de marketing que pretendan aumentar el Valor de Marca de sus enseñas detallistas.

Una situación difícil para la economía española como es la que se viene dando desde 2008, supone un reto importante para el sector y especialmente para la modernización de la gran cantidad de pequeñas y medianas empresas que lo componen. En tiempos de crisis, con importantes caídas del consumo y mayores dificultades para acceder 
al crédito, las empresas deben realizar un esfuerzo suplementario por conseguir diferenciarse con respecto a sus competidores y captar nuevos clientes en un entorno muy competitivo y menos predispuesto al consumo.

Como hemos visto a raíz de los datos expuestos, se da una escasa penetración de las nuevas tecnologías de la información y la comunicación en los pequeños comercios minoristas tradicionales que suponen gran parte del sector comercial español. Esto es así porque la adopción de estas nuevas tecnologías que pueden ayudar y facilitar la innovación del comercio minorista, suele ser vista por los empresarios de menor tamaño como algo difícil, caro e incluso complejo y de difícil acceso.

Aun así, estas tecnologías resultan de gran importancia a la hora de que la empresa minorista entre en contacto con su cliente, le pueda atender y entender de mejor manera, pudiendo así adaptarse a las nuevas necesidades y requerimientos del mercado. Sólo de esta manera serán capaces de detectar nuevas oportunidades y formas de negocio que les permitan sobrevivir en su entorno competitivo.

La innovación y sofisticación en la calidad pueden contribuir al incremento del valor para el cliente. De hecho, una de las fuentes para el éxito del comercio detallista viene dada por su calidad percibida que conduce a una diferenciación del comercio, así como a la creación de lealtad hacia el mismo (Burt y Sparks, 2002; Rondan, 2006). De hecho, como consecuencia de esto, y tal y como apuntan autores como Huang y Huddleston (2009), en la actualidad se está dando una tendencia hacia el aumento de la calidad percibida de la marca del comercio minorista en numerosos países, como consecuencia de su creciente importancia. Como hemos visto a lo largo del análisis de resultados, la calidad percibida de la marca del detallista influye positivamente en el valor percibido de marca del mismo, así como en su imagen y en la creación de lealtad hacia el establecimiento.

A la hora de construir lealtad hacia el comercio detallista, se debe tener en cuenta que el consumidor se ve muy influenciado por la gestión del punto de venta. Así, cobran especial importancia aspectos como la apariencia de la tienda, la disposición del espacio, la 
organización de la mercancía, la música o el espíritu de aventura que se pueda asociar a la compra (Dabija y Babut, 2014).

Otro aspecto que debe ser considerado por el gerente del punto de venta detallista es la imagen de marca, puesto que ésta influirá en el valor percibido del establecimiento, así como también en la lealtad hacia el mismo. Es por ello que los responsables de los establecimientos necesitarán conocer cómo se forma su imagen para posteriormente poder modificarla con la finalidad de atraer a su público objetivo.

La imagen y el valor de las marcas de los comercios minoristas, según Deepra y Chitramani (2013), dependen, en parte, de las marcas de fabricante que comercialicen, así como del valor de las mismas.

Gracias a las marcas de los fabricantes el comercio detallista puede generar interés en los consumidores, así como lealtad hacia su establecimiento. De esta forma, las marcas del fabricante comercializadas por un comercio minorista ayudarán a éste a crear su propia imagen y a posicionarse en el mercado.

Para diferenciar su oferta de la de su competencia, construir lealtad del cliente y desarrollar ventajas competitivas sostenibles, Grewal y Levy (2007) indican que los minoristas pueden ofrecer un servicio excelente a sus clientes. Para ello pueden optar por prestar servicios personalizados, proporcionar excelencia a través de la innovación en tecnologías en el punto de venta (como, por ejemplo, los kioscos interactivos, probadores virtuales, códigos QR, etcétera) y en el entorno multicanal pueden ofrecer servicios de chats o conversaciones instantáneas con personal del comercio, modelos virtuales que ayuden al consumidor a ver cómo le quedaría el producto en su cuerpo, etcétera.

Los consumidores buscan en sus visitas a los comercios no solo para comprar, sino también disfrutar y entretenerse, evaluando el servicio en términos de cuánto placer o diversión han recibido (Srivastava y Kaul, 2016). 
Actualmente, las propiedades y beneficios de lo ofertado, pese a ser necesarios, ya no son suficientes para incentivar la compra, pues la calidad y la innovación en éstos se sobreentiende. En consecuencia, hay necesidad de ofrecer productos atractivos o satisfactorios y que además tengan un valor adicional basado en aspectos emocionales y vivenciales, adquiriendo aquí importancia el Marketing Experiencial.

Para Blázquez (2014) los consumidores actuales están inmersos en la búsqueda de experiencias en sus procesos de compra, de acuerdo con el paradigma de la economía de las experiencias.

Estas experiencias, desde el punto de vista sensorial, se pueden crear a través de la vista, el oído, el tacto, el gusto y el olfato, siendo así que el marketing, en este ámbito, tendría como objetivo la gestión de la comunicación impactando en los cinco sentidos del consumidor con el fin de influir sobre su comportamiento de compra.

Como indican Kotler y Armstrong (2009), el marketing busca enriquecer la vida de los consumidores ampliando sus experiencias físicas, mostrándoles formas alternativas de hacer las cosas y persiguiendo impactar en sus estilos de vida.

El gestor del comercio detallista debe tener en cuenta que el proceso de creación de experiencias para el consumidor se forma a partir de los diferentes puntos de contacto de éste con el minorista a lo largo de todo el proceso de intercambio.

Por su parte, Yeng y Mat (2013) afirman que tanto la calidad del servicio y de los productos, la atmósfera del establecimiento y las actividades de promoción, como la satisfacción, los programas de fidelización y el valor de marca del comercio, afectan directamente a la lealtad.

Aunque los consumidores tienen la posibilidad de moverse entre diferentes canales, todavía quieren ver, sentir, tocar y probar el producto, así como sentir la atmósfera de la tienda. Piotrowicz y Cuthbertson (2014) indican que el comercio tradicional podría convertirse en una especie de centro que integrase todos los canales de venta. 
Como hemos visto, el canal online también contribuye al proceso de creación de lealtad del cliente. En este sentido, el valor que aporta el canal electrónico no solo es importante por sí mismo, sino que también se debe tener en cuenta la manera en que ambos se combinan para ofrecer una experiencia total de servicio. Así, el cliente valora el canal online no de manera independiente, sino teniendo en cuenta también sus experiencias previas en su relación con la empresa a través del canal tradicional.

Con la tendencia apuntada por Verhoef et al. (2015) hacia una presencia omnicanal, el comercio minorista puede ofrecer a su cliente una experiencia de compra en la que se eliminen las distinciones y los límites entre los diferentes canales. La gestión omnicanal conlleva un desarrollo de las estrategias del comercio minorista hacia una integración que permita la desaparición de barreras entre los distintos canales. Las empresas podrán ofrecer este tipo de experiencias, por ejemplo, con la presencia de terminales móviles en la tienda de manera que el consumidor pueda usarlos para buscar información, facilitando redes $\mathrm{Wi}$ Fi o a través de aplicaciones móviles con las que interactuar con el cliente, tanto en el punto de venta como fuera de él.

En el entorno actual un comprador podría buscar las características de un producto utilizando una app de su móvil, comparar precios en diferentes webs a través de su ordenador y finalmente comprar el producto en una tienda física.

Así pues, en función de lo apuntado por Juaneda-Ayensa et al. (2016) el comercio detallista podría optar por una estrategia "omnicanal" que, gracias a la interacción real, permitiese a los clientes comprar a través de canales en cualquier lugar y en cualquier momento, proporcionándoles de esta manera una experiencia única, completa y sin fisuras, que rompe las barreras entre canales.

Por último, siguiendo con la propuesta de Court et al. (2009) de la consultora McKinsey\&Company, se deberá tener en cuenta el viaje de decisión del consumidor (The Consumer Decision Journey) para explicar el nuevo comportamiento de compra del consumidor actual. Si el gestor del comercio detallista es consciente de este nuevo comportamiento del consumidor, sus objetivos de marketing pasarán por alcanzar a los 
consumidores en el momento en el que más se influencie su decisión de compra, proporcionándoles una experiencia consistente y única que aumente tanto la lealtad como el Valor de Marca del comercio detallista.

\subsection{Limitaciones y futuras líneas de investigación}

Como limitación de estudio de la presente tesis se puede apuntar el ámbito geográfico que, en este caso, ha sido la Comunidad Valenciana. Además, las encuestas fueron realizadas todas ellas de manera presencial y no online, lo que hubiese podido ampliar el universo de estudio a un ámbito geográfico mayor.

En este sentido, como futura línea de investigación se puede plantear la aplicación de los modelos propuestos en un ámbito nacional o incluso internacional, lo que permitiría descubrir posibles diferencias entre ellos o ratificar los aspectos comunes.

Por otra parte, en cuanto a la tipología de comercio detallista, los datos se han obtenido a partir de diversidad de formatos, es decir, tanto supermercados, como hipermercados, tiendas de conveniencia, pequeño comercio tradicional, etcétera. Esto deja la puerta abierta a una aplicación futura más centrada en alguna tipología concreta de comercio de manera que se puedan ofrecer conclusiones más centradas en dicha tipología, a fin de que los responsables de los distintos comercios detallistas dispongan de herramientas más directamente aplicables a sus situaciones concretas.

De la misma manera, el estudio también ha tenido en cuenta comercios detallistas de diferentes sectores (alimentación, moda y complementos, librería, etcétera). Al igual que se ha comentado con la tipología de comercio detallista, en este caso se podría proponer una investigación más exhaustiva para distintos sectores, lo que permitiría detectar posibles diferencias a la hora de la creación del Valor de Marca del comercio detallista de diferentes productos. 
Por otra parte, si bien se ha introducido la experiencia de compra en su relación con el Valor de Marca, es este un campo en el que no es abundante la literatura y menos con una aplicación directa al comercio detallista, por lo que se abre aquí una línea de investigación que puede aportar novedades para la mejora de la gestión del comercio minorista, a la vista de los resultados obtenidos. Estamos ante un campo que ofrece posibilidades de investigación y que, en opinión de diversos autores, merece una mayor atención por parte de la literatura.

Por último, más allá de la lealtad del cliente y de su experiencia de compra en el comercio detallista (bien a través de un único canal o bien en combinación de varios de ellos), se plantea el tema del compromiso del cliente con el comercio detallista. Se trataría de una línea de investigación que estudiase la relación que el engagement o compromiso activo del cliente tiene con la creación del Valor de Marca para el comercio detallista.

Así pues, el estudio del Valor de Marca aplicado al caso concreto del comercio minorista abre numerosas posibilidades, teniendo en cuenta aspectos como la experiencia del cliente o su compromiso activo hacia el establecimiento comercial. 

8 - BIBLIOGRAFÍA 



\section{BIBLIOGRAFÍA}

Aaker, D. (1991). Managing Brand equity: Capitalizing on the Value of a Brand name. New York: The Free Press.

Aaker. D. (1992). Building strong brands. New York: Free Press.

Aaker, D.; Biel, A. (1993). Brand equity and advertising; adevertising's role in building strong brands. Hillsdale, NJ: Lawrence Erlbaum Associate, pp. 333-341.

Aaker, D. (1996). "Measuring brand equity across products and markets", California Managment Review, Vol. 38, nº. 3, pp. 102-120.

Aaker, D.; Fournier, S.; Brasel, S.A. (2004). "When good brands do bad", Journal of Consumer Research, Vol. 31, nº.1, pp. 1-16.

Abell, D.F. (1980). Defining the business: The starting point of strategic planning. Englewood Cliffs, N.J.: Prentice-Hall.

Abratt, R.; Kleyn, N. (2012). "Corporate identity, corporate branding and corporate reputations: Reconciliation and integration”, European Journal of Marketing, Vol. 46, n. 7/8, pp. 1048-1063.

Addis, M.; Holbrook, M.B. (2001). "On the conceptual link between mass customisation and experiential: consumption: an explosion of subjectivity", Journal of Consumer Behaviour, Vol. 1, nº. 1; pp. 50-66.

Adelaar, T.; Bouwman, H.; Steinfield, C. (2004). "Enhacing customer value through clickand-mortar e-commerce: implications for geographical market reach and customer type", Telematics and Informatics, Vol. 21, pp.167-182. 
Ailawadi, K. y Keller, K.L. (2004). "Understanding retail branding: conceptual insights and research priorities", Journal of Retailing, Vol. 80, nº 4, pp. 331-342.

Alba, J.; Lynch, J.; Weitz, B.; Janiszewski, C. (1997). "Interactive home shopping: consumer, retailer and manufacturer incentives to participate in electronic marketplaces", Journal of Marketing, Vol. 61, no. 3, pp. 38-53.

Alrubaiee, L.; Al-Nazer, N. (2010). "Investigate the impact of relationship marketing orientation on customer loyalty: the customer's perspective", International Journal of Marketing Studies, Vol. 2, pp. 155- 173.

Al-Shirawi, A.; Hajjar, S. (2004). Developing a scale to measure the level of market orientation in the financial services sector within a resource-based economy. International Conference on Economics, Business Innovation. IPEDR Vol. 38 (2012) IACSIT Press, Signapore.

Allred, A.; Addams, H L.; Chakraborty (2007). "Is informal planning the key to the success of the INC. 500?” Journal of Small Business Strategy, Vol. 18, nº 1, pp. 95-104.

Allaway, A.W.; Huddleston, P.; Whipple, J.; Ellinger, A.E. (2011). “Customer-based brand equity, equity drivers, and customer loyalty in the supermarket industry", Journal of Product Brand Management, Vol. 20, n. 3, pp. 190-204.

Ambler, T.; Styles, C. (1995). “Brand equity: Towards measures that matter”, PAN'AGRA Working Paper, London Business School; nº 902.

Ambler, T.; Styles, C. (1997). "Brand development versus new product development: Toward a process model of extension decisions", The Journal of Product and Brand Management, Vol. 6 (4), pp. 222-234.

Ambler, T.; Bhattacharya, C.B.; Edell, J.; Keller, K.L.; Lemon, K.L.; Mittal, V. (2002). "Relating brand and customer perspectives on marketing management", Journal of Service Research, Vol. 5, nº 1, pp. 13-25. 
American Marketing Association (1960). Marketing Definitions: A Glossary of Marketing Terms. Chicago, IL: AMA.

American Marketing Association (2016). AMA website for professional marketers. http://www.marketingpower.com/_layouts/Dictionary.aspx?dLetter=B

Andajani, E. (2015). “Understanding customer experience management in retailing”, Social and Behavioral Sciences, Vol. 211, pp. 629-633.

Anderl, E.; Becker, I.; von Wangenheim, F.; Schumann, J.H. (2016a). "Mapping the customer journey: Lessons learned from graph-based online attribution modeling”, International Journal of Research Marketing, Vol. 33, pp. 457-474.

Anderl, E.; Schumann, J.H.; Kunz, W. (2016b). "Helping firms reduce complexity in multichannel online data: a new taxonomy-based approach for customer journeys", Journal of Retailing, Vol. 92, no. 2, pp. 185-203.

Anderson, J.C.; Gerbing, D.W. (1988). "Structural Equation Modeling in Practice: A Review and Recommended Two-step Approach", Psychological Bulletin, Vol. 103, pp. 411-423.

Anderson, Ch. (2004): "The Long Tail", The Wired Magazine, disponible en https://www.wired.com/2004/10/tail/. Acceso, 30 octubre 2016.

Anderson, Ch. (2006). The Long Tail: Why the Future of Business is Selling Less of More. Edit Hyperion.

Anderson, J.C.; Hakansson, H.; Johanson, J. (1994). "Dyadic Business Relationships within a Business Network Context”, Journal of Marketing, Vol. 58, n 4, pp. 1-15.

Ansari, A.; Mela C.F.; Neslin, S.A. (2008). "Customer channel migration”. Journal of Marketing Research, Vol. 45, nº1, pp. 60-76. 
Arce-Urriza, M.; Cebollada, J. (2007). "Comparing loyalty and prices effects between online and offline channels into the grocery industry: the moderating effects of product categories characteristics",

Arce-Urriza, M.; Cebollada, J. (2013). "Elección de canal de compra y estrategia multicanal: internet vs. tradicional. Aplicación a la compra en una cadena de supermercados", Cuadernos de Economía y Dirección de la Empresa, Vol. 16, pp. 108122.

Ares, G.; Giménez, A.; Gambaro, A.; Varela, P. (2010). "Influence of brand information on consumers' expectations and linking of powdered drinks in central location tests", Food Quality and Preference, Vol. 21, nº. 7, pp. 873-880.

Argarwal, P. (2004). "The effects of brand relationship norms on consumer attitudes and behavior", Journal of Consumer Research, Vol. 31, nº. 1, pp. 87-101.

Armstrong, G; Kotler, P.; Merino, M.J.; Pintado, T.; Juan, J.M. (2011). Introducción al Marketing ( $3^{\mathrm{a}}$ edición), Madrid: Pearson Educación

Arnett, D.B.; Laverie, D.A.; Meiers, A. (2003). "Developing parsimonious retailer equity indexes using partial least squares analysis: a method and applications", Journal of Retailing, Vol. 79, pp. 161-170.

Auger, P.; Gallaugher, J. (1997). "Factors affecting the adoption of an Internet-based sales presence for small businesses", The Information Society, Vol. 13, p. 55-74.

Avery, J.; Steenburgh, T.J.: Deighton, J.; Caravella, M. (2012). “Adding bricks to clicks: predicting the patterns of cross-channel elasticities over time", Journal of Marketing, Vol. 76, nº. 3, pp. 96-111.

Babin, B.J.; Darden, W.R.; Griffin, M. (1994). "Work and/or fun: measuring hedonic and utilitarian shopping value", Journal of Consumer Research, Vol. 20, pp. 644-656. 
Bäckström, K.; Johansson, U. (2006). "Creating and consuming experiences in retail store environments: Comparing retailer and consumer perspectives", Journal of Retailing and Consumer Services, Vol. 13, pp. 417-430.

Badi. S.; Wang, L.; Pryke, S. (2016). "Relationship marketing in Guanxi networks: A social network analysis study of Chinese construction small and medium-sized enterprises", Industrial Marketing Management.

Bagozzi, R. (1980). Causal Modeling in Marketing. Wiley \& Sons, New York.

Bagozzi R. y Yi, Y. (1988): “On the evaluation of structural equation models”, Journal of the Academy of Marketing Science, Vol. 16, n 1, pp. 74-94.

Bailey, R.; Ball, S. (2006). "An exploration of meanings of hotel brand equity”, The Service Industries Journal, Vol. 2, nº 1, pp. 15-38.

Bardhi, F.; Arnould, E. (2005). "Thrift shopping: combining utilitarian thrift and hedonic treat benefits", Journal of Consumer Behaviour, Vol. 4, pp. 223-233.

Baloglu, S. (2002). "Dimensions of customer loyalty: separating friends from wellwishers", Cornell Hotel and Restaurant Administration Quarterly, Vol. 43, pp. 47-59.

Baloglu, S.; McCleary, K. W. (1999). “A model of destination image formation”, Annals of Tourism Research, Vol. 26, pp. 868-897.

Baltas, G.; Argouslidis, P. (2007). "Consumer characteristics and demand for store brands", International Journal of Retail \& Distribution Management, Vol. 35, nº. 5, pp. 328-341.

Bauer, H.; Heinrich, D.; Albrecht, C.M. (2009). "All you need is love: assessing consumers' brand love" en Proceedings of the American Marketing Association Summer Educators Conference, Michael Kamin y Ingrid M. Martin, eds. Chicago: American Marketing Association, pp. 252-253. 
Bell, D.; Gallino, S.; Moreno, A. (2014). "Showrooms and information provision in omnichannel retail", Production and Operations Management, Vol. 24, nº. 3, pp. 359-368.

Bello, L.; Gómez, J. (1997). "Interacciones entre marketing industrial y marketing de relaciones", Revista Asturiana de Economía, Vol. 9, pp. 7-21.

Belo, F.; Lin, X.; Vitorino, M.A. (2012). "Brand capital and firm value". Unpublished working paper. University of Minnesota and Ohio State University. .

Bendoly, E.; Blocher, J.; Bretthauer, K.; Krishnan, S.; Venkataramanan, M. (2005). "Online/In-store integration and customer retention", Journal of Service Research, Volume $7, n^{\circ} .4,313-327$.

Bennett, P.D. (1988). Dictionary of Marketing Terms. Chicago (IL): The American Marketing Association.

Beristain, J.J.; Zorrilla, P. (2011). "The relationship between store image and store brand equity: a conceptual framework and evidence from hypermarkets", Journal of Retailing and Consumer Services, Vol. 18, pp. 562-574.

Berrozpe, A. (2015). "La identificación con la marca: conceptualización, caracterización y consecuencias", Opción, Año 31, №. especial 2, pp. 144-161.

Berry L.L. and Parasuraman A. (1991). Marketing Services: Competing Through Quality. New York: The Free Press.

Berry, L.L. (2000). "Cultivating service brand equity", Journal of the Academy of Marketing Science, Vol. 28, $\mathrm{n}^{\circ}$ 1, pp. 128-137.

Berry, L.L.; Carbone, L.P. (2002). "Managing the total customer experience", MIT Sloan Management Review, Vol. 43, pp. 85-89. 
Berry, L.L.; Carbone, L.P. (2007). "Build loyalty through experience management", Quality Progress, Vol. 40, no ${ }^{\text {oo }}$ 9, pp. 26-33.

Berry, L.L.; Bolton, R.N.; Bridges, C.H.; Meyer, J.; Parasuraman, A.; Seiders, K. (2010). "Opportunities for innovation in the delivery of Internet retail services", Journal of Interactive Marketing, Vol. 24, nº. 2, pp. 155-167.

Bhimrao, M.G. (2008). "Building brand identity in competitive markets: a conceptual model”, Journal of Product \& Brand Management, Vol. 17, $\mathrm{n}^{\circ} .1$, pp. $4-12$.

Bian, X.; Moutinho, L. (2011). "The role of brand image, product involvement, and knowledge in explaining consumer purchase behaviour of counterfeits: direct and indirect effects", European Journal of Marketing, Vol.45, n 1/2, pp. 191-216.

Biedenbach, G.; Marell, A. (2010). "The impact of customer experience on brand equity in a business-to-business services setting", Journal of Brand Management, Vol. 17, $\mathrm{n}^{\mathrm{o}}$. 6, pp. 446-458.

Bigné, J.E.; Moliner, M.A.; Callarisa, L.J. (2001). "El valor y la fidelización de clientes: una propuesta de modelo dinámico de comportamiento", Revista Europea de Dirección y Economía de la Empresa, Vol. 9, nº. 3, pp.65-78.

Biyalogorsky, E. y Naik, P. (2003). Clicks and Mortar: The Effect of On-line Activities on Off-line Sales. Marketing Letters, 14: 1, 21-32, 2003.

Bitner, M. J., Ostrom, A. L. y Meuter, M. L. (2002). Implementing successful self-service technologies. Academy of Management Executive, Vol. 16, nº 4, pp. 96-109.

Blázquez, M. (2014). "Fashion shopping in multichannel retail: the role of technology in enhancing the customer experience", International Journal of Electronic Commerce, Vol. $18, \mathrm{n}^{\circ} .4$, pp. $97-116$. 
Blázquez, M. (2014b). "La experiencia del consumidor en un entorno de distribución multicanal: un análisis transnacional del sector textil", Tesis Doctoral, Madrid: Universidad Complutense.

Blázquez, M.; Puelles, M. (2014). "La importancia de la experiencia de compra en tiempos de recesión económica: un análisis del sector textil”, ESIC Market Economics and Business Journal, Vol. 45, nº. 2, pp. 299-325.

Blythe, J. (2005). Essentials of Marketing. $3^{\mathrm{a}}$ ed. Harlow. Pearson Education.

Boo, S.; Busser, J.; Baloghu, S. (2008). "A model of customer-based brand equity and its application to multiple Destinations”, Tourism Management, Vol. 30, nº 1, pp. 219-231.

Bowen, J.T.; Chen, S.L. (2001). "The relationship between customer loyalty and customer satisfaction", International Journal of Contemporary Hospitality Management, Vol. 13, $\mathrm{n}^{\mathrm{o}}$ 4/5, pp. 213-217.

Brakus, J.J.; Schmitt, B.; Zarantonello, L. (2009). "Brand experience: What is it? How is it? Does it affect loyalty", Journal of Marketing, Vol. 73, n², pp.410-425.

Breugelmans, E.; Campo, K. (2016). "Cross-channel effects of price promotions: an empirical analysis of the multi-channel grocery retail sector", Journal of Retailing, Vol. 92, $n^{\text {o. }}$ 3, pp. 333-351.

Brown, G. (1992). People, Brands and Advertising. Warwick, UK: Millward Brown International.

Brown, M. (2010). "Growing a strong brand: defining your meaningful point of difference", disponible en http:/www.millwardbrown.com/docs/default-source/insightdocuments/points-of-view/MillwardBrown_POV_GrowingStrongBrand.pdf

Brynjolfsson, E.; Hu, Y. J.; Rahman, M. S. (2013). "Competing in the age of omnichannel retailing”, MIT Sloan Management Revue, Vol. 54, pp. 23-29. 
Budac, C.; Baltador, L. (2013). "The value of brand equity", Procedia Economics and Finance, Vol. 6, pp. 444-448.

Buil, I.; de Chernatony, L.; Martínez, E. (2013). "La importancia de medir el valor de marca desde la perspectiva del consumidor: Evidencia empírica en España y el Reini Unido", Revista de Ciencias Sociales, Vol. 19, nº. 2, pp. 226-237.

Burruezo, J. C. (1999). La gestión moderna del comercio minorista: el enfoque práctico de las tiendas de éxito. Madrid: ESIC Editorial.

Burt, S.; Sparks, L. (2002). "Corporate branding, internationalization and the retailer as a brand", Corporate Reputation Review, Vol. 5, n. 2/3, pp. 194-212.

Burton, S.; Lichtenstein, D.; Netemeyer, R.; Garreston, J. (1998). "A scale for measuring attitude toward private label products and a $\mathrm{n}$ examination of its psychological and behavioral correlates", Journal of The Academy of Marketing Science, Vol. 4, pp. 293-306.

Butz, H.E.; Goldstein, L.D. (1996). "Measuring customer value: gaining the strategic advantage", Organizational Dynamics, Vol. 24, pp. 66-77.

Cai, Y.; Zhao, G.; He., J. (2015). "Influences of two modes of intergenerational communication on brand equity", Journal of Business Research, Vol. 68, pp. 553-560.

Callarisa, L.; Moliner, M.A.; Rodríguez, R.M. (2002). "El componente emocional del valor percibido: un estudio cualitativo", Proceedings of XIV Encuentro de Profesores Universitarios de Marketing, Granada, pp. 429-446.

Callarisa, L.; Moliner, M.A.; Sánchez. (2011). "Multidimensional perspective of perceived value in industrial clusters", Journal of Business and Industrial Marketing, Vol. 26, nº. 2, pp. 132-145.

Camarero, C.; Garrido, M.J.; Vicente E. (2010). "Components of art exhibition brand equity for internal and external visitors", Tourism Management, Vol. 31, nº. 4, pp. 495-504. 
Camacho, J. (2008). El valor de la marca: Brand equity. Datos, Diagnóstico y Tendencias. Nielsen. http://mx.nielsen.com/press

Campo, S.; Rubio, N.; Yagüe, M.J. (2008). "Beneficios y costes del uso de las TIC para las empresas minoristas de distribución de electrodomésticos", Distribución y Consumo, $\mathrm{n}^{\circ}$ 102, pp. 94-101.

Candia, C.; Aguirre, M. (2015). "Modelo de valor de marca para medios de prensa escritos en un contexto regional", Estudios Gerenciales, Vol. 31, pp. 150-162.

Cao, L.; Li, L. (2015). "The impact of cross-channel integration on retailers' sales growth", Journal of Retailing, Vol. 91, nº.2, pp. 198-216.

Caridad, M; Castellano, M.I.; Hernández, M.F. (2015). "Marketing experiencial para la promoción del proceso educativo a nivel de pregrado: un estudio de dos universidades privadas", Revista Facultad de Ciencias Económicas: Investigación y Reflexión, Vol. 23, $\mathrm{n}^{\mathrm{o}}$. 2, pp. 81-95.

Carroll, B.A; Ahuvia, A.C. (2006). "Some antecedents and outcomes of brand love", Marketing Letters, Vol.17, n. 2, pp. 79-89.

Carù, A.; Cova, B. (2003). "Revisiting consumption experience: a more humble but complete view of the concept", Marketing Theory, Vol. 3, nº. 2, pp. 267-286.

Carù, A.; Cova, B. (2006). "How to facilitate immersion in a consumption experience: appropriation operations and service elements", Journal of Consumer Vehaviour, Vol. 5, pp. 4-14.

Caruana, A. (2004). "The impact of switching costs on consumer loyalty: A study among corporate customers of mobile telephony", Journal of Targeting Measurement and Analysis of Marketing, Vol. 13, nº. 2, pp. 118-140. 
Casares, J.; Martín, V.J. (2011). “Creatividad, innovación y tecnología en la distribución comercial”, Distribución y Consumo, no 115, pp. 5-25.

Castaldo, S.; Grosso, M.; Mallarini, E.; Rindone, M. (2015). "The missing path to gain customers loyalty in pharmacy retail: the role of the store in developing satisfaction and trust", Research in Social and Administrative pharmacy, disponible online.

Castells, M. (2009). La sociedad red: una visión global, Madrid: Alianza Editorial.

Castelo, J.S.F.; Coelho, A.F.M.; Cabral, J.E.O. (2012). “Análise comparativa dos antecedentes e dimensoes do Brand equity entre marcas de fabricantes e marcas própias no setor de vestuario".

Celly, K. S.; Knepper, B. (2010). "The California State University: A case on branding the largest public university system in the US", International Journal of Nonprofit and Voluntary Sector Marketing, Vol. 15, n. 2, pp. 137-156.

Chandon, P.; Hutchinson, J.; Bradlow, E.; Young, S. (2009). "Does in store marketing work? Effects of the number and position of shelf facings on brand attention and evaluation at the point of purchase" Journal of Marketing Research, Vol. 73, pp. 1-17.

Chang, H.P.; Ma, C.C. (2015). "Managing the service brand value of the hotel industry in.

Chapleo, C. (2011). "Branding a university: Adding real value or smoke and mirrors?" En, The marketisation of higher education and the student as consumer (pp. 101-114). London: Routledge.

Chaudhuri, A. (1995). "Brand equity or double jeopardy?" Journal of Product \& Brand Managemen, Vol. 4, no. 1, pp. 26-32.

Chen, C.F.; Tseng, W.S. (2010). "Exploring customer-based airline brand equity: evidence from Taiwan", Transportation Journal, Vol. 49, n.1, pp. 24-34.

Chevan, H. (1992). “What's in a name?”, Catalog Age, Vol. 9, no. 9, pp. 28. 
Chiu, Y.L.; Chen, T. (2014). "Environmentally responsible behavior in ecotourism: antecedents and implications", Tourism Management, Vol. 40, pp. 321-329.

Cho, Y.K. (2015). "Creating consumer repurchase intention in Internet retailing: the effects of multiple service events and product type", Journal of Retailing and Consumer Services, Vol. 22, pp. 213-222.

Choi, S.H.; Yang, Y.X.; Yang, B.; Cheung, H.H. (2015). "Item-level RFID for enhancement of customer shopping experience in appareal retail", Computers in Industry, Vol. 71, pp. 10-23.

Çifci, S.; Ekinci, Y.; Whyatt, G.; Japutra, A.; Molinillo, S.; Siala, H. (2016). "A cross validation consumer-based brand equity models: driving customer equity in retail brands", Journal of Business Research, Vol. 69, pp. 3740-3747.

Citrin, A.V.; Stem, D.E.; Spangenberg, E.R.; Clark, M.J. (2003). "Consumer need for tactile input. An Internet retailing challenge", Journal of Business Research, Vol. 56, pp. 915-922.

Clifford, E. (2012). "Fashion on line UK". Mintel, marzo 2012.

Coates, V. (1998). Buying and selling on the Internet: retail electronic commerce. The Institute for Technology Assessment.

Cobo, J.C. (2009). "El concepto de tecnologías de la información. Benchmarking sobre las definiciones de las TIC en la sociedad del conocimiento", Zer, Revista de Estudios de Comunicación, Vol. 14, no. 27, pp. 295-318.

Cooil, C.; Keiningham, T.L.; Aksoy, L.; Hsu, M. (2007). "A longitudinal analysis of customer charasteristics", Journal of Marketing, Vol. 71, n. 1, pp. 67-83. 
Cook, G. (2014). "Customer experience in the omni-channel world and the challenges and opportunities this presents", Journal of Direct Data and Digital Marketing Practice, Vol. 15, pp. 262-266.

Corstjens, M.; Lal, R. (2000). "Building store loyalty trough store brands", Journal of Marketing Research, Vol. 37, pp. 281-291.

Corte-Real (2007). O Valor da Marca. Porto: Prisma.

Court, D.; Elzinga, D.; Mulder, S.; Vetvik, O.J. (2009). “The consumer decision journey”, McKinsey Quarterly, disponible en http://www.mckinsey.com/business-functions/marketingand-sales/our-insights/the-consumer-decision-journey

Cretu, A.E.; Brodie, R.J. (2007). "The influence of brand image and company reputation where manufacturers market to small firms: a customer value perspective", Industrial Marketing Management, Vol. 36, pp. 230-240.

Crittenden, V.L.; Peterson, R.A.; Albaum, G. (2010). "Technology and business to consumer selling: contemplating research and practice", Journal of Personal Selling and Sales Management, Vol. 30, pp. 103-110.

Crosby, L.A.; Johnson, S.L. (2007). "Experience required", Marketing Management, Vol.16, n'. 4, pp. 20-28.

Cuneo, A.; López, P.; Yagüe, M.J. (2012). "Measuring private labels brand equity: a consumer perspective", European Journal of Marketing, Vol. 46, nº. 7/8, pp. 952-964.

Cunningham, R.M. (1956). "Brand loyalty: what, where, how much?”, Harvard Business Review, no. 34, pp. 116-128.

Dabija, D.C.; Babut, R. (2014). "Building loyalty in retailing through in-store management and communication", 
Das, G. (2014). "Linkages of retailer awareness, retailer association, retailer perceive quality and retailer loyalty with purchase intention: a study of Indian food retail brands", Journal of Retailing and Consumer Services. Vol. 21, pp. 284-292.

Davcik, N.S.; Vinhas, R.; Hair, J.F. (2015). "Towards a unified theory of brand equity: conceptualizations, taxonomy and avenues for future research", Journal of Product \& Brand Management, Vol. 24, $\mathrm{n}^{\mathrm{o}} .1$, pp. 3-17.

Davies, G.; Harris, K. (1990). Small Business, The Independent Retailer, London: MacMillan.

Davis, S. (1995). "A vision for the year 2000: brand asset management", Journal of Consumer Marketin, Vol. 12, nº 4, pp. 65-82.

De Chernatony, L.; Dall'Olmo, F. (1998). "Defining a Brand: beyond the literature with experts' interpretations", Journal of Marketing Management, Vol. 5, pp. 417-443.

De Chernatony, L.; McDonald, M. (2003). Creating powerful brands in consumer service and industrial markets ( $3^{\mathrm{a}}$ ed.). Oxford: Butterworth Heinemann.

De Chernatony, L.; Cottam, S.; Segal-Horn, S. (2006). “Communicating services brands' values internally and externally", The Service Industry Journal, Vol. 26, no . 8, pp. 819-836.

De Chernatony, L.; McDonald, M.; Wallace, E. (2013). Creating Powerful Brands (4 ed.). London: Routledge.

De Juan, M.D. (2005). Comercialización y retailing: distribución comercial aplicada. Madrid: Pearson Educación.

Deepa, S. y Chitramani, P. (2013). "Brand building of retail Stores", Journal of Contemporary Research in Management. Vol. 8, n 2, pp. 9-24. 
Dehning, B.; Richardson, V. J., (2002). "Returns on investments in information technology: a research synthesis", Journal of Information Systems, Vol. 16, $\mathrm{n}^{\circ} .1$, pp. 7-30.

Deleersnyder, B.; Geyskens, I.; Gielens, K.; Dekimpe, M.G. (2002). "How cannibalistic is the Internet channel? A study of the newspaper industry in the United Kingdom and the Netherlands", International Journal of Research in Marketing, Vol. 19, pp. 337-348.

Del Rio, A.B.; Vázquez, R.; Iglesias, V. (2002). "El valor de marca: perspectivas de análisis y criterios de estimación”, Cuadernos de Gestión, Vol. 1, n 2, pp. 87-102.

Delgado-Ballester, E.; Munuera, J.L. (2005). "Does brand trust matter to brand equity?", Journal of Product \& Brand Management, Vol. 14, nº. 3, pp. 187-196.

Delgado, E.; Palazón, M.; Sicilia, M. (2013). "All brands need is love: las comunidades virtuales como generadoras de amor a la marca", AEMARK, 2013.

Deloitte. Global Powers of Retailing 2016. Navigating the new digital divide (2016). https://www2.deloitte.com/global/en/pages/consumer-business/articles/global-powers-ofretailing.html. Acceso 29/11/2016

DelVecchio, S; Anselmi, K. (2006): "Sales force automation tools for small businesses", Journal of Small Business Strategy, Vol. 16, n 2, pp.15-27.

Dekimpe, M.G.; Gielens, K.; Raju, J.; Thomas, J.S. (2011). "Strategic assortment decisions in information-intensive and turbulent environments", Journal of Retailing, Vol. 87, $\mathrm{n}^{\circ} .1$, pp. 17-S28.

Dennis, C.; Brakus J.J.; Alamanos, E. (2013), "The Wallpaper Matters: The Influence of the Content of Digital Ads on Cus-tomer In-Store Experience," Journal of Marketing Management, Vol. 29, nº. 3-4, pp. 338-55. 
Dennis, C.; Brakus J.J.; Gupta S.; Alamanos, E. (2014), “The Effect of Digital Signage on Shoppers' Behavior: TheRole of the Evoked Experience," Journal of Business Research, Vol. 67, no. 11, pp. 2250-7.

Deshpande, R.; Farley, J. U. (1998). "Measuring Market Orientation: Generalization and Synthesis", Journal of Market Focus Management, Vol. 2, pp. 213 - 232.

Deulofeu, J. (2002). Gestión de calidad total en el comercio detallista, Barcelona: Pirámide.

Díez de Castro, E.C. [coord.] (1997). Distribución Comercial, Madrid: McGraw Hill.

Ding, C,G.; Tseng, T.H. (2015), "On the relationshpis among brand experience, hedonic emotions, and brand equity", European Journal of Marketing, Vol.49, nº. 7/8, pp. 9941015.

Dobni, D.; Zinkhan, G.M. (1990). "In search of brand image: a foundation analysis", Advances for Consumer Research, Vol. 17, pp. 110-118.

Dodds, W.B.; Monroe, K.B.; Grewal, D. (1991). "Effects of Price, Brand, and Store Information on Buyer's Product Evaluations", Journal of Marketing Research, Vol. 28, nº. 3, pp. $307-319$.

Doz, Y., Santos, J.; Williamson, P.J. (2004). "Marketing Myopia Re-visited: Why Every Company Needs to Learn from the World". Ivey Business Journal, enero - febrero 2004.

East, R.; Harris, P.; Willson, G.; Lomax, W. (1995). "Loyalty to supermarkets", The International Review of Retail, Distribution and Consumer Research, Vol. 5, $\mathrm{n}^{\circ} .1$, pp. 99109.

Eid, R.; El-Gohary, H. (2015). "The impact of E-marketing use on small business enterprises' marketing success", The Service Industries Journal, Vol. 33, nº 1, pp. 31-50. 
Eiriz, V.; Wilson, D. (2006). "Research in relationship marketing: antecedents, traditions and integration”, European Journal of Marketing, Vol. 40, nº. 3/4, pp. 275-291.

Eisend, M.; Stokburger-Sauer, N. E. (2013). "Brand personality: A meta-analytic review of antecedents and consequences", Marketing Letters, Vol. 24, nº. 3, pp. 205-216.

El-Adly, M.I.; Eid, R. (2016). “An empirical study of the relationship between shopping environment, customer perceived value, satisfaction, and loyalty in the UAE malls context”, Journal of Retailing and Consumer Services, Vol. 31, pp. 217-227.

Ellram, L.M.; La Londe, B. J.; Weber, M. M. (1999). "Retail logistics", International Journal of Physical Distribution \& Logistics Management, Vol. 29, nº 7/8, pp. 477-494.

Ellram, L.M.; Zsidisin, G.A. (2002). "Factors that drive purchasing and supply management's use of information technology", IEEE Transactions on Engineering Management, Vol. 49, n. 3, pp. 269-281.

Emrich, O.; Verhoef, P.C. (2014). “The Interplay Between WebDesign and Customers' Cognitive Shopping Orientation in a MultichannelEnvironment", working paper, University of St. Gallen.

Erdem, T.; Swait (1998). "Brand equity as a signaling phenomenon", Journal of Consumer Psychology, Vol. 7, nº. 2, pp. 131-157.

Eroglu, S.A.; Machleit, K.A.; Davis, L.M. (2003). "Empirical testing of a model of online store atmospherics and shopper responses", Psychology \& Marketing, Vol. 20, nº. 2, pp. $139-150$.

Evert de, H.; Wiesel, T.; Pauwels, K. (2013), "Which advertising forms make a difference in online path to purchase?" Boston, MA, disponible en http://www.msi.org/reports/whichadvertising-forms-make-a-difference-in-online-path-to-purchase/

Fandos, J.C. (2010). "La lealtad del consumidor y el efecto moderador de la implicación con el product: una aplicación al sector bancario español”, Tesis Doctoral. Castellón: Universitat Jaume I. 
Fandos, J.C.; Sánchez, J.; Moliner, M.A.; Llorens, J. (2006). “Customer perceived value in banking services”, International Journal of Bank Marketing, Vol. 24, n. 5, pp. 266-283.

Farquhar, P.H. (1989). “Managing brand equity”, Marketing Research, Vol. 1, no. 3, pp. 2433.

Feldwick, P. (1996). "Do we really need brand equity?" The Journal of Brand Management, Vol. 4, n 1, pp. 9-28.

Fernández, R. (1999). "La importancia estratégica del comercio tradicional en la distribución comercial española", Documentos de trabajo de la Facultad de Ciencias Económicas y Empresariales, $\mathrm{n}^{\circ}$. 99-15, Universidad Complutense de Madrid.

Fernández, P. (2002). "Valuation of brands intellectual capital”, Research Paper, n”. 456. España. IESE Universidad de Navarra.

Fernández, R. (2005). "Marco conceptual de las nuevas tecnologías aplicadas a la educación”, Universidad de Castilla-La Mancha, España. http://www.uclm.es/profesorado/ricardo/DefinicionesNNTT.html

Fernández-Sabiote, E.; Román, S. (2012). "Adding clicks to bricks: a study of the consequences on customer loyalty in a service context", Electronic Commerce Research and Applications, Vol. 11, nº 1, pp. 36-48.

Fernie, J.; Fernie, S.; Moore C. (2003). Principles of Retailing. Oxford: Butterworth Heinemaa.

Fiore, M. (2016). 'Direct selling in the wine sector: lessons from cellars in Italy's Apulia region”, British Food Journal, Vol. 118, no. 8, pp. 1926-1939.

Flavián, C.; Gurrea, R. (2003). "El empleo de Internet como nuevo canal de distribución: un análisis de sus principales ventajas e inconvenientes”, Distribución y Consumo, n 72, pp. 64-78. 
Florenthal, B. y Shoham, A. (2010). "Four-mode channel interactivity concept and channel preferences", Journal of Services Marketing, Vol. 24, nº 1, pp. 29-41.

Forero, M.F.; Duque, E.J. (2014). "Evolución y caracterización de los modelos de Brand Equity”, Suma de Negocios, Vol. 5, nº. 12, pp. 158-168.

Forrester. Predictions 2017: Mobile Is The Face Of Digital (2016). https://www.forrester.com/report/Predictions+2017+Mobile+Is+The+Face+Of+Digital/-/ERES136714?docid=136714. Acceso 03/12/2016

Forrester. Predictions 2017: Dynamics That Will Shape The Future In The Age Of The Customer (2016). https://go.forrester.com/wp-content/uploads/Forrester-2017-Predictions.pdf. Acceso 29/11/2016.

Fornell, C.; Larcker, D.F. (1981). "Evaluating structural equations models with unobservable variables and measurement error", Journal of Marketing Research, Vol.18, pp. 39-50.

Frank, B.; Herbas, B.; Enkawa, T.; Schvaneveldt, S.J. (2014). “Affect versus cognition in the chain form preceived quality to customer loyalty: the roles of product beliefs and experience", Journal of Retailing, Vol. 90, nº. 4, pp. 567-586.

Fundación Telefónica (2007). "Preguntas más frecuentes sobre la Sociedad de la Información: ¿Qué son las TIC y qué beneficios aportan a la sociedad?’. http://info.telefonica.es/sociedaddelainformacion/html/faq home.shtml

Fundación Telefónica (2016): La Sociedad de la Información en España 2015. http://www.fundaciontelefonica.com/arte_cultura/publicaciones-listado/pagina-itempublicaciones/itempubli/483/. Acceso 20/10/2016

Fung, K.K.; King, C. (2010). "When experience matters: building and measuring hotel brand equity", International Journal of Contemporary Hospitality Management, Vol. 22, $n^{\circ} .5$, pp. 589-608. 
Gale, B.T. (1994). Managing customer value. New York: The Free Press.

Gallino, S.; Moreno, A. (2014). "Integration of Online and Offline Channles in Retail: The Impact of Sharing Reliable Inventory Availability Information", Management Science, Vol. 60, no. 6, pp. 1434-1451.

García, M. L.; Alcaraz, A.; Fernández, I. (2013). "La distribución comercial en la comunicación con el pequeño comercio independiente en el marco de la web 2.0. Historia y Comunicación Social”, Vol. 18. № Especial Diciembre, pp. 687-702.

Garnica Andrade, A. (2000). "Brand equity: El valor de marca", Segmento, Vol. 2, nº. 8, pp. 1-5.

Gensler, S.; Dekimpe, M.G.; Skiera, B. (2007). "Evaluating channel performance in multichannel environments", Journal of Retailing and Consumer Services, Vol. 14, pp. 17-23.

Gentile, C.; Spiller, N.; Noci, G. (2007). "How to sustain the customer experience: an overview of experience components that co-create value with the customer", European Management Journal, Vol. 25, $\mathrm{n}^{\circ}$. 5, pp 395-410.

Gaffney, J. (2015). "Omnishopper 2016: Taking the Long-Term View on Keeping the Customer", Omnishopper Report, edited by Mastercard.

Gil, I.; Berenguer, G. y Cervera, A. (2008a). "The role of services encounters, services value and job satisfaction in achieving customer satisfaction in business relationship", Industrial Marketing Management, Vol. 37, nº 8, pp. 921-939.

Gil, I.; Servera, D.; Berenguer, G.; Fuentes, M. (2008b). "Logistics service quality: a new way to loyalty", Industrial Management \& Data Systems, Vol. 108, no . 5, pp. 650-668.

Gil Saura, I.; Ruiz Molina, M.E. (2012). "Las tecnologías que implementan los minoristas y las tecnologías que gustan a los clientes, Distribución y Consumo, Vol. 22, nº. 121, pp. 7278. 
Gilmore, H.; Pine, B. II (2002). "Differentiating hospitality operations via experiences: why selling services is not enough", Cornell Hotel and Restaurant Administration Quarterly, Vol. 43, n. 3, pp. 87-96.

Godás, L. (2007). “La distribución: comercio mayorista y minorista”, Gestión Farmaceútica, Vol. 26, nº 3, pp. 110-114.

González-Benito, J., (2007). "Information technology investment and operational performance in purchasing”, Industrial Management \& Data Systems, Vol. 107, nº. 2, pp. 201-228.

González-Benito, Ó. y Martos-Partal, M. (2012). Precio versus calidad en la compra de marca de distribuidor: efecto moderador del posicionamiento del distribuidor. Working Paper, Universidad de Salamanca.

Goodman, S.; Remaud, H. (2015). "Store choice: How understanding consumer choice of "where" to shop may assist the small retailer", Journal of Retailing and Consumer Services, Vol. 23, pp. 118-124.

Goodyear, M. (1996). "Divided by a common language", Journal of the Market Research Society, Vol. 38, nº. 2, pp. 105-122.

Google/Purchased Digital Diary (2016), "How Consumers Solve Their Needs in the Moment" ["Cómo los consumidores resuelven sus necesidades en el momento"], muestra representativa de usuarios de smartphones en EE. UU. $=1000$, respuestas $=14.840$, necesidades $=10.540 ;$ usuarios de smartphones por tipo de necesidad =614-940; compradores por tipo de necesidad $=228-763$, mayo de 2016. https://www.thinkwithgoogle.com/intl/es-es/article/como-el-movil-ha-transformado-el-modo-enque-los-usuarios-consiguen-lo-que-desean-datos-sobre-el-nuevo-comportamiento-de-losconsumidores/. Acceso, 15 noviembre 2016 
Gounaris, S. (2008). "The Notion of Internal Market Orientation and Employee Job Satisfaction: Some Preliminary Evidence”, The Journal of Services Marketing, Vol. 22, No. 1 , pp. 68-90.

Gourio, F.; Rudanko, L. (2011) “Customer capital”. Unpublished working paper. Boston University.

Graeber, C. (2013). "Trends 2013: Five trends shaping the next generation of North American digital banking”, Cambridge, MA: Forrester Research.

Grégoire, Y.; Fisher, R. J. (2008). "Customer betrayal and retaliation: when your best customers become your worst enemies", Journal of the Academy of Marketing Science, Vol. 36, n'. 2, pp. 247-261.

Gremler, D. D.; S. W. Brown (1996), "Service Loyalty: Its Nature, Importance, and Implications," en "Advancing Service Quality: A Global Perspective”, B. Edvardsson, S. W. Brown, R. Johnston, et al. Ed. International Service Quality Association.

Grewal, D.; Baker, J.; Krishnan, R.; Borin, N. (1998). "The effect of store name, brand name and price discounts on consumers' evaluations and purchase intentions", Journal of Retailing, Vol. 174, nº. 23, pp. 331-352.

Grewal, D.; Baker, J.; Levy, M.; Voss, B.G. (2003). "The effects of wait expectations and store atmosphere evaluations on patronage intentions in service-intensive retail stores", Journal of Retailing, Vol. 79, nº 4, pp. 259-268.

Grewal, D.; Levy, M. (2007). "Retailing research: past, present, and future", Journal of Retailing, Vol. 83, nº 4, pp. 447-464.

Grewal, D.; Levy, M.; Kumar, V. (2009). "Customer experience management in retailing: an organizing framework", Journal of Retailing, Vol. 85, nº. 1, pp. 1-14. 
Grewal, D.; Roggeveen, A.L.; Compeau, L.D.; Levy, M. (2012). "Retail value-based pricing strategies: new times, new technologies, new consumers", Journal of Retailing, Vol. 88, no. 1, pp. 1-6.

Grönroos, C. (1984). “A Service Quality Model and Its Marketing Implications”, European Journal of Marketing, Vol. 18, No. 4, pp. 36-44.

Grundey, D. (2008). "Editorial applying sustainability principles in the economy", Technological and Economic Development of Economy, Vol. 14, nº. 2, pp. 101-106.

Guenzi, P. y Pelloni, O. (2004). "The impact of interpersonal relationships on customer satisfaction and loyalty to the service provider", International Journal of Service Industry Management, Vol. 15, n 3, pp. 365-384.

Guillén, T. (2007). Las TIC en la estrategia empresarial. Valencia: Ed. Anetcom.

Guimaraes, T., Cook, D., y Natarajan, N., (2002). "Exploring the importance of business clock speed as a moderator for determinants of supplier network performance”, Decision Sciences, Vol. 33, n 4, pp. 629-644.

Gulati, R.; Garino, J. (2000). "Get the Right Mix of Bricks \& Clicks,”, Harvard Business Review, Vol. 78, no. 3, pp. 107-14.

Gupta, S.; Lehmann, D.R.; Stuart, J.A. (2004). "Valuing Customers", Journal of Marketing Research, Vol. 41, pp. 7-18.

Gurau, C. y Ranchhod, A. (2002). "How to calculate the value of a customer-Measuring customer satisfaction: A platform for calculating, predicting and increasing customer profitability", Journal of Targeting, Measurement \& Analysis for Marketing, Vol. 10, n 3, pp. 203-219. 
Gwinner, K.P.; Gremler, D.; Bitner, M.J. (1998). "Relational benefits in services industries: the consumers' perspective", Journal of the Academy of Marketing Science, Vol. 26, $\mathrm{n}^{\circ} .2$, pp. 101-114.

Hair, J.H.; Black, W.C.; Babin, B.J.; Anderson, R.E.; Tatham, R.L. (2006). Multivariate Data Analysis. 6 Ed. Upper Saddle River, NJ: Prentice Hall.

Halstead, D. and Ward, C.B. (1995). "Assessing the vulnerability of private label brands", Journal of Product and Brand Management, Vol. 4, nº. 3, pp. 38-48.

Halvena, W.J.; Holbrook, M.B. (1986). "The varieties of consumption experience: comparing two typologies of emotion in consumer behavior", Journal of Consumer Research, Vol. 13, n. 3, pp. 394-404.

Hamzah, Z.L.; Syed Alwi, S.F.; Othman, M.N. (2014). "Designing corporate brand experience in an online context: A qualitative insight", Journal of Business Research, Vol. 67, pp. 2299-2310.

Hartman, K.B.; Spiro, R.L. (2005). "Recapturing store image in customer-based store equity: a construct conceptualization, Journal of Business Research, Vol. 58, pp. 11121120 .

Haydock, M. (2000). Multichannel strategies win confidence. DM News, $21^{\text {st }}$ August.

Healy, M.J.; Beverland, M.B.; Oppewal, H.; Sands, S. (2007). "Understanding retail experiences - the case for ethnography", International Journal of Market Research, Vol. $49, n^{\circ} .6$, pp. $751-778$.

Heikkila, J. (1991). "Success of software packages in small businesses", European Journal of Information Systems, Vol. 1, nº.pp. 159-169. 
Hellier, P.K.; Geursen, G.M.; Carr, R.A.; Rickard, J.A. (2003). "Customer repurchase intention: A general structural equation model", European Journal of Marketing, Vol. 37, pp. $1762-1800$.

Hemsley-Brown, J.; Oplatka, I. (2006). "Universities in a competitive global marketplace: A systematic review of the literature on higher education marketing", International Journal of Public Sector Management, Vol. 19, n'. 4, pp. 316-338.

Herhausen, D.; Binder, J.; Schoegel, M.; Herrman, A. (2015). "Integrating bricks with clicks: retaier-level and channel-level outcomes of online-offline channel integration", Journal of Retailing, Vol. 91, nº. 9, pp. 309-325.

Hoffman, K.D.; Turley, L.W. (2002). "Atmospherics, service encounters and consumer decision making: an integrative perspective", Journal of Marketing Theory and Practice, Vol. 10, $\mathrm{n}^{\circ} 3$, pp. 33-47.

Holbrook, M.; Hirschman, E.C. (1982). "The experiential aspects of consumption: consumer fantasies, feelings and fun", Journal of Consumer Research, Vol. 9, nº 2, pp. $132-140$.

Holbrook, M. (2000). "The millennial consumer in the texts of our times: experience and entertainment", Journal of Macromarketing, Vol. 20, nº. 2, pp. 178-192.

Hong-bumm, K.; Woo, G.K.; Jeong, A.A. (2003). "The effect of consumer-based brand equity on firms' financial performance", Journal of Consumer Marketing, Vol. 20, n 4, pp. 335-351.

Hormigo, E. (2002). Dominar el Marketing es Fácil: Revisión de Conceptos de Marketing. Madrid: ESIC Editorial.

Hoyer, W.D.; Brown, S.P. (1990). "Effects of brand awareness on choice for a common, repeat-purchase product", Journal of Consumer Research, Vol. 17, pp. 141-148. 
Huang, M. (2015). "The influence of relationship marketing investments on customer gratitude in retailing", Journal of Business Research, Vol. 68, pp. 1318-1323.

Huang, R.; Sarigöllü, E. (2012). "How brand awareness relates to market outcome, brand equity, and the marketing mix", Journal of Business Research, Vol. 65, pp. 92-99.

Huang, Y.; Huddleston, P. (2009). "Retailer premium own-brands: creating customer loyalty through own-brand products advantage", International Journal of Retail and Distribution Management, Vol. 37, nº. 11, pp. 975-992.

Huang, L.; Lu, X.; Ba, S. (2016). "An empirical study of the cross-channel effects between web and mobile shopping channels", Information and Management, Vol. 53, pp. 265-278.

Hyman, David (2012), "Deloitte 2011 Global Powers of Retailing Report", disponible en https://nrf.com/news/sneak-peek-stores-global-powers-of-retailing-2011].

Iglesias, O.; Singh, J.J.; Batista-Foguet, J.M. (2011). "The role of brand experience and affective commitment in determining brand loyalty", Journal of Brand Management, Vol. $18, n^{\circ} .8$, pp. 570-582.

INE (2016). Encuesta de uso de TIC y Comercio Electrónico en las empresas 2013-2016. http://www.ontsi.red.es/ontsi/es/indicador/empresas-realizan-ventas-comercioelectr\%C3\%B3nico-sobre-el-total-de-empresas. Acceso 20 noviembre 2016

Jacoby, J.; Kynner, D.B. (1973). "Brand loyalty versus repeat purchasing behavior", Journal of Marketing Research, Vol. 10, pp. 1-9.

Janda, S.; Seshadri, S., (2005). "The influence of purchasing strategies on performance", Journal of Business \& Industrial Marketing, Vol. 16, nº. 4, pp. 294-308.

Jara, M.; Cliquet, G. (2007). "Retail brand equity: a conceptual and differentiated approach", en $14^{\text {th }}$ European Association of Education and Research in Commercial Distribution. Alemania. 
Jara, M.; Cliquet, G. (2012). "Retail brand equity: Conceptualization and measurement", Journal of Retailing and Consumer Services, Vol. 19, nº. 1, January, pp. 140-149.

Jia, Y.; Zhang, W. (2013). "Brand equity valuation: an optimized Interbrand model which is based on the consumer perspective", International Academic Workshop on Social Science. Atlantis Press, pp. 325-330.

Jinfeng, W.; Zhilong, T. (2009). "The impact of selected store image dimensions on retailer equity: evidence from 10 Chinese hypermarkets", Journal of Retailiing and Consumer Services, Vol. 16, pp. 486-494.

Johnson, M.D.; Herrmann, A.; Huber, F. (2006). "The evolution of loyalty intention", Journal of Marketing, Vol. 70, n. 2 pp 122-132.

Jones, J.T.; Pelham, B.U.L.; Mirenberg, M.; Hetts, J.J. (2002). "Mame letter preferences are not merely mere exposure: implicit egotism as self regulation", Journal of Experimental Social Psychology, Vol. 38, pp. 170-177.

Jones, M.A.; Reynolds, K.E.; Arnold, M.J. (2006). "Hedonic and utilitarian shopping value: investigating differential effects on retail outcomes", Journal of Business Research, Vol. 59, pp. 974-981.

Jorgensen, F.; Mathisen, T.A.; Pedersen, H. (2016). "Brand loyalty among Norwegian car owners", Journal of Retailing and Consumer Services, Vol. 31, pp. 256-264.

Juaneda-Ayensa, E.; Mosquera, A.; Sierra, Y. (2016). "Omnichannel Customer Behavior: key drivers of technology acceptance and use and the effects on purchase intention". Frontiers in Psychology, Vol. 7, art. 1117, pp. 1-11.

Jüttner, U.; Schaffner, D.; Windler, K.; Maklan, S. (2013). “Customer service experiences: developing and applying a sequential incident laddering technique", European Journal of Marketing, Vol. 47, nº 5/6, pp. 738-769. 
Kallweit, K.; Spreer, P.; Toporowski, W. (2014). "Why do customers use self-service information technologies in retail? The mediating effect of perceived service quality", Journal of Retailing and Consumer Services, Vol. 21, pp. 268-276.

Kalakota, R. y Whinston, A.B. (1996). Frontiers of Electronic Commerce. Reading, Mass: Addison-Wesley.

Kamakura, W.A.; Russell, G.J. (1993). "Measuring brand value with scanner data", International Journal of Research in Marketing, Vol. 10, pp. 9-22.

Kang, J.M.; Mun, J.M.; Johnson, K.K.P. (2015). "In-store mobile usage: downloading and usage intention toward mobile location-based retail apps", Computers in Human Behaviour, Vol. 46, pp. 210-217.

Kang, J.; Park-Poaps, H. (2010). "Hedonic and utilitarian shopping motivations of fashion leadership", Journal of Fashion Marketing and Management, Vol. 14, pp. 312-328.

Kapferer, J.N. (2004). The New Strategic Brand Management: Creating and Sustaining Brand Equity Long Term. London: Kogan Page.

Katros, V. (2000). "A note on Internet technologies and retail industry trends", Technology in society, Vol. 22, $\mathrm{n}^{\mathrm{o}} 1$, pp. 75-81.

Keaveney, S.M.; Hunt, K.A. (1992). “Conceptualization and operationalization of retail store image: a case of rival middle-level theories", Journal of the Academy of Marketing Science, Vol. 20, nº.2, pp.165-175.

Keith, R. J. (1960). “The marketing revolution”, Journal of Marketing, Vol. 24, nº. 1, pp. 35-38.

Keller, K. L. (1993). “Conceptualizing, measuring, and managing consumer-based brand equity", Journal of Marketing, Vol. 57, n. 1, pp. 1-22. 
Keller, K.L. (1998). Strategic Brand Management: Building, Measuring and Managing Brand Equity. Upper Saddle River, NJ: Prentice-Hall.

Keller, K. L. (2003). Strategic brand management: Building, measuring, and managing brand equity. Upper Saddle River, NJ: Prentice-Hall.

Keller, K. L. (2010). "Brand Equity Management in a Multichannel, Multimedia Retail Environment", Journal of Interactive Marketing, Vol. 24, nº 3, pp. 58-70.

Kerin, R.A.; Jain, A.; Howard, D.J. (1992). "Store shopping experience and consumer price-quality-value perceptions", Journal of Retailing, Vol. 68, n.4, pp. 376-397.

Kerin, R.A.; Sethuraman, R. (1998). "Exploring the brand value-shareholder value nexus for consumer goods companies", Journal of the Academy of Marketing Science, Vol. 26, nº. 4; pp. 260-273.

Khan, Z. (2007). "Best and worst of European cross-channel experience, 2007". Forrester Research, September, 2007.

Kim, J.; Forsythe, S. (2007). "Hedonic usage of product virtualization technologies in online apparel shopping”, International Journal of Retail and Distribution Management, Vol. 35, no. 6, pp. 502-514.

Kim, W.G.; Jin-Sun, B.; Kim, H.J. (2008). "Multidimensional customer-based Brand equity and its consequences in mid-priced hotels", Journal of Hospitality and Tourism Research, Vol. 32, pp. 235-254

Kim, C., Tao, W., Shin, N. and Kim, K. (2010). “An empirical study of customers' perceptions of security and trust in e-payment systems", Electronic Commerce Research and Applications, Vol. 9, $\mathrm{n}^{\circ}$ 1, 2010, 84-95.

Kim, S.; Cha, J.; Knutson, B.J.; Beck, J.A. (2011). "Development and testing of the Consumer Experience Index”, Managing Service Quality, Vol. 21, n. 2, pp. 112-132. 
Kim, W.G.; Jin-Sun, B.; Kim, H.J. (2008). "Multidimensional customer-based brand equity and its consequences in midpriced hotels", Journal of Hospitality \& Tourism Research, Vol. 32, n'. 2, pp. 235-254.

Kimpakorn, N.; Tocquer, G. (2010). "Service brand equity and employee brand commitment", Journal of Services Marketing, Vol. 24, nº 5, pp. 378-388.

Klaus, Ph. (2013). "The case of Amazon.com: Towards a conceptual framework of online customer service experience (OCSE) using emerging consensus technique (EC)", Journal of Services Marketing, Vol. 27, nº. 6, pp. 443-457.

Komarov, M.; Avdeeva, Z. (2015). "Customer experience management for smart commerce based on cognitive maps”, Procedia Computer Science, Vol. 55, pp. 970-979.

Konecnik, M.; Gartner, W.C. (2007). "Customer-based brand equity for a destination", Annals of Tourism Research, Vol. 34, nº. 2, pp. 400-421.

Konecnik, M.; Ruzzier, M. (2013). “A modern approach to brand conceptualization”, Transformations in Business \& Economics, Vol. 12, no 1 (28), pp. 121-134.

Konus,, U.; Verhoef, P.C.; Neslin, S.A. (2008), "Multichannel shopper segments and their covariates", Journal of Retailing, Vol. 84, n. 4, pp. 398-413.

Konus, U.; Verhoef, P.C.; Neslin, S.A. (2014), “The effect of search channel elimination on purchase incidence, order size and channel choice," International Journal of Research in Marketing, Vol. 31, nº 1, pp. 49-64.

Kotler, P. (1973) “Atmospherics as a marketing tool”, Journal of Retailing, Vol. 49, n. 4.

Kotler, P. (1992). Dirección de Marketing. Madrid: Prentice Hall International.

Kotler, P. (1994). Marketing Management. Analysis, Planning, Implementation and Control. Englewood Cliffs: Prentice Hall. 
Kotler P.; Armstrong, G. (2008). Fundamentos de Marketing ( $8^{\circ}$ ed.). México: Pearson Educación.

Kotler, P.; Kartajaya, H.; Setiawan, I. (2010). Marketing 3.0: From Products to Customers to the Human Spirit. New Jersey: John Wiley \& Sons, Inc.

Kotler, P.; Keller, K.L. (2012). Marketing Management (14 ${ }^{\text {th }}$ Edition). Essex: Pearson Education Limited.

Kotler, P.; Keller, K.L. (2016). Marketing Management (15 ${ }^{\text {th }}$ Edition). Essex: Pearson Education Limited.

Krafft, M.; Goetz, O.; Mantrala, M.; Sotgiu, F.; Tillmanns, S. (2015). "The evolution of marketing channel research domains and methodologies: an integrative review and future directions", Jourmal of Retailing, Vol. 91, nº 4, pp. 569-585.

Krishnan, H.S. (1996). “Characteristics of memory associations: a consumer-based brand equity perspective", International Journal of Research in Marketing, Vol. 13, nº. 4, pp. 389-405.

Kumar, V.; Venkatesan, R. (2005). "Who are the multichannel shoppers and how do they perform?: correlates of multichannel shopping behaviour", Journal of Interactive Marketing, Vol. 19, nº 2, pp. 44-62.

Kumar, U.; Mishra, P. (2012). "What is a brand? A perspective on brand meaning", European Journal of Business and Management, Vol. 4, nº. 3, pp. 122-133.

Kurnia, S.; Choudrie, J.; Manbubur, R.M.; Alzougool, B. (2015). "E-commerce technology adoption: a Malasyan grocery SME retail sector study", Journal of Business Research, Vol. 68, pp. 1906-1918. 
Küster, I.; Vila, N.; Aldás, J. (2011). "Brand equity innovation. El uso de las nuevas tecnologías en el sector del vino para el incremento del valor de marca", Distribución y consumo, año no 21, nº 116, pág. 1-15.

Laforet, S.; Saunders, J. (1994). "Managing Brand portfolios: how the leaders do it", Journal of Advertising Research, Vol. 34, nº. 5, pp. 64-76.

Lai, F.; Griffin, M.; Babin, B.J. (2009). "How quality, value, image, and satisfaction create loyalty at a Chinese telecom", Journal of Business Research, Vol. 62, n. 10, pp. 980-986.

Lambin, J.J. (2009). Marketing estratégico. Madrid: ESIC Editorial.

Lambin, J.J.; Galluci, C.; Sicurello, C. (2009). Dirección de Marketing. Gestión estratégica y operativa del mercado. Mexico D.F.: McGraw-Hill.

Lapierre, J. (2000). "Customer-perceived value in an industrial context", Journal of Business \& Industrial Marketing, Vol. 15, n. 2/3, pp. 122-140.

Larkin, Y. (2013). "Brand perception, cash flow stability and financial policy", Journal of Financial Economics, Vol. 110, pp. 232-253.

Lassar, W.; Mittal, B.; Sharma, A. (1995). "Measuring customer-based brand equity", Journal of Consumer Marketing, Vol.12, nº 4, pp. 11-19.

Lee, G. (2010), “Death of 'Last Click Wins': Media Attribution and the Expanding Use of Media Data," Journal of Direct, Data and Digital Marketing Practice, Vol. 12, nº. 1, pp. $16-26$.

Lee, J.S.; Back, K.J. (2010). "Reexamination of attendee-based brand equity", Tourism Management, Vol. 31, nº. 3, June, pp. 395-401. 
Lee, H.; Kim, J.; Fiore, A.M. (2010). "Affective and cognitive online shopping experience. Effects of Image Interactivity Technology and experimenting with appearance", Clothing and Textiles Research Journal, Vol. 28, $\mathrm{n}^{\circ}$. 2, pp. 140-154.

Leggett, K.; Schoeller, A.; Band, W.; Bookstein, S. (2013). "Tech Radar for AD\&D pros: Contact center solutions for customer service", Cambridge, MA: Forrester Research.

Lemke, F.; Clark, M.; Wilson, H. (2011). "Customer experience quality: an exploration in business and consumer contexts using repertory grid technique". Journal of the Academy of Marketing Science. Vol. 39, pp. 846-869.

Lenderman, M.; Sánchez, R. (2008). Marketing Experiencial. La Revolución de las Marcas. Madrid: ESIC Editorial.

Leuthesser, L. (1988). Defining, measuring and managing Brand Equity. Philadelphia: Marketing Science Institute.

Levenburg, N.M; Schwarz, T.V; Motwani, J. (2005): “Understanding adoption of internet technologies among SMEs", Journal of Small Business Strategy. Vol. 16, nº 1, pp. 51-69.

Levitt, T. (1960). "Marketing Myopia”, Harvard Business Review, July - August, pp 45 56.

Lewis, J.; Whysall, P.; Foster, C. (2014). "Drivers and technology-related obstacles in moving to multichannel retailing", International Journal of Electronic Commerce, Vol. 18, $n^{\circ} .4$, pp. 43-67.

Li, H. A.; Kannan, P. K. (2014). "Attributing conversions in a multichannel online marketing environment: An empirical model and a field experiment", Journal of Marketing Research, Vol. 51, nº. 1, pp. 40-56.

Liang, C.; Wang, W. (2005). "Integrative research into the financial services industry in Taiwan: relationship bonding tactics, relationship quality and behavioural loyalty", Journal of Financial Services Marketing, Vol. 10, nº 1, pp. 65-83. 
Liang, H.; Zhang, Z. (2012). "The effects of industry characteristics on the sources of technological product and process innovation", The Journal of Technology Transfer, Vol. $37, n^{\circ} .6$, pp. 867-884.

Liao, C., Liu, C. y Chen, K. (2011). "Examining the impact of privacy, trust and risk perceptions beyond monetary transactions: An integrated model", Electronic Commerce Research and Applications, Vol.10, pp. 702-715.

Light, L. (1990). "Point of view: advertising and the law of dominance", Journal Advertising Research, August-September, pp. 49-52.

Liljander, V.; Polsa, P.; Van Riel, A. (2009). "Modelling consumer responses to an apparel store brand: Store image as a risk reducer", Journal of Retailing and Consumer Services, Vol. 16, no. 4, pp. 281-290.

Lin, J.; Lu, Y.; Wang, B.; Weei, K. (2011). "The role of inter-channel trust transfer in establishing mobile commerce trust". Electronic Commerce Research and Applications, Vol. 10, pp. 615-625.

Lindgren, A. (2004). "Relationship use and market dynamism: a model of relationship evolution", Journal of Marketing Management, Vol. 20, pp. 25-38.

Lings, I.N.; Greenley, G.E. (2005). "Measuring Internal Market Orientation". Journal of Service Research, Vol. 7, nº. 3, pp. 290-306.

Liu, C.; Guob, Y.; Lee, C. (2011). "The effects of relationship quality and switching barriers on customer loyalty", International Journal of Information Management, Vol. 31, pp. 71-79.

Liu, C.; Liu, H.; Lin, W. (2015). "Constructing customer-based museums brand equity model: the mediating role of brand value", International Journal of Tourism Research, Vol. 17, pp. 229-238. 
Lovelock, C. (1991). Services marketing, text, cases and readings, $2^{\mathrm{a}}$ ed., Prentice Hall International.

Low, G.S.; Lamb, C.W. (2000). "The measurement and dimensionality of brand associations", Journal of Product y Brand Management, Vol. 9, nº, pp. 350-368.

Lowson, R. (2001). "Analysing the Effectiveness of European Retail Sourcing Strategies", European Management Journal, Vol. 19, nº 5, pp. 543-551.

Lu, J.; Yao, J.E.; Yu, C.S. (2005). "Personal innovativeness, social influences and adoption of wireless Internet services via mobile technology", Journal of Strategic Information Systems, Vol.14, pp. 245-268.

Lynch, J.; de Chernatony, L. (2004). "The power of emotion: brand communication in business to business markets". Journal of Brand Management, Vol. 11, no.5, pp. 403-419.

Macdonald, E.K.; Sharp, B.M. (2000). "Brand Awareness effects on consumer decision making for a common, repeat purchase product: a replication", Journal of Business Research, Vol. 48, pp. 5-15.

Madlberger, M., (2006). "Exogenous and endogenous antecedents of online shopping in a multichannel environment: evidence from a catalog retailer in the German-speaking world”, Journal of Electronic Commerce in Organizations, Vol. 4, nº. 4, pp. 29-51.

Manhas, P.S.; Tukamushaba, E.K. (2015). "Understanding service experience and its impact on brand image in hospitality sector". International Journal of Hospitality Management, Vol. 45, pp. $77 * 87$.

Manning, H. and Dorsey, M. (2008). "Customer experience in a down economy". Forrester Research, December 2008. 
Maraver, G. (Coordinador), Camarero, C., Concejero, A., Martínez, F. J., Molinillo, S., Navarro, A., Oubiña, F. J., Parra F., Peral, B. y Tintoré, S. (2006). Distribución Comercial. Barcelona: Ed. UOC.

Marín, A.; Gil-Saura, I. (2016). "Innovar en el comercio minorista: influencia de las TIC y sus efectos en la satisfacción del cliente", Cuadernos de Gestión, 04-05-2016. DOI: 10.5295/cdg.150556am

Martin-Guart, R.F..; Fernández, C.J. (2014). "La publicidad y la agencia de medios frente al cambio en el ecosistema mediático", Cuadernos.info, Vol. 34, pp. 13-25.

Martin-Ruíz, D.; Gremler, D.D.; Washburn, J.H.; Cepeda-Carrión, G. (2008). "Service value revisited: specifying a higher-order, formative measure", Journal of Business Research, Vol. 61, pp. 1278-1291.

Mathwick, C.; Malhotra, N.K.; Rigdon, E. (2002). "The effect of dynamic retail experiences on experiential perceptions of value: an Internet and catalog comparison”. Journal of Retailing, Vol. 78, pp. 51-60.

Martineau, P. (1958). "The personality of the retail store", Business Harvard Review, Vol. 36, pp. $47-55$.

Matusitz, J.; Leanza, K. (2011). "ASDA: Organic growth of a Retailer in the United Kingdom?” Journal of International Food \& Agribusiness Marketing, Vol. 23, n 2, pp. 128-150.

Maxwell, J. (2013, January). "Demystifying the online shopper: 10 myths of multichannel retailing", PricewaterhouseCoopers.

Mazursky, D.; Jacoby, J. (1986), "Exploring the development of store images”, Journal of Retailing, Vol. 62, n. 2, pp. 145-165.

McGoldrick, P. (2002). Retail Marketing. New York: McGraw-Hill Education. 
McPartlin, S.; Dugal, L.F. (2012). "Understanding how US online shoppers are reshaping the retail experience”, PricewaterhouseCoopers.

Miseberg, B. (2016). "The effectiveness of e-tailers' communication practices in stimulating sales of niche versus popular products”, Journal of Retailing, Vol. 92, n 3, pp. 319-332

Medrano, N.; Olarte-Pascual, C.; Pelegrín-Borondo, J.; Sierra-Murillo, Y. (2016). "Consumer Behavior in Shopping Streets: The Importance of the Salesperson's Professional Personal Attention", Frontiers in Psychology, Vol. 7.

Melero, I.; Sese, F.; Verhoef, P.C. (2016). "Recasting the customer experience in today's omni-channel environment”, Universia Business Revue, Vol. 2016, pp. 18-37.

Mellens, M.; Dekimpe, M.G.; Steenkamp, E.M. (1996). “A review of brand-loyalty measures in marketing”, Tijdschrift voor Economie en Management, Vol. 36, pp. 507-533.

Messinger, P.R.; Narasimhan, C. (1997). “A model of retail formats based on consumers' economizing on shopping time", Marketing Science, Vol. 16, n 1, pp. 1-23.

Meyer, C.; Schwager, A. (2007). "Understanding customer experience”. Harvard Business Review, Vol. 85, n², pp. 116-126.

Michell, P.; King, J.; Reast, J. (2001). "Brand Values Related to Industrial Products". Industrial Marketing Management, Vol. 30, pp. 415-425.

Miller, D., Clemons, E. y Row, M. (1993). Information technology and the global virtual corporation. In S. Bradley, J. Hausman \& R. Nolan (Eds.), Globalization, technology and competition (283-307). Boston MA: Harvard University School Press.

Miquel, S.; Parra, F.; Lhermis, C.; Miquel, M. F. (2008). Distribución Comercial, (6 ${ }^{\mathrm{a}}$ Edición), Madrid: Editorial Esic. 
Mohd, N.; Nasser, M.; Mohamad, O. (2007). "Does Image of Country-of-origin Matter to Brand Equity?”. Journal of Product and Brand Management, Vol. 16, nº 1, pp. 38-48.

Moliner, B.; Giol, I.; Ruiz, M.E. (2011). "Conceptualizing and measuring loyalty: towards a conceptual model of tourist loyalty antecedents", Journal of Vacation Marketing, Vol. 17, pp. $65-81$.

Möller, K.; Halinen, A. (2000). "Relationship Marketing Theory: its roots and directions", Journal of Marketing Management, Vol. 16, nº 1/3, pp. 29-54.

Monroe, K. (2007). Pricing: making profitable decisions. $3^{\mathrm{a}}$ ed. Nueva York: McGrawHill.

Moon, H.; Han, S.H.; Chun, J.; Hong, S.H. (2016). "A design process for a customer journey map: a case study on mobile services", Human Factors and Ergonomics in Manufacturing \& Service Industries, Vol. 26, nº 4, pp. 501-514.

Moore, K.; Reid, S. (2008). "The birth of brand: 4000 years of branding”. Business History, Vol. 50, no 4, pp. 419-432.

Moral, M.; Fernández, M. (2012). "Nuevas tendencias del marketing: El marketing experiencial”, Revista Entelequia, no 14, pp. 237-251.

Morales, E. (2007). Innovar o morir. Cómo obtener resultados excepcionales con baja inversion. Bogotá: CESA-Mayol.

Moreno, A.R.; Miquel, M.J.; Andreu, L. (2013). "Efectos de los componentes congitivos y afectivos de la imagen del establecimiento en la intención de recompra: una aplicación en el pequeño comercio minorista”, AEMARK 2013

Morschett, D.; Swoboda, B.; Schramm-Klein, H. (2005). "Perception of store attributes and overall attitude towards grocery retailers: the role of shopping motives", International Review of Retail Distribution and Consumer Research, Vol. 15, nº. 4, pp. 423-447. 
Moutaftsi, P.; Kyratsis. P. (2016). "Visual brand identity of food products: a customer's perspective", Journal of Applied Packaging Research, Vol. 8, n. 3, pp.1-14.

Mukhopadhyay, R., Kekre, S. y Kalathur, S., (1995). "Business value of information technology: a study of electronic data interchange", MIS Quarterly, Vol. 19, nº 2, 137-156.

Muniz, K.M.; Marchetti, R.Z. (2012). "Brand personality dimensions in the Brazilian context”. Brazilian Administrative Review, Vol. 9, pp. 168-188.

Munuera, J.L.; Rodríguez, A.I. (2007). Estrategias de marketing. Un enfoque basado en el proceso de dirección. Madrid: Ed. ESIC.

Murphy, G B.; Celuch, K.; Callaway, S.K. (2007). "Small business internet use and strategic flexibility". Journal of Small Business Strategy, Vol. 18, nº 1, pp. 57-68.

Musekiwa, A.; Chiguvi, D.; Hogo, H. (2013). "Customer based retail brand equity (RBE) dimensions effect on retail brand equity for OK supermarket in Bindura". International Journal of Business and Management, Vol. 8, $\mathrm{n}^{\circ}$. 19, pp. 45-54.

Nah, F.F.H.; Eschenbrenner, B.; DeWester, D. (2011). "Enhacing Brand Equity through flow and telepresence: a comparison of 2D and 3D virtual worlds". MIS Quarterly, Vol. 35, no. 3, pp. 731-747.

Nam, J.; Ekinci, Y; Whyatt, G. (2011). "Brand equity, brand loyalty and consumer satisfaction", Annals of Tourism Research, Vol. 38, n. 3, pp. 1009-1030.

Naylor, G.; Kleiser, S.B.; Baker, J.; Yorkston, E. (2008). "Using transformational appeals to enhance the retail experience". Journal of Retailing, Vol. 84, $\mathrm{n}^{\circ}$ 1, pp. 49-57.

Ndubisi, N.O.; Matanda, M.J. (2011). "Industrial marketing strategy and B2B management by SMEs”. Industrial Marketing Management, Vol. 40, pp. 334-335. 
Neslin, S.; Grewal, D.; Leghorn, R.; Shankar, V.; Teerling, M.; Thomas, J.; Verhoef, P. (2006). "Challenges and opportunities in multichannel customer management". Journal of Service Research, Vol. 9, no 2, pp. 91-112.

Neslin, S.A.; Shankar, V. (2009). "Key issues in multichannel customer management: current knowledge and future directions", Journal of Interactive Marketing, Vol. 23, $\mathrm{n}^{\mathrm{o}}$. 1, pp. 70-81.

Nicholson, M.; Clarke, J.; Blakemore, M. (2002). "One brand, three ways to shop: situational variables and multichannel consumer behaviour", Review of Retail, Distribution and Consumer Research, Vol.12, nº. 2, pp. 131-148.

Niels, S.; Natter, M. (2012). "Does private label quality influence consumers' decisión on where to shop?”, Journal of Psychology and Marketing, Vol. 29, n. 4, pp. 279-292.

Nielsen (2014). The digital consumer. Consultado 2 de agosto de 2016. http://www.nielsen.com/content/dam/corporate/us/en/reportsdownloads/2014\%20Reports/the-digital-consumer-report-feb-2014.pdf>

Nielsen (2016). “Comercio Global Conectado: ¿es la e-tail la nueva terapia para los retailers?" Consultado 3 de diciembre de 2016. http://www.nielsen.com/content/dam/nielsenglobal/latam/docs/reports/2016/EstudioGlobal ComercioConectado.pdf

Nunes, G.; Haigh, D. (2003). Marca: valor do intangivel, medindo e gerenciando seu valor economico. Sao Paulo: Atlas.

Nyadzayo, M.W.; Matanda, M.J.; Ewing, M.T. (2011). "Brand relationship and brand equity in franchising”. Industrial Marketing Management, Vol 40, pp. 1103-1115.

Nyadzayo, M.W.; Khajehzadeh, S. (2016). "The antecedents of customer loyalty: A moderated mediation model of customer relationship management quality and brand image", Journal of Retailing and Consumer Services, Vol. 30, pp. 262-270. 
Nysveen, H.; Pedersen, P.E.; Skard, S. (2013). "Brand experiences in service organizations: exploring the individual effects of brand experience dimensions". Journal of Brand Management, Vol. 20, nº 5, pp. 404-423.

Observatorio de las Telecomunicaciones y la Sociedad de la Información-Entidad Pública Empresarial Red.es (2012). La sociedad en red. Informe anual 2011. Las TICs en las microempresas españolas. Recuperado el 21 de octubre de 2012, de http://www.ontsi.red.es/ontsi/sites/default/files/informe anual 2012 v10 ultima.pdf

O'Cass, A.; Grace, D. (2004). "Exploring consumer experiences with a service brand". Journal of Product Brand Management, Vol. 13, nº. 4, pp. 257-268.

Odin, Y.; Odin, N.; Valette-Florence, P. (2001). "Conceptual and operational aspects of brand loyalty: An empirical investigation", Journal of Business Research, Vol. 53, $\mathrm{n}^{\mathrm{o}} 2$, pp. $7-84$.

Ogba, I.; Zhenzhen, T. (2009). "Exploring the impact of brand image on customer loyalty and commitment in China", Journal of Technology Management, Vol. 4, nº. 2, pp. 132-144.

Oh, H. (2003). "Price fairness and its asymmetric effects on overall price, quality, and value judgements: the case of a upscale hotel", Tourism Management, Vol. 24, pp. 241249.

Ojiako, U.; Maguire, S. (2009). "Seeking the perfect customer experience: a case study of British Telecom”. Strategic Change, Vol. 18, no. 5-6, pp. 179-193.

Olabarrieta, X; Zorrilla, P. (2016). "El índice de comercio independiente y diversidad (ICID) como herramienta de análisis comercial. Aplicación a la ciudad de Bilbao" (19902014)”. AEMARK 2016.

Olins, W. (2008). The Brand Handbook. London: Thames \& Hudson. 
Oliver, R. (1997). Satisfaction: A behavioral perspective on the consumer. New York: McGraw-Hill.

Oliver, R. (1999). "Whence consumer loyalty?", Journal of Marketing, Vol. 63, no. 4, pp. 33-44.

ONTSI (2016). El sector TIC y de los contenidos en España 2016. Informe Anual. http://www.ontsi.red.es/ontsi/es/content/informe-anual-del-sector-tic-y-de-los-contenidos-enespa\%C3\%B1a-2016. Acceso, 21 de noviembre de 2016

Osman, M.Z. (1993). “A conceptual model of retail image influences on loyalty patronage behavior", The International Review of Retail, Distribution and Consumer Research, Vol. $3, \mathrm{n}^{\circ} .2$, pp. 133-148.

Palmatier, R.W.; Jarvis, C.B.; Benchkoff, J.R.; Kardes, F.R. (2009). "The role of customer gratitude in relationship marketing”, Journal of Marketing, Vol. 73, pp. 1-18.

Palmatier, R. W.; Louis W. S.; Adel I.; Erin A. (2014), Marketing Channel Strategy, (8th ed.). Upper Saddle River, NJ: PearsonPrentice Hall.

Palmeira, M.M.; Thomas, D. (2011). "Two-tier store brands: the benefic impact of a value brand on perceptions of premium brand", Journal of Retailing, Vol. 87, nº. 4, pp. 540-548.

Pan, Y., Zinkhan, G.M., (2006). "Determinants of retail patronage: a meta-analytical perspective", Journal of Retailing, Vol. 82, n. 3, pp. 229-243.

Pantano, E. (2014). "Innovation drivers in retail industry", International Journal of Information Management, Vol. 34, pp. 344-350.

Pantano, E.; Viassone, M. (2014). "Demand pull and technology push perspective in technology-based innovations for the points of sale: the retailers evaluation", Journal of Retailing and Consumer Services, Vol. 21, pp. 43-47. 
Papadopoulos, N.; Heslop, L. (2002). “Country equity and country branding: Problems and prospects”, Journal of Brand Management, Vol. 9, n 4/5, pp. 294-314.

Pappu, R.; Quester, P.; Cooksey, R.W. (2005). "Consumer-based brand equity: improving the measurement-empirical evidence", Journal of Product and Brand Management, Vol. $14, \mathrm{n}^{\circ} .3, \mathrm{pp} .143-154$.

Pappu, R.; Quester, P. (2006). “A consumer-based method for retailer equity measurement: results of an empirical study", Journal of Retailing and Consumer Services, Vol. 13, pp. 317-329.

Pappu, R.; Quester, P. (2006). "Does customer satisfaction lead to improved brand equity? An empirical examination of two categories of retail brands", Journal of Product and Brand Management, Vol. 15, n'. 1, pp. 4-14.

Parasuraman, A.; Zeithaml, V.; Berry, L.L. (1994). "Reassessment of expectations as comparison standard in measuring service quality implications for further research", Journal of Marketing, Vol. 58, no . 1, pp. 111-124.

Parasuraman, A.; Zeithaml, V.; Malhotra, A. (2005). "E-S-QUAL: a multiple-item scale for assessing electronic service quality", Journal of Service Research, Vol. 7, nº. 3, pp. 213233.

Parise, S.; Guinan, P.J.; Kafka, R. (2016). "Solving the crisis of immediacy: How digital technology can transform the customer experience", Business Horizons, Vol. 59, pp. 411420.

Parra, F.; González, E.; Molinillo, S.; VILLAREJO, A. (1998): "Análisis del comercio tradicional", Actas del XII Congreso Nacional de la Asociación Europea de Dirección y Economía de la Empresa (AEDEM), Universidad de Málaga, junio, pp. 1213-1220.

Pascual del Riquelme, I.; Román, S. (2011). "Distribución y consumo de productos tecnológicos en España”, Distribución y Consumo, año 21, nº 117, mayo-junio, pp. 1-18. 
PATECO (2016). Informe anual de la distribución comercial minorista en la Comunitat Valenciana.

Patwardhan, H.; Balasubramanian, S.K. (2011). "Brand romance: a complementary approach to explain emotional attachment toward brands", The Journal of Product and Brand Management, Vol. 20, $\mathrm{n}^{\circ} .4$, pp. 297-308.

Pauwels, K.; Leeflang, P.; Teerling, M.; Huizing, K. (2011). "Does online information drive offline revenues? Only for specific products and consumer segments!", Journal of Retailing, Vol. 87, $\mathrm{n}^{\mathrm{o}}$ 1, pp. 1-17.

Pauwels, K.; Neslin, S.A. (2015). "Buiding with bricks and mortar: the revenue impact of opening physical stores in a multichannel environment", Journal of Retailing, Vol. 91, $\mathrm{n}^{\circ} .2$, pp. 182-197.

Pavlou, P.A.; Fygenson, M. (2006). "Understanding and predicting electronic commerce adoption: an extension of the theory of planned behavior", MIS Quarterly, Vol. 30, n. 1, pp. 115-143.

Pecoraro, M.; Uusitalo, O. (2014). "Exploring the everyday retail experience: the discourses of style and design", Journal of Consumer Behaviour, Vol. 13, pp. 429-441.

Pine, B.J.; Gilmore, J.H. (1999). The Experience Economy. Boston: Harvard Business School Press.

Pine, B.J. and Gilmore, J.H. (2011). The experience economy. Cambridge MS: Harvard Business Press.

Piotrowicz, W.; Cuthbertson, R. (2014). "Information technology in retail: toward omnichannel retailing", International Journal of Electronic Commerce, Vol. 18, $\mathrm{n}^{\mathrm{o}}$. 4, pp. $5-15$. 
Pitta, D. A.; Katsanis, L. P. (1995). "Understanding brand equity for successful brand extension", Journal of Consumer Marketing, Vol. 12, n. 4, pp. 51-64.

Pookulangara, S.; Hawley, J.; Xiao, G. (2011). "Explaining consumers' channel-switching behavior using the theory of planned behaviour", Journal of Retailing and Consumer Services, Vol. 18, pp. 311-321.

Porter, M. (1980). Competitive strategy. Nueva York: Free Press.

Porter, M. (1985). Competitive advantage: creating and sustaining superior performance. Nueva York: Free Press.

Porter, M. (2001). "Strategy and the Internet". Harvard Business Review, March 2001.

Porter, M. E.; Kramer, R. M. (2006). "Strategy and Society: The Link between Competitive Advantage and Corporate Social Responsibility", Harvard Business Review, Vol. 84, nº 12 , pp. $76-92$.

Powell, T. C. y Dent-Mecallef, A., (1997). "Information technology as competitive advantage: the role of human, business, and technology resources", Strategic Management Journal, Vol. 18, n 4, pp. 375-405.

Praharsi, Y.; Wee, H.; Sukwadi, R.; Padilan, M. (2014). "Small-independent retailers vs. organized retailers: An empirical study in Indonesian economics of service industries", Journal of Retailing and Consumer Services, Vol. 21, pp. 108-117.

Pritchard, M.P.; Havitz, M.E.; Howard, D.R. (1999). “Analyzing the commitment-loyalty link in service contexts", Journal of the Academy of Marketing Science, Vol. 27, $\mathrm{n}^{\circ} .3$, pp. $338-348$

Prosenak, D., Matjaz, M. y Snoj, B. (2008). "A requisitely holistic approach to marketing in terms of social well-being”, Kybernetes, Vol. 37, n 9-10, pp. 1508 - 1529. 
Puccinelli, N.M.; Goodstein, R.C.; Grewal, D.; Price, R.; Raghubir, P.; Stewart, D. (2009). "Customer Experience Management in Retailing: understanding the buying process". Journal of Retailing, Vol. 85, nº 1, pp. 15-30.

Rafiq, M. y Ahmed, P.K. (2000). "Advances in the Internal Marketing Concept: Definition, Synthesis and Extension", The Journal of Services Marketing, Vol. 14, nº. 6, pp. 449-62.

Raggio, R.D.; Leone, R.P. (2007). "The theoretical separation of brand equity and brand value: managerial implications for strategic planning", Journal of Brand Management, Vol. 14, no. 5, pp. 380-395.

Ralston, R.W. (2003). "The effects of customer service, branding, and price on the perceived value of local telephone service”, Journal of Business Research, Vol. 53, n 3, pp. 201-213.

Ramakrishnan, K. (2010). "The competitive response of small, independent retailers to organized retail: Study in an emerging economy", Journal of Retailing and Consumer Services, Vol. 17, pp. 251-258

Raman, K.; Mantrala, M. K.; Sridhar, S.; Tang, Y. (2012). "Optimal resource allocation with time-varying marketing effectiveness, margins and costs", Journal of Interactive Marketing, Vol. 26, n. 1, pp. 43-52.

Rao, A.R.; Monroe, K.B. (1989). "The effect of price, brand name and store name on buyers perceptions of product quality: an integrative review", Journal of Marketing Research, Vol. 26, pp. 351-357.

Rao, V.R.; Agarwal, M.K.; Dahlhoff, D. (2004). "How is manifest branding strategy related to the intangible value of a corporation?", Journal of Marketing, Vol. 68, n. 4, pp. 126141.

Rao, K. (2011). Services Marketing. New Delhi: Dorling Kindersley, Pvt. Ltd. 
Rasoolimanesh, S.M.; Dahalan, N.: Jaafar, N. (2016). "Tourists' perceived value and satisfaction in a community-based homestay in the Lenggong Valley World Heritage Site", Journal of Hospitality and Tourism Management, Vol. 26, pp. 72-81.

Rauschnabel, P.A.; Krey, N.; Babin, B.J.; Ivens, B.S. (2016). "Brand management in higher education: the university brand personality scale", Journal of Business Research, Vol. 69, pp. 3077-3086.

Rauyruen, P.; Miller, K.E. (2007). "Relationship quality as a predictor of B2B customer loyalty", Journal of Business Research, Vol. 60, nº 1, pp. 21-31.

Reinartz, W.; Dellaert, B.; Krafft, M.; Kumar, V.; Varadarajan, R. (2011). "Retailing innovations in a globalizing retail market environment", Journal of Retailing, Vol. 87. Pp. 53-66.

Richardson, P.S. (1997). “Are store brands perceived to be just another brand?”, Journal of Product and Brand Management, Vol. 6, nº 6, pp. 388-404.

Rindfleisch, A.; Inman, J.J. (1998). "Explaining the familiarity-linking relationship: mere exposure, information availability or social desirability?", Marketing Letters, Vol. 9, nº. 1, pp. 5-19.

Rodríguez, I. (2008). Marketing.com y comercio electrónico en la sociedad de la información ( $3^{\mathrm{a}}$ ed.). Madrid: Ediciones Piramide y ESIC Editorial.

Roehm, M.L.; Brady, M.K. (2007). "Consumer response to performance failure by highequity brands", Journal of Consumer Research, Vol. 34, nº. 4, pp. 537-545.

Roggenveen, A.; Nordfält, J.; Grewal, D. (2016). "Do digital displays enhance sales? Role of retail format and message content", Journal of Retailing, Vol. 1, pp. 122-131.

Romaniuk, J.; Sharp, B. (2004). "Conceptualizing and measuring brand salience", Marketing Theory, Vol. 4, nº. 4, pp. 327-342. 
Rondán Cataluña, F. J. (2004). "Precio versus lealtad hacia la marca en la elección de compra", Investigaciones Europeas de Dirección y Economía de la Empresa, Vol. 10, $\mathrm{n}^{\circ} 1$, pp. 165-188.

Rondan Cataluña, F.J.; Navarro, A.; Phau, I. (2006). "The influence of price and brand loyalty on store brands versus national brands", The International Retail, Distribution and Consumer Research, Vol. 16, nº. 4, pp. 433-452.

Rossiter, J. R.; Percy, L. (1987). Advertising and promotion management. New York: McGraw-Hill Book Company.

Roster, J. (2012), "Market Insight: Retail Primer, North America," Gartner Report, Vol. 29, pp. 1-21.

Rovedder, M.O.; Schmitt, C.; Bins, F. (2015). "Brand equity estimation model”, Journal of Business Research, Vol. 68, pp. 2560-2568.

Rovira, A.; Estevan, F.; Forés, D.; Hernández, C. (2007). Gestión de Centros Urbanos. Madrid: Consejo de Cámaras Oficiales de Comercio, Industria y Navegación de la Comunidad Valenciana.

Ruiz, M.E.; Gil, I.; Berenguer, G. (2013). "Capital de marca de la tienda e intenciones conductuales: la influencia de las TIC como variable moderadora”. AEMARK 2013

Rundle-Thiele, S.; Macka, M.M. (2001). "Assesing the performance of brand loyalty measures", Journal of Services Marketing, Vol. 15, nº 7, pp. 529-546.

Rust, R.T.; Lemon, K.N.; Zeithaml, V.A. (2004). "Return on marketing: using customer equity to focus marketing strategy", Journal of Marketing, Vol. 68, nº. 1, pp. 109-127.

Sainz de Vicuña, J.M. (2001): La Distribución Comercial. Opciones Estratégicas. (2a edición). Madrid: ESIC Editorial. 
Sainz de Vicuña Ancín, J. M. (1999). Marketing estratégico para el pequeño y mediano comercio. Bilbao: Ediciones PMP.

Saleem, S.; Rahman, S.U.; Umar, R.M. (2015). "Measuring customer based beverage brand equity: investigating the relationship between perceived quality, brand awareness, brand image, and brand loyalty", International Journal of Marketing Studies, Vol. 7, nº.1, pp. 6677 .

San Martín, S.; Camareno, C.; Hernández, C.; Valls, L. (2009). "Risks, drivers and impediments to online shopping in Spain and Japan”, Journal of Euromarketing, Vol. 18, no. 1, pp. 47-64.

Sánchez, J., Callarisa, L., Rodriguez, R. M.; Moliner, M. (2006). "Perceived value of the purchase of a tourism product”, Tourism Management, Vol. 27, pp. 394-409.

Sandulli, F.D. (2011). "Los modelos de negocio de los mercados electrónicos en el sector de la alimentación en España”, Distribución y Consumo, año 21, n 116, pp.33-42.

Santos, L.; González, O. (2000). "El comercio minorista independiente español”, Boletín Económico ICE, $\mathrm{n}^{\circ} .2652$.

Scarpi, D. (2006). "Fashion stores between fun and usefulness", Journal of Fashion Marketing and Management, Vol. 10, pp. 7-24.

Scarpi, D. (2012). "Work and fun on the Internet: the effects of utilitarianism and hedonism online", Journal of Interactive Marketing, Vol. 26, $\mathrm{n}^{\circ} .1$, pp. 53-67.

Schlosser, A.E. (1998). "Applying the functional theory of attitudes to understanding the influence of store atmosphere on store inferences", Journal of Consumer Psychology, Vol. 7, no. 4, pp. 345-369.

Schmitt, B. (1999). "Experiential marketing”, Journal of Marketing Management, Vol. 15, pp. 53-67. 
Schmitt, B. (2006). Experiential Marketing. Cómo conseguir que los clientes se identifiquen en su marca: sensaciones, sentimientos, pensamientos, actuaciones y relaciones. Bilbao: Editorial DEUSTO.

Schmitt, B. (2009). "The concept of brand experience", Journal of Brand Management, Vol. 16, n'. 7, pp. 417-419.

Seo, S.; Jang, S. (2013). "The roles of Brand equity and branding strategy: a study of restaurant food crises”, International Journal of Hospitality Management, Vol. 34, pp. 192201.

Sethuraman, R.; Parasuraman, A. (2005). "Succeeding in the big middle through technology”, Journal of Retailing, Vol. 81, n 2, pp. 107-111.

Sexton, R.S.; Johnson, R.A.; Hignite, M.A. (2002). "Predicting Internet/e-commerce use", Internet Research: Electronic Networking Applications and Policy, Vol. 12, no. 5, pp. 402410.

Shani, A.; Rivera, M. A.; Hara, T. (2009). "Assessing the viability of repeat visitors to cultural events: evidence from the Zora! Festival”, Journal of Convention \& Event Tourism, Vol. 10, n 2, pp. 89-104

Shah, D.; Rust, R.T.; Parasuraman, A.; Staelin, R.; Day, G.S. (2006). "The path to customer centricity", Journal of Services Research, Vol. 9, pp. 113-124.

Shankar, V.; Smith, A.; Rangaswamy, A. (2003). "Customer satisfaction and loyalty in online and offline environments", International Journal of Research in Marketing, Vol. 20; $\mathrm{n}^{\mathrm{o}} .2$, pp 153-175.

Shankar, V., Azar, P., \& Fuller, M. (2008). "Brand Equity: A model and simulator for estimating, tracking, and managing multicategory brand equity", Marketing Science, Vol. $27, \mathrm{n}^{\circ} .4, \mathrm{pp} .567-584$. 
Sharma, S.; Durand, R.M.; Gur-Arie, O. (1981). "Identification and analysis of moderator variables", Journal of Marketing Research, Vol.18, n 3, pp. 291-300.

Shaw, C. (2007). The DNA of customer experience: How emotions drive value. Palgrave Macmillan.

Shen, P. (2010). "A study on the multi-dimensional relationship between consumer shopping value and retailer brand equity", Marketing Science Innovations and Economic Development. Proceedings of 2010 Summit International Marketing Science and Management Technology Conference, pp. 128-132.

Sheng, M.L.; Teo, T.S.H. (2012). "Product attributes and brand equity in the mobile domain: The mediating role of customer experience", International Journal of Information Management, Vol. 32, pp. 139-146.

Sheth, J.N.; Newman, B.I.; Gross, L.G. (1991). "Why we buy what we buy: a theory of consumption values", Journal of Business Research, Vol. 22, pp. 159-170.

Siebel, T. (2001). Principios del e-Business. Barcelona: Ed. Gránica.

Simon, C. J.; Sullivan, M. W. (1993). "The measurement and determinants of Brand equity: a financial approach", Marketing Science, Vol. 12, pp. 28-52.

Simonson, A.; Itamar (1994). "Trademark infringement from the buyer perspective: Conceptual analysis and measurement implications", Journal of Public Policy and Marketing, Vol. 13, nº. 2, pp. 181-199.

Singh, J. (2014). "A review of impact of information technology in retail", International Journal of Management Research \& Review, Vol., 41, nº 11, pp. 1047-1055.

Smith, J. W. (1991). Thinking about bran equity and the analysis of customer transactions. ARF Advertising and Promotion Workshop, febrero, 5 - 6, pp. 35-54. 
Smith, D.N.; Sivakumar, K. (2004). "Flow and Internet shopping behavior. A conceptual model and research propositions", Journal of Business Research, Vol. 57, pp. 1199-1208.

Smith, A.; Sparks, L. (2001). "The role and function of the independent small shop: the situation in Scotland", The International Review of Retail, Distribution and Consumer Research, Vol. 10, n. 2, pp. 205-226.

Söderlund, M. (2004). “The loyal customer”. Oslo: Gyldendal Akademisk.

Sorescu, A.; Frambach, R.; Singh, J.; Rangaswamy, A.; Bridges, C. (2011). "Innovations in retail business models", Journal of Retailing, Vol. 87, n. 1, pp. 3-16.

Spena, T.R.; Carida, A.; Colurico, M.; Melia, M. (2012). "Store experience and cocreation: the case of temporary shop", International Journal of Retail and Distribution Management, Vol. 40, pp. 21-40.

Sriram, V.; Stump, R., (2004). "Information technology investments in purchasing: An empirical investigation of communications, relationship and performance outcomes", The International Journal of Management Science, Vol.32, nº 1, pp. 41-55.

Sriram, V.; Stump, R.; Banerjee, S., (1997). "Information technology investments in purchasing: An empirical study of dimensions and antecedents", Information and Management, Vol. 33, pp. 59-72.

Srinivasan, V.; Park, C.S.; Chang, D.R. (2005). "An Approach to the Measurement, Analysis, and Prediction of Brand Equity and Its Sources”, Management Science, Vol. 51, no 9, pp. 1433-48.

Srivastava, R.K. y Shocker, A.D.A (1991). Brand equity: A perspective on its meaning and measurement, (Paper report $\mathrm{n}^{\circ}$. 91-124). Cambridge, MA: Marketing Science Institute.

Srivastava, M.; Kaul, D. (2016). "Exploring the link between customer experience-loyaltyconsumer spend", Journal of Retailing and Consumer Services, Vol. 31, pp. 277-286. 
Stein, A.; Ramaseshan, B. (2016). "Towards the identification of customer experience touch point elements", Journal of Retailing and Consumer Services, Vol. 30, pp. 8-19.

Steinfield, C., Mahler, A. y Bauer, J. (1999). "Electronic commerce and the local merchant: opportunities for synergy between physical and Web presence", Electronic Markets, Vol. 9. $n^{\circ} .1$.

Steinfield, C.; Bouwman, H.; Adelaar, T. (2002). "The dynamics of click-and-mortar electronic commerce: opportunities and management strategies", International Journal of Electronic Commerce, Vol. 7, $\mathrm{n}^{\circ}$. 1, pp 93-119.

Steinfield, C. (2002). "Understanding click and mortar e-commerce approaches: a conceptual framework and research agenda", Journal of Interactive Advertising, Vol. $2 \mathrm{n}^{\circ}$. 2, pp. 1-10.

Steinfield, C.; Adelaar, T.; Liu, F. (2005). "Click and Mortar strategies viewed from the Web: a content analysis of features illustrating integration between retailers' online and offline presence", Electronic Markets, Vol. 15, nº 3.

Stobart, P. (1994). Brand Power. London: MacMillan.

Sun, Y.; Kim, K. H.; Kim, J. (2014). "Examining relationships among sustainable orientation, perceived sustainable marketing performance, and customer equity in fast fashion industry", Journal of Global Fashion Marketing, Vol. 5, nº. 1, pp. 74-86.

Suri, R.; Monroe, K. B. (2003). "The effects of time pressure on consumers' judgments of prices and products", Journal of Consumer Research, Vol. 30, nº. 1, pp. 92-104.

Swait, J.; Erdem, T.; Louviere, J.; Dubelaar, C. (1993). "The equalization price: a measure of consumer-perceived brand equity", International Journal of Research in Marketing, Vol. 10, pp. $23-45$. 
Sweeney, J.; Soutar, G. N. (2001). "Consumer perceived value: the development of a multiple item scale", Journal of Retailing, Vol. 77, n. 2, pp. 203-220.

Sweeney, J.; Soutra, G.N.; Johnson, L.W. (1999). "The role of perceived risk in the qualityvalue relationship: a study in retail environment”, Journal of Retailing, Vol. 75, $\mathrm{n}^{\circ} .1$, pp. $77-105$.

Swoboda, B.; Berg, B.; Schramm-Klein, H.; Foscht, T. (2013). "The importance of retail brand equity and store accessibility for store loyalty in local competition", Journal of Retailing and Consumer Services, Vol. 20, pp. 251-262.

Swoboda, B.; Berg, B.; Dabija, D.C. (2014). "International transfer and perception of retail formats: a comparison study in Germany and Romania", International Marketing Revue, Vol. 31, no. 2, pp. 155-180.

Swoboda, B.; Weindel, J.; Hälsig, F. (2016). "Predictors and effects of retail brand equity A cross-sectorial analysis", Journal of Retailing and Consumer Services, Vol. 31, pp. 265276.

Tajeddini, K.; Elf, U.; Trueman, M. (2013). "Efficiency and effectiveness of small retailers: The role of customer and entrepreneurial orientation", Journal of Retailing and Consumer Services, Vol. 29, pp. 453-462.

Tasci, A. D.; Gartner, W. C.; Cavusgil, S. T. (2007). "Measurement of destination brand bias using a quasi-experimental design", Tourism Management, Vol. 28, no. 6, pp. 15291540.

Tauber, E. M. (1988). "Brand leverage: strategy for growth in a cost-control world", Journal of Advertising Research, Vol. 28, pp. 26-30.

Teas, R. K.; Laczniak, R. N. (2004). "Measurement process context effects in empirical tests of causal models", Journal of Business Research, Vol. 57, nº. 2, pp. 162-174. 
Teas, R.K.; Agarwal, S. (2000). "The effects of extrinsic products cues on consumers' perceptions of quality, sacrifice and value", Journal of the Academy of Marketing Science, Vol. 28, no. 2, pp. 278-291.

Tena, S. (2016). "Motivación de compra: un estudio comparativo entre el pequeño comercio y los grandes centros comerciales", Tesis Doctoral. Castellón: Universitat Jaume I.

Terblanche, N.; Boshoff, C. (2006). "The relationship between a satisfactory in-store shopping experience and retailer loyalty", South Africa Journal of Business Management, Vol. 37, no. 2, pp. 33-43.

Thompson, M.; MacInnis, D.J.; Park, W.C. (2005). "The ties that bind: Measuring the strength of consumers' emotional attachment to brands", Journal of Consumer Psychology, Vol. 15, no. 1, pp. 77-91.

Tortosa, V.; Llorens, J.; Sánchez, J.; Moliner, M. A. (2011). "La influencia del marketing interno en la calidad de la relación entre la organización y sus empleados", 10th International Marketing Trends Conference, Paris: 20-01-2011.

Tsai, S. (2005). "Utility, cultural symbolism y emotion: a comprehensive model of brand purchase value", International Journal of Research in Marketing, Vol. 22, pp. 277-291.

Tuominen, P. (1999). "Managing brand equity", The Finish Journal of Business Economics, Vol. 1, pp. 65-100.

Turban, E.; Lee, J.K.; King, D.; Mckay, J.; Marshall, P. (2008). Electronic commerce: a managerial perspective, Upper Saddle River, N.J.: Pearson Prentice Hall.

Van Birgelen, M.; de Jong, A.; de Ruyter, K. (2006). "Multi-channel service retailing: The effects of channel performance satisfaction on behavioral intentions", Journal of Retailing, Vol. 82, no . 4, pp. 367-377. 
Van Nierop, J.; Leeflang, P.; Teerling, M.; Huizing, K. (2011). "The impact of the introduction and use of an informational website on offline customer buying behavior", Intenational Journal of Research in Marketing, Vol. 28, pp. 155-165.

Van Riel, C. B.; Balmer, J. M. T. (1997). "Corporate identity: The concept, its measurement, and management”, European Journal of Marketing, Vol. 31, pp. 341-355.

Varadarajan, R.; DeFanti, M. P.; Busch, P. S. (2006). "Brand Portfolio, Corporate Image, and Reputaion: Managing Brand Deletions", Journal of the Academy of Marketing Science, Vol. 34, no. 2, pp. 195-205.

Vázquez, R.; del Río, B.A.; Iglesias, V. (2002). "Consumer-based brand equity: development and validation of a measurement instrument", Journal of Marketing Management, Vol.18, pp. 27-48.

Vázquez, R.; Álvarez, B.; Trespalacios, J.A. (2006). Estrategias de distribución comercial: diseño del canal de distribución y relación entre fabricantes y detallistas. Madrid: Ediciones Paraninfo.

Venkatesan, R.; Farris, P.; Guissoni, L.A.; Neves, M.F. (2015). "Consumer brand marketing through full and self-service channels in an emerging economy", Journal of Retailing, Vol. 4, pp. 644-659.

Verhoef, P.C.; Neslin, S.A.; Vroomen, B. (2007). "Multichannel customer management: understanding the research-shopper phenomenon", International Journal of Research in Marketing, Vol. 24, nº 2, pp. 129-148.

Verhoef, P.C.; Lemon, K.N.; Parasuraman, A.; Roggeveen, A.; Tsiros, M.; Schlesinger, L.A. (2009). "Customer experience creation: determinants, dynamics and management strategies", Journal of Retailing, Vol. 85, nº 1, pp. 31-41. 
Verhoef, P.C.; Kannan, P.K.; Inman, J.J. (2015). "From multi-channel retailing to omnichannel retailing. Introduction to the special issue on multi-channel retailing”, Journal o Retailing, Vol. 91, nº. 2, pp. 174-181.

Virutamasen, P.; Wongpreedee, K.; Kummungwut, W. (2015). "Strengthen brand association through SE: institutional theory revisited", Social and Behavioural Sciences, Vol. 195, pp. 192-196.

Visinescu, L.L.; Sidorova, A.; Jones, M.C.; Prybutok, V.R. (2015). "The influence of website dimensionality on customer experiences, perceptions and behavioral intenttions: An exploratory of 2D vs. 3D web design", Information and Management, Vol. 52, pp. 1-17.

Wallace, D.W.; Joan, L.G.; Johnson (2004). "Customer retailer loyalty in the context of multiple cannel strategies", Journal of Retailing, Vol. 80, n. 4, pp. 249-263.

Walter, U.; Edvardsson, B.; Öström, A. (2010). 'Drivers of customers' service experiences: a study in the restaurant industry”, Managing Service Quality. Vol. 20, nº. 3, pp. 236-258.

Wang, R.J.; Malthouse, E.; Krishnamurthi, L. (2015). “On the go: how mobile shopping affects customer purchase behavior”. Journal of Retailing, Vol. 91, nº. 2, pp. 217-234.

Wang, X.; Yang, Z. (2010) "The effect of brand credibility on consumers' brand purchase intention in emerging economies: the moderating role of brand awareness and brand image", Journal of Global Marketing, Vol. 23, n. 3, pp. 177-188.

Wanga, R.J-H.; Malthouseb, E.C.; Krishnamurthia, L. (2015). "On the Go: How Mobile Shopping Affects Customer Purchase Behavior", Journal of Retailing, Vol. 91, nº. 2, pp. 217-234

Watson IV, G.F.; Worm, S.; Palmatier, R.W.; Ganesan, S. (2015). "The evolution of marketing channels: trends and research directions", Journal of Retailing, Vol. 91, n. 4, pp. 546-568. 
Weber, M.M.; Kantamneni, S.P. (2002). "POS and EDI in retailing: An examination of underlying benefits and barriers", Supply Chain Management: An International Journal, Vol. 7, n' 5, pp. 311-317.

Weinstein, R.; Johnson, W.C. (1999). Designing and delivering superior customer value: concepts, cases, and applications. Londres: Boca Raton, Fla. St. Lucie Press.

White, R.C.; Joshep-Mathews, S.; Voorhees, C.M. (2013). "The effects of service on multichannel retailers' brand equity", Journal of Services Marketing, Vol. 27, no 4, pp. 259270.

Wong, A.; Sohal, A. (2003). "Service quality and customer loyalty perspectives on two levels of retail relationships", Journal of Services Marketing, Vol. 17, n. 5, pp. 459-513.

Wong, A. (2013). "Exploring customer equity and the role of service experience in the casino service encounter", International Journal of Hospitality Management, Vol. 32, pp. 91-101.

Wood, L. (1996). “Added value: marketing basics?” Journal of Marketing Management, Vol. 12, pp. 735-755.

Wood, L. (2000). "Brands and brand equity: definition and management", Management Decision, Vol. 38, nº. 9, pp. 662-669.

Woodruff, R. B. (1997). "Customer value: the next source for competitive advantage", Journal of the Academy of Marketing Science, Vol. 25, n. 2, pp. 139-153.

Xiucheng, F.; Yan, L. (2000). "Loyalty factor method of brand valuation", Scientific Management Research, Vol. 5, pp. 23-25.

Xu, J.B.; Chan, A. (2010). "A conceptual framework of hotel experience and customerbased brand equity: some research questions and implications", International Journal of Contemporary Hospitality Management, Vol. 22, n. 2, pp. 174-193. 
Xu, L.; Duan, J.A.; Andrew, B. W. (2014), "Path to Purchase: A Mutually Exciting Point Process Model for Online Advertising and Conversion," Management Science, Vol. 60, nº 6, pp. 1392-412.

Yang, D. (2012). “The Strategic Management of Store Brand Perceived Quality", Physics Procedia, Vol. 24, pp. 1114-1119.

Yeng, L.C.; Mat, N.K. (2013). "The Antecedents of Customer Loyalty in Malaysian Retailing: Capitalizing the Strategic Tool", Proceedings of $3^{\text {rd }}$ Asia-Pacific Business Research Conference, pp.25-26.

Yoganathan, D.; Jebarajakirthy, C.; Traichon, P. (2015). "The influence of relationship marketing orientation on brand equity in Banks", Journal of Retailing and Consumer Services, Vol. 26, pp. 14-22.

Yoo, B. y Donthu, N. (2001). "Developing y validating a multidimensional consumer based brand equity scale”, Journal of Business Research, Vol. 52, pp. 1-14.

Yoo, B.; Donthu, N.; Lee, S. (2000). “An examination of selected marketing mix elements y brand equity", Journal of Marketing Research, Vol. 24, pp. 258-270.

Yoon, S.; Oh, S.; Song, S.; Kim, K.; Kim, Y. (2014). "Higher quality or lower price? How value-increasing promotions affect retailer reputation via perceived value", Journal of Business Research, Vol. 67, pp. 2088-2096.

Yurova, Y.; Rippé, C.B.; Weisfeld-Spolter, S.; Sussan, F.; Arndt, A. (2016). 'Not all adaptive selling to omni-consumers is influential: the moderating effect of product type”, Journal of Retailing and Consumer Services, January, 2016 (article in press).

Zablah, A.R.; Johnston, W.J.; Bellenger, D.N. (2005). "Transforming partner relationships through technological innovation", Journal of Business and Industrial Marketing, Vol. 20, no. 7, pp. 355-363. 
Zeithaml, V. A. (1988). "Consumer perception of price, quality, and value: a means-end model and synthesis of evidence”, Journal of Marketing, Vol. 52, nº. 3, pp. 2-22.

Zettelmeyer, F. (2000). "Expanding to the Internet: pricing and communications strategies when firms compete on multiple channels", Journal of Marketing Research, Vol. 37, nº. 3, pp. 292-308.

Zhang, J.; Farris, P.W.; Irvin, J.W.; Kushwaha, T.; Steenburg, T.J.; Weitz, B.A. (2010). "Crafting integrated multichannel retailing strategies", Journal of Interactive Marketing, Vol. 24, n' .2 , pp. 168-180.

Zhang, H.; Ko, E.; Kim, K. H. (2010). "The influences of customer equity drivers on customer equity and loyalty in the sports shoe industry: Comparing Korea and China", Journal of Global Fashion Marketing, Vol. 1, n. 2, pp. 110-118.

Zinkhan, G.; Haytko, D.; Ward, A. (1996). "Self-concept theory”, Journal of Marketing Communication, Vol. 2, nº. 1, pp. 1-19.

Zott, C.; Amit, R. (2010). "Business model design: an activity system perspective", Long Range Planning, Vol. 43, nº. 2/3, pp. 216-222. 